\title{
ENERGY HARVESTING FROM ELLIPTICAL MACHINES USING FOUR-SWITCH BUCK-BOOST TOPOLOGY
}

\author{
A Thesis \\ presented to \\ the Faculty of California Polytechnic State University, \\ San Luis Obispo
}

\author{
In Partial Fulfillment \\ of the Requirements for the Degree \\ Master of Science in Electrical Engineering
}

by

Alvin Jay Hilario

May 2011 
(C) 2011

Alvin Jay Hilario

ALL RIGHTS RESERVED 
COMMITTEE MEMBERSHIP

TITLE: ENERGY HARVESTING FROM ELLIPTICAL MACHINES USING FOUR-SWITCH BUCK-BOOST TOPOLOGY

AUTHOR: $\quad$ Alvin Jay Hilario

DATE SUBMITTED: May 2011

COMMITTEE CHAIR: $\quad$ Dr. David Braun, Professor, Electrical Engineering

COMMITTEE MEMBER: $\quad$ Dr. Taufik, Professor, Electrical Engineering

COMMITTEE MEMBER: $\quad$ Dr. Dale Dolan, Assistant Professor, Electrical Engineering 


\begin{abstract}
Energy Harvesting From Elliptical Machines Using Four-Switch Buck-Boost Topology

Alvin Jay Hilario
\end{abstract}

This thesis presents the topic of using the Four-Switch Buck-Boost topology as a DC-DC converter for the Energy Harvesting from Elliptical Machines Project. The project works toward providing a modular synchronous power generation system. Due to the dynamic and sporadic output voltage and power characteristics of the Precor elliptical machine, the system requires a DC-DC converter as a voltage preregulator. The inherent wide input range, high efficiency, and low parts cost of this converter well suit the application. This paper further discusses other topologies and their shortcomings, as well as characterizes the Precor elliptical machine and Enphase Microinverter for interfacing. This report contains a detailed discussion on component selection and PCB layout. The converter averages $94 \%$ efficiency during a normal workout power range. This paper also derives a system level control scheme for a modular grid-tie energy harvesting power electronics unit. The Four-Switch Buck-Boost topology efficiently and effectively harvests energy from the Precor elliptical machine as a constant input impedance and wide input voltage regulator for a constant voltage grid-tie inverter.

Keywords: DC-DC Converter, Four-Switch Buck-Boost Topology, Energy

Harvesting from Exercise Machines, Precor Elliptical Machine, Enphase Microinverter 


\section{ACKNOWLEDGMENTS}

First and foremost, I would like to thank my parents, Pedro and Estella Hilario, and girlfriend, Heather Brown, for their perpetual emotional support and encouragement.

I also would like to thank my thesis advisor, Dr. David Braun, and the members

of the Energy Harvesting From Exercise Machines team, past and present, some of whom include Jonathan Yuen, Nick Lovgren, Martin Kou, and Greg Hollister. I also received much counsel from my thesis committee members, Dr. Taufik and Dr. Dale Dolan. Also, Dr. Pan allowed and taught me how to use the reflow oven for my PCB fabrication. The team effort helped me realize my thesis to what it is today. 


\section{TABLE OF CONTENTS}

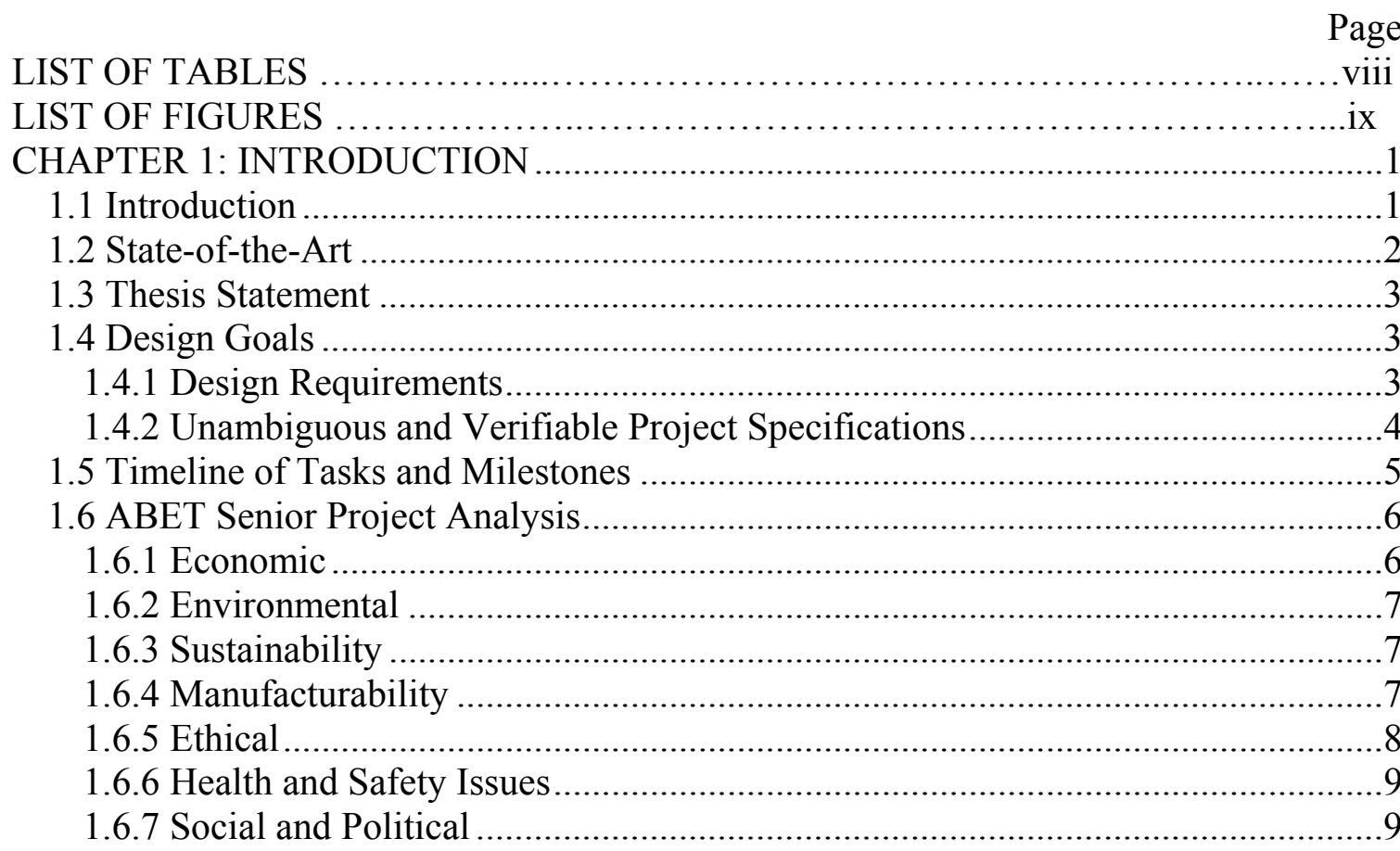

CHAPTER 2: CHARACTERIZATION OF CURRENT SYSTEM ….............................11

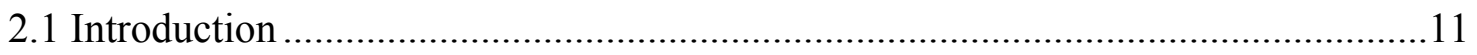

2.2 Precor Elliptical Machine ..............................................................................11

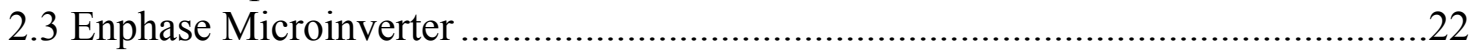

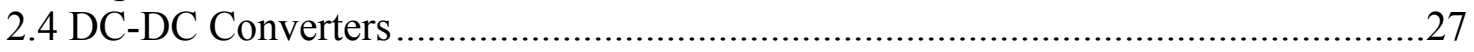

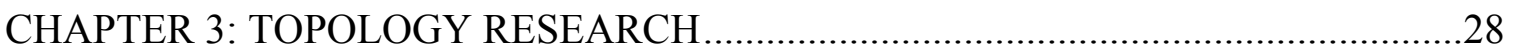

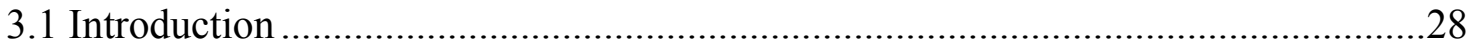

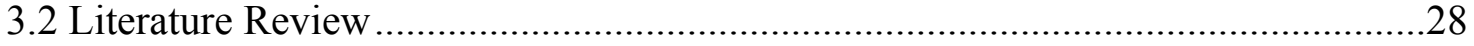

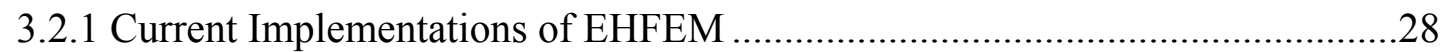

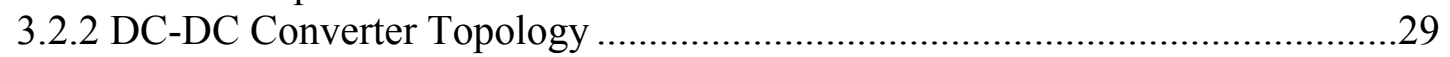

3.3 Chronologic Thought Process for Topology Decision...............................................30

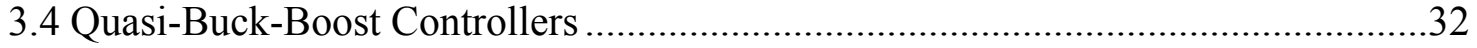

3.5 SEPIC and Four Switch Buck Boost Designs ……...............................................34

3.6 Dual Converter Design - Buck and Boost ...............................................................38

3.7 Modified LTC3780 Four Switch Buck-Boost Design ...............................................44

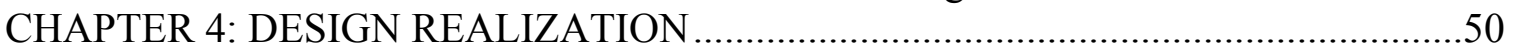

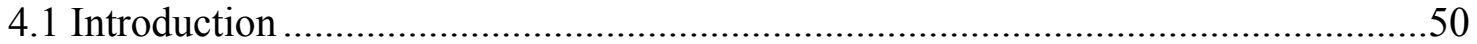

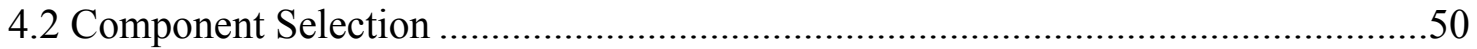

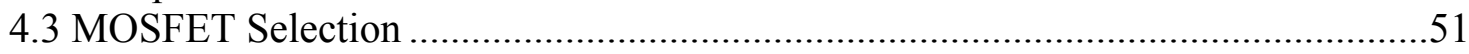

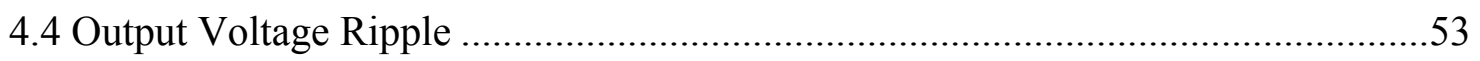

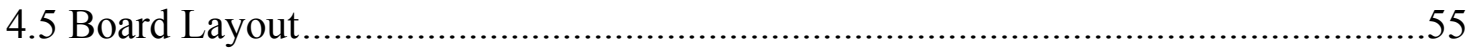

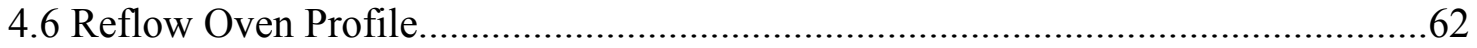

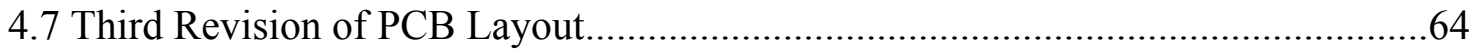

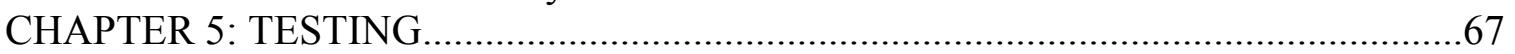

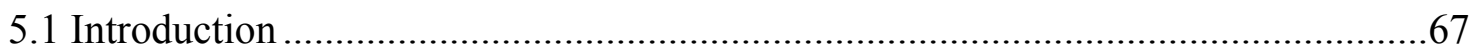

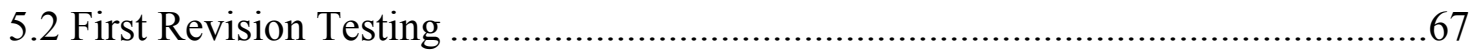




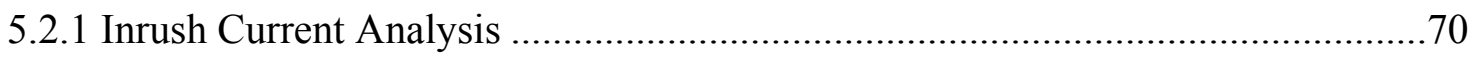

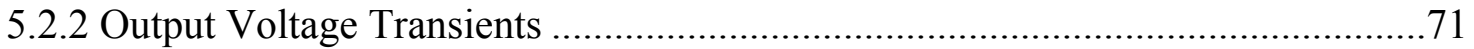

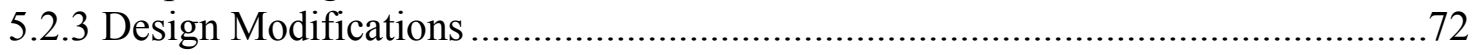

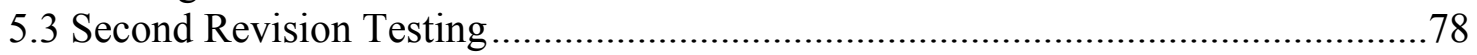

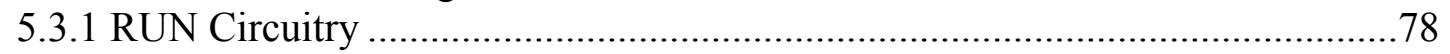

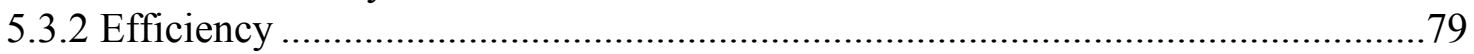

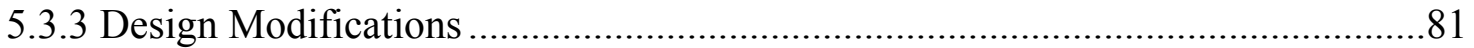

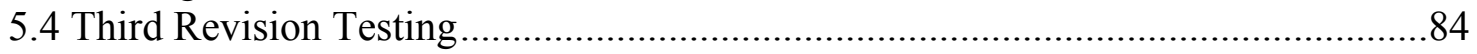

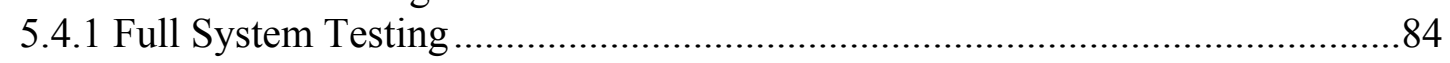

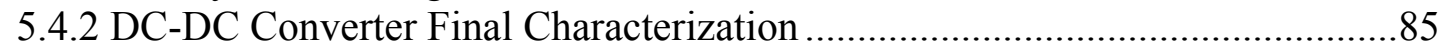

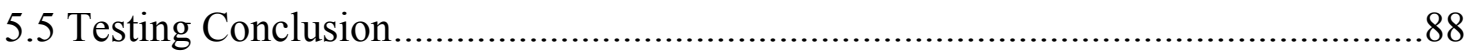

CHAPTER 6: PROPOSED CONSTANT IMPEDANCE CONTROL SCHEME ............89

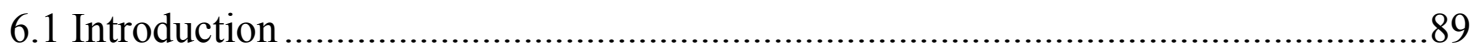

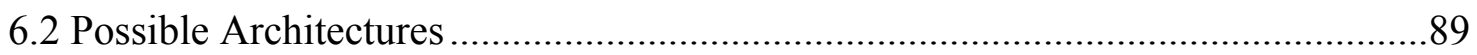

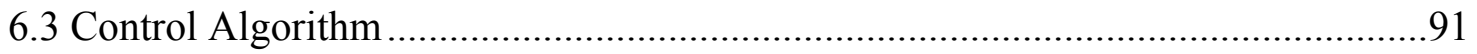

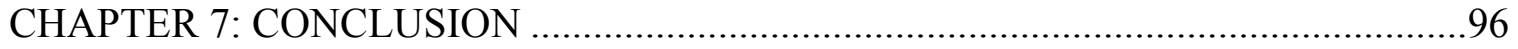

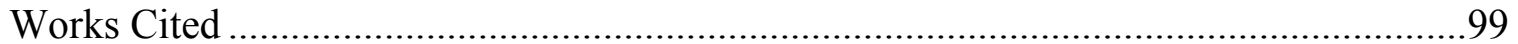

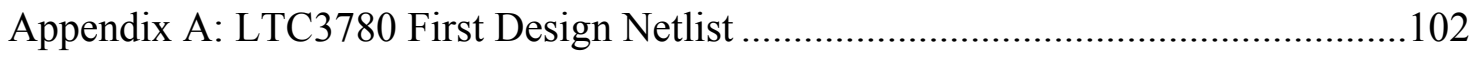

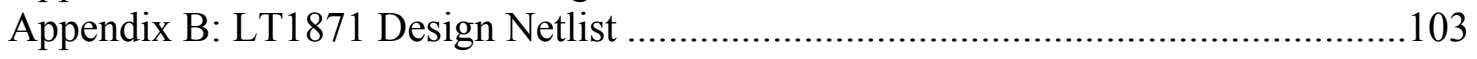

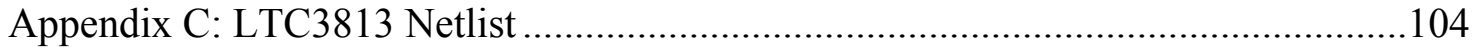

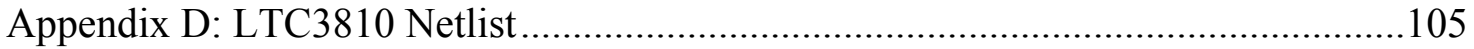

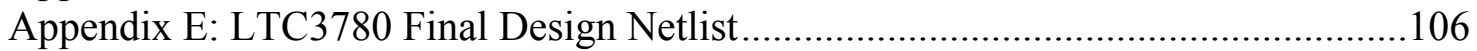

Appendix F: EE513 FSBB Controller Design Project Excerpt.................................108 


\section{LIST OF TABLES}

Table

Page

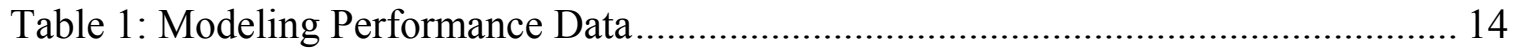

Table 2: Elliptical Machine Output Data ........................................................................ 20

Table 3: Enphase M175-24-240 Microinverter Datasheet Specifications ...................... 22

Table 4: Microinverter Efficiency and Input Resistance Data...................................... 23

Table 5: Values for Duty Cycle Calculations ............................................................ 32

Table 6: Preliminary Duty Cycle Calculations .......................................................... 32

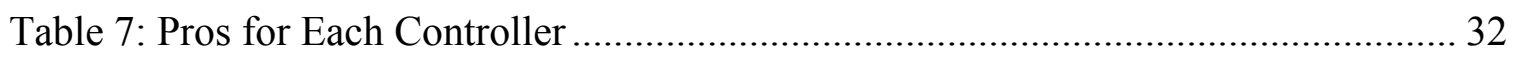

Table 8: Input Voltage and Load Current Simulation Parameters.................................... 36

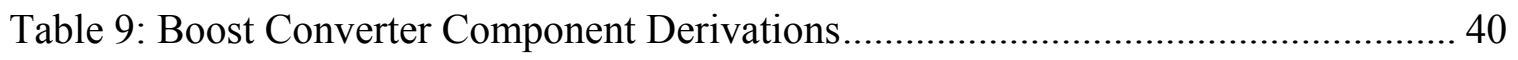

Table 10: Buck Converter Component Derivations...................................................... 41

Table 11: Simulation Parameters for Dual Converter Topology .................................... 43

Table 12: Switching Frequency Vs Frequency Set Resistor ....................................... 45

Table 13: Simulation Parameters for the Modified LTC3780 Converter ......................... 46

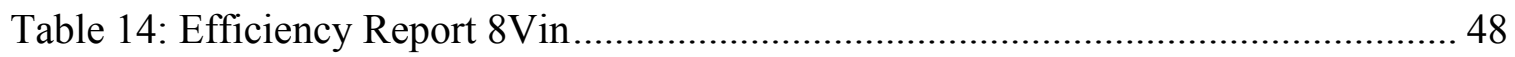

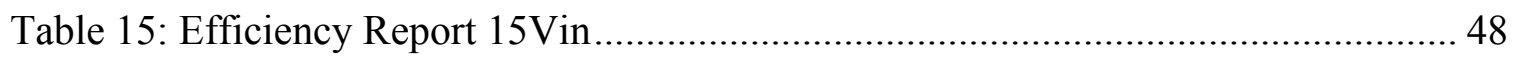

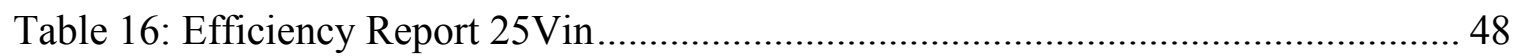

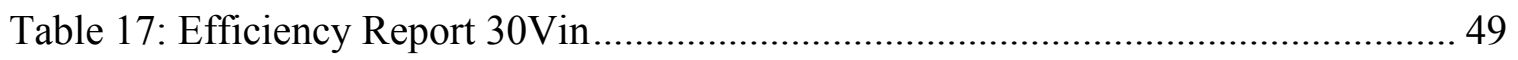

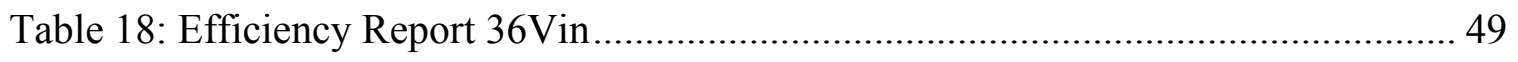

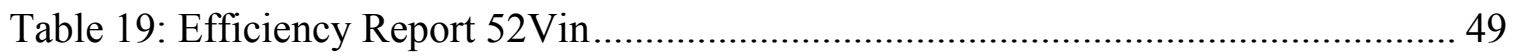

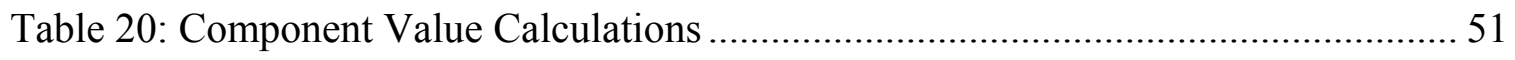

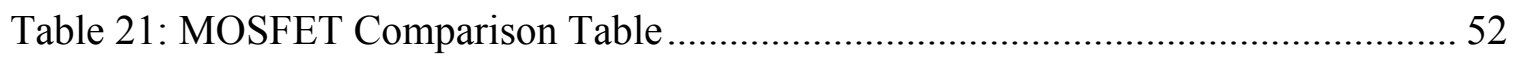

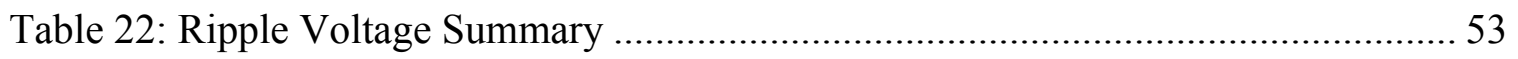

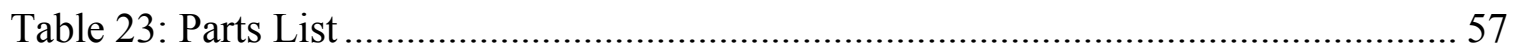

Table 24: Efficiency Data at Various Input Voltages and Power Levels .......................... 68

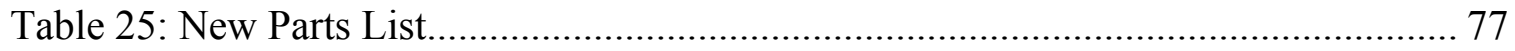

Table 26: Second Revision Testing Efficiency Data ..................................................... 79

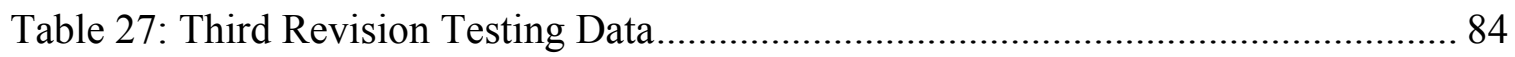

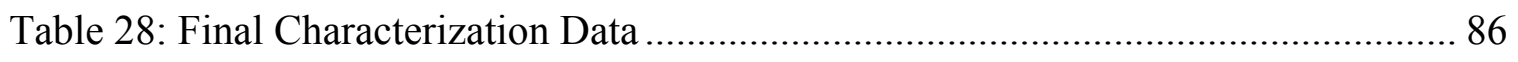




\section{LIST OF FIGURES}

Figure

Page

Figure 1: System Block Diagram.............................................................................2

Figure 2: Project Gantt Chart ................................................................................

Figure 3: Output Voltage versus Physical Resistance Level .........................................12

Figure 4: Regression Trendlines for Slope versus Strides Per Minute ............................. 13

Figure 5: Characterization Models versus Experimental Data ........................................15

Figure 6: Elliptical Machine Output Voltage - Resistance Level 5 @ 150SPM ..............17

Figure 7: Elliptical Machine Output Voltage - Resistance Level 10 @ 100SPM ............17

Figure 8: Elliptical Machine Output Voltage - Resistance Level 10 @ 120SPM .............18

Figure 9: Elliptical Machine Output Voltage - Resistance Level $10 @ 150$ SPM .............18

Figure 10: Elliptical Machine Output Voltage - Resistance Level 10 @ 180SPM ..........19

Figure 11: Elliptical Machine Output Voltage - Resistance Level 17 @ 180SPM ..........19

Figure 12: Speculated Power Electronics Architecture for Precor Elliptical Machine .....21

Figure 13: Enphase Microinverter Testing Block Diagram..........................................23

Figure 14: Input Power versus Effective Input Resistance of the Microinverter ..............24

Figure 15: Input Voltage versus Effective Input Resistance of the Microinverter ............24

Figure 16: Input Voltage versus Efficiency of the Microinverter..................................25

Figure 17: Input Power versus Efficiency of the Microinverter .....................................26

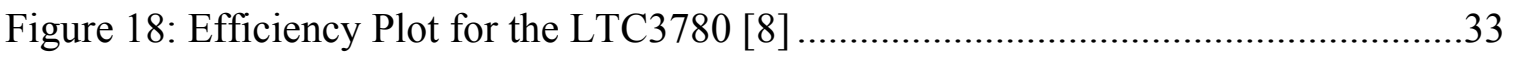

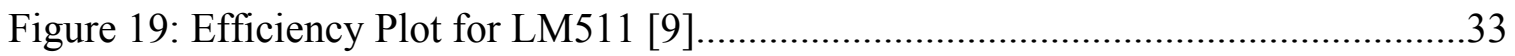

Figure 20: Linear Technology LTC3780 FSBB Design Schematic ................................34

Figure 21: Linear Technology LT1871 SEPIC Design Schematic ..................................34

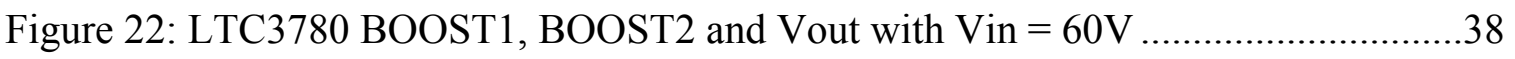

Figure 23: Linear Technology LTC3813 Boost Converter Schematic ............................42

Figure 24: Linear Technology LTC3810 Buck Converter Schematic .............................42

Figure 25: Modified LTC3780 Design for High Voltage Use........................................47

Figure 26: Steady State Voltage Ripple 8Vin ..................................................................54

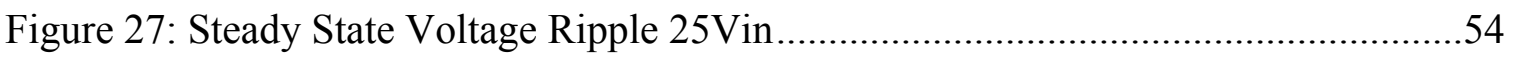

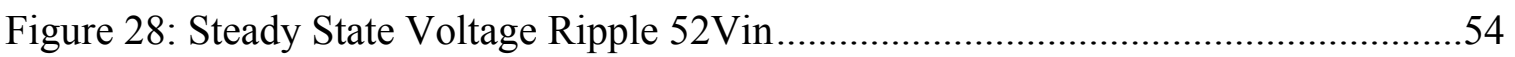

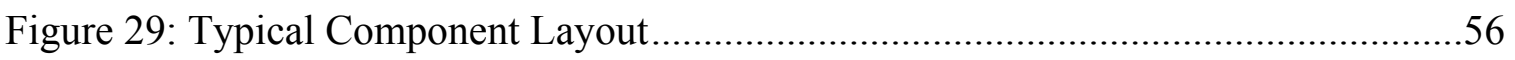

Figure 30: Current Sense Circuit Routing Example ...................................................56

Figure 31: Second Revision Converter Design............................................................58

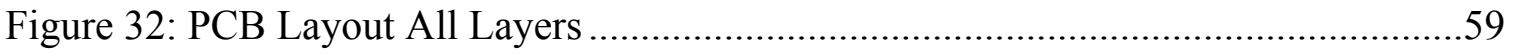

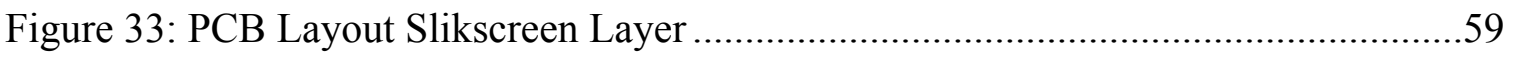

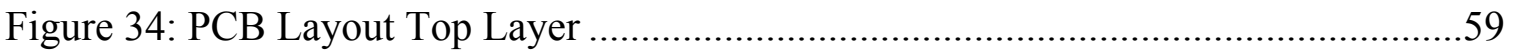

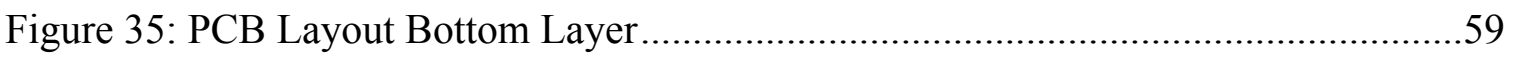

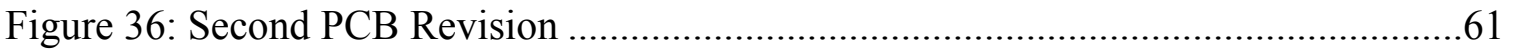

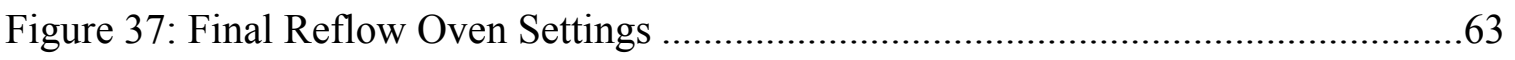

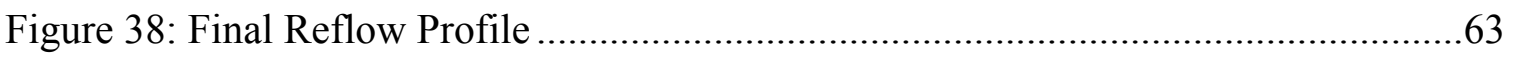




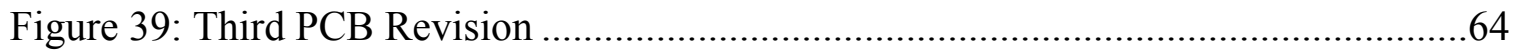

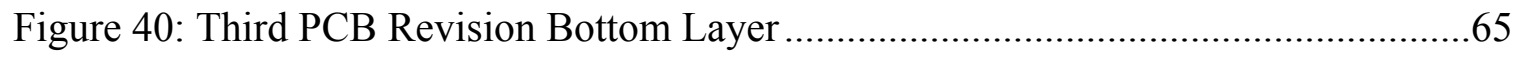

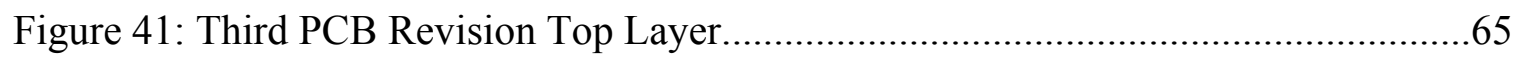

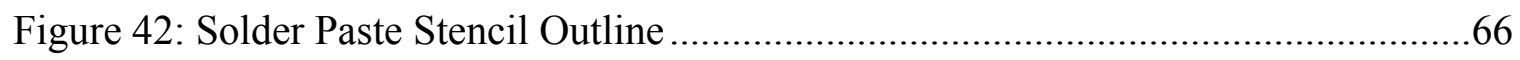

Figure 43: Converter Testing Schematic Block Diagram................................................67

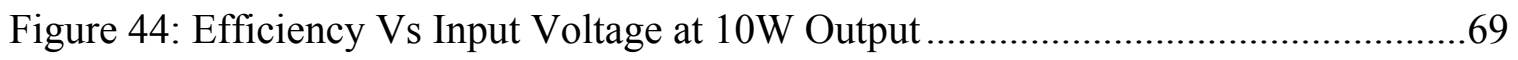

Figure 45: Efficiency Vs Output Power at $\sim 9 \Omega$ Input Impedance.....................................69

Figure 46: Startup Vout (Green) and Inductor L1 Current (Blue) Waveforms ..................71

Figure 47: Vout(Yellow) Vcc(Blue) Transients Original Design......................................72

Figure 48: Vout(Yellow) Vcc(Blue) Transients with added capacitors ..............................72

Figure 49: PCB Layout Fourth Revision ...................................................................74

Figure 50: PCB Layout Fourth Revision Top Layer ……….........................................75

Figure 51: PCB Layout Fourth Revision Bottom Layer .................................................75

Figure 52: Design with First Modifications ..................................................................

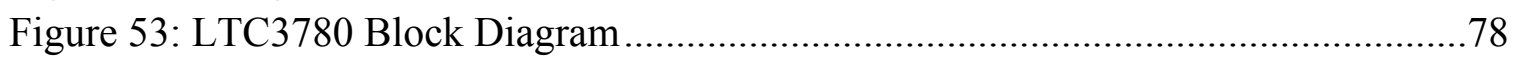

Figure 54: 2nd Rev. Efficiency Vs Input Power with Input Resistance $=10 \Omega \ldots \ldots \ldots \ldots \ldots \ldots . . .80$

Figure 55: 2nd Rev. Output Voltage Vs Input Power with Input Resistance $=10 \Omega \ldots \ldots \ldots . .80$

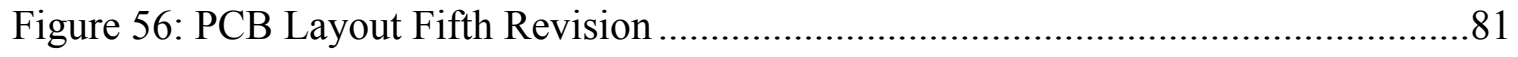

Figure 57: PCB Layout Fifth Revision Top Layer ......................................................8

Figure 58: PCB Layout Fifth Revision Bottom Layer....................................................82

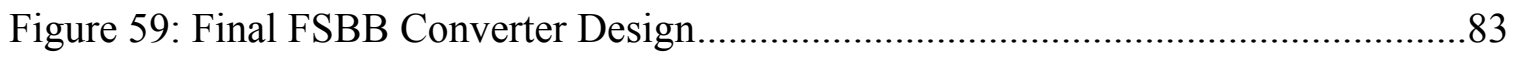

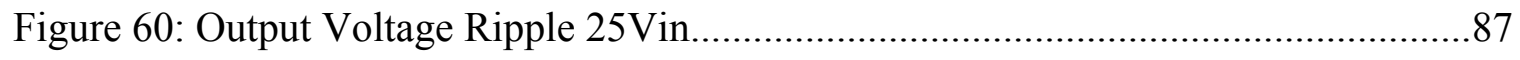

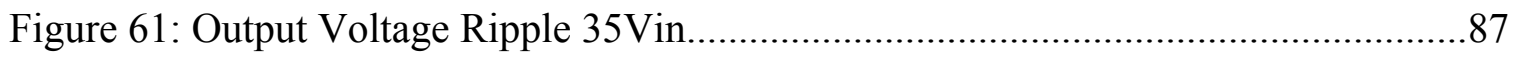

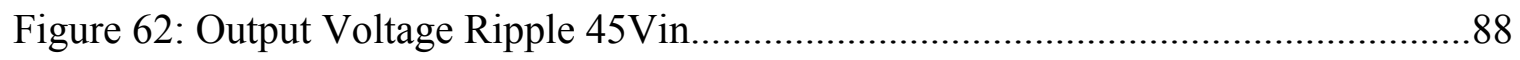

Figure 63: First Proposed Architecture ...................................................................90

Figure 64: Second Proposed Architecture ………………........................................90

Figure 65: Third Proposed Architecture …………………............................................ 


\section{CHAPTER 1: INTRODUCTION}

\subsection{Introduction}

This DC-DC converter project aims for functionality, power delivery optimization, and safety standard compliance. The Cal Poly REC Center's current renovation provides an opportunity for the Energy Harvesting from Exercise Machines Project, EHFEM for short, as shown in the Figure 1 block diagram area of focus. The DC-DC converter stabilizes the output voltage of the Precor elliptical machine for direct input into the Enphase Microinverter. In previous projects, the converters did not fully meet the demanding design specifications required by the application to fully extract the energy from the elliptical machine. This thesis discusses various topologies and their suitability for this application. My research shows that the Four-Switch Buck-Boost (FSBB) topology best suits the current system, but some companies have already implemented their own solution. 


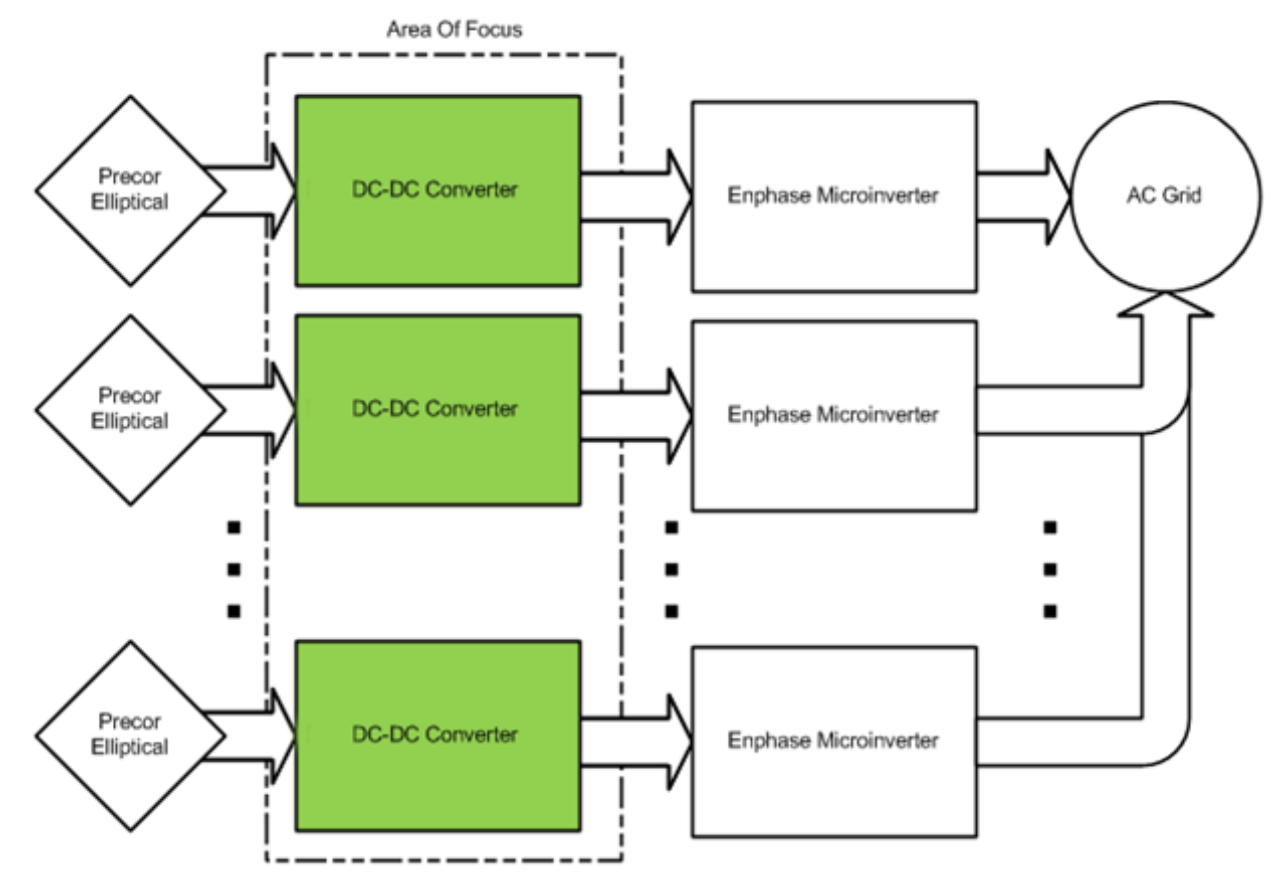

Figure 1: System Block Diagram

\subsection{State-of-the-Art}

Currently, a few companies provide energy harvesting solutions for exercise machines, such as ReSource Fitness, ReRev, and The Green Revolution. ReSource Fitness and The Green Revolution manufacture stationary spin bicycles to harvest energy. ReRev offers a different EHFEM solution. They retrofit old machines to harvest energy to feed it back into the grid. Their main focus lies with the Precor's elliptical trainers. According to ReRev's website, about 28 university recreational centers implement their system for energy harvesting [1].

The Precor elliptical machine provides physical resistance for the user using a permanent magnet synchronous generator. The generator outputs six phases, which it later rectifies into a $\mathrm{DC}$ voltage. A resistor then takes the $\mathrm{DC}$ voltage and dissipates it as heat. 
Cal Poly's first attempts to harvest energy included purchasing off-the-shelf DCDC converters and an Enphase Microinverter. The project group managed to harvest energy with $40 \%$ efficiency for lower power levels, but their system failed to provide any power generation at higher power levels. Thus, the project necessitates an application specific DC-DC converter design.

\subsection{Thesis Statement}

This report provides research, analysis, and experimentation results to defend the following thesis statement.

The Four-Switch Buck-Boost topology efficiently and effectively harvests energy from the Precor elliptical machine as a constant input impedance and wide input voltage regulator for a constant voltage grid-tie inverter.

\subsection{Design Goals}

The following design requirements and specifications for the proposed DC-DC converter derive from safety, economic, sustainability, and system interfacing considerations.

\subsubsection{Design Requirements}

- Conform to all safety requirements outlined in UL 1741

- Conform to IEEE code 1547

- Maintain the exercise machine's overall experience

- Cost less and/or recover initial investment faster than current system

- Meet and/or exceed the current system's life expectancy 


\subsubsection{Unambiguous and Verifiable Project Specifications}

- $\quad$ DC Input $=5-52 \mathrm{~V}$

- $\quad$ Maximum Input current $=5 \mathrm{~A}$

- $\quad$ Maximum Output current $=7.5 \mathrm{~A}$

- $\quad$ Nominal Output Voltage $=36 \mathrm{~V}$

- $\quad$ Maximum Output Power $=275 \mathrm{~W}$

- Full Load Efficiency $\geq 90 \%$

- Efficiency at System Typical Power Levels $\geq 90 \%$

- $\quad$ Output Voltage Ripple $\leq 5 \%$

- Fit within the confines of the elliptical machine 


\subsection{Timeline of Tasks and Milestones}

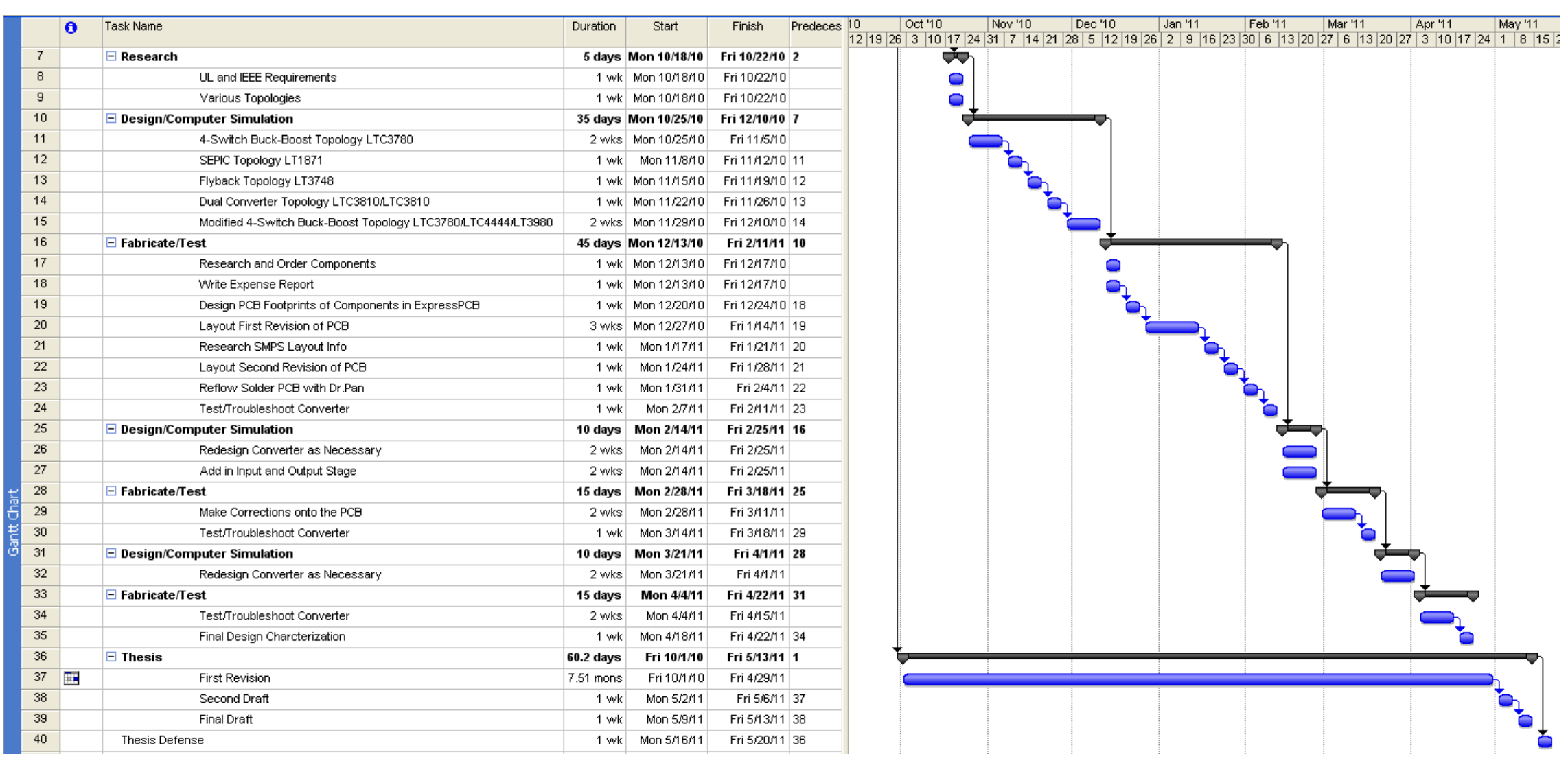

Figure 2: Project Gantt Chart 


\subsection{ABET Senior Project Analysis}

\subsubsection{Economic}

The economic impacts of this project include potential money savings for both consumers and utility companies. Consumers who generate their own power will start saving money after the recovery period for the primary sunk investment passes. By generating electricity at the point of use, consumers and utility companies can save on the power lost as heat in long electrical transmission lines. Furthermore, avoiding HVAC cooling for the heat dissipating resistor and reducing greenhouse gas emissions will contribute to savings. Also, business opportunities will arise to utilize this new technology. Gyms incorporating these machines may earn money through means other than membership fees.

As outlined in Dr. Braun's EHFEM proposal, deploying these synchronous power exercise machines in 3,000 fitness centers conservatively generate 7.2GWh of electricity per year, and on a national scale, 51.2GWh [2]. These numbers derive from a conservative estimation of a $100 \mathrm{~W}$ workout, with $90 \%$ inverter efficiency, DC-DC converter efficiency of $80 \%, 0.5 \%$ efficiency degradation, and 12 hours of machine use per day for 41 weeks out of a year [2]. Electricity costs 11.9 cents/kWh for the first year, and then the costs increase 3\% annually [2]. Avoided HVAC cooling saves \$7/MMBTU, 2.4 cent $/ \mathrm{kWh}$, and avoided greenhouse gas emissions save $\$ 40.2 /$ ton $\mathrm{CO} 2,2.8$ cents $/ \mathrm{kWh}$ [2]. Along with these parameters achieving a zero lifecycle cost, the added cost to modifying the machine for synchronous power generation must lie under $\$ 360$ [2]. By achieving a DC-DC converter with $94 \%$ efficiency, this value raises to $\$ 425$. 


\subsubsection{Environmental}

The use and growth of energy harvesting from exercise machines could relieve some of the dependence on non-renewable energy sources such as petroleum, steam, nuclear, and coal. Some of the processes used to extract energy from these sources produce negative byproducts such as chemical, air, and thermal pollution. Although diverting some power generation to a renewable source such as the EHFEM project will reduce pollution from power generation, the processes used to manufacture the parts and components for the electronics and plastics to harvest the energy still produce pollutants.

\subsubsection{Sustainability}

Sustainability arises often today with our planet's diminishing natural resources and ever expanding population. This in turn promotes the innovation of technology with a focus on renewability and efficiency. In normal unaltered operation, the Precor elliptical machine dissipates energy in resistive coils as heat to provide physical resistance for the user. Harvesting this energy and feeding it back into the AC grid provides a pseudodistributed power generation infrastructure. This type of infrastructure saves the electricity utility companies from the loss of power as heat through long transmission lines, thereby making power delivery more efficient. Lastly, replacing the heat dissipating resistors decreases the HVAC cooling load.

\subsubsection{Manufacturability}

By design, the new electronics for energy harvesting utilizes generic printed circuit board fabrication and component placement as used in other PCBs inside the Precor elliptical machine. These PCBs allow for quick duplication via solder reflow ovens. Interconnections between the machines, microinverters, and the $\mathrm{AC}$ grid prompt a 
safe and easy scheme. Manufacturing new machines with the new hardware, or retrofitting machines to accommodate the new hardware, represent viable options. Retrofitting requires a professional and certified touch to ensure proper installation and safety, as well as an additional fee for labor costs.

Using this modular approach for interconnecting each exercise machine, the project becomes easily scalable, as opposed to having a minimum and maximum number of machines per centralized inverter. This also minimizes the cost of construction for accommodating the larger and more hazardous infrastructure of a high voltage centralized inverter design.

\subsubsection{Ethical}

The ethical concerns mainly lie with energy harvesting from a human being and the concept of lowering overall power consumption. Harvesting energy from a human brings the question of ownership. Who gets to claim the energy harvested? The owner of the equipment or the user? Ownership eventually translates to a monetary value in this case. In an ethical egoism point of view, this adds incentive for working out more, but then again the fitness center owner provides the equipment for harvesting energy originally lost as heat. In an altruistic and eudemonia sense, the user experiences selfgratification from generating usable energy for the greater good.

In designing this product, engineering ethics plays a role in the allowable tolerance for safety. One must ensure that the product not only meets but also exceeds safety measure to account for unexpected factors. Another issue involves the breakeven point on one's electricity bill. The utility companies do not refund or rollover credit for 
the extra power generated. In other words, the utility companies do not pay for the surplus power from the labor.

\subsubsection{Health and Safety Issues}

In order to safely harvest energy from the exercise machines, the modifications need to implement necessary precautions and comply with industry safety standards. The strictly electrical, in other words non kinetic, modifications require sufficient insulation from the user directly and indirectly through any conduction path. Such precautions include insulation, properly sized and rated components, non-obstructive placement, and built-in fault protection circuitry. Unlike other forms of power generation, EHFEM uses the kinetic energy from humans that also burns calories and gives a cardiovascular workout.

\subsubsection{Social and Political}

In today's society, health and environmental awareness lack popularity. With the added incentive of power generation for cost savings, a shift may occur to promote healthy and environmentally friendly practices. This shift can produce a subculture of environmental and health minded groups devoted to the cause that can have a broader reach than ever before. Many power generation projects, such as off shore windmills, do not bode too well with local residents due to unsightliness and other small factors, but the footprint of energy harvesting machines will essentially replace the footprint of old model exercise machines. It seems the public will most likely accept this form of power generation more readily than others.

In politics, especially in California, a large portion of the budget falls into the promotion of renewable practices and power generation. Businesses choosing to employ 
this technology may receive incentives if a push for such "green" practices becomes large enough. To draw from the ethical considerations, a proposed bill may solve the controversy regarding compensation or lack thereof for surplus power generation. 


\section{CHAPTER 2: CHARACTERIZATION OF CURRENT SYSTEM}

\subsection{Introduction}

This chapter provides characterization models for the various parts of the system. Interfacing the converter to these components together through understanding of the system requires an accurate model. For microinverter testing, the output connects to a 240VAC source while the input connects to a 190W DC power supply. Testing the elliptical machine requires a digital multimeter and oscilloscope connected across the onboard resistive load.

\subsection{Precor Elliptical Machine}

Figure 3 models the Precor elliptical machine through the use of previous data collected by colleagues who previously worked on the EFHEM Project [3]. The data shows the positive correlation between the rectified and filtered average output voltage of the machine to a $10 \Omega$ resistor, physical resistance level of the machine, and the user's strides per minute (SPM). 


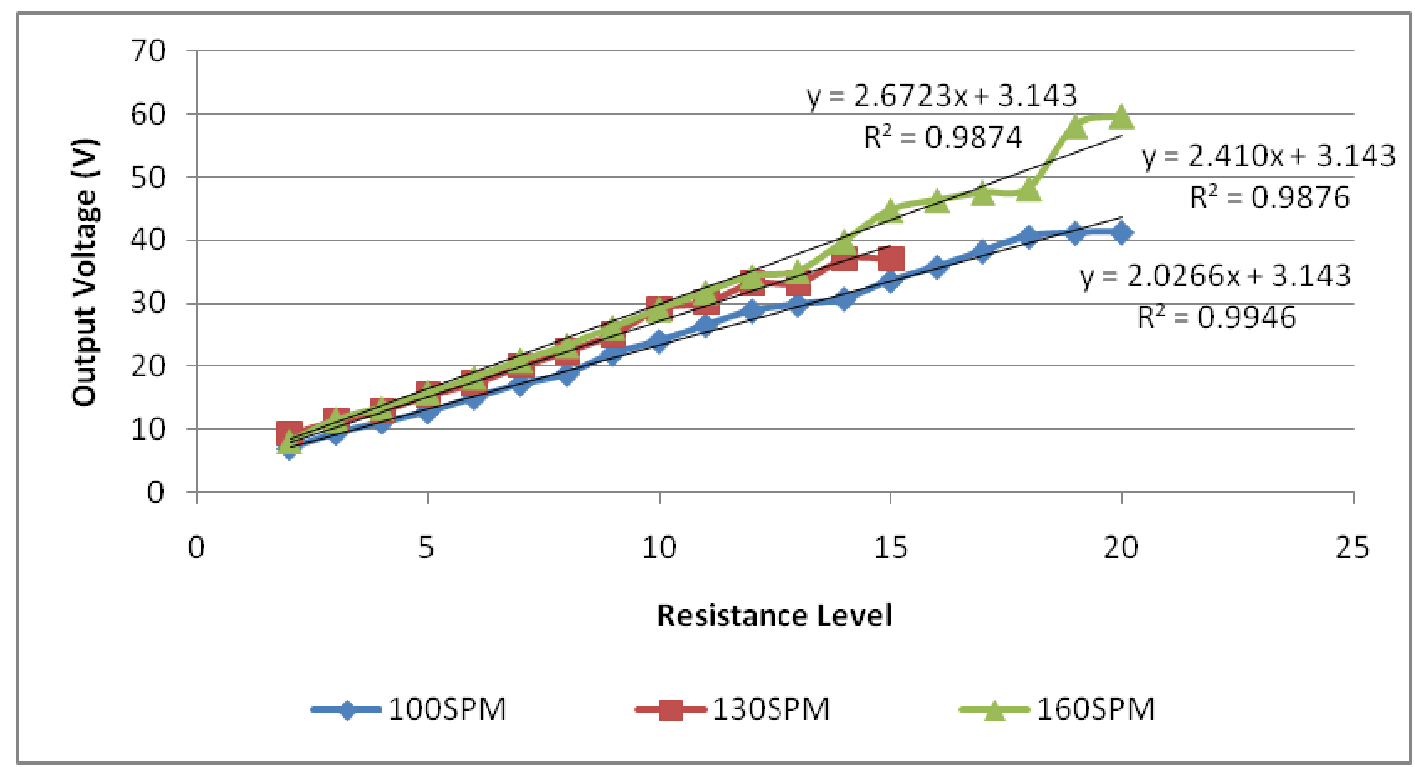

Figure 3: Output Voltage versus Physical Resistance Level

Using the preliminary trendlines derived by Microsoft Excel's linear regression function, I averaged output voltages at the theoretical " 0 " physical resistance level, otherwise known as the y-intercept, of each data set and set that average voltage of 3.143V to the $\mathrm{y}$-intercept for all the trendlines. This provides a characteristic equation of output voltage given physical resistance level in the format of $y=m x+b$, where $y, m, x$, and b correspond to output voltage, slope, physical resistance level, and output voltage at the " 0 " physical resistance level. The slope, $\mathrm{m}$, expresses a function of strides per minute. 


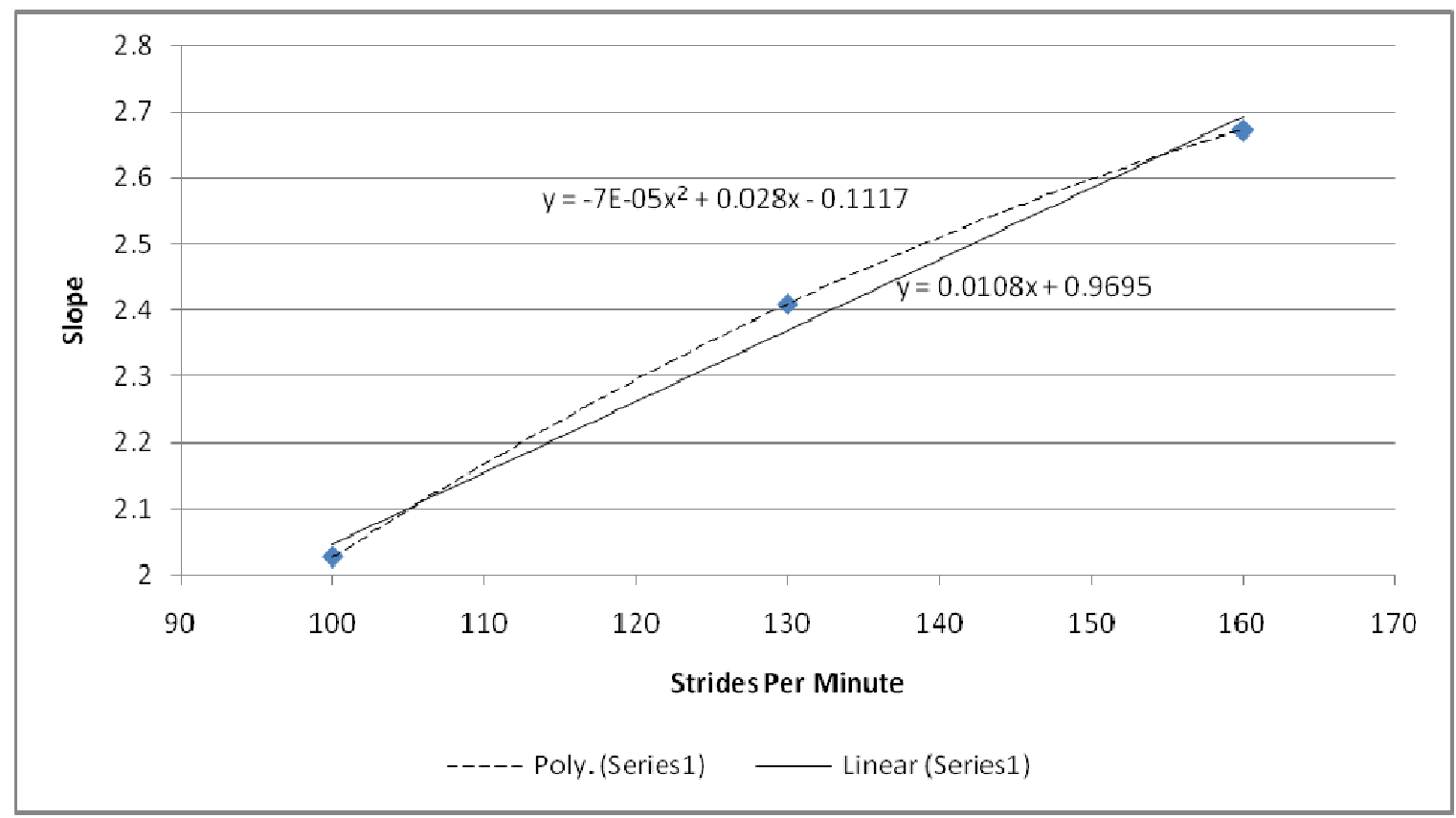

Figure 4: Regression Trendlines for Slope versus Strides Per Minute

The slopes versus their strides per minute speed from Figure 3 create a relationship shown in Figure 4. Regression analysis can model this relationship into a linear or polynomial equation. By comparing the data for the actual output voltage and theoretical output voltage derived from a linear and quadratic regression, a two-variable equation of strides per minute (SPM) and physical resistance level can closely model the Precor elliptical machine. Equation 1 and Equation 2 model the elliptical machine via two different forms of regression:

Equation 1: Quadratic Regression Derived Model Equation

Output Voltage $[V]$

$$
=\left(-7 * 10^{-5} *(S P M)^{2}+0.028 * S P M-0.117\right) * \text { Resistance Level }+3.143
$$

Equation 2: Linear Regression Derived Model Equation

$$
\text { Output Voltage }[V]=(0.0108 * S P M+.9695) * \text { Resistance Level }+3.143
$$


Table 1: Modeling Performance Data

\begin{tabular}{|c|c|c|c|c|c|c|}
\hline \multirow{2}{*}{$\begin{array}{c}\text { Ellitpical } \\
\text { Resistance } \\
\text { Level Setting }\end{array}$} & \multirow{2}{*}{$\begin{array}{c}\text { Strides Per } \\
\text { Minute }\end{array}$} & \multirow[b]{2}{*}{ Vo $\operatorname{Exp}[\mathrm{V}]$} & \multicolumn{2}{|c|}{ Quadratic } & \multicolumn{2}{|c|}{ Linear } \\
\hline & & & Vo Theo [V] & $\%$ Error & Vo Theo [V] & $\%$ Error \\
\hline 1 & 188 & 0.04 & 5.82 & N/A & 6.14 & $\mathrm{~N} / \mathrm{A}$ \\
\hline 2 & 166 & 9.87 & 8.35 & $15.43 \%$ & 8.67 & $12.18 \%$ \\
\hline 3 & 158 & 12.76 & 10.82 & $15.19 \%$ & 11.17 & $12.46 \%$ \\
\hline 4 & 170 & 15.29 & 13.62 & $10.90 \%$ & 14.37 & $6.05 \%$ \\
\hline 5 & 148 & 16.29 & 15.61 & $4.16 \%$ & 15.98 & $1.89 \%$ \\
\hline 6 & 162 & 20.45 & 18.63 & $8.88 \%$ & 19.46 & $4.85 \%$ \\
\hline 7 & 150 & 22.54 & 20.70 & $8.17 \%$ & 21.27 & $5.64 \%$ \\
\hline 8 & 174 & 26.5 & 24.23 & $8.57 \%$ & 25.93 & $2.14 \%$ \\
\hline 9 & 164 & 29.26 & 26.47 & $9.52 \%$ & 27.81 & $4.96 \%$ \\
\hline 10 & 158 & 30.75 & 28.74 & $6.54 \%$ & 29.90 & $2.76 \%$ \\
\hline 11 & 172 & 35.63 & 32.05 & $10.04 \%$ & 34.24 & $3.90 \%$ \\
\hline 12 & 162 & 37.3 & 34.13 & $8.51 \%$ & 35.77 & $4.10 \%$ \\
\hline 13 & 160 & 40.01 & 36.57 & $8.61 \%$ & 38.21 & $4.50 \%$ \\
\hline 14 & 115 & 37.48 & 33.62 & $10.29 \%$ & 34.10 & $9.01 \%$ \\
\hline 15 & 104 & 37.16 & 33.71 & $9.28 \%$ & 34.53 & $7.07 \%$ \\
\hline 16 & 98 & 33.98 & 34.42 & $1.29 \%$ & 35.59 & $4.74 \%$ \\
\hline 17 & 100 & 36.9 & 36.85 & $0.12 \%$ & 37.98 & $2.94 \%$ \\
\hline 18 & 80 & 29.22 & 33.29 & $13.94 \%$ & 36.15 & $23.70 \%$ \\
\hline 19 & 94 & 34.9 & 39.18 & $12.25 \%$ & 40.85 & $17.06 \%$ \\
\hline 20 & 100 & 42.84 & 42.80 & $0.09 \%$ & 44.13 & $3.02 \%$ \\
\hline & & & Average & $8.52 \%$ & Average & $7.00 \%$ \\
\hline
\end{tabular}




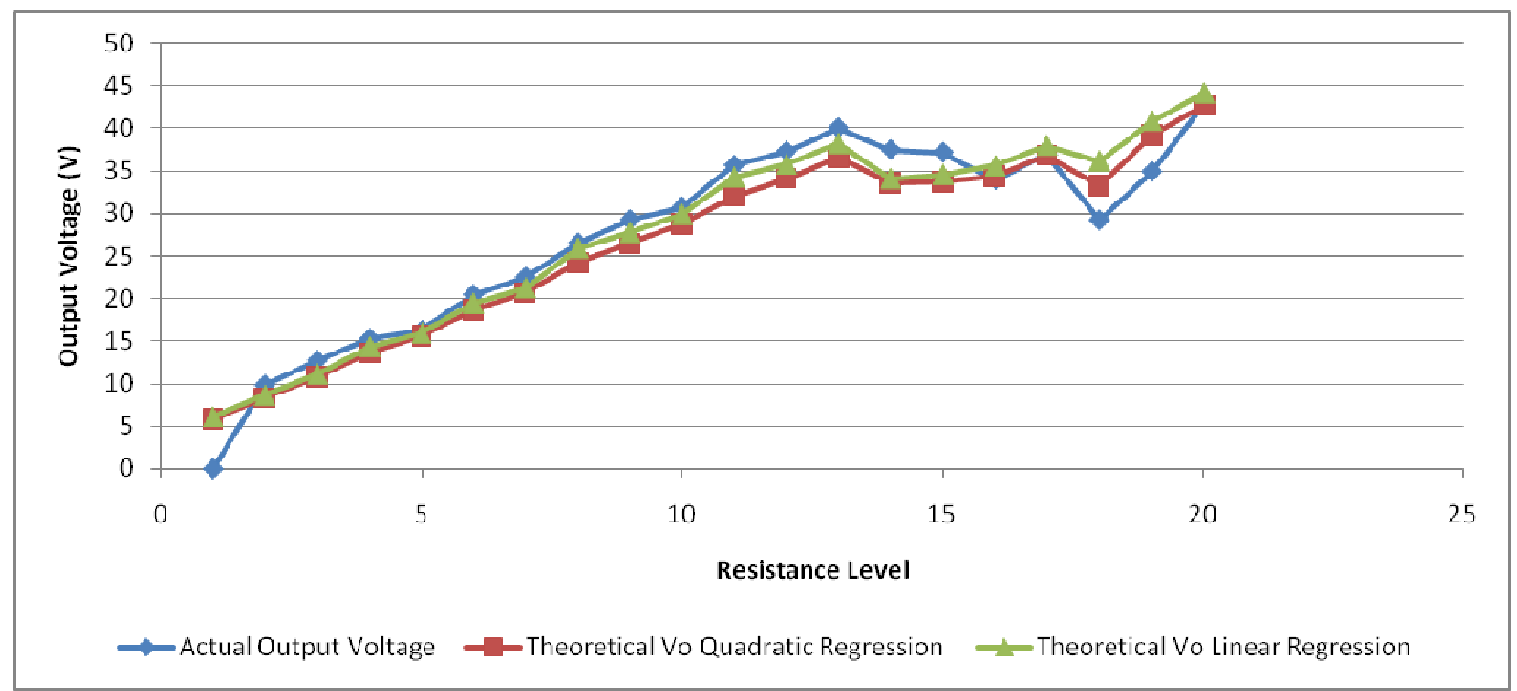

Figure 5: Characterization Models versus Experimental Data

Figure 5 and Table 1 illustrates the performance of the two model equations compared to a sample experimental data set. Overall, the linear regression method model, with an average percent error of roughly $7 \%$, tracks the actual output voltage better than the quadratic model at an average percent error of $8.5 \%$.

According to a survey taken by a previous group of EHFEM Project students, Jonathan Chan, Chris Cinkornpumin, Michelle Lum, and Jonathan Yuen, typical physical resistance level settings vary from five to ten with typical strides per minute speeds between 140 and 180 [3]. This translates to a power range of $60-100 \mathrm{~W}$. These typical values serve as criteria to choose an appropriate equation to model the elliptical machine. As shown in Table 1 at resistance levels five through ten, the percent error using the linear regression method outperforms the quadratic method indefinitely with an average of $3.7 \%$ as opposed to $7.64 \%$. In higher physical resistance levels above seventeen, the quadratic method proves more adequate than the linear model, but proves irrelevant considering the typical usage of the machine. Thus, the linear regression method 
equation models the Precor elliptical machine output voltage for future reference. In addition, the output current equation equals the output voltage equation divided by $10 \Omega$. Hooking up the elliptical machine to an electronic load at different resistance levels varied the user experience. Any deviation from $10 \Omega$ leads to a decreased physical resistance experienced by the user.

Further system testing shows the elliptical machine does not output a flat DC voltage. The onboard power electronics unit denotes the generator as a six phase synchronous generator. Most likely, the power electronics unit rectifies these six phases from the stator into a DC voltage then dumps it into the $10 \Omega$ resistor. As speculated by Professor Dolan, the changes in physical resistance felt by the user through the use of the 'resistance level' buttons derives from changing the firing angle of the controlled rectifier. This allows for more current/power transfer into the $10 \Omega$ resistor. Typical outputs appear as in the following waveforms captured via the HP 54645A Oscilloscope. 


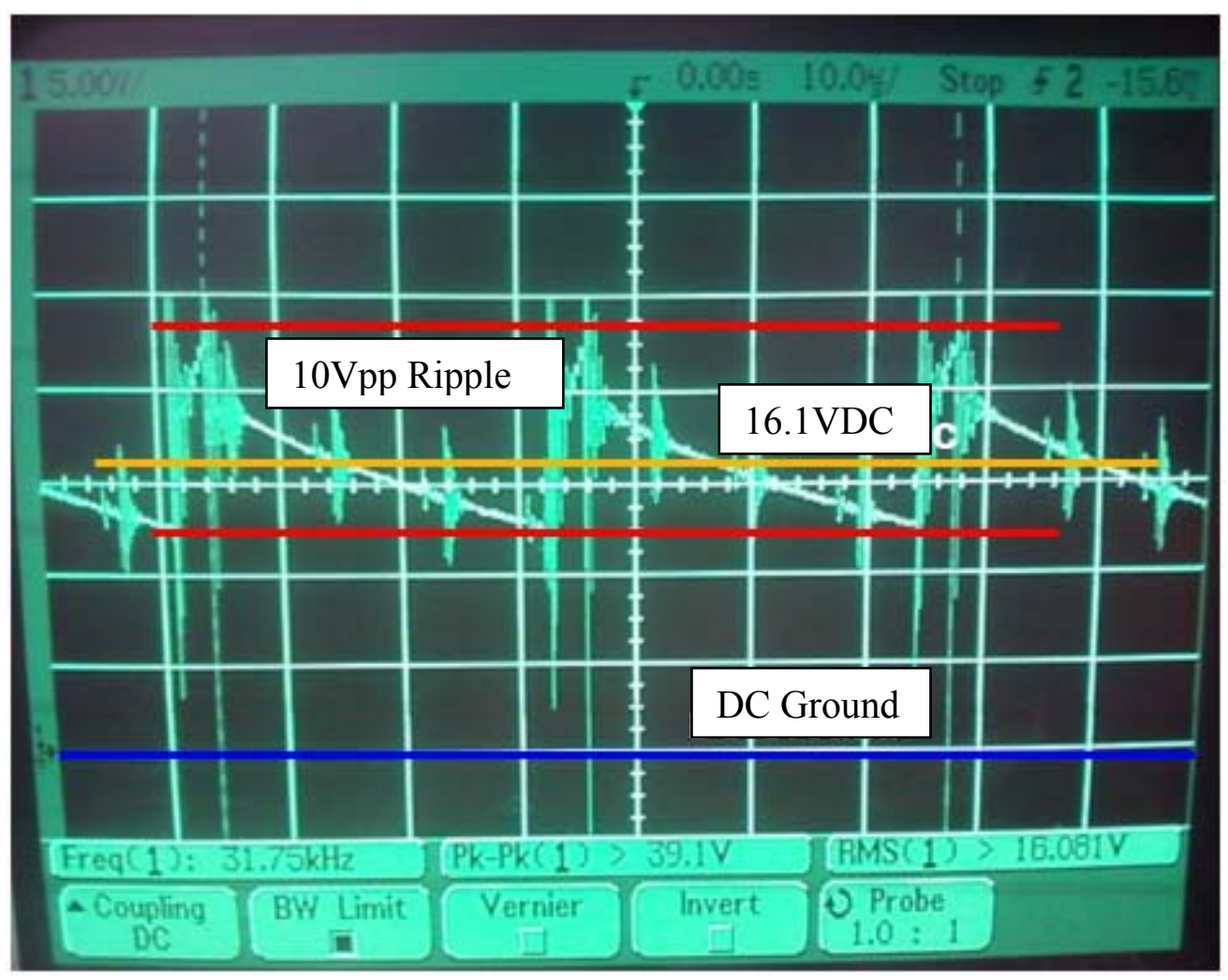

Figure 6: Elliptical Machine Output Voltage - Resistance Level 5 @ 150SPM

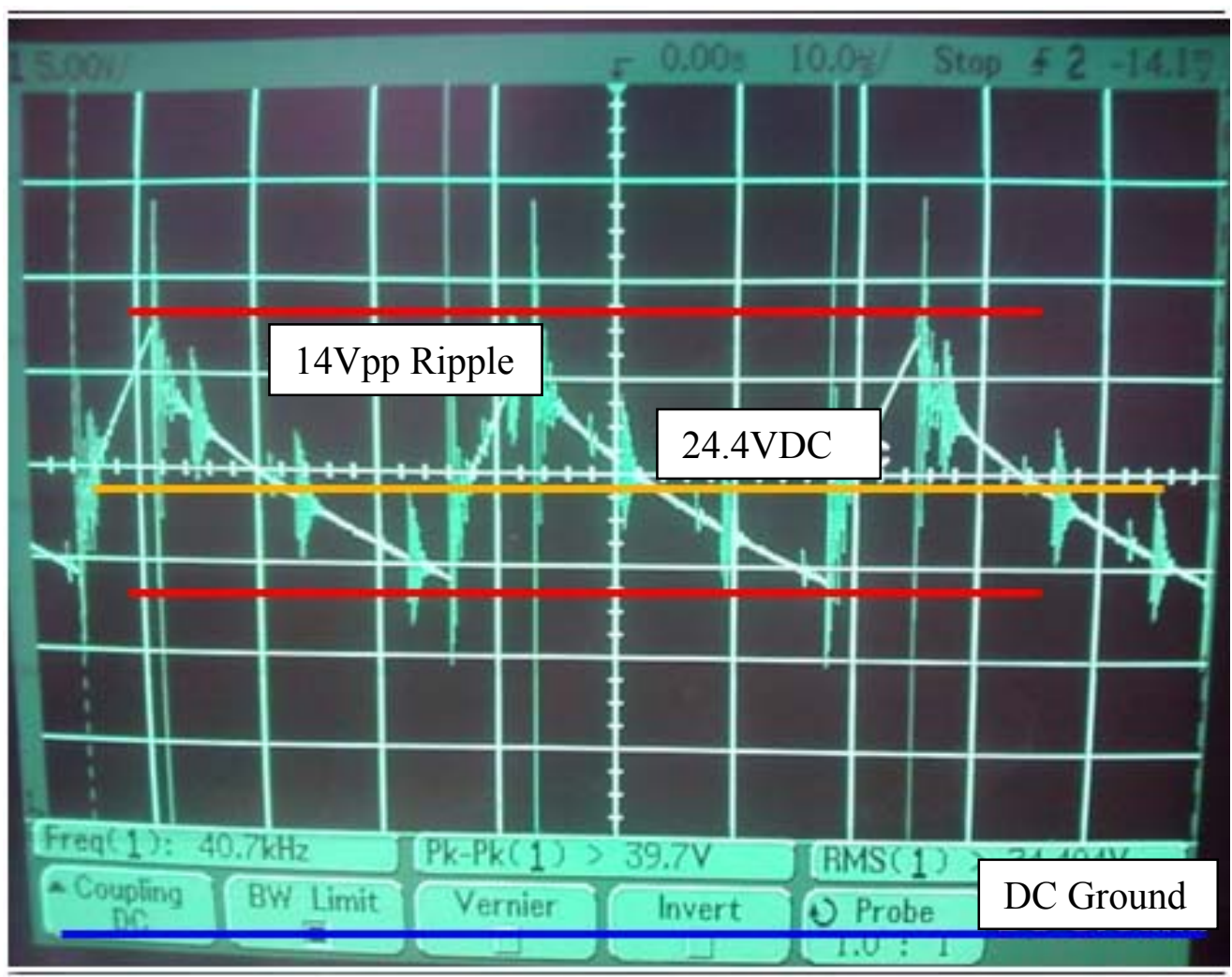

Figure 7: Elliptical Machine Output Voltage - Resistance Level $10 @ 100$ SPM 


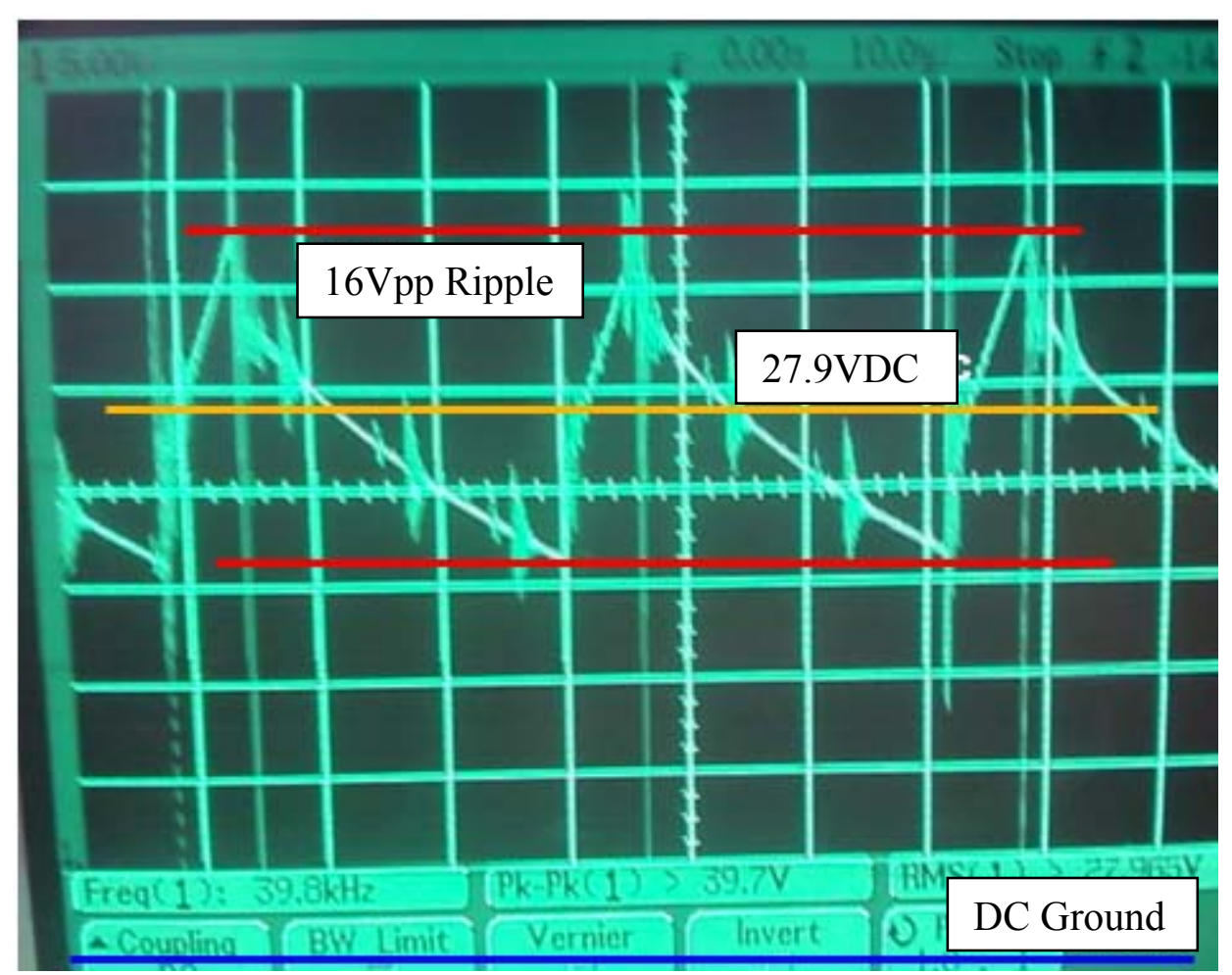

Figure 8: Elliptical Machine Output Voltage - Resistance Level $10 @ 120$ SPM

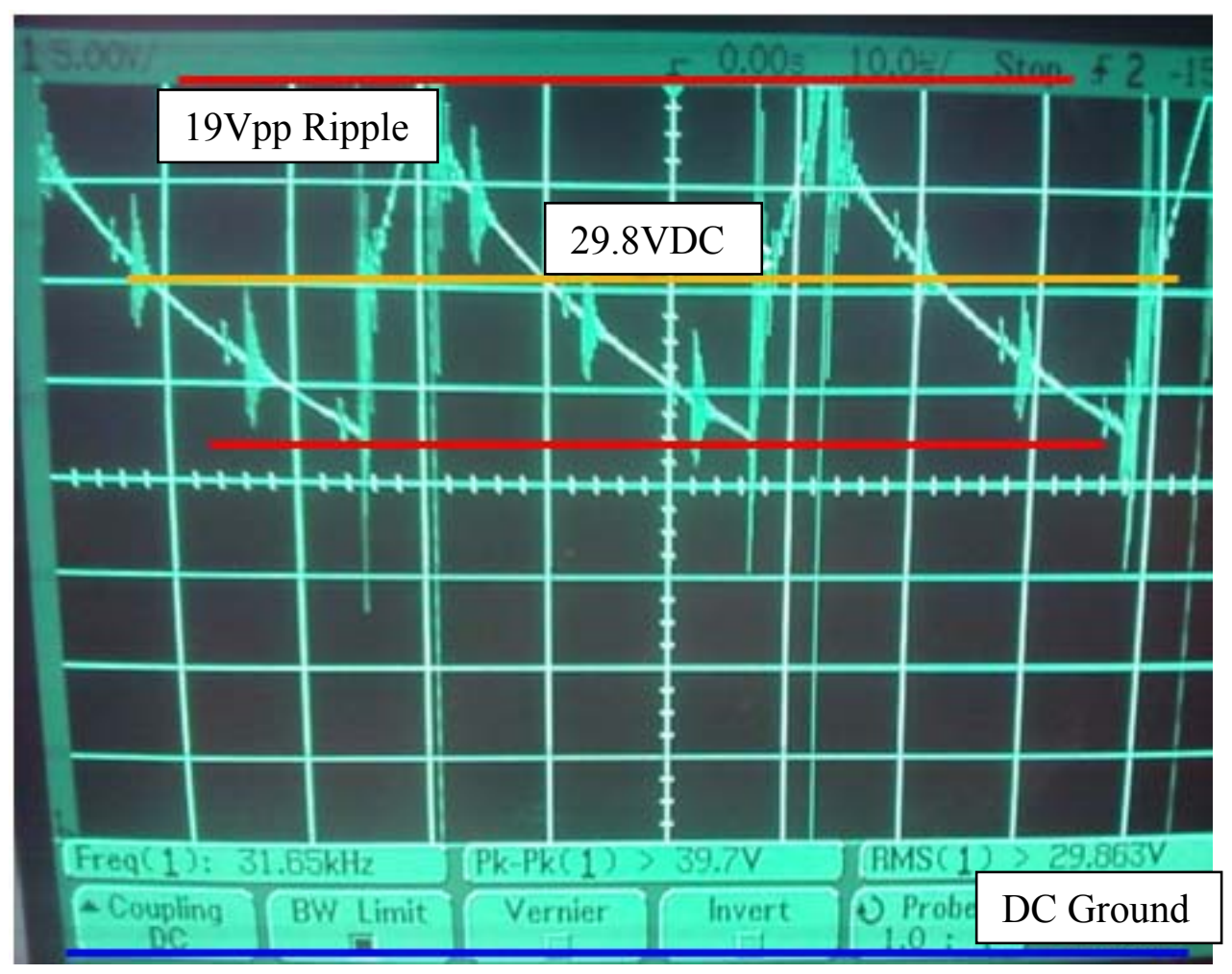

Figure 9: Elliptical Machine Output Voltage - Resistance Level $10 @ 150$ SPM 


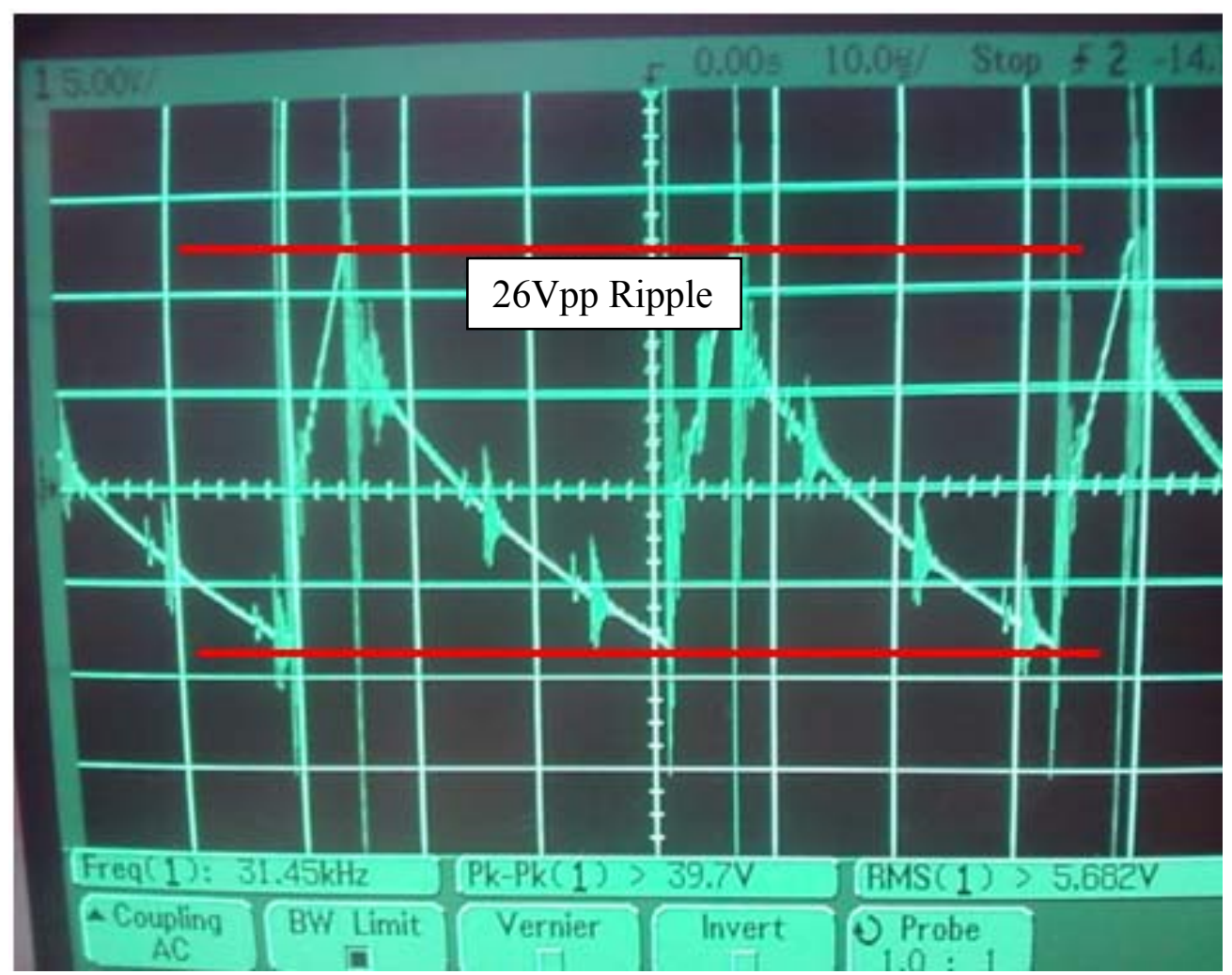

Figure 10: Elliptical Machine Output Voltage - Resistance Level $10 @ 180$ SPM AC Coupled

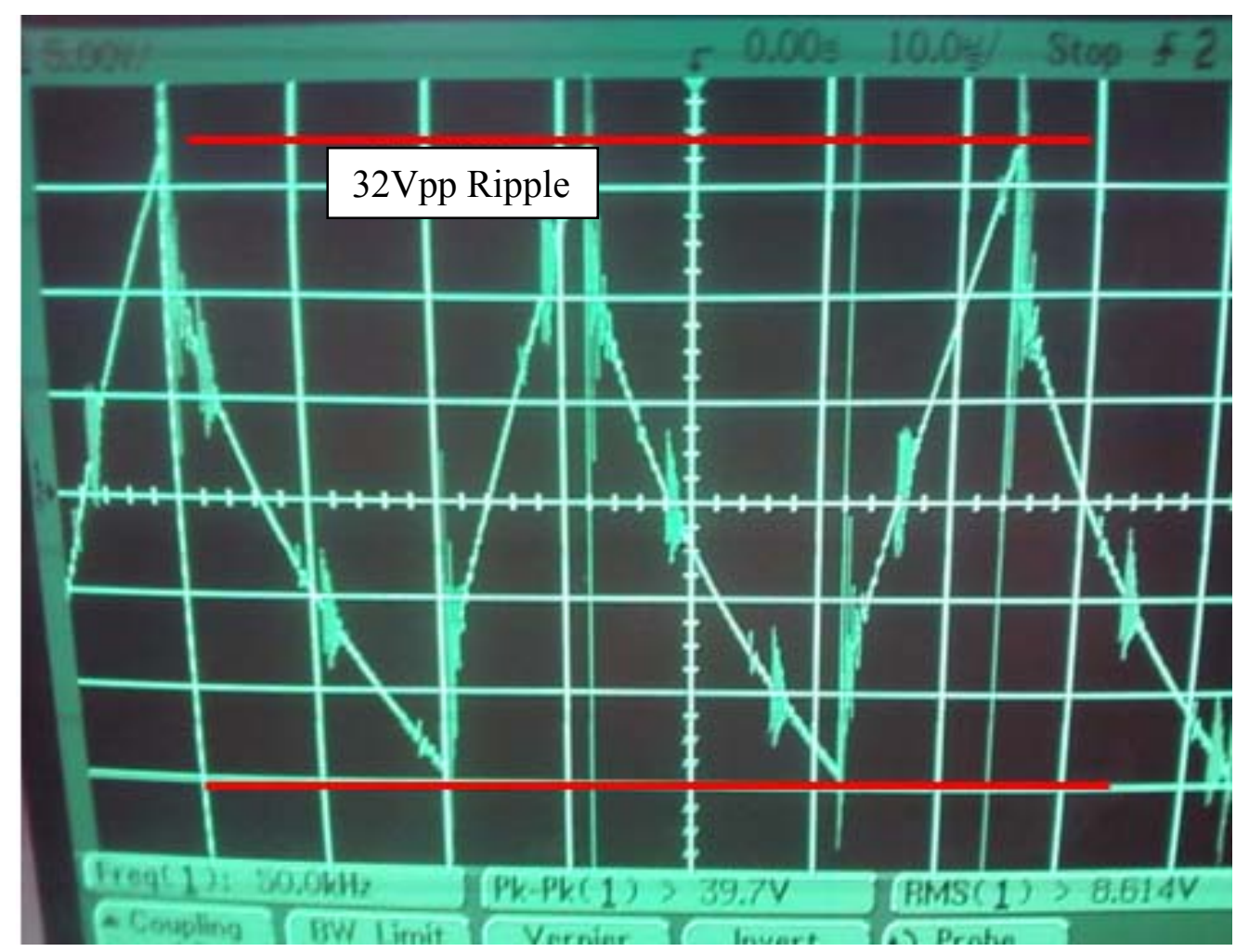

Figure 11: Elliptical Machine Output Voltage - Resistance Level 17 @ 180SPM AC Coupled 
Table 2: Elliptical Machine Output Data

\begin{tabular}{|c|c|c|c|c|c|}
\hline Resistance Level & SPM & $\mathbf{f}[\mathbf{k H z}]$ & Vrms [V] & Vpp [V] & Figure \# \\
\hline 2 & 150 & 31.85 & 9.1 & 5 & - \\
\hline 5 & 150 & 31.75 & 16.1 & 10 & 6 \\
\hline 10 & 100 & 40.7 & 24.4 & 14 & 7 \\
\hline 10 & 120 & 39.81 & 27.9 & 16 & 8 \\
\hline 10 & 150 & 31.65 & 29.8 & 19 & 9 \\
\hline 10 & 180 & 31.45 & 32.6 & 26 & 10 \\
\hline 15 & 150 & 31.3 & 40.7 & - & - \\
\hline 17 & 180 & 32.3 & - & 32 & 11 \\
\hline
\end{tabular}

From Table 2 and the previous figures, the elliptical machine outputs a sawtooth waveform with a DC offset. The peak to peak ripple voltage grows proportionally with respect to resistance level and strides per minute, with peak to peak voltages above $30 \mathrm{~V}$. A large input stage capacitor can addresses the large voltage ripple. Also, the elliptical machine outputs a near 40kHz signal at lower speeds at the order of 100-120SPM, and averages $31 \mathrm{kHz}$ from speeds from $150-180$. The control system inside the onboard power electronics unit dictates the output based on parameters such as strides per minute and resistance level. It may also sense the present load and adjust for it. The typical waveform figures show the changes in the controlled rectifier firing angle. The resistance level on the elliptical machine's user terminal ultimately sets the firing angle. The firing angle increases proportionally with the resistance level. In Figure 6 the duty cycle stays at 5\%, while in Figure 11 the duty cycle maintains $50 \%$. As the resistance level increases, the time for the rising slope also increases for a given SPM. This allows the voltage to attain a higher peak voltage, thus giving the increased peak to peak ripple voltage. In addition, at a higher SPM, the induced voltage on the synchronous generator increases. This also contributes to the increase in average and peak to peak ripple voltage. At the same resistance level, the DC offset and ripple voltage proportionally increasing with the SPM. 
Figure 12 displays a possible architecture for the power electronics system. For now, these waveforms encompass the typical output of the elliptical machine to a $10 \Omega$ resistor, and will suffice until testing of the proposed converter since ultimately the microinverter dictates the load demand.

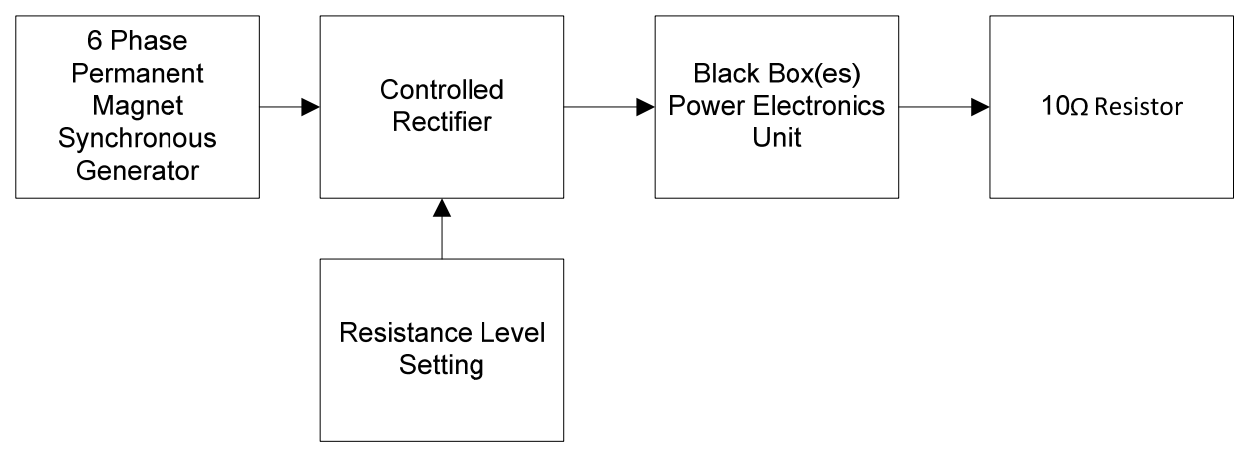

Figure 12: Speculated Power Electronics Architecture for Precor Elliptical Machine

With capacitor current equivalent to the capacitance multiplied by the derivative of voltage with respect to time, the following calculates the voltage ripple.

Equation 3: Elliptical Machine Output Voltage Ripple

$$
i_{C}=C \frac{d v_{C}}{d t}=C \frac{\Delta v_{C}}{\Delta t} \rightarrow \Delta v_{C}=\frac{i_{C} * \Delta t}{C}=\frac{i_{C}}{C * f}=\frac{5 A}{1000 \mu F * 35 k H z}=143 m V
$$

Using a maximum input current of $5 \mathrm{~A}$ based on the maximum input current design specification, input capacitance of $1000 \mu \mathrm{F}$, and a $35 \mathrm{kHz}$ frequency waveform, the voltage ripple reduces to $143 \mathrm{mV}$. This suffices for a stable input voltage. If later testing shows the application requires more filtering, the design will incorporate a larger capacitance. 


\subsection{Enphase Microinverter}

Currently the system uses the Enphase M175-24-240 microinverter. In addition to the specifications listed in Table 3, the M175 utilizes Maximum Power Point Tracking and complies with UL1741, IEEE1547, and FCC Part 15 Class B. The microinverter also requires a five minute synchronization period when first connected to the $\mathrm{AC}$ grid [3].

Table 3 displays a few specifications of the microinverter.

Table 3: Enphase M175-24-240 Microinverter Datasheet Specifications [4]

\begin{tabular}{|c|c|}
\hline \multicolumn{2}{|c|}{ Input (DC) } \\
\hline $\begin{array}{l}\text { Recommended Input } \\
\text { Power }\end{array}$ & $210 \mathrm{~W}$ \\
\hline Max. Input Voltage & $54 \mathrm{~V}$ \\
\hline Input Voltage Range & $25-40 \mathrm{~V}$ \\
\hline $\begin{array}{l}\text { Max. Short Circuit } \\
\text { Current }\end{array}$ & $10 \mathrm{~A}$ \\
\hline Max. Input Current & $8 \mathrm{~A}$ \\
\hline \multicolumn{2}{|c|}{ Output (AC) } \\
\hline Max. Output Power & $175 \mathrm{~W}$ \\
\hline $\begin{array}{l}\text { Nominal Output } \\
\text { Current }\end{array}$ & $750 \mathrm{~mA}$ \\
\hline Nominal Voltage/Range & $\begin{array}{l}240 \mathrm{~V}(211- \\
264 \mathrm{~V})\end{array}$ \\
\hline Nominal Frequency & $\begin{array}{c}60 \mathrm{~Hz}(59.3- \\
60.5 \mathrm{~Hz})\end{array}$ \\
\hline Power Factor & $>0.95$ \\
\hline Max. Units per Branch & 16 \\
\hline Peak Efficiency & $95 \%$ \\
\hline
\end{tabular}

The previously mentioned EHFEM Project group concluded that the inverter performs optimally with an input voltage of 36V [3]. Also after discussing with them regarding the method they used to test the microinverter, I realized they incorrectly tied the microinverter output to a three phase line-to-line voltage, which resulted in a voltage of $208 \mathrm{VAC}$ at $60 \mathrm{~Hz}$. With a voltage of $208 \mathrm{VAC}$, the microinverter still operated since 
this voltage lies within the extended voltage range of 206-269VAC. With this discovery, microinverter data previously taken by that group proves irrelevant. Figure 13 shows the setup for the new characterization. The two sets of crossed out efficiency data points display erroneous results.

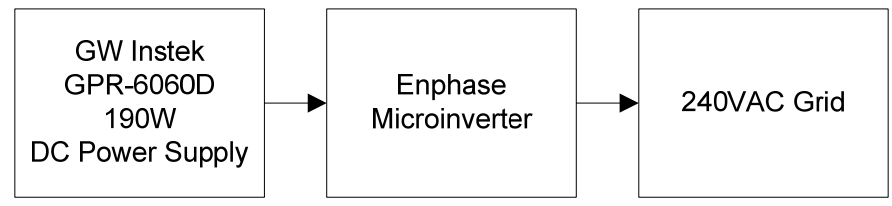

Figure 13: Enphase Microinverter Testing Block Diagram

Table 4: Microinverter Efficiency and Input Resistance Data

\begin{tabular}{|c|c|c|c|c|c|c|c|c|}
\hline & $\begin{array}{c}V_{\text {in }} \\
{\left[V_{\text {DC }}\right]}\end{array}$ & $\begin{array}{c}\mathbf{I}_{\text {in }} \\
{\left[\mathbf{A}_{\mathrm{DCC}}\right]}\end{array}$ & $\mathbf{V}_{\mathbf{0}}\left[\mathrm{V}_{\mathrm{RMS}}\right]$ & $\mathbf{I}_{\mathbf{0}}\left[\mathbf{A}_{\mathrm{RMS}}\right]$ & $\begin{array}{l}P_{\text {in }} \\
{[\mathbf{W}]}\end{array}$ & $\mathbf{P}_{\mathbf{0}}[\mathbf{W}]$ & $\begin{array}{c}\text { Efficiency } \\
{[\%\}}\end{array}$ & $\mathbf{R}_{\text {in }}[\mathbf{\Omega}]$ \\
\hline \multirow{10}{*}{ 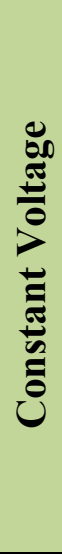 } & 36.0 & 5.23 & 242.00 & 0.67 & 188.28 & 162.14 & 86.12 & 6.88 \\
\hline & 36.0 & 5.00 & 241.90 & 0.64 & 180.00 & 154.82 & 86.01 & 7.20 \\
\hline & 36.0 & 4.49 & 241.70 & 0.57 & 161.64 & 137.77 & 85.23 & 8.02 \\
\hline & 36.0 & 4.00 & 241.60 & 0.50 & 144.00 & 120.80 & 83.89 & 9.00 \\
\hline & 36.0 & 3.50 & 241.50 & 0.43 & 126.00 & 103.85 & 82.42 & 10.29 \\
\hline & 36.0 & 3.00 & 241.10 & 0.36 & 108.00 & 86.80 & 80.37 & 12.00 \\
\hline & 36.0 & 2.50 & 240.80 & 0.30 & 90.00 & 72.24 & 80.27 & 14.40 \\
\hline & 36.0 & 2.00 & 240.50 & 0.17 & 72.00 & 40.89 & 56.78 & 18.00 \\
\hline & 36.0 & 1.50 & 239.70 & 0.27 & 54.00 & 64.72 & 119.85 & 24.00 \\
\hline & 36.0 & 1.00 & 240.00 & 0.11 & 36.00 & 26.40 & 73.33 & 36.00 \\
\hline \multirow{11}{*}{ 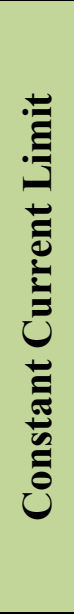 } & 40.0 & 4.75 & 242.20 & 0.67 & 190.00 & 162.27 & 85.41 & 8.42 \\
\hline & 39.0 & 4.87 & 242.18 & 0.67 & 189.93 & 162.26 & 85.43 & 8.01 \\
\hline & 38.0 & 5.00 & 242.12 & 0.68 & 190.00 & 164.64 & 86.65 & 7.60 \\
\hline & 37.0 & 5.12 & 242.29 & 0.68 & 189.44 & 164.76 & 86.97 & 7.23 \\
\hline & 36.0 & 5.25 & 242.14 & 0.68 & 189.00 & 164.66 & 87.12 & 6.86 \\
\hline & 35.0 & 5.41 & 242.16 & 0.68 & 189.35 & 164.67 & 86.97 & 6.47 \\
\hline & 34.0 & 5.57 & 242.21 & 0.68 & 189.38 & 164.70 & 86.97 & 6.10 \\
\hline & 33.0 & 5.77 & 242.18 & 0.68 & 190.41 & 164.68 & 86.49 & 5.72 \\
\hline & 32.0 & 5.99 & 242.25 & 0.68 & 191.68 & 164.73 & 85.94 & 5.34 \\
\hline & 31.0 & 6.12 & 242.30 & 0.67 & 189.72 & 162.34 & 85.57 & 5.07 \\
\hline & 30.0 & 6.12 & 242.11 & 0.65 & 183.60 & 157.37 & 85.71 & 4.90 \\
\hline
\end{tabular}




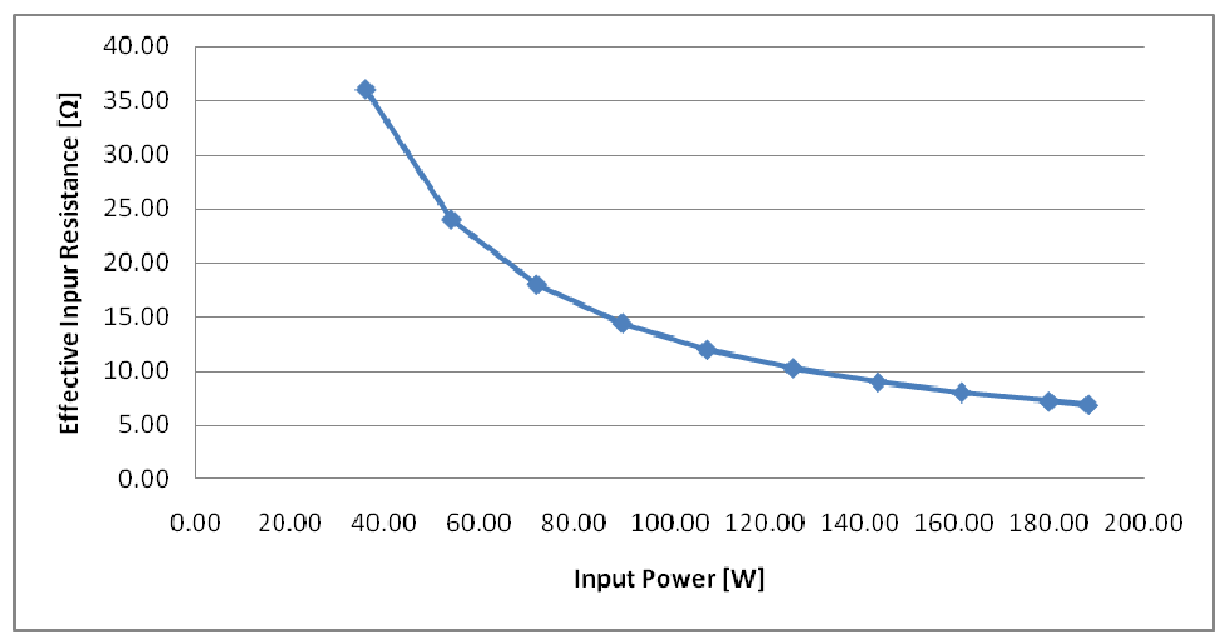

Figure 14: Input Power versus Effective Input Resistance of the Microinverter

Table 4 and Figure 14 shows the relationship between input power and the effective input resistance of the microinverter, keeping in mind that power, voltage and current increase together with respect to the Precor elliptical machine. The current inversely tracks the input voltage, while the input resistance increases as input voltage increases.

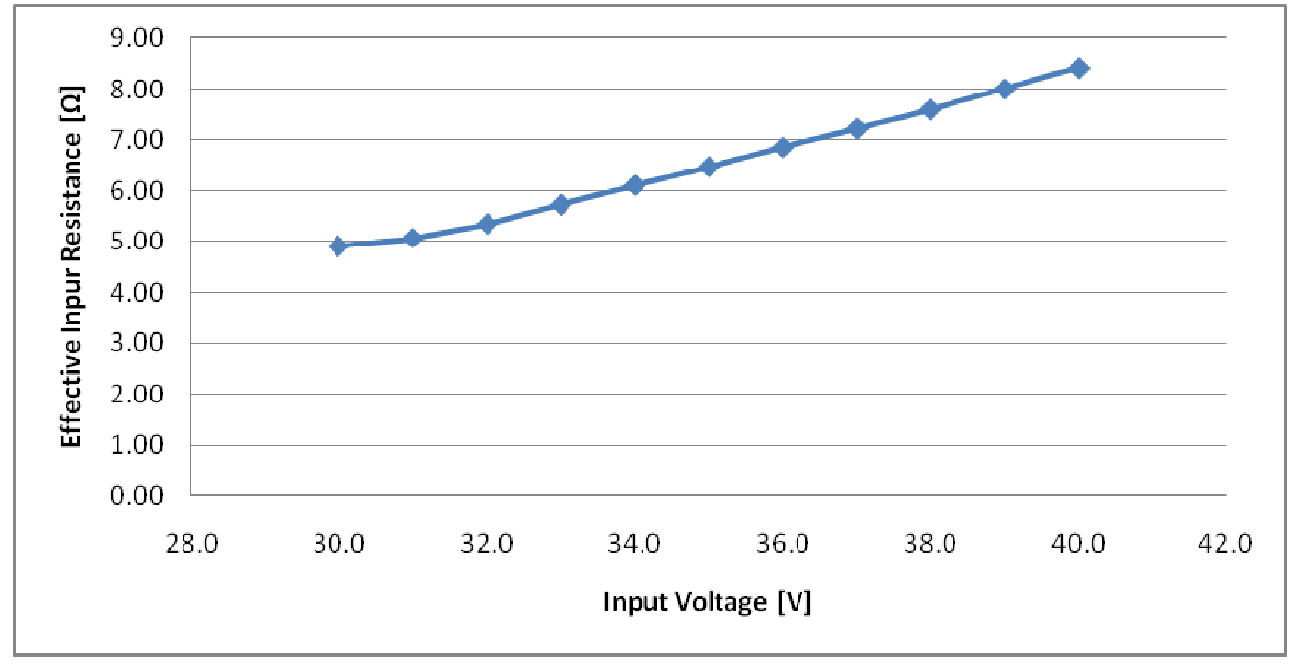

Figure 15: Input Voltage versus Effective Input Resistance of the Microinverter 
Figure 14 and Figure 15 show the Maximum Power Point Tracking capability of the microinverter. In this experiment, a DC power supply, with a maximum output power of roughly $190 \mathrm{~W}$, set to $36 \mathrm{~V}$ varies its current limit for Figure 14. In Figure 15, the input power stays constant and the input voltage varies. As the current limit lowers, the microinverter changes its input resistance to match a suitable input current for maximum power transfer. Due to the $190 \mathrm{~W}$ limit of the power supply, the highest efficiency topped out at $86.12 \%$ and it lowered steadily as the current limit decreased until the input current reached two amps. The last two data points reveal erroneous results.

Figure 16 verifies the optimal input voltage of the microinverter at $190 \mathrm{~W}$, previously tested by a prior group [3]. 36V stays as the optimal point of interest, and the graph shows a steady efficiency curve with a variation below $2 \%$.

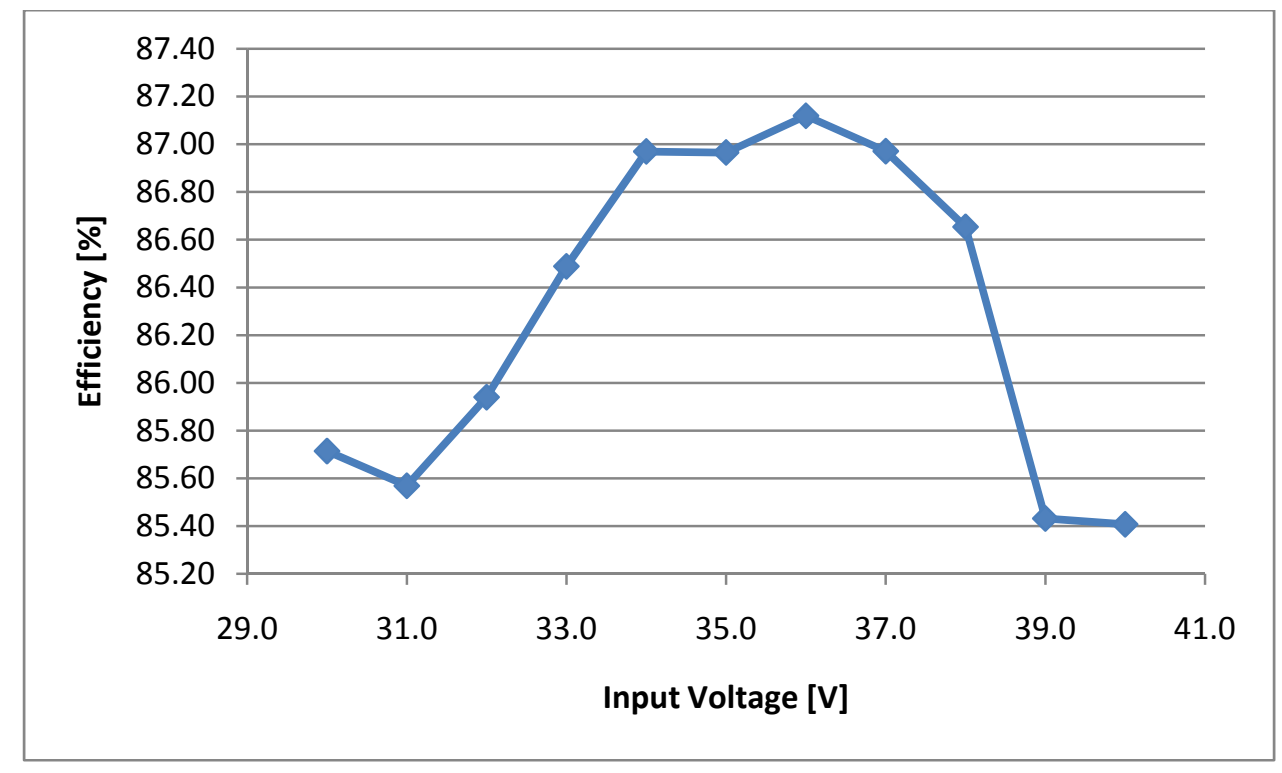

Figure 16: Input Voltage versus Efficiency of the Microinverter 
Figure 17 illustrates the sharp drop-off in efficiency for the input power range below $80 \mathrm{~W}$. This may pose a problem in the future for overall system efficiency since most energy harvesting occurs in that range. At lower input power levels, the data appeared erroneous. Due to the 190W output power capability of the GW Instek GPR6060D DC power supply, testing concluded at 190W. Power levels above 190W prove irrelevant since they exceed power levels of a typical human workout.

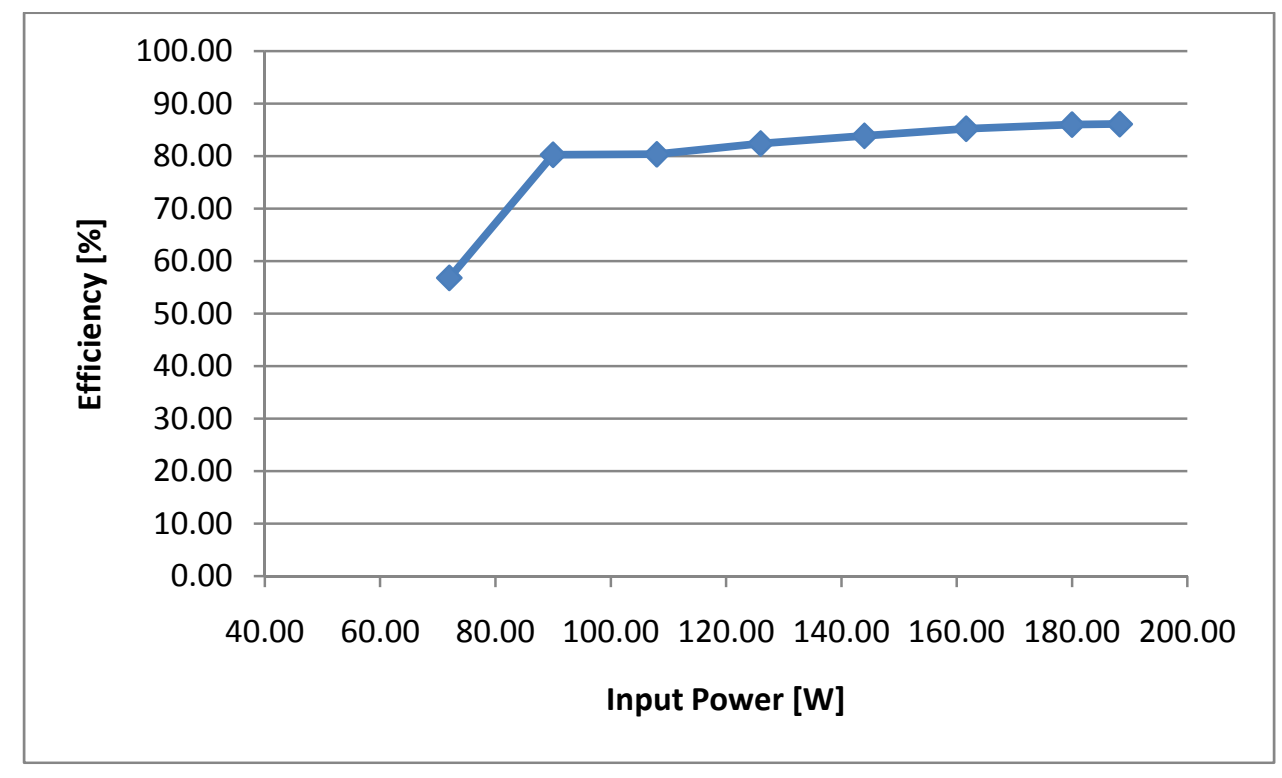

Figure 17: Input Power versus Efficiency of the Microinverter 


\subsection{DC-DC Converters}

In this section, a full characterization doesn't prove necessary since the system will not utilize the previously used DC-DC converters. Instead, this projects benefits more from information regarding the performance and shortcomings of the converters.

"At higher resistance levels, if the user decreases pace, he or she feels a large spike of physical resistance against their feet." [Yuen] This change in physical resistance may cause a safety hazard since it's an unexpected and abrupt change. The microinverter and its maximum power point tracking algorithm may cause this problem. Also, this affects the user experience, which opposes a design requirement.

Maximum input voltage doesn't fulfill the full range of voltage outputted by the elliptical machine. This causes the converter to shutdown from an overvoltage protection circuit, and thus provides no physical resistance to the user [Yuen]. The converters will not function for all resistance levels and speeds. This also poses as a safety hazard due to the loss of physical resistance.

Lastly, the maximum efficiency reaches only as high as $80 \%$ [Yuen]. With a low efficiency, the maximum parts cost to achieve zero life cycle cost decreases dramatically. 


\section{CHAPTER 3: TOPOLOGY RESEARCH}

\subsection{Introduction}

In choosing an appropriate topology, one must consider not only the full range of input power and input voltage, but more importantly, the typical input values. The maximum efficiency should occur at these typical input ranges. For this application, the input power spans from 5-275W, but the user usually outputs $60-100 \mathrm{~W}$ as inferred by the elliptical machine characterization section. This translates as a voltage of roughly $5-52 \mathrm{~V}$ full range, and 15-30V typical input range. With the output of the DC-DC converter specified as $36 \mathrm{~V}$, the converter steps up the voltage most of the time. This necessitates a converter with optimal performance in boost mode operation. The following sections cover a literature review and the chronologically walk through my thought process for methodically finding an appropriate topology for the project.

\subsection{Literature Review}

\subsubsection{Current Implementations of EHFEM}

ReRev is one of the main leaders in EHFEM. They retrofit Precor elliptical machines for energy harvesting in a way that does not void warranty or violate UL standards. They utilize a centralized wind inverter with a $600 \mathrm{~V}$ input, 240VAC split or single phase output, and $6 \mathrm{~kW}$ capability [5]. Their controller utilizes the local power grid as a load. The only other technical specific written in their patent submission specifies the use of a diode for unidirectional current flow [5]. 


\subsubsection{DC-DC Converter Topology}

In the topology research, I found many similarities with telecom converter applications in terms of specifications. They usually employ a converter with voltage step up and down capabilities, input voltage range of $36-72 \mathrm{~V}, 48 \mathrm{~V}$ output, and some have a $300 \mathrm{~W}$ power capability. The main difference in specifications lies with this application's input voltage range extending down to $5 \mathrm{~V}$. This value sets a minimum inductance value, discussed in the components selection section further in the paper. By having such a low input voltage, the converter requires a higher than normal minimum inductance, thus driving up the cost and limiting the stock of usable inductors capable of withstanding high currents. Inductor current capability and inductance are inversely proportional in commercially available components. Custom inductors and transformers increase the cost of components significantly, thus are not considered in the converter design.

A couple technical papers regarding the Four-Switch Buck-Boost converter state telecom converters use a two-stage or more configuration for the highest efficiency [6]. The first stage employs a non-isolated preregulator to stabilize the wide input range to a fixed $48 \mathrm{~V}$. Then, an isolated topology tightly regulates this voltage to $12 \mathrm{~V}[7]$. Some nonisolated converters that have the step up and down ability include the Buck-Boost, Cuk, SEPIC, and Zeta converters. The Buck-Boost and Cuk converters are not desirable due to their negative output voltage. This leads to complex control circuitry. The SEPIC and Zeta resemble slightly reconfigured topologies based on the Cuk. Such converters have low power densities due to far too many passive components [7]. The two inductors/one transformer utilized by these topologies contribute towards low power density. For the same design specifications, Linear Technology's LTC3780 Four-Switch Buck-Boost 
converter maintains a higher power density; the inductor takes up one-fifth the footprint and one-fifteenth the volume of a SEPIC's transformer [8]. In addition, the components of these four topologies experience high voltage stresses equal to the sum of the input and output voltages [6]. This causes more expensive components, and lower reliability. These considerations further reinforce my decision for the Four-Switch Buck-Boost topology.

\subsection{Chronologic Thought Process for Topology Decision}

The system may employ many topologies. One must decide between an isolated or non-isolated topology and a regular, otherwise known as "hard-switching," or resonant topology, "soft-switching". According to UL standards when dealing with voltages above $42.5 \mathrm{~V}$, the converter must use an isolated topology to prevent user access. Using the premise that the Precor elliptical machine already deals with voltages above $42.5 \mathrm{~V}$ by providing an enclosure to prevent and user access, this project may utilize non-isolated topologies. After talking with Professor Taufik regarding suitable topologies, high efficiencies do not require the use of a resonant DC-DC converter for the typical input the converter receives, even though resonant converters usually provide higher efficiency. This leaves many possible topologies to choose from.

After researching controllers for different designs, the zero voltage switching, ZVS, resonant flyback topology controllers seem as the only option for a quasi-resonant topology. Other usable topologies include buck-boost, Quasi-Buck-Boost, SEPIC, Cuk, Forward, and Flyback converters. Half Bridge and Full bridge topologies do not suit such low input voltages. Also the Push-Pull topology's four winding transformer drives up the converter cost significantly, thus it also does not suffice. 
Table 5 and Table 6 show some preliminary duty cycle calculations for continuous conduction mode. The regular Buck-Boost and Cuk converters supply a negative output voltage, thus the switches will incur high voltage stresses and require more complex control circuitry. With higher voltage rated components, also comes incurring more cost. The forward converter requires a very low duty cycle for operation, which may prove unattainable for a controller to effectively implement. In addition, to get the duty cycle values down below $50 \%$, the maximum duty cycle for the forward converter, the turns ratio increased to 10 . With such a large turns ratio, the converter requires a custom transformer, and for cost effectiveness, disqualifies the forward converter from consideration. Also as an isolated topology like the flyback, the transformer raises the power loss, making these topologies less desirable. Using Equation 4, Equation 5 and a typical switching frequency of $300 \mathrm{kHz}$, the converter requires a critical magnetizing inductance of $51.5 \mathrm{uH}$. The equations use output voltage of the converter, the turns ratio, and the duty cycle from Table 5 and Table 6 . Such a large inductance value also necessitates a custom transformer. This leaves the SEPIC and Quasi-Buck-Boost converters left to evaluate. The LTC3780 datasheet gives the four switch Buck-Boost equations for duty cycles and minimum input voltages [9].

$$
\begin{aligned}
& \text { Equation 4: Average Current in Flyback Magnetizing Inductance } \\
& I_{L m}=\frac{V_{O}}{(1-D) \frac{N 1}{N 2} \frac{V_{O}}{I_{O}}}=\frac{36 \mathrm{~V}}{(1-.878) 2 * \frac{36}{.069 \mathrm{~A}}}=0.284 \mathrm{~A}
\end{aligned}
$$

Equation 5: Critical Magnetizing Inductance in Flyback Transformer

$$
L_{m c}=\frac{V_{O}(1-D) \frac{N 1}{N 2}}{2 I_{L m} f_{s}}=\frac{36 V(1-0.878) 2}{2 * 0.284 \mathrm{~A} * 300 \mathrm{kHz}}=51.5 u \mathrm{H}
$$


Table 5: Values for Duty Cycle Calculations

\begin{tabular}{|c|c|c|}
\hline & Values & Notes \\
\hline $\mathbf{V}_{\text {in } \min }[\mathbf{V}]$ & 5 & \\
\hline $\mathbf{V}_{\text {in } \max }[\mathbf{V}]$ & 60 & \\
\hline $\mathbf{V}_{\mathbf{o}}[\mathbf{V}]$ & 36 & \\
\hline $\mathbf{N} 2 / \mathbf{N} 1$ & 10 & For Forward \\
\hline $\mathbf{N} 1 / \mathbf{N} 2$ & 2 & For Flyback \\
\hline
\end{tabular}

Table 6: Preliminary Duty Cycle Calculations

\begin{tabular}{|c|c|c|c|c|}
\hline & Duty Cycle Equation & $D$ for $V_{\min }$ & $D$ for $V_{\max }$ & Notes \\
\hline Buck-Boost/Cuk & $D=-V_{o} /\left(V_{o}-V_{i n}\right)$ & $87.80 \%$ & $37.50 \%$ & Both negative and duty cycles above $100 \%$ \\
\hline Sepic & $\mathrm{D}=\mathrm{Vo} /(\mathrm{Vin}+\mathrm{Vo})$ & $87.80 \%$ & $37.50 \%$ & \\
\hline Forward & $\mathrm{D}=(\mathrm{Vo} / \mathrm{Vin}) *(\mathrm{~N} 1 / \mathrm{N} 2)$ & $48.00 \%$ & $4.00 \%$ & \\
\hline Flyback & $\mathrm{D}=(\mathrm{N} 2 / \mathrm{N} 1)^{*} \mathrm{Vo} /(\mathrm{Vin}+\mathrm{Vo})$ & $87.80 \%$ & $37.50 \%$ & \\
\hline \multicolumn{4}{|c|}{ Four Switch Buck Boost } & $D_{\text {Buck-Boost }}=(200 \mathrm{~ns} * 300 \mathrm{kHz}) * 100 \%=6 \%$ \\
\hline Buck Mode & $\mathrm{D}=\mathrm{Vo} / \mathrm{Vin}$ & $94.00 \%$ & $60.00 \%$ & $\begin{array}{l}D_{\text {MaxBuck }}=100 \%-D_{\text {Buck-Boost }}=94 \% \\
V_{\min }=V_{0} / D_{\text {MaxBuck }}=38.3 \mathrm{~V}\end{array}$ \\
\hline Boost Mode & $\mathrm{D}=1-\mathrm{Vin} / \mathrm{Vo}$ & $86.11 \%$ & $6.00 \%$ & $\begin{array}{l}D_{\text {MinBoost }}=D_{\text {Buck-Boost }}=6 \% \\
V_{\text {min }}=V_{0} /\left(1-D_{\text {MinBoost })}=33.84 \mathrm{~V}\right.\end{array}$ \\
\hline
\end{tabular}

\subsection{Quasi-Buck-Boost Controllers}

Regarding the Quasi-Buck-Boost topologies, two controllers stand out above the rest; Linear Technology's LTC3780 and National Semiconductor's LM5118. The following table provides the advantages of each controller.

Table 7: Pros for Each Controller

\begin{tabular}{|l|l|}
\hline \multicolumn{1}{|c|}{ LTC3780 } & \multicolumn{1}{c|}{ LM5118 } \\
\hline Typically runs in Boost Mode & $\begin{array}{l}\mathrm{V}_{\text {supply }} \text { can handle voltages up to } \\
75 \mathrm{~V}\end{array}$ \\
\hline Has simulation program & Less Components \\
\hline Synchronous rectification & Excel Component Design Sheet \\
\hline Output overvoltage protection & Soft-Start \\
\hline $\begin{array}{l}\text { Peak output switch drive current } \\
\text { 3A }\end{array}$ & \\
\hline
\end{tabular}


Figure 18 and Figure 19 show the efficiency plots versus input voltage for each controller taken from their datasheets $[9,10]$. As illustrated, the LTC3780 provides a better efficiency curve especially at the targeted output voltage. The different ways the controllers implement the buck-boost algorithm cause this phenomenon. The LTC3780 either operates in boost, buck, or a combination of the two modes to provide the output voltage. The LM5118 on the other hand, operates as a buck until some voltage threshold, and then it operates in a buck-boost mode. For this application, the boosting mode characteristics are paramount, thus the LTC3780 trumps the LM5118 for its inherently better efficiency performance. After reviewing the datasheet more, the maximum duty cycle of the LM5118 reaches its peak at $80 \%$. According to the buck-boost duty cycle function, Equation 6, shown below, with an output voltage of 36V and maximum duty cycle of $80 \%$, the lowest input voltage required goes as high as $9 \mathrm{~V}$. This doesn't suit the application well.

Equation 6: Buck-Boost Duty Cycle in Continuous Conduction Mode

$$
\text { Duty Cycle }=\frac{\text { Vout }}{\text { Vin }+ \text { Vout }}
$$

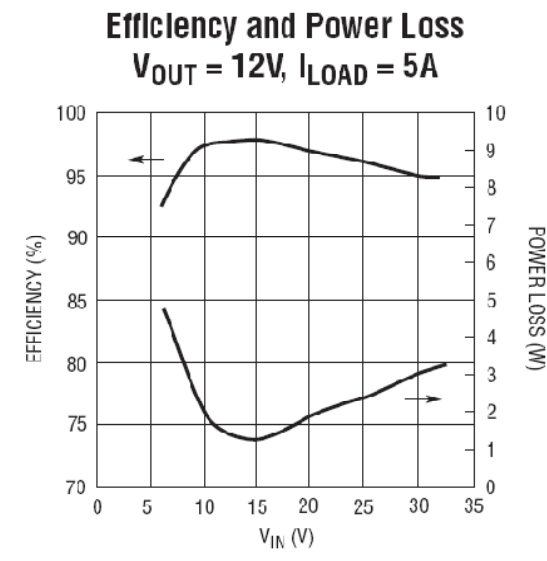

Figure 18: Efficiency Plot for the LTC3780 [8]

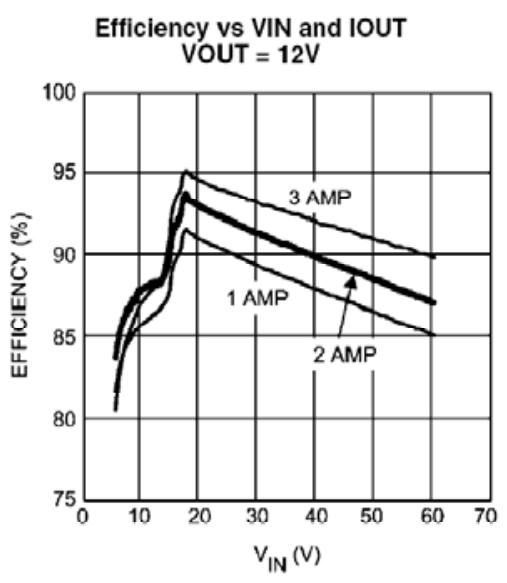

Figure 19: Efficiency Plot for LM511 [9] 


\subsection{SEPIC and Four Switch Buck Boost Designs}

Choosing between a SEPIC or Quasi-Buck-Boost converter requires further analysis using Linear Technology's simulation program LTSPICE. A possible SEPIC converter design may use Linear Technology's LTC1871. Figure 20 and Figure 21 show the schematics for each configuration.

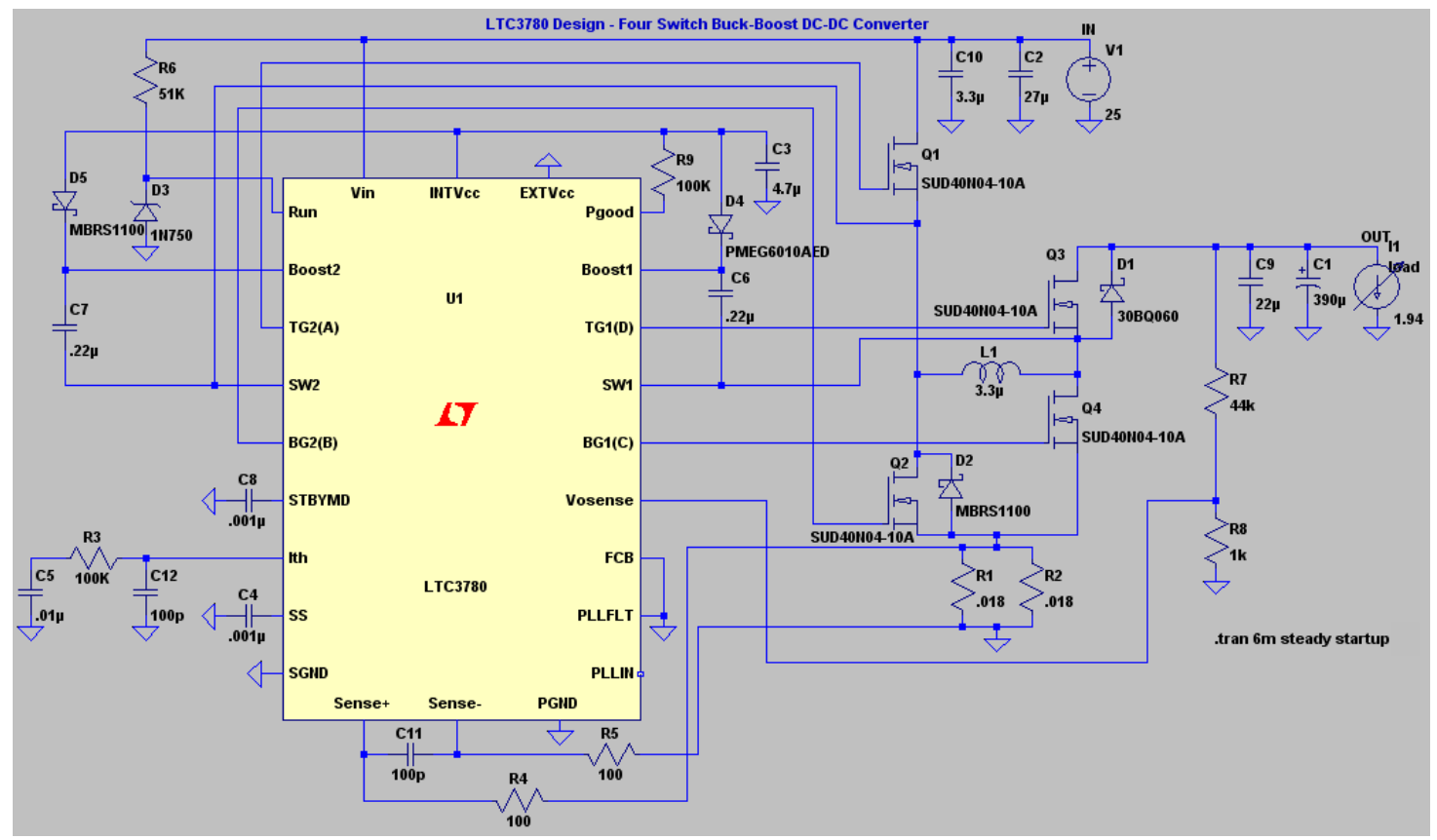

Figure 20: Linear Technology LTC3780 FSBB Design Schematic [11]

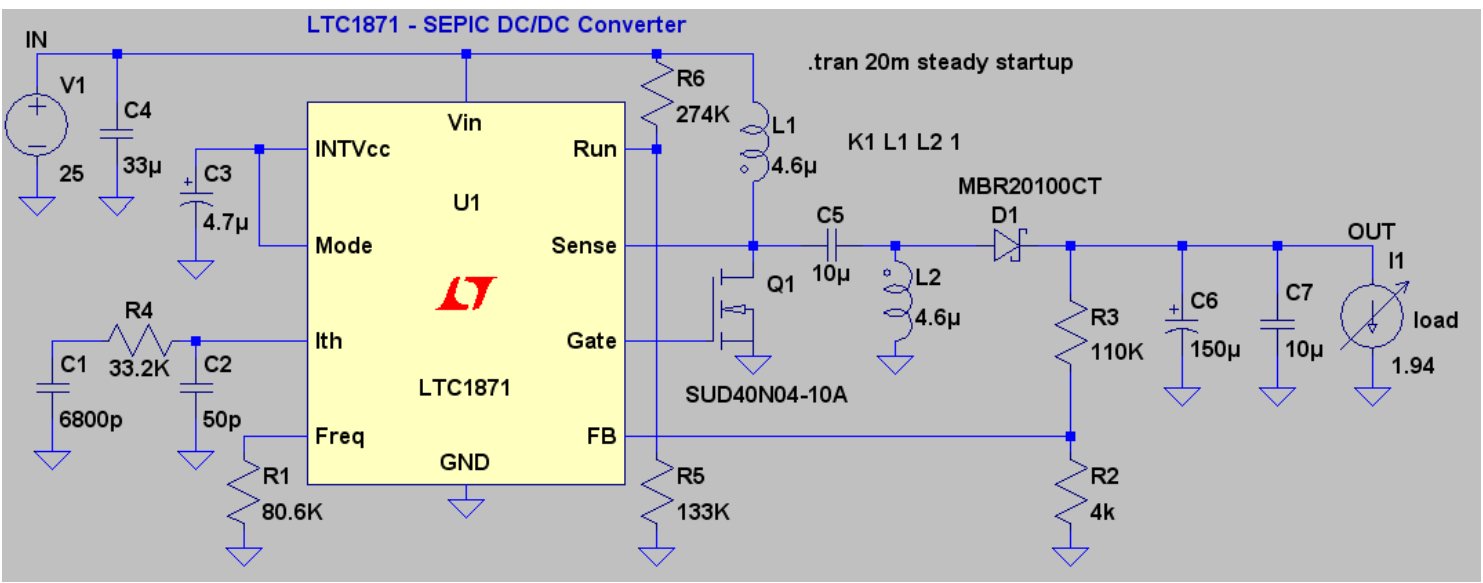

Figure 21: Linear Technology LT1871 SEPIC Design Schematic [12] 
Table 8 displays the testing parameters both of these converters use for simulation. For a given power level, one uses the associated input voltage and output current from the table. The input power dictates the input voltage assuming that the input impedance for the converter remains at ten ohms. Using a no power loss assumption, the output current derives from dividing the input power by the output voltage, $36 \mathrm{~V}$. Blue cells represent input values the converter can handle, and the red cells designate values outside the specification of the proposed converter. The dark blue cells show the typical input from an elliptical machine user. The simulation command employs steady state identification, denoted by "steady" in the command line, for the efficiency report. Also the simulation starts up external DC supplies at 0V, denoted by "startup." In transient mode analysis, the simulation runs for several milliseconds depending on the converter's settling time. 
Table 8: Input Voltage and Load Current Simulation Parameters

\begin{tabular}{|c|c|c|c|c|c|c|c|c|c|}
\hline$V_{\text {in }}[V]$ & $\mathrm{I}_{\text {in }}[\mathrm{A}]$ & $P_{\text {in }}=P_{o}[\mathbf{W}]$ & $\mathrm{V}_{\mathrm{o}}[\mathrm{V}]$ & $\mathrm{I}_{\mathrm{o}}[\mathrm{A}]$ & $V_{\text {in }}[V]$ & $I_{\text {in }}[A]$ & $P_{\text {in }}=P_{o}[W]$ & $v_{o}[V]$ & $\mathrm{I}_{\mathrm{o}}[\mathrm{A}]$ \\
\hline 5 & 0.5 & 2.5 & 36 & 0.07 & 33 & 3.3 & 108.9 & 36 & 3.03 \\
\hline 6 & 0.6 & 3.6 & 36 & 0.10 & 34 & 3.4 & 115.6 & 36 & 3.21 \\
\hline 7 & 0.7 & 4.9 & 36 & 0.14 & 35 & 3.5 & 122.5 & 36 & 3.40 \\
\hline 8 & 0.8 & 6.4 & 36 & 0.18 & 36 & 3.6 & 129.6 & 36 & 3.60 \\
\hline 9 & 0.9 & 8.1 & 36 & 0.23 & 37 & 3.7 & 136.9 & 36 & 3.80 \\
\hline 10 & 1 & 10 & 36 & 0.28 & 38 & 3.8 & 144.4 & 36 & 4.01 \\
\hline 11 & 1.1 & 12.1 & 36 & 0.34 & 39 & 3.9 & 152.1 & 36 & 4.23 \\
\hline 12 & 1.2 & 14.4 & 36 & 0.40 & 40 & 4 & 160 & 36 & 4.44 \\
\hline 13 & 1.3 & 16.9 & 36 & 0.47 & 41 & 4.1 & 168.1 & 36 & 4.67 \\
\hline 14 & 1.4 & 19.6 & 36 & 0.54 & 42 & 4.2 & 176.4 & 36 & 4.90 \\
\hline 15 & 1.5 & 22.5 & 36 & 0.63 & 43 & 4.3 & 184.9 & 36 & 5.14 \\
\hline 16 & 1.6 & 25.6 & 36 & 0.71 & 44 & 4.4 & 193.6 & 36 & 5.38 \\
\hline 17 & 1.7 & 28.9 & 36 & 0.80 & 45 & 4.5 & 202.5 & 36 & 5.63 \\
\hline 18 & 1.8 & 32.4 & 36 & 0.90 & 46 & 4.6 & 211.6 & 36 & 5.88 \\
\hline 19 & 1.9 & 36.1 & 36 & 1.00 & 47 & 4.7 & 220.9 & 36 & 6.14 \\
\hline 20 & 2 & 40 & 36 & 1.11 & 48 & 4.8 & 230.4 & 36 & 6.40 \\
\hline 21 & 2.1 & 44.1 & 36 & 1.23 & 49 & 4.9 & 240.1 & 36 & 6.67 \\
\hline 22 & 2.2 & 48.4 & 36 & 1.34 & 50 & 5 & 250 & 36 & 6.94 \\
\hline 23 & 2.3 & 52.9 & 36 & 1.47 & 51 & 5.1 & 260.1 & 36 & 7.23 \\
\hline 24 & 2.4 & 57.6 & 36 & 1.60 & 52 & 5.2 & 270.4 & 36 & 7.51 \\
\hline 25 & 2.5 & 62.5 & 36 & 1.74 & 53 & 5.3 & 280.9 & 36 & 7.80 \\
\hline 26 & 2.6 & 67.6 & 36 & 1.88 & 54 & 5.4 & 291.6 & 36 & 8.10 \\
\hline 27 & 2.7 & 72.9 & 36 & 2.03 & 55 & 5.5 & 302.5 & 36 & 8.40 \\
\hline 28 & 2.8 & 78.4 & 36 & 2.18 & 56 & 5.6 & 313.6 & 36 & 8.71 \\
\hline 29 & 2.9 & 84.1 & 36 & 2.34 & 57 & 5.7 & 324.9 & 36 & 9.03 \\
\hline 30 & 3 & 90 & 36 & 2.50 & 58 & 5.8 & 336.4 & 36 & 9.34 \\
\hline 31 & 3.1 & 96.1 & 36 & 2.67 & 59 & 5.9 & 348.1 & 36 & 9.67 \\
\hline 32 & 3.2 & 102.4 & 36 & 2.84 & 60 & 6 & 360 & 36 & 10.00 \\
\hline
\end{tabular}

After simulating these circuits with a typical input voltage of $25 \mathrm{~V}$ and input power of $70 \mathrm{~W}$, the four-switch buck-boost topology maintained an efficiency of $97.9 \%$, and the SEPIC topology performed worse with an efficiency of $94.1 \%$. The SEPIC design requires fewer components making it less expensive to implement, thus lowering the payback period for the initial investment even with the $4 \%$ lower efficiency. But after simulating the SEPIC with the maximum input voltage of $52 \mathrm{~V}$ and input power of $275 \mathrm{~W}$, the controller did not regulate the output voltage with a load current of $7.5 \mathrm{~A}$. The voltages across the drain to source of the MOSFET reached voltages nearing $100 \mathrm{~V}$. This 
requires a new transistor, but when choosing a new FET the $\mathrm{R}_{\mathrm{ds}(\mathrm{on})}$ also increased. In this controller, the $\mathrm{R}_{\mathrm{ds}(\mathrm{on})}$ also functions as the current sense resistor. In essence, no one transistor that meets all the criteria. Paralleling MOSFETs, IPB065N15N3, resolved this issue, but in turn added cost. These two transistors equaled the cost of the four transistors for the LTC3780 design. With the added inductor for the SEPIC design and the lower efficiency the Four-Switch Buck-Boost design seems like a better option.

Looking through the datasheet for the LTC3780, the maximum voltage supplied to $\mathrm{V}_{\text {in }}$ of the chip limits the voltage to $36 \mathrm{~V}$ [9]. This prompts a separate means of stepping down the voltage from the elliptical machine to the chip by means of a buck converter or an alternative to handle the full range output of the elliptical machine. This makes the complexity and cost rise. When running the circuit in LTSPICE and powering the chip externally with a $30 \mathrm{~V}$ supply, I noticed that the BOOST1 and BOOST 2 pins, maximum voltage rating of $42 \mathrm{~V}$, rose to a voltage roughly $\mathrm{INTV}_{\mathrm{cc}}, 6 \mathrm{~V}$, plus $\mathrm{V}_{\text {out }}, 36 \mathrm{~V}$, adding up to $42 \mathrm{~V}$ and $\mathrm{INTV}_{\mathrm{cc}}, 6 \mathrm{~V}$, plus $\mathrm{V}_{\text {in }}, 60 \mathrm{~V}$, adding up to $66 \mathrm{~V}$ [9]. These pins served as a boosted floating driver supply with the help of the bootstrap capacitors. Figure 22 illustrates these violations of the maximum voltage ratings. V(n008), green, and V(n009), blue, represent the voltage waveforms of BOOST2 and BOOST 1. 


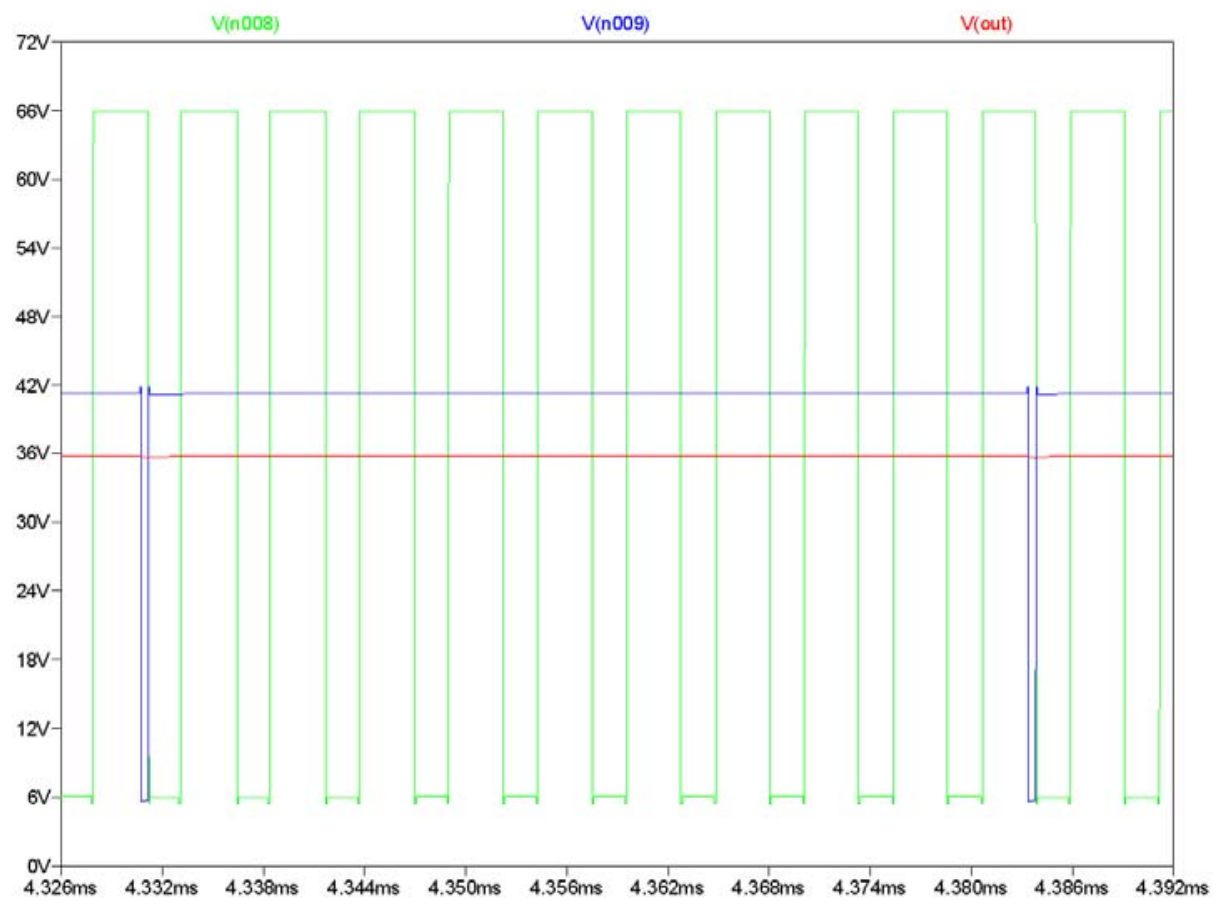

Figure 22: LTC3780 BOOST1, BOOST2 and Vout with Vin $=60 \mathrm{~V}$

\subsection{Dual Converter Design - Buck and Boost}

Taking all this into consideration, no one commercial available controller exists to handle the wide output power range of the Precor elliptical machine. In this case, a converter that mimics the ideology behind the LTC3780 provides a feasible solution, which one converter would operate as a buck and another as a boost. The only downside to this solution lies in the fact that the output voltage of each converter cannot equal each other due to duty cycle limitations. Thus, the output voltages must differ in a way such that the input voltage ranges of the two converters slightly overlap.

Other considerations include the fact that the boost converter handles all of the input power for a typical scenario. Also, the lowering the output voltage of the buck converter lowers the input power range, since the microinverter's current limit maxes out 
at $7.5 \mathrm{~A}$ with power equaling voltage times current. Interfacing these two converters requires an under voltage lockout for the buck converter and an overvoltage lockout for the boost converter. Also, in choosing the frequency, one must keep in mind that the values of the inductor and resistors stay within a rational range. For example, lowering the switching frequency enhances the efficiency, but increases the inductance and resistors $\mathrm{R}_{\mathrm{on}}$ and $\mathrm{R}_{\mathrm{off}}$ as shown in the equations in Table 9. Lowering the frequency to $100 \mathrm{kHz}$ raises the inductance to about $30 \mu \mathrm{H}$ and $\mathrm{R}_{\text {on }}$ and $\mathrm{R}_{\text {off }}$ values above $1 \mathrm{M} \Omega$.

Table 9 and Table 10 show a preliminary derivation of the main components used in each design. Linear Technology's datasheets provide the equations for calculating the component values $[13,14]$. As seen in the table, the boost converter's capabilities determine the buck converter's specifications. In other words, at a certain output voltage, the minimum off time of the boost controller limits the maximum input voltage of the boost converter. Thus, to cover the full range of input voltages, I set the minimum input voltage of the buck converter one volt lower than the maximum input voltage of the boost converter. This lowers the output voltage of the buck converter, which also lowers the maximum input power since the microinverter only handles currents up to $7.5 \mathrm{~A}$. Assuming that the user typically does not supply these high power levels, on the order of $230 \mathrm{~W}$, for an extended time, this lowering of the design specification proves acceptable. In the future, however, circuitry needs to address these transient input voltages, perhaps using a metal oxide varistor. Using LTSPICE, I built the schematics for the two DC-DC converter designs as shown in Figure 23 and Figure 24. The efficiency reports display efficiencies around 99\%. 
Table 9: Boost Converter Component Derivations

\begin{tabular}{|c|c|c|c|}
\hline & & Boost & \\
\hline Vout & 37.00 & Constant & V \\
\hline tonmin & $3.50 \mathrm{E}-07$ & Constant & $\mathrm{s}$ \\
\hline toffmin & $1.00 \mathrm{E}-07$ & Constant & s \\
\hline frequency & 250.00 & Constant & $\mathrm{kHz}$ \\
\hline Toff (tonmin case) & $4.00 \mathrm{E}-06$ & $=1 /$ (frequency-tonmin) & $\mathrm{s}$ \\
\hline ton (tofftmin case) & - & - & $\mathrm{s}$ \\
\hline Vinmax & 34.02 & =Vout*toffmin/(toffmin+Ton) & V \\
\hline Vinmin & 5.00 & Constant & V \\
\hline linmax & 3.40 & $=$ Vinmax/100hms & A \\
\hline Pinmax & 115.76 & =Vinmax*linmax & W \\
\hline Iomax & 3.13 & =Pinmax/Vout & A \\
\hline Dmin & $8.05 \%$ & =1-Vinmax/Vout & $\%$ \\
\hline Dmax & $86.49 \%$ & $=1-$ Vinmin/Vout & $\%$ \\
\hline deltalL\% & $40.00 \%$ & Constant & $\%$ \\
\hline deltalLmax & 1.25 & =lomax*deltalL\% & A \\
\hline Lmin uH & 13.82 & =Vinmin*Dmax/(frequency*deltalLmax) & $\mathrm{uH}$ \\
\hline ILSatmin & 23.78 & $=\operatorname{lomax} /(1-$ Dmax $)+$ Delta IL/2 & A \\
\hline R1:R2 ratio & 11.59 & $=$ Vinmedian $/ 1.55 \mathrm{~V}$ & \\
\hline R1 & 200.00 & Constant & kOhms \\
\hline $\mathbf{R 2}$ & 17.26 & $=\mathrm{R} 1 /(\mathrm{R} 1: \mathrm{R} 2$ ratio $)$ & kOhms \\
\hline Roff & 609.90 & $=(1+\mathrm{R} 1: \mathrm{R} 2$ ratio $) /($ frequency*76pF) & kOhms \\
\hline INTVcC & - & - & V \\
\hline Ron & - & - & kOhms \\
\hline RFB1 & 300 & Constant & kOhms \\
\hline RFB2 & 6.63 & $=$ RFB1/[(Vout/0.8V)-1] & kOhms \\
\hline RNDRVmax & 50 & Typical Component & kOhms \\
\hline Rc & 300 & & kOhms \\
\hline Cc1 & 150 & & $\mathrm{pF}$ \\
\hline $\mathrm{Cc} 2$ & 330 & & $\mathrm{pF}$ \\
\hline Css & 1000 & Typical Component & $\mathrm{pF}$ \\
\hline Cintvcc & 1 & Typical Component & uF \\
\hline Cboost-sw & 0.1 & Typical Component & uF \\
\hline Cin1 & 1 ceramic & Irms rating $=0.3^{*}$ Vinmin $*$ Dmax $/(L *$ frequency $)=370 \mathrm{~mA}$ & uF \\
\hline Cin2 & 68 electrolytic & Typical Components, Low ESR, surge tested, high Q & uF \\
\hline Cout1 & 220 electrolytic & 54V, Low ESR, High Q, Typical Components & uF \\
\hline Cout2 & 220 electrolytic & 54V, Low ESR, High Q, Typical Components & uF \\
\hline Cout3 & 10 ceramic & 54V, Low ESR, High Q, Typical Components & uF \\
\hline Cout4 & 10 ceramic & 54V, Low ESR, High Q, Typical Components & uF \\
\hline D1 & $1 \mathrm{~N} 4148$ & Typical Component & \\
\hline D2 & MBRS1100 & Typical Component & \\
\hline Q1 & $\mathrm{BSH} 114$ & Typical Component & \\
\hline MOSFET & Si7848DP & Typical Component & \\
\hline
\end{tabular}


Table 10: Buck Converter Component Derivations

\begin{tabular}{|c|c|c|c|}
\hline & & Buck & \\
\hline Vout & 31.08 & $=$ Vinmin $*$ ton/(ton+toffmin) & $\mathrm{V}$ \\
\hline tonmin & $2.50 \mathrm{E}-07$ & Constant & $s$ \\
\hline toffmin & - & - & $s$ \\
\hline frequency & 250.00 & Constant & $\mathrm{kHz}$ \\
\hline Toff (tonmin case) & - & - & $s$ \\
\hline ton (tofftmin case) & 4.00E-06 & $=1 /$ (frequency-toffmin) & $\mathrm{s}$ \\
\hline Vinmax & 48.28 & $=$ sqrt(Pinmax*100hms) & $\mathrm{V}$ \\
\hline Vinmin & 33.02 & $=$ VinmaxBoost -1 & $\mathrm{~V}$ \\
\hline linmax & 4.83 & $=$ Vinmax $/ 100 \mathrm{hms}$ & A \\
\hline Pinmax & 233.10 & $=$ Vout*Iomax & $W$ \\
\hline Iomax & 7.50 & Constant & A \\
\hline Dmin & $64.37 \%$ & $=$ Vinmax/Vout & $\%$ \\
\hline Dmax & $94.12 \%$ & $=$ Vinmin/Vout & $\%$ \\
\hline deltalL\% & $40.00 \%$ & Constant & $\%$ \\
\hline deltalLmax & 3.00 & $=$ =lomax*deltalL\% & A \\
\hline Lmin uH & 14.76 & $=($ Vout $/($ frequency*deltalLmax $) *(1-$ Vout/Vinmax $)$ & $\mathrm{uH}$ \\
\hline ILSatmin & - & - & A \\
\hline R1:R2 ratio & - & - & \\
\hline R1 & - & - & kOhms \\
\hline $\mathbf{R 2}$ & - & - & kOhms \\
\hline Roff & - & - & kOhms \\
\hline INTVcc & 2.4 & Constant & $\mathrm{V}$ \\
\hline Ron & 681.58903 & $=$ Vout/(INTVcc*frequency*76pF) & kOhms \\
\hline RFB1 & 300 & Constant & kOhms \\
\hline RFB2 & 7.93 & $=$ RFB1/[(Vout/0.8V)-1] & kOhms \\
\hline RNDRVmax & 72.30736484 & $=($ Vinmin $-10 \mathrm{~V}-3.5 \mathrm{~V}) / 270 \mathrm{uA}$ & kOhms \\
\hline Rc & 90.9 & Typical Component & kOhms \\
\hline Cc1 & 220 & Typical Component & $\mathrm{pF}$ \\
\hline Cc2 & 33 & Typical Component & $\mathrm{pF}$ \\
\hline Css & 1000 & Typical Component & $\mathrm{pF}$ \\
\hline Cintvcc & 1 & Typical Component & $\mathrm{uF}$ \\
\hline Cboost-sw & 0.1 & Typical Component & $\mathrm{uF}$ \\
\hline Cin1 & 1 ceramic & Irms rating $=$ lomax $*$ Vout $/$ Vinmax $*$ sqrt $($ Vinmax $/$ Vout -1$)=3.64 \mathrm{~A}$ & $\mathrm{uF}$ \\
\hline Cin2 & 68 electrolytic & Typical Components, Low ESR, surge tested, high Q & $\mathrm{uF}$ \\
\hline Cout1 & 270 electrolytic & 54V, Low ESR, High Q, Typical Components & $\mathrm{uF}$ \\
\hline Cout2 & 10 ceramic & 54V, Low ESR, High Q, Typical Components & $\mathrm{uF}$ \\
\hline Cout3 & - & - & $\mathrm{uF}$ \\
\hline Cout4 & - & - & $\mathrm{uF}$ \\
\hline D1 & $1 \mathrm{~N} 4148$ & Typical Component & \\
\hline D2 & MBRS1100 & Typical Component & \\
\hline Q1 & IRF1310 & Typical Component & \\
\hline MOSFET & SI7852DP & Typical Component & \\
\hline
\end{tabular}




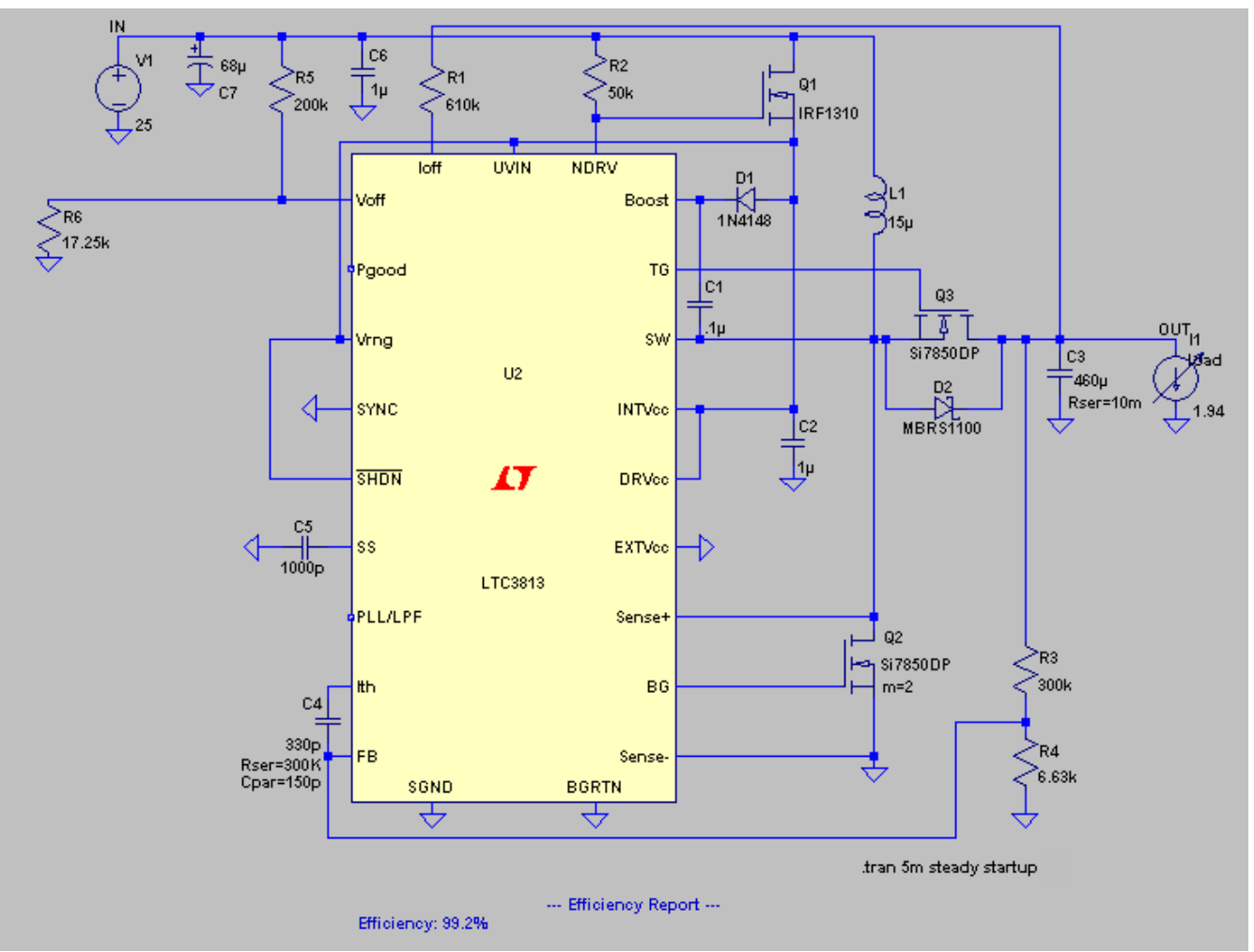

Figure 23: Linear Technology LTC3813 Boost Converter Schematic [15]

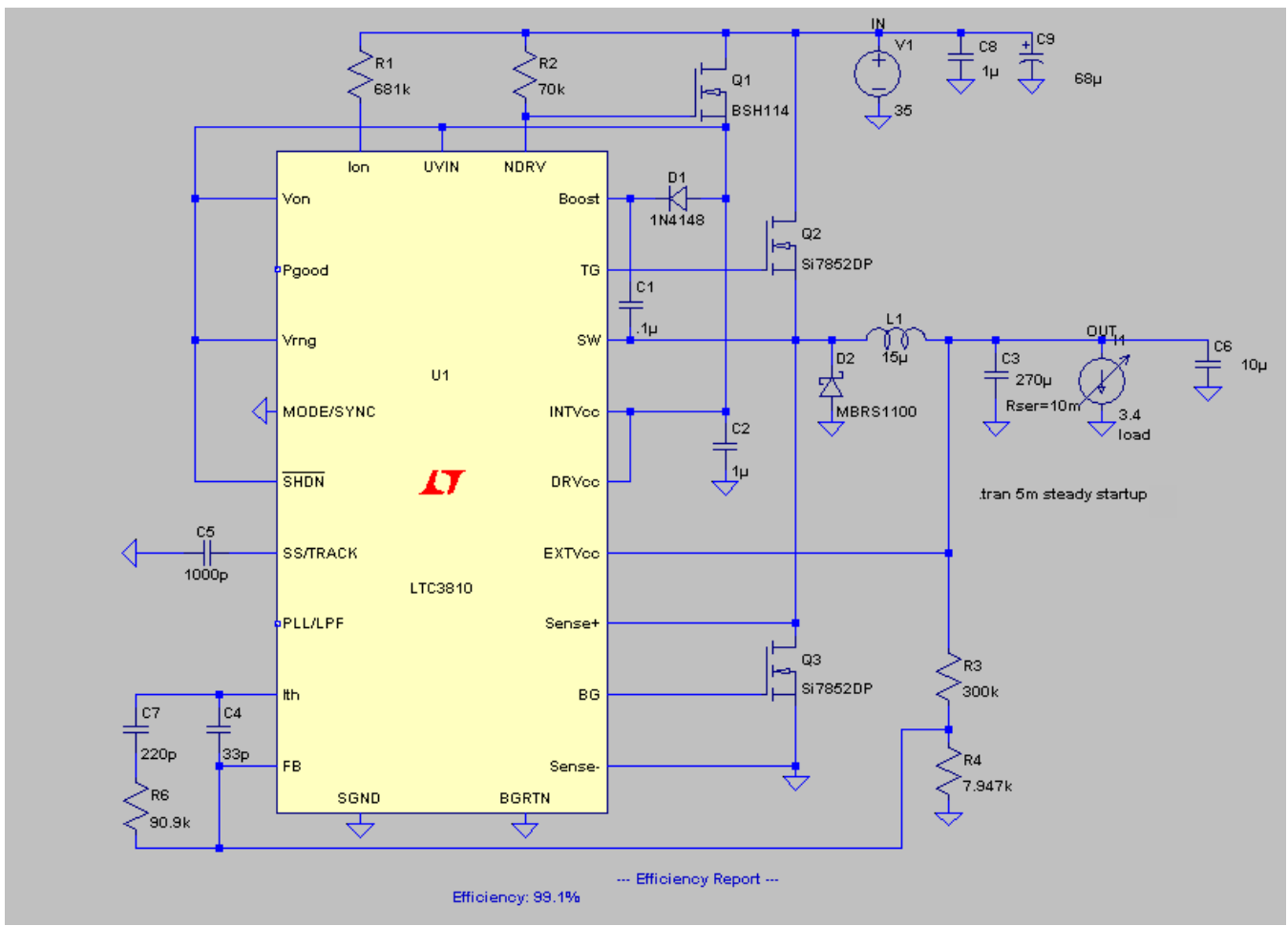

Figure 24: Linear Technology LTC3810 Buck Converter Schematic [16] 
Since the design utilizes two converters with two different output voltages and input voltage ranges, the simulation requires new input voltage and load current parameters. Table 11 displays these values. The cells in blue and dark green represent values for the boost converter, cells in light green and yellow represent buck converter parameters, and once again red cells represent values outside the specification of the converter. The dark blue cells designate the typical values the elliptical machine users supply.

Table 11: Simulation Parameters for Dual Converter Topology

\begin{tabular}{|c|c|c|c|c|c|c|c|c|c|}
\hline$V_{\text {in }}[\mathbf{V}]$ & $I_{\text {in }}[A]$ & $P_{\text {in }}=P_{o}[W]$ & $v_{o}[V]$ & $\mathrm{I}_{0}[\mathrm{~A}]$ & $\mathbf{V}_{\text {in }}[\mathbf{V}]$ & $I_{\text {in }}[A]$ & $P_{\text {in }}=P_{0}[W]$ & $v_{o}[V]$ & $\mathrm{I}_{\mathrm{o}}[\mathrm{A}]$ \\
\hline 5 & 0.5 & 2.5 & 37 & 0.07 & 33 & 3.3 & 108.9 & 31 & 3.51 \\
\hline 6 & 0.6 & 3.6 & 37 & 0.10 & 34 & 3.4 & 115.6 & 31 & 3.73 \\
\hline 7 & 0.7 & 4.9 & 37 & 0.13 & 35 & 3.5 & 122.5 & 31 & 3.95 \\
\hline 8 & 0.8 & 6.4 & 37 & 0.17 & 36 & 3.6 & 129.6 & 31 & 4.18 \\
\hline 9 & 0.9 & 8.1 & 37 & 0.22 & 37 & 3.7 & 136.9 & 31 & 4.42 \\
\hline 10 & 1 & 10 & 37 & 0.27 & 38 & 3.8 & 144.4 & 31 & 4.66 \\
\hline 11 & 1.1 & 12.1 & 37 & 0.33 & 39 & 3.9 & 152.1 & 31 & 4.91 \\
\hline 12 & 1.2 & 14.4 & 37 & 0.39 & 40 & 4 & 160 & 31 & 5.16 \\
\hline 13 & 1.3 & 16.9 & 37 & 0.46 & 41 & 4.1 & 168.1 & 31 & 5.42 \\
\hline 14 & 1.4 & 19.6 & 37 & 0.53 & 42 & 4.2 & 176.4 & 31 & 5.69 \\
\hline 15 & 1.5 & 22.5 & 37 & 0.61 & 43 & 4.3 & 184.9 & 31 & 5.96 \\
\hline 16 & 1.6 & 25.6 & 37 & 0.69 & 44 & 4.4 & 193.6 & 31 & 6.25 \\
\hline 17 & 1.7 & 28.9 & 37 & 0.78 & 45 & 4.5 & 202.5 & 31 & 6.53 \\
\hline 18 & 1.8 & 32.4 & 37 & 0.88 & 46 & 4.6 & 211.6 & 31 & 6.83 \\
\hline 19 & 1.9 & 36.1 & 37 & 0.98 & 47 & 4.7 & 220.9 & 31 & 7.13 \\
\hline 20 & 2 & 40 & 37 & 1.08 & 48 & 4.8 & 230.4 & 31 & 7.43 \\
\hline 21 & 2.1 & 44.1 & 37 & 1.19 & 49 & 4.9 & 240.1 & 31 & 7.75 \\
\hline 22 & 2.2 & 48.4 & 37 & 1.31 & 50 & 5 & 250 & 31 & 8.06 \\
\hline 23 & 2.3 & 52.9 & 37 & 1.43 & 51 & 5.1 & 260.1 & 31 & 8.39 \\
\hline 24 & 2.4 & 57.6 & 37 & 1.56 & 52 & 5.2 & 270.4 & 31 & 8.72 \\
\hline 25 & 2.5 & 62.5 & 37 & 1.69 & 53 & 5.3 & 280.9 & 31 & 9.06 \\
\hline 26 & 2.6 & 67.6 & 37 & 1.83 & 54 & 5.4 & 291.6 & 31 & 9.41 \\
\hline 27 & 2.7 & 72.9 & 37 & 1.97 & 55 & 5.5 & 302.5 & 31 & 9.76 \\
\hline 28 & 2.8 & 78.4 & 37 & 2.12 & 56 & 5.6 & 313.6 & 31 & 10.12 \\
\hline 29 & 2.9 & 84.1 & 37 & 2.27 & 57 & 5.7 & 324.9 & 31 & 10.48 \\
\hline 30 & 3 & 90 & 37 & 2.43 & 58 & 5.8 & 336.4 & 31 & 10.85 \\
\hline 31 & 3.1 & 96.1 & 37 & 2.60 & 59 & 5.9 & 348.1 & 31 & 11.23 \\
\hline 32 & 3.2 & 102.4 & 37 & 2.77 & 60 & 6 & 360 & 31 & 11.61 \\
\hline 33 & 3.3 & 108.9 & 37 & 2.94 & & & & & \\
\hline 34 & 3.4 & 115.6 & 37 & 3.12 & & & & & \\
\hline
\end{tabular}




\subsection{Modified LTC3780 Four Switch Buck-Boost Design}

After further research, a solution emerged involving the use of the four switch buck-boost converter controller LTC3780 for this project. As stated before, the problem with using the LTC3780 lies with the absolute maximum voltage rating of $\mathrm{V}_{\mathrm{in}}$, BOOST1, and BOOST2 pins. Linear Technology manufactures a high voltage synchronous Nchannel MOSFET driver, the LTC4444. This driver provides isolation from the high voltage bootstrapping circuitry required to turn on the top MOSFETs. In addition to the MOSFET drivers, the design needs a buck converter to bring the high voltages down to a usable supply voltage for the LTC3780 and the LTC4444s. The minimum operating voltage for the LTC4444 sets the output voltage of the buck converter to $7.2 \mathrm{~V}$ [17]. Linear Technology makes a switching regulator, the LT3980, to handle voltages up to $58 \mathrm{~V}$ that covers the wide input voltage specification of project [18]. By setting this output voltage at $7.2 \mathrm{~V}$, the elliptical machine fails to produce a physical resistance at voltages lower than $8 \mathrm{~V}$. This issue requires further research on if and how to address the problem since power harvested at this voltage proves minimal.

With the new MOSFET drivers, the four switch buck-boost converter replaces the previously proposed dual converter as the final design topology due to the complexity of interfacing the two converters and its limited input power. Also, the simulation uses the parameters specified in Table 8 instead of Table 11, SPICE parameters for the dual converter design, with the exception of voltages below $8 \mathrm{~V}$. Figure 25 shows the preliminary design, and Table 14 through Table 17 shows the efficiency reports at different power levels. Table 13 contains the parameters for the LTSPICE simulation. 
While designing the buck converter for the supply voltage, the maximum duty cycle limits the minimum input voltage. For the lowest minimum input voltage possible, the design dictates the lowest possible frequency. In other words for a low input voltage, the frequency set resistor should set the frequency as low as possible. This raises the maximum duty cycle as shown in the relationship given by Equation 7 below with $\mathrm{t}_{\mathrm{OFF}(\mathrm{MIN})}$ at 200ns[18]. According to Table 12 from the LT3980 datasheet, to set the frequency to $100 \mathrm{kHz}$ the frequency set resistor equals $432 \mathrm{k} \Omega$ [18].

Equation 7: LT3980 Maximum Duty Cycle [18]

$$
D C_{M A X}=1-f_{S W} * t_{O F F(M I N)}
$$

Table 12: Switching Frequency Vs Frequency Set Resistor [18]

\begin{tabular}{c|c}
\hline SWITCHING FREQUENCY $(\mathrm{MHz})$ & RT VALUE $(\mathrm{k} \Omega)$ \\
\hline 0.1 & 432 \\
0.2 & 215 \\
0.3 & 137 \\
0.4 & 97.6 \\
0.5 & 76.8 \\
0.6 & 60.4 \\
0.7 & 51.1 \\
0.8 & 43.2 \\
0.9 & 35.7 \\
1.0 & 32.4 \\
1.2 & 24.9 \\
1.4 & 20 \\
1.6 & 16.2 \\
1.8 & 14 \\
2.0 & 11 \\
\hline
\end{tabular}


Table 13: Simulation Parameters for the Modified LTC3780 Converter

\begin{tabular}{|c|c|c|c|c|c|c|c|c|c|}
\hline $\mathbf{V}_{\text {in }}[\mathbf{V}]$ & $\mathbf{I}_{\text {in }}[\mathbf{A}]$ & $\mathbf{P}_{\text {in }}=\mathbf{P}_{\mathbf{o}}[\mathbf{W}]$ & $\mathbf{V}_{\mathbf{o}}[\mathbf{V}]$ & $\mathbf{I}_{\mathbf{o}}[\mathbf{A}]$ & $\mathbf{V}_{\text {in }}[\mathbf{V}]$ & $\mathbf{I}_{\text {in }}[\mathbf{A}]$ & $\mathbf{P}_{\text {in }}=\mathbf{P}_{\mathbf{o}}[\mathbf{W}]$ & $\mathbf{V}_{\mathbf{o}}[\mathbf{V}]$ & $\mathbf{I}_{\mathbf{o}}[\mathbf{A}]$ \\
\hline 5 & 0.5 & 2.5 & 36 & 0.07 & 33 & 3.3 & 108.9 & 36 & 3.03 \\
\hline 6 & 0.6 & 3.6 & 36 & 0.10 & 34 & 3.4 & 115.6 & 36 & 3.21 \\
\hline 7 & 0.7 & 4.9 & 36 & 0.14 & 35 & 3.5 & 122.5 & 36 & 3.40 \\
\hline 8 & 0.8 & 6.4 & 36 & 0.18 & 36 & 3.6 & 129.6 & 36 & 3.60 \\
\hline 9 & 0.9 & 8.1 & 36 & 0.23 & 37 & 3.7 & 136.9 & 36 & 3.80 \\
\hline 10 & 1 & 10 & 36 & 0.28 & 38 & 3.8 & 144.4 & 36 & 4.01 \\
\hline 11 & 1.1 & 12.1 & 36 & 0.34 & 39 & 3.9 & 152.1 & 36 & 4.23 \\
\hline 12 & 1.2 & 14.4 & 36 & 0.40 & 40 & 4 & 160 & 36 & 4.44 \\
\hline 13 & 1.3 & 16.9 & 36 & 0.47 & 41 & 4.1 & 168.1 & 36 & 4.67 \\
\hline 14 & 1.4 & 19.6 & 36 & 0.54 & 42 & 4.2 & 176.4 & 36 & 4.90 \\
\hline 15 & 1.5 & 22.5 & 36 & 0.63 & 43 & 4.3 & 184.9 & 36 & 5.14 \\
\hline 16 & 1.6 & 25.6 & 36 & 0.71 & 44 & 4.4 & 193.6 & 36 & 5.38 \\
\hline 17 & 1.7 & 28.9 & 36 & 0.80 & 45 & 4.5 & 202.5 & 36 & 5.63 \\
\hline 18 & 1.8 & 32.4 & 36 & 0.90 & 46 & 4.6 & 211.6 & 36 & 5.88 \\
\hline 19 & 1.9 & 36.1 & 36 & 1.00 & 47 & 4.7 & 220.9 & 36 & 6.14 \\
\hline 20 & 2 & 40 & 36 & 1.11 & 48 & 4.8 & 230.4 & 36 & 6.40 \\
\hline 21 & 2.1 & 44.1 & 36 & 1.23 & 49 & 4.9 & 240.1 & 36 & 6.67 \\
\hline 22 & 2.2 & 48.4 & 36 & 1.34 & 50 & 5 & 250 & 36 & 6.94 \\
\hline 23 & 2.3 & 52.9 & 36 & 1.47 & 51 & 5.1 & 260.1 & 36 & 7.23 \\
\hline 24 & 2.4 & 57.6 & 36 & 1.60 & 52 & 5.2 & 270.4 & 36 & 7.51 \\
\hline 25 & 2.5 & 62.5 & 36 & 1.74 & 53 & 5.3 & 280.9 & 36 & 7.80 \\
\hline 26 & 2.6 & 67.6 & 36 & 1.88 & 54 & 5.4 & 291.6 & 36 & 8.10 \\
\hline 27 & 2.7 & 72.9 & 36 & 2.03 & 55 & 5.5 & 302.5 & 36 & 8.40 \\
\hline 28 & 2.8 & 78.4 & 36 & 2.18 & 56 & 5.6 & 313.6 & 36 & 8.71 \\
\hline 29 & 2.9 & 84.1 & 36 & 2.34 & 57 & 5.7 & 324.9 & 36 & 9.03 \\
\hline 30 & 3 & 90 & 36 & 2.50 & 58 & 5.8 & 336.4 & 36 & 9.34 \\
\hline 31 & 3.1 & 96.1 & 36 & 2.67 & 59 & 5.9 & 348.1 & 36 & 9.67 \\
\hline 32 & 3.2 & 102.4 & 36 & 2.84 & 60 & 6 & 360 & 36 & 10.00 \\
\hline
\end{tabular}




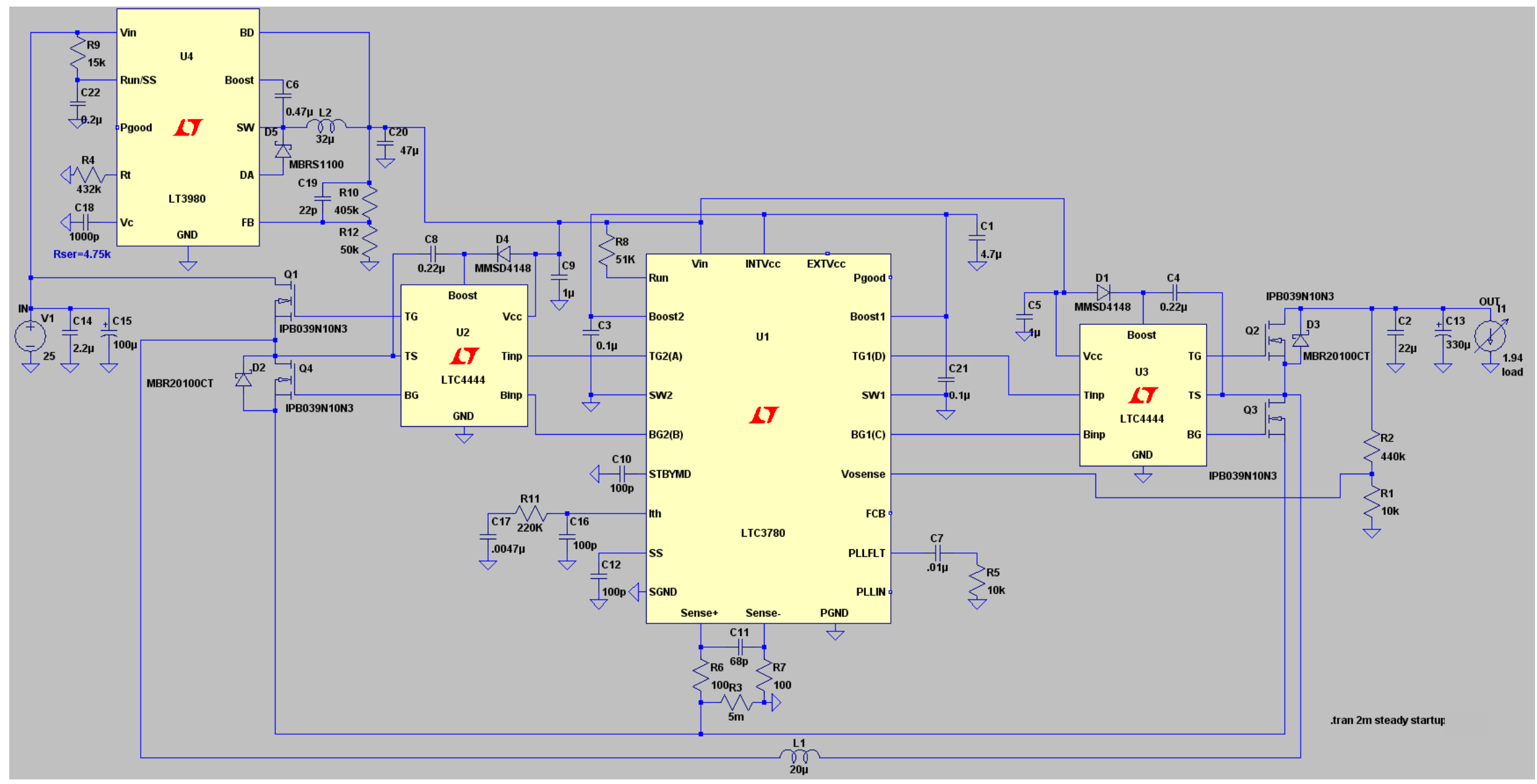

Figure 25: Modified LTC3780 Design for High Voltage Use 
Table 15: Efficiency Report 8Vin

\begin{tabular}{|c|c|c|c|}
\hline Efficiency: $\mathbf{8 6 . 4 \%}$ & \multicolumn{2}{|c|}{$\begin{array}{l}\text { Input: } 7.49 W @ 8 \mathrm{~V} \\
\text { Output: } 6.47 W @ 35.9 \mathrm{~V}\end{array}$} & \\
\hline Ref. & Irms & Ipeak & Dissipation \\
\hline C1 & $2 \mathrm{~mA}$ & $49 \mathrm{~mA}$ & $0 \mathrm{~mW}$ \\
\hline C2 & $202 \mathrm{~mA}$ & $5482 \mathrm{~mA}$ & $0 \mathrm{~mW}$ \\
\hline C3 & $0 \mathrm{~mA}$ & $1 \mathrm{~mA}$ & $0 \mathrm{~mW}$ \\
\hline C4 & $23 \mathrm{~mA}$ & $210 \mathrm{~mA}$ & $0 \mathrm{mw}$ \\
\hline C5 & $4 \mathrm{~mA}$ & $32 \mathrm{~mA}$ & $0 \mathrm{~mW}$ \\
\hline C6 & $3 \mathrm{~mA}$ & $126 \mathrm{~mA}$ & $0 \mathrm{~mW}$ \\
\hline C7 & $0 \mathrm{~mA}$ & $0 \mathrm{~mA}$ & $0 \mathrm{mw}$ \\
\hline C8 & $88 \mathrm{~mA}$ & $1043 \mathrm{~mA}$ & $0 \mathrm{~mW}$ \\
\hline c9 & $4 \mathrm{~mA}$ & $32 \mathrm{~mA}$ & $0 \mathrm{~mW}$ \\
\hline C10 & $0 \mathrm{~mA}$ & $0 \mathrm{~mA}$ & $0 \mathrm{mw}$ \\
\hline C11 & $0 \mathrm{~mA}$ & $0 \mathrm{~mA}$ & $0 \mathrm{mw}$ \\
\hline C12 & $0 \mathrm{~mA}$ & $0 \mathrm{~mA}$ & $0 \mathrm{~mW}$ \\
\hline C13 & $261 \mathrm{~mA}$ & $3532 \mathrm{~mA}$ & $0 \mathrm{mw}$ \\
\hline C14 & $0 \mathrm{~mA}$ & $0 \mathrm{~mA}$ & $0 \mathrm{~mW}$ \\
\hline C15 & $0 \mathrm{~mA}$ & $0 \mathrm{~mA}$ & $0 \mathrm{~mW}$ \\
\hline C16 & $0 \mathrm{~mA}$ & $0 \mathrm{~mA}$ & $0 \mathrm{~mW}$ \\
\hline c17 & $0 \mathrm{~mA}$ & $0 \mathrm{~mA}$ & $0 \mathrm{~mW}$ \\
\hline C18 & $0 \mathrm{~mA}$ & $0 \mathrm{~mA}$ & $0 \mathrm{mw}$ \\
\hline C19 & $0 \mathrm{~mA}$ & $0 \mathrm{~mA}$ & $0 \mathrm{mw}$ \\
\hline $\mathrm{C20}$ & $168 \mathrm{~mA}$ & $1483 \mathrm{~mA}$ & $0 \mathrm{~mW}$ \\
\hline C21 & $0 \mathrm{~mA}$ & $1 \mathrm{~mA}$ & $0 \mathrm{mw}$ \\
\hline $\mathrm{C} 22$ & $0 \mathrm{~mA}$ & $0 \mathrm{~mA}$ & $0 \mathrm{mw}$ \\
\hline D1 & $23 \mathrm{~mA}$ & $210 \mathrm{~mA}$ & $9 \mathrm{~mW}$ \\
\hline D2 & $0 \mathrm{~mA}$ & $2 \mathrm{~mA}$ & $0 \mathrm{~mW}$ \\
\hline D3 & $158 \mathrm{~mA}$ & $929 \mathrm{~mA}$ & $23 \mathrm{mw}$ \\
\hline D4 & $42 \mathrm{~mA}$ & $422 \mathrm{~mA}$ & $10 \mathrm{~mW}$ \\
\hline D5 & $13 \mathrm{~mA}$ & $641 \mathrm{~mA}$ & $2 \mathrm{~mW}$ \\
\hline L1 & $543 \mathrm{~mA}$ & $1074 \mathrm{~mA}$ & $1 \mathrm{~mW}$ \\
\hline L2 & $45 \mathrm{~mA}$ & $97 \mathrm{~mA}$ & $0 \mathrm{~mW}$ \\
\hline Q1 & $525 \mathrm{~mA}$ & $1166 \mathrm{~mA}$ & $50 \mathrm{~mW}$ \\
\hline Q2 & $329 \mathrm{~mA}$ & $8826 \mathrm{~mA}$ & $314 \mathrm{mw}$ \\
\hline Q3 & $595 \mathrm{~mA}$ & $8556 \mathrm{~mA}$ & $338 \mathrm{~mW}$ \\
\hline Q4 & $117 \mathrm{~mA}$ & $1449 \mathrm{~mA}$ & $38 \mathrm{~mW}$ \\
\hline R1 & $0 \mathrm{~mA}$ & $0 \mathrm{~mA}$ & $64 \mu \mathrm{WW}$ \\
\hline R2 & $0 \mathrm{~mA}$ & $0 \mathrm{~mA}$ & $3 \mathrm{~mW}$ \\
\hline R3 & $648 \mathrm{~mA}$ & $9276 \mathrm{~mA}$ & $2 \mathrm{~mW}$ \\
\hline R4 & $0 \mathrm{~mA}$ & $0 \mathrm{~mA}$ & $1 \mu \mathrm{W}$ \\
\hline R5 & $0 \mathrm{~mA}$ & $0 \mathrm{~mA}$ & $0 \mu w$ \\
\hline R6 & $0 \mathrm{~mA}$ & $0 \mathrm{~mA}$ & $0 \mu w$ \\
\hline R7 & $0 \mathrm{~mA}$ & $0 \mathrm{~mA}$ & $0 \mu w$ \\
\hline R8 & $0 \mathrm{~mA}$ & $0 \mathrm{~mA}$ & $116 \mu \mathrm{W}$ \\
\hline R9 & $0 \mathrm{~mA}$ & $0 \mathrm{~mA}$ & $166 \mu \mathrm{w}$ \\
\hline R10 & $0 \mathrm{~mA}$ & $0 \mathrm{~mA}$ & $101 \mu \mathrm{W}$ \\
\hline R11 & $0 \mathrm{~mA}$ & $0 \mathrm{~mA}$ & $0 \mu \mathrm{W}$ \\
\hline R12 & $0 \mathrm{~mA}$ & $0 \mathrm{~mA}$ & $12 \mu \mathrm{W}$ \\
\hline U1 & $2 \mathrm{~mA}$ & $26 \mathrm{~mA}$ & $22 \mathrm{~mW}$ \\
\hline U2 & $164 \mathrm{~mA}$ & $2632 \mathrm{~mA}$ & $103 \mathrm{mw}$ \\
\hline U3 & $101 \mathrm{~mA}$ & $1775 \mathrm{~mA}$ & $60 \mathrm{~mW}$ \\
\hline U4 & $46 \mathrm{~mA}$ & $684 \mathrm{~mA}$ & $45 \mathrm{~mW}$ \\
\hline
\end{tabular}

Table 14: Efficiency Report 15Vin

\begin{tabular}{|c|c|c|c|}
\hline \multicolumn{4}{|c|}{$\begin{array}{l}\text { Efficiency: } 94.5 \% \quad-- \text { Efficiency Report --- } \\
\text { Input: } 24 \mathrm{~W} @ 15 \mathrm{~V} \\
\text { Output: } 22.6 \mathrm{~W} @ 35.9 \mathrm{~V}\end{array}$} \\
\hline Ref. & Irms & Ipeak & Dissipation \\
\hline C1 & $1 \mathrm{~mA}$ & $49 \mathrm{~mA}$ & $0 \mathrm{~mW}$ \\
\hline C2 & $301 \mathrm{~mA}$ & 7493mA & $0 \mathrm{~mW}$ \\
\hline C3 & $0 \mathrm{~mA}$ & $1 \mathrm{~mA}$ & $0 \mathrm{mw}$ \\
\hline C4 & $75 \mathrm{~mA}$ & 1159mA & $0 \mathrm{~mW}$ \\
\hline C5 & $4 \mathrm{~mA}$ & $42 \mathrm{~mA}$ & $0 \mathrm{mw}$ \\
\hline C6 & $5 \mathrm{~mA}$ & $218 \mathrm{~mA}$ & $0 \mathrm{mw}$ \\
\hline C7 & $0 \mathrm{~mA}$ & $0 \mathrm{~mA}$ & $0 \mathrm{mw}$ \\
\hline C8 & $79 \mathrm{~mA}$ & $1430 \mathrm{~mA}$ & $0 \mathrm{~mW}$ \\
\hline c9 & $4 \mathrm{~mA}$ & $42 \mathrm{~mA}$ & $0 \mathrm{mw}$ \\
\hline C10 & $0 \mathrm{~mA}$ & $0 \mathrm{~mA}$ & $0 \mathrm{mw}$ \\
\hline C11 & $0 \mathrm{~mA}$ & $0 \mathrm{~mA}$ & $0 \mathrm{~mW}$ \\
\hline C12 & $0 \mathrm{~mA}$ & $0 \mathrm{~mA}$ & $0 \mathrm{~mW}$ \\
\hline C13 & $810 \mathrm{~mA}$ & $4704 \mathrm{~mA}$ & $3 \mathrm{mw}$ \\
\hline C14 & $0 \mathrm{~mA}$ & $0 \mathrm{~mA}$ & $0 \mathrm{mw}$ \\
\hline C15 & $0 \mathrm{~mA}$ & $0 \mathrm{~mA}$ & $0 \mathrm{mw}$ \\
\hline C16 & $0 \mathrm{~mA}$ & $0 \mathrm{~mA}$ & omw \\
\hline C17 & $0 \mathrm{~mA}$ & $0 \mathrm{~mA}$ & $0 \mathrm{mw}$ \\
\hline C18 & $0 \mathrm{~mA}$ & $0 \mathrm{~mA}$ & $0 \mathrm{~mW}$ \\
\hline C19 & $0 \mathrm{~mA}$ & $0 \mathrm{~mA}$ & $0 \mathrm{mw}$ \\
\hline C20 & $170 \mathrm{~mA}$ & $1981 \mathrm{~mA}$ & $0 \mathrm{mw}$ \\
\hline C21 & $0 \mathrm{~mA}$ & $1 \mathrm{~mA}$ & $0 \mathrm{~mW}$ \\
\hline C22 & $1 \mathrm{~mA}$ & $1 \mathrm{~mA}$ & $0 \mathrm{mw}$ \\
\hline D1 & $19 \mathrm{~mA}$ & $187 \mathrm{~mA}$ & $7 \mathrm{mw}$ \\
\hline D2 & $30 \mathrm{~mA}$ & $481 \mathrm{~mA}$ & $2 \mathrm{~mW}$ \\
\hline D3 & $367 \mathrm{~mA}$ & $2550 \mathrm{~mA}$ & $59 \mathrm{~mW}$ \\
\hline D4 & $58 \mathrm{~mA}$ & $1019 \mathrm{~mA}$ & $10 \mathrm{~mW}$ \\
\hline D5 & $54 \mathrm{~mA}$ & $643 \mathrm{~mA}$ & $9 \mathrm{~mW}$ \\
\hline L1 & $1701 \mathrm{~mA}$ & $2718 \mathrm{~mA}$ & $14 \mathrm{~mW}$ \\
\hline L2 & $79 \mathrm{~mA}$ & $328 \mathrm{~mA}$ & $0 \mathrm{~mW}$ \\
\hline Q1 & $1687 \mathrm{~mA}$ & $4822 \mathrm{~mA}$ & $188 \mathrm{~mW}$ \\
\hline Q2 & $1074 \mathrm{~mA}$ & $11555 \mathrm{~mA}$ & $26 \mathrm{~mW}$ \\
\hline Q3 & $1349 \mathrm{~mA}$ & $11827 \mathrm{~mA}$ & $685 \mathrm{~mW}$ \\
\hline Q4 & $288 \mathrm{~mA}$ & $4566 \mathrm{~mA}$ & $30 \mathrm{~mW}$ \\
\hline R1 & $0 \mathrm{~mA}$ & $0 \mathrm{~mA}$ & $64 \mu \mathrm{W}$ \\
\hline R2 & $0 \mathrm{~mA}$ & $0 \mathrm{~mA}$ & $3 \mathrm{~mW}$ \\
\hline R3 & $1391 \mathrm{~mA}$ & $12348 \mathrm{~mA}$ & $10 \mathrm{~mW}$ \\
\hline R4 & $0 \mathrm{~mA}$ & $0 \mathrm{~mA}$ & $1 \mu \mathrm{W}$ \\
\hline R5 & $0 \mathrm{~mA}$ & $0 \mathrm{~mA}$ & $0 \mu \mathrm{w}$ \\
\hline R6 & $0 \mathrm{~mA}$ & $0 \mathrm{~mA}$ & $0 \mu \mathrm{W}$ \\
\hline R7 & $0 \mathrm{~mA}$ & $0 \mathrm{~mA}$ & $0 \mu w$ \\
\hline R8 & $0 \mathrm{~mA}$ & $0 \mathrm{~mA}$ & $116 \mu \mathrm{w}$ \\
\hline R9 & $1 \mathrm{~mA}$ & $1 \mathrm{~mA}$ & $4 \mathrm{~mW}$ \\
\hline R10 & $0 \mathrm{~mA}$ & $\mathrm{OmA}$ & $101 \mu \mathrm{W}$ \\
\hline R11 & $0 \mathrm{~mA}$ & $0 \mathrm{~mA}$ & $0 \mu w$ \\
\hline R12 & $0 \mathrm{~mA}$ & $0 \mathrm{~mA}$ & $12 \mu \mathrm{W}$ \\
\hline U1 & $2 \mathrm{~mA}$ & $26 \mathrm{~mA}$ & $22 \mathrm{mw}$ \\
\hline U2 & $145 \mathrm{~mA}$ & $2632 \mathrm{~mA}$ & $84 \mathrm{~mW}$ \\
\hline U3 & $151 \mathrm{~mA}$ & $2638 \mathrm{~mA}$ & $87 \mathrm{~mW}$ \\
\hline U4 & $58 \mathrm{~mA}$ & $869 \mathrm{~mA}$ & $72 \mathrm{~mW}$ \\
\hline
\end{tabular}

Table 16: Efficiency Report 25Vin

\begin{tabular}{|c|c|c|c|}
\hline \multicolumn{4}{|c|}{$\begin{array}{l}\text { Efficiency: } 95.9 \% \\
\text { Input: } 65 \mathrm{~W} @ 25 \mathrm{~V} \\
\text { Output: } 62.3 \mathrm{~W} @ 35.8 \mathrm{~V}\end{array}$} \\
\hline Ref. & Irms & Ipeak & Dissipation \\
\hline C1 & $2 \mathrm{~mA}$ & $49 \mathrm{~mA}$ & $0 \mathrm{~mW}$ \\
\hline C2 & $564 \mathrm{~mA}$ & $9686 \mathrm{~mA}$ & $1 \mathrm{~mW}$ \\
\hline C3 & $0 \mathrm{~mA}$ & $1 \mathrm{~mA}$ & $0 \mathrm{~mW}$ \\
\hline C4 & $68 \mathrm{~mA}$ & $1075 \mathrm{~mA}$ & $0 \mathrm{~mW}$ \\
\hline C5 & $4 \mathrm{~mA}$ & $38 \mathrm{~mA}$ & $0 \mathrm{~mW}$ \\
\hline C6 & $2 \mathrm{~mA}$ & $279 \mathrm{~mA}$ & $0 \mathrm{~mW}$ \\
\hline C7 & $O \mathrm{~mA}$ & $0 \mathrm{~mA}$ & $0 \mathrm{~mW}$ \\
\hline C8 & $91 \mathrm{~mA}$ & 2038mA & $0 \mathrm{~mW}$ \\
\hline C9 & $4 \mathrm{~mA}$ & $38 \mathrm{~mA}$ & $0 \mathrm{~mW}$ \\
\hline C10 & $0 \mathrm{~mA}$ & $0 \mathrm{~mA}$ & $0 \mathrm{~mW}$ \\
\hline C11 & $0 \mathrm{~mA}$ & $0 \mathrm{~mA}$ & $0 \mathrm{~mW}$ \\
\hline C12 & $0 \mathrm{~mA}$ & $0 \mathrm{~mA}$ & $0 \mathrm{~mW}$ \\
\hline C13 & $2184 \mathrm{~mA}$ & $4679 \mathrm{~mA}$ & $24 \mathrm{~mW}$ \\
\hline C14 & $0 \mathrm{~mA}$ & $0 \mathrm{~mA}$ & $0 \mathrm{mw}$ \\
\hline C15 & $0 \mathrm{~mA}$ & $0 \mathrm{~mA}$ & $0 \mathrm{~mW}$ \\
\hline C16 & $0 \mathrm{~mA}$ & $0 \mathrm{~mA}$ & $0 \mathrm{~mW}$ \\
\hline C17 & $0 \mathrm{~mA}$ & $0 \mathrm{~mA}$ & $0 \mathrm{~mW}$ \\
\hline C18 & $0 \mathrm{~mA}$ & $0 \mathrm{~mA}$ & $0 \mathrm{~mW}$ \\
\hline C19 & $0 \mathrm{~mA}$ & $0 \mathrm{~mA}$ & $0 \mathrm{~mW}$ \\
\hline C20 & $195 \mathrm{~mA}$ & $1799 \mathrm{~mA}$ & $0 \mathrm{~mW}$ \\
\hline C21 & $0 \mathrm{~mA}$ & $1 \mathrm{~mA}$ & $0 \mathrm{~mW}$ \\
\hline C22 & $1 \mathrm{~mA}$ & $1 \mathrm{~mA}$ & $0 \mathrm{~mW}$ \\
\hline D1 & $19 \mathrm{~mA}$ & $165 \mathrm{~mA}$ & $6 \mathrm{~mW}$ \\
\hline D2 & $526 \mathrm{~mA}$ & $3519 \mathrm{~mA}$ & $58 \mathrm{~mW}$ \\
\hline D3 & $1327 \mathrm{~mA}$ & $5154 \mathrm{~mA}$ & $300 \mathrm{~mW}$ \\
\hline D4 & $68 \mathrm{~mA}$ & $1591 \mathrm{~mA}$ & $12 \mathrm{~mW}$ \\
\hline D5 & $93 \mathrm{~mA}$ & $764 \mathrm{~mA}$ & $13 \mathrm{~mW}$ \\
\hline L1 & $4384 \mathrm{~mA}$ & $5613 \mathrm{~mA}$ & $96 \mathrm{~mW}$ \\
\hline L2 & $112 \mathrm{~mA}$ & $569 \mathrm{~mA}$ & $0 \mathrm{mw}$ \\
\hline Q1 & $4223 \mathrm{~mA}$ & $10868 \mathrm{~mA}$ & $675 \mathrm{~mW}$ \\
\hline Q2 & $3201 \mathrm{~mA}$ & $12408 \mathrm{~mA}$ & $123 \mathrm{~mW}$ \\
\hline Q3 & $2723 \mathrm{~mA}$ & $15548 \mathrm{~mA}$ & $928 \mathrm{~mW}$ \\
\hline Q4 & $1084 \mathrm{~mA}$ & $7752 \mathrm{~mA}$ & $40 \mathrm{~mW}$ \\
\hline R1 & $0 \mathrm{~mA}$ & $0 \mathrm{~mA}$ & $63 \mu \mathrm{W}$ \\
\hline R2 & $0 \mathrm{~mA}$ & $0 \mathrm{~mA}$ & $3 \mathrm{mw}$ \\
\hline R3 & $2976 \mathrm{~mA}$ & $13172 \mathrm{~mA}$ & $44 \mathrm{~mW}$ \\
\hline R4 & $0 \mathrm{~mA}$ & $0 \mathrm{~mA}$ & $1 \mu \mathrm{W}$ \\
\hline R5 & $0 \mathrm{~mA}$ & $0 \mathrm{~mA}$ & ouw \\
\hline R6 & $0 \mathrm{~mA}$ & $0 \mathrm{~mA}$ & $0 \mu w$ \\
\hline R7 & $0 \mathrm{~mA}$ & $0 \mathrm{~mA}$ & $0 \mu w$ \\
\hline R8 & $0 \mathrm{~mA}$ & $0 \mathrm{~mA}$ & $116 \mu \mathrm{W}$ \\
\hline R9 & $1 \mathrm{~mA}$ & $1 \mathrm{~mA}$ & $11 \mathrm{~mW}$ \\
\hline R10 & $0 \mathrm{~mA}$ & $0 \mathrm{~mA}$ & $101 \mu \mathrm{W}$ \\
\hline R11 & $0 \mathrm{~mA}$ & $0 \mathrm{~mA}$ & ouw \\
\hline R12 & $0 \mathrm{~mA}$ & $0 \mathrm{~mA}$ & $12 \mu \mathrm{W}$ \\
\hline U1 & $2 m A$ & $26 \mathrm{~mA}$ & $22 \mathrm{mw}$ \\
\hline U2 & $151 \mathrm{~mA}$ & $2635 \mathrm{~mA}$ & $97 \mathrm{~mW}$ \\
\hline U3 & $152 \mathrm{~mA}$ & $2640 \mathrm{~mA}$ & $86 \mathrm{~mW}$ \\
\hline U4 & $93 \mathrm{~mA}$ & $1099 \mathrm{~mA}$ & $112 \mathrm{~mW}$ \\
\hline
\end{tabular}


Table 17: Efficiency Report 30Vin

\begin{tabular}{|c|c|c|c|}
\hline \multicolumn{4}{|c|}{$\begin{array}{l}\text { Efficiency: } 98.9 \% \\
\text { Input: } 90.5 \mathrm{~W} @ 30 \mathrm{~V} \\
\text { Output: } 89.6 \mathrm{~W} @ 35.8 \mathrm{~V}\end{array}$} \\
\hline Ref. & Irms & Ipeak & Dissipation \\
\hline C1 & $1 \mathrm{~mA}$ & $46 \mathrm{~mA}$ & $0 \mathrm{~mW}$ \\
\hline C2 & $286 \mathrm{~mA}$ & $9901 \mathrm{~mA}$ & $0 \mathrm{~mW}$ \\
\hline C3 & $0 \mathrm{~mA}$ & $1 \mathrm{~mA}$ & $0 \mathrm{~mW}$ \\
\hline C4 & $58 \mathrm{~mA}$ & $1071 \mathrm{~mA}$ & $0 \mathrm{~mW}$ \\
\hline C5 & $2 \mathrm{~mA}$ & $38 \mathrm{~mA}$ & $0 \mathrm{mw}$ \\
\hline C6 & $1 \mathrm{~mA}$ & $2 \mathrm{~mA}$ & $0 \mathrm{~mW}$ \\
\hline C7 & $0 \mathrm{~mA}$ & $\mathrm{OmA}$ & $0 \mathrm{~mW}$ \\
\hline C8 & $44 \mathrm{~mA}$ & $2104 \mathrm{~mA}$ & $0 \mathrm{mw}$ \\
\hline C9 & $2 \mathrm{~mA}$ & $38 \mathrm{~mA}$ & $0 \mathrm{~mW}$ \\
\hline C10 & $0 \mathrm{~mA}$ & $0 \mathrm{~mA}$ & $0 \mathrm{~mW}$ \\
\hline C11 & $0 \mathrm{~mA}$ & $0 \mathrm{~mA}$ & $0 \mathrm{~mW}$ \\
\hline C12 & $0 \mathrm{~mA}$ & $0 \mathrm{~mA}$ & $0 \mathrm{~mW}$ \\
\hline C13 & $2229 \mathrm{~mA}$ & $5120 \mathrm{~mA}$ & $25 \mathrm{~mW}$ \\
\hline C14 & $0 \mathrm{~mA}$ & $0 \mathrm{~mA}$ & $0 \mathrm{~mW}$ \\
\hline C15 & $0 \mathrm{~mA}$ & $0 \mathrm{~mA}$ & $0 \mathrm{mw}$ \\
\hline C16 & $0 \mathrm{~mA}$ & $0 \mathrm{~mA}$ & $0 \mathrm{~mW}$ \\
\hline C17 & $0 \mathrm{~mA}$ & $0 \mathrm{~mA}$ & $0 \mathrm{~mW}$ \\
\hline C18 & $0 \mathrm{~mA}$ & $0 \mathrm{~mA}$ & $0 \mathrm{mw}$ \\
\hline C19 & $0 \mathrm{~mA}$ & $0 \mathrm{~mA}$ & $0 \mathrm{~mW}$ \\
\hline C20 & $98 \mathrm{~mA}$ & $1777 \mathrm{~mA}$ & $0 \mathrm{~mW}$ \\
\hline C21 & $0 \mathrm{~mA}$ & $1 \mathrm{~mA}$ & $0 \mathrm{~mW}$ \\
\hline C22 & $1 \mathrm{~mA}$ & $1 \mathrm{~mA}$ & $0 \mathrm{~mW}$ \\
\hline D1 & $50 \mathrm{~mA}$ & $551 \mathrm{~mA}$ & $9 \mathrm{~mW}$ \\
\hline D2 & $300 \mathrm{~mA}$ & 4124mA & $16 \mathrm{~mW}$ \\
\hline D3 & $1050 \mathrm{~mA}$ & $4700 \mathrm{~mA}$ & $200 \mathrm{~mW}$ \\
\hline D4 & $35 \mathrm{~mA}$ & $1653 \mathrm{~mA}$ & $3 \mathrm{~mW}$ \\
\hline D5 & $7 \mathrm{~mA}$ & $12 \mathrm{~mA}$ & $-0 \mathrm{mw}$ \\
\hline L1 & $1532 \mathrm{~mA}$ & $5033 \mathrm{~mA}$ & $12 \mathrm{~mW}$ \\
\hline L2 & $9 \mathrm{~mA}$ & $16 \mathrm{~mA}$ & $0 \mathrm{~mW}$ \\
\hline Q1 & $1093 \mathrm{~mA}$ & $12027 \mathrm{~mA}$ & $180 \mathrm{~mW}$ \\
\hline Q2 & $588 \mathrm{~mA}$ & $12507 \mathrm{~mA}$ & $57 \mathrm{~mW}$ \\
\hline Q3 & $936 \mathrm{~mA}$ & $15812 \mathrm{~mA}$ & $240 \mathrm{mw}$ \\
\hline Q4 & $1026 \mathrm{~mA}$ & $8735 \mathrm{~mA}$ & $-17 \mathrm{~mW}$ \\
\hline R1 & $0 \mathrm{~mA}$ & $0 \mathrm{~mA}$ & $63 \mu \mathrm{W}$ \\
\hline R2 & $0 \mathrm{~mA}$ & $0 \mathrm{~mA}$ & $3 \mathrm{mw}$ \\
\hline R3 & $1368 \mathrm{~mA}$ & $13787 \mathrm{~mA}$ & $9 \mathrm{~mW}$ \\
\hline R4 & $0 \mathrm{~mA}$ & $0 \mathrm{~mA}$ & $1 \mu w$ \\
\hline R5 & $0 \mathrm{~mA}$ & $0 \mathrm{~mA}$ & $0 \mu \mathrm{W}$ \\
\hline R6 & $0 \mathrm{~mA}$ & $0 \mathrm{~mA}$ & $0 \mu \mathrm{w}$ \\
\hline R7 & $0 \mathrm{~mA}$ & $0 \mathrm{~mA}$ & $0 \mu \mathrm{W}$ \\
\hline R8 & $0 \mathrm{~mA}$ & $0 \mathrm{~mA}$ & $116 \mu \mathrm{W}$ \\
\hline R9 & $1 \mathrm{~mA}$ & $1 \mathrm{~mA}$ & $16 \mathrm{~mW}$ \\
\hline R10 & $0 \mathrm{~mA}$ & $0 \mathrm{~mA}$ & $101 \mu \mathrm{W}$ \\
\hline R11 & $0 \mathrm{~mA}$ & $0 \mathrm{~mA}$ & $0 \mu \mathrm{W}$ \\
\hline R12 & $0 \mathrm{~mA}$ & $0 \mathrm{~mA}$ & $12 \mu w \mathrm{w}$ \\
\hline U1 & $2 \mathrm{~mA}$ & $26 \mathrm{~mA}$ & $21 \mathrm{~mW}$ \\
\hline U2 & $74 \mathrm{~mA}$ & $2633 \mathrm{~mA}$ & $29 \mathrm{~mW}$ \\
\hline U3 & $68 \mathrm{~mA}$ & $2630 \mathrm{~mA}$ & $22 \mathrm{mw}$ \\
\hline U4 & $9 \mathrm{~mA}$ & $20 \mathrm{~mA}$ & $127 \mathrm{~mW}$ \\
\hline
\end{tabular}

Table 18: Efficiency Report 36Vin

\begin{tabular}{|c|c|c|c|}
\hline \multicolumn{2}{|c|}{ Efficiency: 96.0\% } & \multicolumn{2}{|c|}{-.- Efficiency Report -.- } \\
\hline \multicolumn{4}{|c|}{$\begin{array}{l}\text { Input: } 134 \mathrm{~W} @ 36 \mathrm{~V} \\
\text { Output: } 129 \mathrm{~W} @ 35.8 \mathrm{~V}\end{array}$} \\
\hline Ref. & Irms & Ipeak & Dissipation \\
\hline C1 & $2 \mathrm{~mA}$ & $49 \mathrm{~mA}$ & $0 \mathrm{~mW}$ \\
\hline C2 & $975 \mathrm{~mA}$ & $21989 \mathrm{~mA}$ & $3 \mathrm{mw}$ \\
\hline c3 & $0 \mathrm{~mA}$ & $1 \mathrm{~mA}$ & $0 \mathrm{~mW}$ \\
\hline C4 & $72 \mathrm{~mA}$ & $1090 \mathrm{~mA}$ & $0 \mathrm{mw}$ \\
\hline C5 & $6 \mathrm{~mA}$ & $41 \mathrm{~mA}$ & $0 \mathrm{mw}$ \\
\hline C6 & $4 \mathrm{~mA}$ & $317 \mathrm{~mA}$ & $0 \mathrm{mw}$ \\
\hline C7 & $0 \mathrm{~mA}$ & $0 \mathrm{~mA}$ & $0 \mathrm{~mW}$ \\
\hline C8 & 97mA & $3075 \mathrm{~mA}$ & $0 \mathrm{~mW}$ \\
\hline c9 & $6 \mathrm{~mA}$ & $41 \mathrm{~mA}$ & $0 \mathrm{~mW}$ \\
\hline C10 & $0 \mathrm{~mA}$ & $0 \mathrm{~mA}$ & $0 \mathrm{~mW}$ \\
\hline C11 & $0 \mathrm{~mA}$ & $1 \mathrm{~mA}$ & $0 \mathrm{mw}$ \\
\hline C12 & $0 \mathrm{~mA}$ & $0 \mathrm{~mA}$ & $0 \mathrm{~mW}$ \\
\hline C13 & $3731 \mathrm{~mA}$ & $10223 \mathrm{~mA}$ & $70 \mathrm{~mW}$ \\
\hline C14 & $0 \mathrm{~mA}$ & $0 \mathrm{~mA}$ & $0 \mathrm{~mW}$ \\
\hline C15 & $0 \mathrm{~mA}$ & $0 \mathrm{~mA}$ & $0 \mathrm{mw}$ \\
\hline C16 & $0 \mathrm{~mA}$ & $0 \mathrm{~mA}$ & $0 \mathrm{mw}$ \\
\hline C17 & $0 \mathrm{~mA}$ & $0 \mathrm{~mA}$ & $0 \mathrm{~mW}$ \\
\hline C18 & $0 \mathrm{~mA}$ & $0 \mathrm{~mA}$ & $0 \mathrm{~mW}$ \\
\hline C19 & $0 \mathrm{~mA}$ & $0 \mathrm{~mA}$ & $0 \mathrm{~mW}$ \\
\hline $\mathrm{C20}$ & $292 \mathrm{~mA}$ & $1939 \mathrm{~mA}$ & $0 \mathrm{~mW}$ \\
\hline C21 & $0 \mathrm{~mA}$ & $1 \mathrm{~mA}$ & $0 \mathrm{~mW}$ \\
\hline $\mathrm{c} 22$ & $1 \mathrm{~mA}$ & $1 \mathrm{~mA}$ & $0 \mathrm{mw}$ \\
\hline D1 & $12 \mathrm{~mA}$ & $138 \mathrm{~mA}$ & $2 \mathrm{mw}$ \\
\hline D2 & $1111 \mathrm{~mA}$ & $6457 \mathrm{~mA}$ & $142 \mathrm{~mW}$ \\
\hline D3 & $2447 \mathrm{~mA}$ & $6884 \mathrm{~mA}$ & $621 \mathrm{~mW}$ \\
\hline D4 & $74 \mathrm{~mA}$ & $2629 \mathrm{~mA}$ & $14 \mathrm{~mW}$ \\
\hline D5 & $219 \mathrm{~mA}$ & $839 \mathrm{~mA}$ & $55 \mathrm{~mW}$ \\
\hline L1 & $7772 \mathrm{~mA}$ & $8053 \mathrm{~mA}$ & $302 \mathrm{~mW}$ \\
\hline L2 & $253 \mathrm{~mA}$ & $812 \mathrm{~mA}$ & $0 \mathrm{~mW}$ \\
\hline Q1 & $7356 \mathrm{~mA}$ & $28490 \mathrm{~mA}$ & $1764 \mathrm{~mW}$ \\
\hline Q2 & $6787 \mathrm{~mA}$ & $30165 \mathrm{~mA}$ & $324 \mathrm{~mW}$ \\
\hline Q3 & $2733 \mathrm{~mA}$ & $35505 \mathrm{~mA}$ & $1453 \mathrm{~mW}$ \\
\hline Q4 & $2262 \mathrm{~mA}$ & $23085 \mathrm{~mA}$ & $76 \mathrm{~mW}$ \\
\hline R1 & $0 \mathrm{~mA}$ & $0 \mathrm{~mA}$ & $63 \mu \mathrm{W}$ \\
\hline R2 & $0 \mathrm{~mA}$ & $0 \mathrm{~mA}$ & $3 \mathrm{~mW}$ \\
\hline R3 & $3743 \mathrm{~mA}$ & $30503 \mathrm{~mA}$ & $70 \mathrm{mw}$ \\
\hline R4 & $0 \mathrm{~mA}$ & $0 \mathrm{~mA}$ & $1 \mu W$ \\
\hline R5 & OmA & $0 \mathrm{~mA}$ & $0 \mu \mathrm{w}$ \\
\hline R6 & $0 \mathrm{~mA}$ & $1 \mathrm{~mA}$ & $0 \mu w$ \\
\hline R7 & $0 \mathrm{~mA}$ & $1 \mathrm{~mA}$ & ouw \\
\hline R8 & $0 \mathrm{~mA}$ & $0 \mathrm{~mA}$ & $116 \mu \mathrm{W}$ \\
\hline R9 & $1 \mathrm{~mA}$ & $1 \mathrm{~mA}$ & $23 \mathrm{~mW}$ \\
\hline R10 & $0 \mathrm{~mA}$ & $0 \mathrm{~mA}$ & $102 \mu \mathrm{W}$ \\
\hline R11 & $\mathrm{OmA}$ & $0 \mathrm{~mA}$ & $0 \mu \mathrm{W}$ \\
\hline R12 & $0 \mathrm{~mA}$ & $0 \mathrm{~mA}$ & $13 \mu \mathrm{W}$ \\
\hline U1 & $2 \mathrm{~mA}$ & $26 \mathrm{~mA}$ & $22 \mathrm{~mW}$ \\
\hline U2 & $152 \mathrm{~mA}$ & $2630 \mathrm{~mA}$ & $100 \mathrm{~mW}$ \\
\hline U3 & $163 \mathrm{~mA}$ & $2634 \mathrm{~mA}$ & $93 \mathrm{~mW}$ \\
\hline U4 & $219 \mathrm{~mA}$ & $1299 \mathrm{~mA}$ & $225 \mathrm{~mW}$ \\
\hline
\end{tabular}

\section{Table 19: Efficiency Report 52Vin}

\begin{tabular}{|c|c|c|c|}
\hline \multicolumn{4}{|c|}{$\begin{array}{l}\text { Efficiency: 98.4\% } \\
\text { Input: 273W @ Efficiency Report - 52V } \\
\text { Output: 269W @ 35.9V }\end{array}$} \\
\hline Ref. & Irms & Ipeak & Dissipation \\
\hline C1 & $1 \mathrm{~mA}$ & $25 \mathrm{~mA}$ & $0 \mathrm{~mW}$ \\
\hline C2 & $125 \mathrm{~mA}$ & 434mA & $0 \mathrm{~mW}$ \\
\hline C3 & $0 \mathrm{~mA}$ & $1 \mathrm{~mA}$ & $0 \mathrm{~mW}$ \\
\hline C4 & $0 \mathrm{~mA}$ & $0 \mathrm{~mA}$ & $0 \mathrm{~mW}$ \\
\hline C5 & $2 \mathrm{~mA}$ & $29 \mathrm{~mA}$ & $0 \mathrm{~mW}$ \\
\hline C6 & $0 \mathrm{~mA}$ & $0 \mathrm{~mA}$ & $0 \mathrm{~mW}$ \\
\hline C7 & $0 \mathrm{~mA}$ & $0 \mathrm{~mA}$ & $0 \mathrm{~mW}$ \\
\hline C8 & $90 \mathrm{~mA}$ & $1133 \mathrm{~mA}$ & $0 \mathrm{~mW}$ \\
\hline C9 & $2 \mathrm{~mA}$ & $29 \mathrm{~mA}$ & $0 \mathrm{~mW}$ \\
\hline C10 & $0 \mathrm{~mA}$ & $0 \mathrm{~mA}$ & $0 \mathrm{~mW}$ \\
\hline C11 & $0 \mathrm{~mA}$ & $1 \mathrm{~mA}$ & $0 \mathrm{~mW}$ \\
\hline C12 & $0 \mathrm{~mA}$ & $\mathrm{OmA}$ & $0 \mathrm{~mW}$ \\
\hline C13 & $764 \mathrm{~mA}$ & $1362 \mathrm{~mA}$ & $3 \mathrm{mw}$ \\
\hline C14 & $0 \mathrm{~mA}$ & $0 \mathrm{~mA}$ & $0 \mathrm{~mW}$ \\
\hline C15 & $0 \mathrm{~mA}$ & $0 \mathrm{~mA}$ & $0 \mathrm{mw}$ \\
\hline C16 & $0 \mathrm{~mA}$ & $0 \mathrm{~mA}$ & $0 \mathrm{~mW}$ \\
\hline C17 & $0 \mathrm{~mA}$ & $0 \mathrm{~mA}$ & $0 \mathrm{mw}$ \\
\hline C18 & $0 \mathrm{~mA}$ & $0 \mathrm{~mA}$ & $0 \mathrm{~mW}$ \\
\hline C19 & $0 \mathrm{~mA}$ & $0 \mathrm{~mA}$ & $0 \mathrm{~mW}$ \\
\hline C20 & $93 \mathrm{~mA}$ & $1355 \mathrm{~mA}$ & $0 \mathrm{~mW}$ \\
\hline C21 & $0 \mathrm{~mA}$ & $1 \mathrm{~mA}$ & $0 \mathrm{~mW}$ \\
\hline C22 & $2 \mathrm{~mA}$ & $2 \mathrm{~mA}$ & $0 \mathrm{mw}$ \\
\hline D1 & $0 \mathrm{~mA}$ & $0 \mathrm{~mA}$ & $0 \mathrm{~mW}$ \\
\hline D2 & $2877 \mathrm{~mA}$ & $7344 \mathrm{~mA}$ & $817 \mathrm{~mW}$ \\
\hline $\begin{array}{l}\text { D3 } \\
\text { D3 }\end{array}$ & $0 \mathrm{~mA}$ & $1 \mathrm{~mA}$ & $0 \mathrm{~mW}$ \\
\hline D4 & $40 \mathrm{~mA}$ & $294 \mathrm{~mA}$ & $11 \mathrm{~mW}$ \\
\hline D5 & $2 \mathrm{~mA}$ & $4 \mathrm{~mA}$ & $0 \mathrm{mw}$ \\
\hline L1 & $7536 \mathrm{~mA}$ & $9028 \mathrm{~mA}$ & $284 \mathrm{~mW}$ \\
\hline L2 & $3 \mathrm{~mA}$ & $5 \mathrm{~mA}$ & $0 \mathrm{mw}$ \\
\hline Q1 & $6203 \mathrm{~mA}$ & $27013 \mathrm{~mA}$ & $2432 \mathrm{~mW}$ \\
\hline Q2 & $7536 \mathrm{~mA}$ & $9027 \mathrm{~mA}$ & $270 \mathrm{~mW}$ \\
\hline Q3 & $2 \mathrm{~mA}$ & $286 \mathrm{~mA}$ & $0 \mathrm{~mW}$ \\
\hline Q4 & $2798 \mathrm{~mA}$ & $22292 \mathrm{~mA}$ & $196 \mathrm{~mW}$ \\
\hline R1 & $0 \mathrm{~mA}$ & $0 \mathrm{~mA}$ & $63 \mu \mathrm{W}$ \\
\hline $\begin{array}{l}\mathrm{R} 2 \\
\mathrm{R} 2\end{array}$ & $0 \mathrm{~mA}$ & $0 \mathrm{~mA}$ & $3 \mathrm{~mW}$ \\
\hline R3 & $4330 \mathrm{~mA}$ & $20550 \mathrm{~mA}$ & $94 \mathrm{~mW}$ \\
\hline R4 & $0 \mathrm{~mA}$ & $0 \mathrm{~mA}$ & $1 \mu w$ \\
\hline R5 & $0 \mathrm{~mA}$ & $0 \mathrm{~mA}$ & $0 \mu \mathrm{W}$ \\
\hline R6 & $0 \mathrm{~mA}$ & $1 \mathrm{~mA}$ & $0 \mu w$ \\
\hline R7 & $0 \mathrm{~mA}$ & $1 \mathrm{~mA}$ & $0 \mu \mathrm{W}$ \\
\hline R8 & $0 \mathrm{~mA}$ & $0 \mathrm{~mA}$ & $115 \mu w$ \\
\hline R9 & $2 \mathrm{~mA}$ & $2 \mathrm{~mA}$ & $48 \mathrm{~mW}$ \\
\hline R10 & $0 \mathrm{~mA}$ & $0 \mathrm{~mA}$ & $101 \mu \mathrm{W}$ \\
\hline R11 & $0 \mathrm{~mA}$ & $0 \mathrm{~mA}$ & $0 \mu \mathrm{W}$ \\
\hline R12 & $0 \mathrm{~mA}$ & $0 \mathrm{~mA}$ & $12 \mu \mathrm{W}$ \\
\hline U1 & $2 \mathrm{~mA}$ & $26 \mathrm{~mA}$ & $21 \mathrm{~mW}$ \\
\hline U2 & $151 \mathrm{~mA}$ & $2630 \mathrm{~mA}$ & $102 \mathrm{~mW}$ \\
\hline U3 & $1 \mathrm{~mA}$ & $55 \mathrm{~mA}$ & $4 \mathrm{~mW}$ \\
\hline U4 & $6 \mathrm{~mA}$ & $9 \mathrm{~mA}$ & $216 \mathrm{~mW}$ \\
\hline
\end{tabular}




\section{CHAPTER 4: DESIGN REALIZATION}

\subsection{Introduction}

This chapter walks through the prototyping of the Four-Switch Buck-Boost converter. It begins with the component selection, and it then progresses to the PCBA layout and fabrication. In each step, the consideration of many factors provided the most efficient and cost effective solution.

\subsection{Component Selection}

The datasheets for the three different chips specify the typical component values used in the schematic $[9,17,18]$. Table 20 shows the calculation of some of the components used to set the output voltage, and meet the design specifications. The table includes both the critical components for the Four-Switch Buck-Boost and its supply rail Buck converter. The LTSPICE simulations help determine the MOSFET and diode breakdown voltages and average current ratings, by analyzing the maximum voltage and current characteristics of each component. The inductor for the LT3980 specifies $41 \mu \mathrm{H}$, but the converter may run in discontinuous conduction mode. This doesn't pose a problem since the circuitry it powers doesn't demand much current. For now, the buck converter utilizes a $32 \mu \mathrm{H}$ inductor, and the four switch buck-boost converter uses a $20 \mu \mathrm{H}$ inductor. The converter maintains efficiencies around $95 \%$ across all typical input voltages, $15-30 \mathrm{~V}$, as listed in Table 14 and Table 16 . It also maintains relatively high efficiencies of $86 \%$ at the minimum input voltage, $8 \mathrm{~V}$, and $98 \%$ at the maximum input voltage, $52 \mathrm{~V}$. All the components meet the voltage and current requirement at the worst case scenario, $52 \mathrm{~V}$ input. 
Table 20: Component Value Calculations

\begin{tabular}{|c|c|c|c|}
\hline \multicolumn{4}{|c|}{ LTC3780 } \\
\hline Vinmin & 7.2 & Constant & $\mathrm{V}$ \\
\hline loutmaxboost & 3.6 & Constant & A \\
\hline loutminboost & 0.1 & Constant & A \\
\hline Vout & 36 & Constant & $\mathrm{V}$ \\
\hline DeltalL & 1.08 & $=$ loutmaxboost*30\% & A \\
\hline Dcvmin & $86.11 \%$ & $=1-\mathrm{Vinmin} / \mathrm{Vo}$ & $\%$ \\
\hline Frequencymin & 200000 & Constant & $\mathrm{Hz}$ \\
\hline Rsensemax & 0.0070 & $=(2 * 160 \mathrm{mV} * \operatorname{Vinmin}) /(2 *$ Iomaxboost*Vout*DeltalL*Vinmin $)$ & Ohms \\
\hline R1 & 10 & Constant & kOhms \\
\hline R2 & 440 & $=($ Vout $/ 0.8 \mathrm{~V}-1) * \mathrm{R} 1$ & kOhms \\
\hline Lmin & 14.95 & $=$ DCvmin*(1-DCvmin)^2*Vout/(loutmin*2*frequencymin) & $\mathrm{uH}$ \\
\hline \multicolumn{4}{|c|}{ LT3980 } \\
\hline Vinmin & 8 & Constant & $\mathrm{V}$ \\
\hline Vinmax & 52 & Constant & $\mathrm{V}$ \\
\hline Vout & 7.2 & Constant & $\mathrm{V}$ \\
\hline Frequency & 100000 & Constant & $\mathrm{Hz}$ \\
\hline Iomax & 4 & Constant & A \\
\hline DeltalL & 1.6 & $=$ loutmaxboost $* 40 \%$ & A \\
\hline R1 & 405.70 & $=\mathrm{R} 2 *($ Vout $/ 0.79 \mathrm{~V}-1)$ & kOhms \\
\hline R2 & 50 & Constant & kOhms \\
\hline Lmin & 41.00 & $=[(\text { Vout }+0.5 \mathrm{~V}) /(\text { frequency*DeltalL })]^{*}[1-($ Vout $+0.5 \mathrm{~V}) /$ Vinmax $]$ & $\mathrm{uH}$ \\
\hline
\end{tabular}

\subsection{MOSFET Selection}

Shown in Table 17, transistor Q1 dissipates the most power at 2.432W. This occurs during the maximum power level. This makes Q1 the limiting factor for deciding on a MOSFET. In choosing an appropriate transistor, the application dictates at least an $80 \mathrm{~V}$ drain-source breakdown voltage and a 7.5A DC current rating. Models available on LTSPICE and in stock at either Digikey.com or Mouser.com also narrow the selection.

Based on modeling in LTSPICE, the three candidates in Table 21 provide the best overall power efficiency. 
Table 21: MOSFET Comparison Table

\begin{tabular}{|l|c|c|c|c|c|}
\hline \multicolumn{3}{|c|}{ BSC042NE7N53 } & BSZ123N08N53G & IPB039N10N3G & Units \\
\hline Cost & $\$ 3.16$ & $\$ 1.39$ & $\$ 3.24$ & $\$$ \\
\hline Vds Breakdown & 75 & 80 & 100 & $\mathrm{~V}$ \\
\hline Current Rating & 100 & 40 & 160 & $\mathrm{~A}$ \\
\hline Rds on & 4.2 & 12.3 & 3.9 & $\mathrm{~m} \Omega$ \\
\hline Input Capacitance & 3600 & 1300 & 6320 & $\mathrm{pF}$ \\
\hline Total Gate Charge & 52 & 19 & 88 & $\mathrm{nC}$ \\
\hline Max Power Dissipation & 125 & 66 & 214 & $\mathrm{~W}$ \\
\hline Thermal Resistance JA & 50 & 60 & 62 & $\mathrm{~K} / \mathrm{W}$ \\
\hline Maximum Junction Temp. & 150 & 150 & 175 & ${ }^{\circ} \mathrm{C}$ \\
\hline & \multicolumn{3}{|c|}{ Design Performance } & & \\
\hline System Efficiency Full Load & $98.60 \%$ & $98.60 \%$ & $98.40 \%$ & $\%$ \\
\hline Q1 Power Dissipated at Full Load & 1.773 & 1.069 & 2.432 & $\mathrm{~W}$ \\
\hline Junction Temp. @ 25 ${ }^{\circ}$ C Ambient & 113.65 & 89.14 & 175.784 & ${ }^{\circ} \mathrm{C}$ \\
\hline Maximum Ambient Temp. & 61.35 & 85.86 & 24.216 & ${ }^{\circ} \mathrm{C}$ \\
\hline
\end{tabular}

Equation 8: Junction Temperature to Power Dissipation Relationship

Junction Temp. $=$ Ambient Temp. + Thermal Resistance $*$ Power Dissapated

Table 21 lists the MOSFETs' specifications [19, 20, 21]. Digikey.com and Mouser.com provide the prices for each transistor. The datasheets use a $6 \mathrm{~cm}^{2}$ pads as a standard for heat sinking when dealing with thermal properties. A pad larger than $6 \mathrm{~cm}^{2}$ would further lower the thermal resistance, leading to a lower operating temperature and maximum allowable ambient temperature. Equation 8 shows the relationship between maximum junction temperature, ambient air temperature, and power dissipation by the package. From Table 21, the BSZ123N08N53G proves best with respect to cost, efficiency, and thermal considerations due to its low capacitance, not $\mathrm{R}_{\mathrm{DS} \text { ON. }}$.

With regard to the typical operation at $30 \mathrm{~V}_{\text {in }}$, MOSFET Q3 dissipates the most power, 240mW, as heat. Using Equation 8 and a 240mW typical power dissipation, the MOSFETs can function properly until the ambient temperature reaches $135.6^{\circ} \mathrm{C}$ without 
any additional heat sinking. At the normal $25^{\circ} \mathrm{C}$ ambient temperature, the junction temperature stays around $39.4^{\circ} \mathrm{C}$. This gives a $110.6^{\circ} \mathrm{C}$ cushion in ambient temperature rise. The typical mode of operation allows for a good tolerance for both ambient temperature changes and the absolute maximum junction temperature of the transistor, $150^{\circ} \mathrm{C}$.

\subsection{Output Voltage Ripple}

Table 22 summarizes the steady state voltage ripple data of the converter. Figure 26 through Figure 28 show the ripple characteristics at various input voltages that represent all cases of ripple voltage waveforms. Using Table 22 and Equation 9 for output voltage regulation, the converter attains low regulations with $0.21 \%$ for the full range and $0.43 \%$ for the typical input voltage range.

\section{Equation 9: Voltage Regulation}

$$
\text { Voltage Regulation }=\frac{V_{o \text { High }}-V_{o \text { Low }}}{V_{\text {o Nominal }}}
$$

Table 22: Ripple Voltage Summary

\begin{tabular}{|l|c|c|c|c|c|c|c|c|}
\hline Vin & 8 & 15 & 25 & 30 & 36 & 40 & 52 & $\mathrm{~V}$ \\
\hline Vo & 35.781 & 35.956 & 35.8 & 35.8 & 35.8 & 35.82 & 35.856 & $\mathrm{~V}$ \\
\hline \%Vripple & $0.02 \%$ & $0.04 \%$ & $0.50 \%$ & $0.75 \%$ & $0.92 \%$ & $1.00 \%$ & $0.04 \%$ & $\%$ \\
\hline Ripple Freq 1 & 185 & 180 & 200 & 200 & 230 & 230 & 170 & $\mathrm{kHz}$ \\
\hline Ripple Freq 2 & - & - & 10 & 10 & 15 & 15 & - & $\mathrm{kHz}$ \\
\hline
\end{tabular}

As shown in Table 22 and Figure 26 through Figure 28, the voltage ripple frequencies lie above $180 \mathrm{kHz}$. The sinusoidal hump in Figure 26 occurs from the resonant frequency of the converter while in boost mode. Tests determine whether the design requires filtering. An oscillation also occurs with a frequency around $10 \mathrm{kHz}$, 
which may require error amplifier compensation adjustment in the actual implementation. Adjusting the slope compensation occurs after building the prototype. This allows for precise tuning for the non-idealities of the fabricated design.
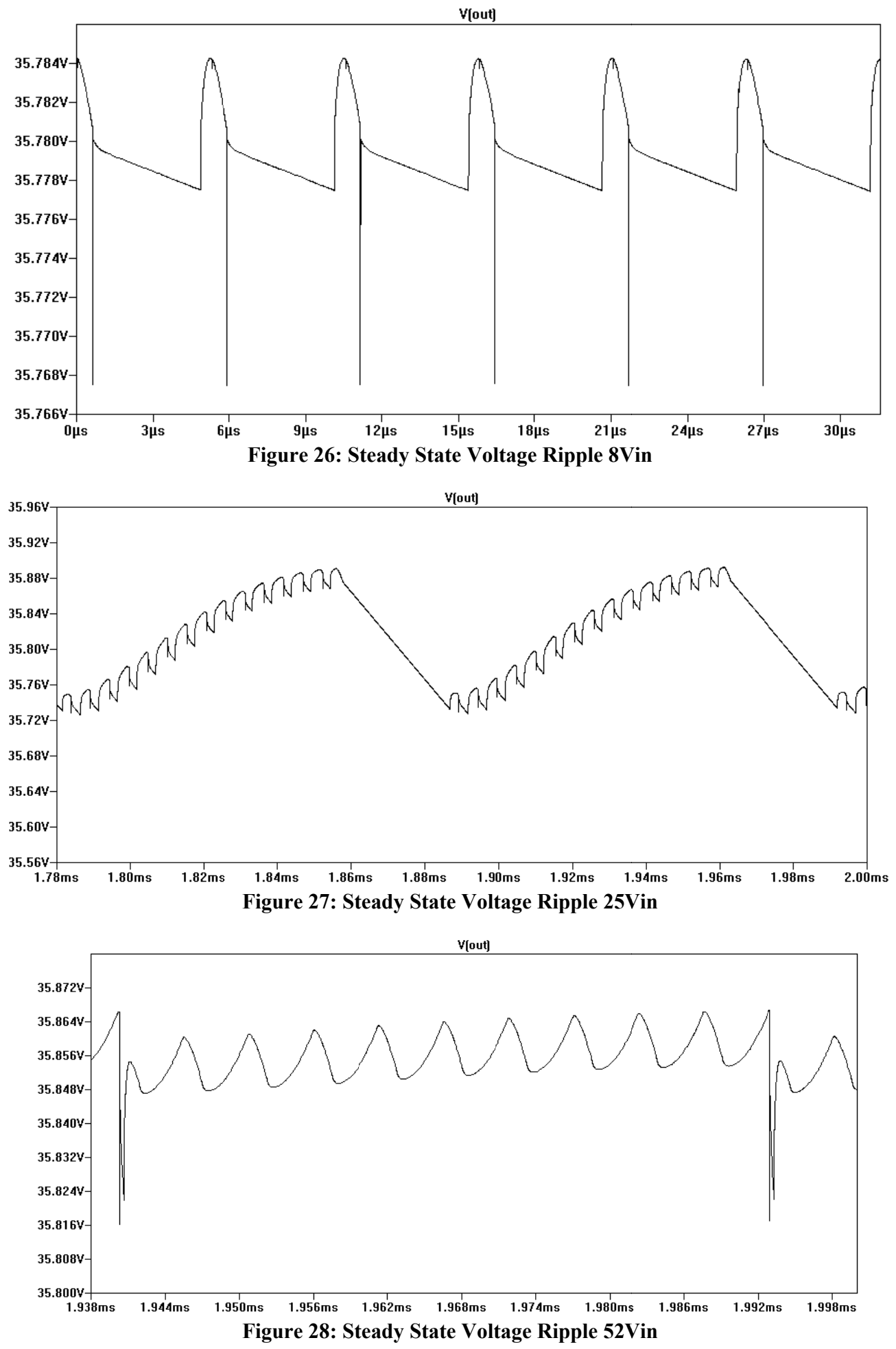
Parameters such as voltage ratings, current ratings, frequency ratings, package footprint, and price allow for choosing the appropriate components. Part availability also determined the component values, for instance, only specific standard values for the resistors and inductors such as replacing $440 \mathrm{k} \Omega$ with a $442 \mathrm{k} \Omega$ resistor. I chose nearest valued component to the original, without disrupting the design too much. For the inductors, the original design specified the minimum inductance, so now the design uses higher valued inductors, which also helps with current ripple. To better suit the design, two $10 \mathrm{~m} \Omega$ resistors in parallel replace the original $5 \mathrm{~m} \Omega$. This allows better current sensing from transistors Q3 and Q4, because one sense resistor lies in close proximity to each transistor. As for diodes D2 and D3, the MBR20100CT only comes in a dual diode package. Connecting these diodes in parallel distributes the power dissipation and stresses an individual diode experiences. Figure 31 contains all the changes to the design and denotes some critical current paths. The green traces represent high current and frequency paths. The red traces show high frequency signals. All the above changes minimally improved the converter's performance, and Table 18 shows the parts and some parameters used to choose them. Table 23 estimates a preliminary cost of $\$ 77.97$ for the converter.

\subsection{Board Layout}

Before laying out the board design in ExpressPCB, some of the components required custom footprints as dimensioned in their datasheets. The LTC3780 datasheet provides helpful information regarding laying out the PCB. Some notable examples include, the placement of various components as shown in Figure 29, using planes for Vin and Vout for good filtering and efficiency, segregating the SGND and PGND, close 
proximity placement of bypass capacitors to certain components, and how to route the current sensing circuit as shown in Figure 30 [9].

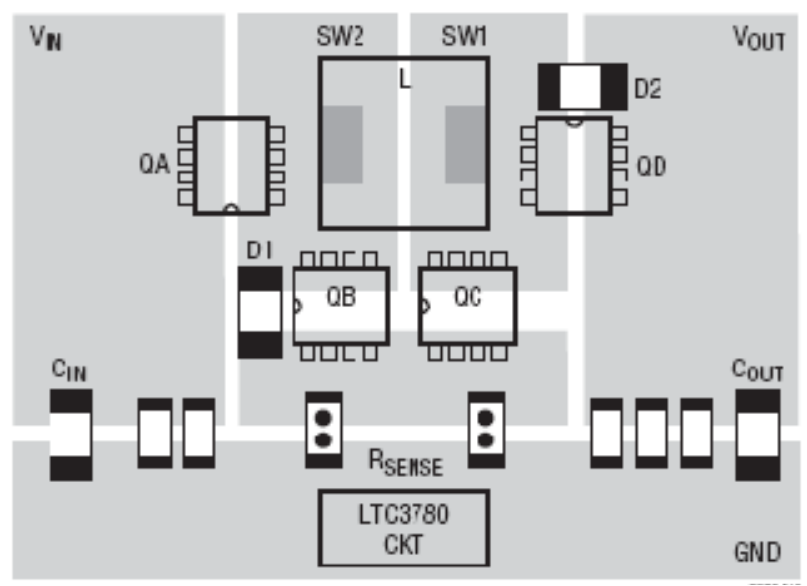

Figure 29: Typical Component Layout [9]

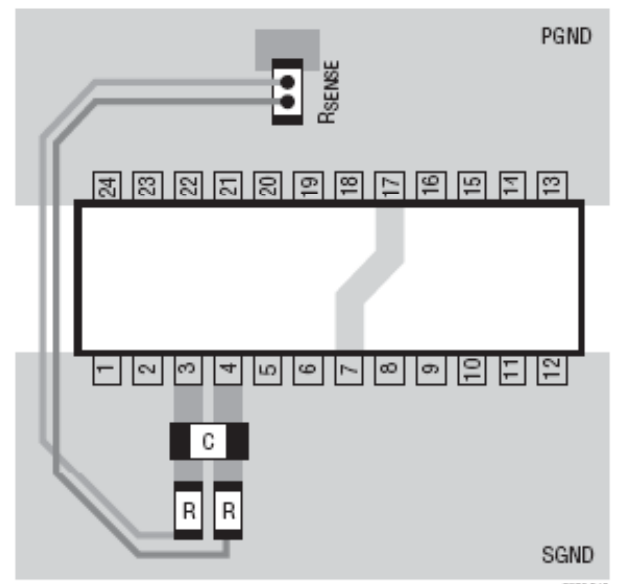

Figure 30: Current Sense Circuit Routing Example [9]

The LTC4444 and LT3980 also noted close placement of bypass capacitors as well as soldering the exposed pad underneath the chip $[17,18]$. The ExpressPCB website also offers tips on laying out the PCB such as same direction orientation of polar components and trace widths for high current lines [22]. Also noting that the MOSFETs specified a minimum exposed pad of $6 \mathrm{~cm}^{2}$ for heat sinking, the planes covered enough area far beyond $6 \mathrm{~cm}^{2}$ for better temperature management. The layout incorporates pads for a transient voltage suppressing zener diode and a metal oxide varistor in case the design requires them. The output capacitor allows for the adjustment of capacitance using many footprints of radial electrolytic capacitors. Also, signal traces avoided routes under inductors to prevent noise from the generated electromagnetic fields from the inductors. The MiniBoardPro Service on Express PCB limits the layout to a 3.8" x 2.5" area. This puts a constraint on the size and number of components allowed on the board. Figure 33 through Figure 35 show the first revision of the board layout. The large planes allow for short low resistance paths for the green high current paths shown Figure 31. 
Table 23: Parts List

\begin{tabular}{|c|c|c|c|c|c|c|c|c|c|}
\hline Reference Designator & Value & Note 1 & Note 2 & \begin{tabular}{|l|} 
Note3 \\
\end{tabular} & Package Footprint & $\mathrm{P} / \mathrm{N}$ & Price & Quantity & \begin{tabular}{|l|} 
Total Price/Part \\
\end{tabular} \\
\hline $\mathrm{C} 1$ & $4.7 \mathrm{uF}$ & Tantalum & - & $6 \mathrm{Vpk}$ & 1206 & 647-F931A475KAA & $\$ 0.15$ & 1 & $\$ 0.15$ \\
\hline $\mathrm{C} 2$ & $22 \mathrm{uF}$ & Ceramic & - & $36 \mathrm{Vpk}$ & $7.5 \mathrm{~mm} \times 6.3 \mathrm{~mm}$ & 661-KHC500E226Z76R0T & $\$ 2.76$ & 1 & $\$ 2.76$ \\
\hline $\mathrm{C} 3, \mathrm{C} 21$ & $0.1 \mathrm{uF}$ & Ceramic & X7R or X5R & $60 \mathrm{Vpk}$ & 1206 & 81-GRF31MR72A104KA1L & $\$ 0.06$ & 2 & $\$ 0.12$ \\
\hline $\mathrm{C} 4, \mathrm{C} 8, \mathrm{C} 22$ & $0.22 \mathrm{uF}$ & Ceramic & X7R or X5R & $60 \mathrm{~V}$ & 0805 & 81-GRM21AR72A224KC5L & $\$ 0.38$ & 3 & $\$ 1.14$ \\
\hline $\mathrm{C} 5, \mathrm{C9}$ & $1 \mathrm{uF}$ & Ceramic & - & $8 \mathrm{Vkk}$ & 0805 & $810-C 2012$ Y 5V1C105Z-2 & $\$ 0.05$ & 2 & $\$ 0.10$ \\
\hline $\mathrm{C6}$ & $0.47 \mathrm{uF}$ & Ceramic & - & $60 \mathrm{Vpk}$ & 1210 & 581-12101C474K4 & $\$ 0.40$ & 1 & $\$ 0.40$ \\
\hline $\mathrm{C7}$ & $0.01 \mathrm{uF}$ & Ceramic & - & $5 \mathrm{Vpk}$ & 0805 & 77-VJ0805Y103MXQPBC & $\$ 0.09$ & 1 & $\$ 0.09$ \\
\hline $\mathrm{C} 10, \mathrm{C} 12, \mathrm{C} 16$ & $100 \mathrm{pF}$ & Ceramic & - & $5 \mathrm{Vpk}$ & 0805 & 81-GRM2167U1H101IZ1D & $\$ 0.13$ & 3 & $\$ 0.39$ \\
\hline $\mathrm{C} 11$ & $68 \mathrm{pF}$ & Ceramic & - & $1 \mathrm{Vpk}$ & 0805 & 81-GRM2167U1H680JZ1D & $\$ 0.15$ & 1 & $\$ 0.15$ \\
\hline $\mathrm{C} 13$ & $330 \mathrm{uF}$ & Electrolytic & - & $36 \mathrm{Vpk}$ & $5 \mathrm{~mm}$ Dia. $0.6 \mathrm{~mm}$ holes & 140-RGA331M1HBK1320P & $\$ 0.34$ & 1 & $\$ 0.34$ \\
\hline C14 & $2.2 \mathrm{uF}$ & Ceramic & X7R or X5R & $52 \mathrm{Vpk}$ & 1210 & 587-1778-1-ND & $\$ 0.88$ & 1 & $\$ 0.88$ \\
\hline $\mathrm{C} 15$ & $1000 \mathrm{uF}$ & Electrolytic & - & $52 \mathrm{Vpk}$ & 7.5mm Dia. $0.8 \mathrm{~mm}$ holes & 647-UVR2A102MRD6 & $\$ 1.21$ & 1 & $\$ 1.21$ \\
\hline C17 & $0.0047 \mathrm{uF}$ & Ceramic & - & $1 \mathrm{Vpk}$ & 0805 & 140-CC501B472K-RC & $\$ 0.04$ & 1 & $\$ 0.04$ \\
\hline $\mathrm{C} 18$ & $1000 \mathrm{pF}$ & Ceramic & - & $2 \mathrm{Vpk}$ & 0805 & 80-C0805C102K5R7215 & $\$ 0.02$ & 1 & $\$ 0.02$ \\
\hline $\mathrm{C} 19$ & $22 \mathrm{pF}$ & Ceramic & - & $8 \mathrm{Vpk}$ & 0805 & $80-\mathrm{C0} 0805 \mathrm{C} 220 \mathrm{~J} 1 \mathrm{G}$ & $\$ 0.05$ & 1 & $\$ 0.05$ \\
\hline $\mathrm{C} 20$ & $47 \mathrm{uF}$ & Ceramic & X7R or X5R & $8 \mathrm{Vpk}$ & 1210 & "587-1436-1-ND & $\$ 1.38$ & 1 & $\$ 1.38$ \\
\hline $\mathrm{R} 1, \mathrm{R} 5$ & $10 \mathrm{~K}$ & - & - & - & 0805 & 667-ERJ-6GEYJ103V & $\$ 0.04$ & 2 & $\$ 0.08$ \\
\hline R2 & $442 \mathrm{~K}$ & - & - & - & 0805 & 292-442K-RC & $\$ 0.04$ & 1 & $\$ 0.04$ \\
\hline R3A/B & $5 \mathrm{~m}$ (two $10 \mathrm{~m}$ in parallel) & Sensing Resistor & - & - & 1210 & 652-CRA2010FZRO10ELF & $\$ 0.46$ & 2 & $\$ 0.92$ \\
\hline R4 & $432 \mathrm{~K}$ & - & - & - & 0805 & $292-432 K-R C$ & $\$ 0.04$ & 1 & $\$ 0.04$ \\
\hline R6, R7 & 100 & - & - & - & 0805 & 667-ERJ-6GEYJ101V & $\$ 0.04$ & 2 & $\$ 0.08$ \\
\hline R8 & $51 \mathrm{~K}$ & - & - & - & 0805 & 260-51K-RC & $\$ 0.04$ & 1 & $\$ 0.04$ \\
\hline R9 & $15 \mathrm{~K}$ & - & - & - & 0805 & 667-ERJ-6GEYJ153V & $\$ 0.04$ & 1 & $\$ 0.04$ \\
\hline R10 & $402 \mathrm{~K}$ & - & - & - & 0805 & 292-402K-RC & $\$ 0.04$ & 1 & $\$ 0.04$ \\
\hline R11 & $220 \mathrm{~K}$ & - & - & - & 0805 & 260-220K-RC & $\$ 0.04$ & 1 & $\$ 0.04$ \\
\hline R12 & $50 \mathrm{~K}$ & - & - & - & 0805 & $292-49.9 \mathrm{~K}-\mathrm{RC}$ & $\$ 0.04$ & 1 & $\$ 0.04$ \\
\hline R13 & $4.75 \mathrm{~K}$ & - & - & - & 0805 & 292-4.75K-RC & $\$ 0.04$ & 1 & $\$ 0.04$ \\
\hline $\mathrm{L} 1$ & $20 \mathrm{uH}$ & $7.5 \mathrm{ADC}$ & 9Apk & - & $18.54 \mathrm{~mm} \times 15.24 \mathrm{~mm}$ & 553-1636-5-ND & $\$ 2.46$ & 1 & $\$ 2.46$ \\
\hline $\mathrm{L} 2$ & $50 \mathrm{uH}$ & $22 \mathrm{uADC}$ & 4Apk & - & $23.87 \mathrm{~mm} \times 20.83 \mathrm{~mm}$ & 732-1385-1-ND & $\$ 1.66$ & 1 & $\$ 1.66$ \\
\hline $\mathrm{D} 1, \mathrm{D} 4$ & MMSD4148 & - & - & - & SOD-123 & MMSD4148T1GOSCT-ND & $\$ 0.42$ & 2 & $\$ 0.84$ \\
\hline D2/D6,D3/D7 parallel & MBR20100CT & - & - & - & TO-220 & MBR20100CT-BPMS-ND & $\$ 0.88$ & 2 & $\$ 1.76$ \\
\hline D5 & MBRS1100 & - & - & - & $403 \mathrm{~A}$ & 641-1104-1-ND & $\$ 0.42$ & 1 & $\$ 0.42$ \\
\hline Q1,Q2.Q3.Q4 & BSZ123N08NS3 & - & - & - & 8-PowerVDFN & BSZ123N08NS3GINCT-ND & $\$ 1.39$ & 4 & $\$ 5.56$ \\
\hline U1 & LTC3780 & - & - & - & 24-SSOP & "LTC3780EG\#PBF-ND & $\$ 9.50$ & 1 & $\$ 9.50$ \\
\hline U2, U3 & LTC4444 & - & - & - & 8-MSOP & LTC4444EMS8E\#PBF-ND & $\$ 3.38$ & 2 & $\$ 6.76$ \\
\hline U4 & LT3980 & - & - & - & 16-MSOP Exposed Pad & LT3980EMSE\#PBF-ND & $\$ 7.55$ & 1 & $\$ 7.55$ \\
\hline $\mathrm{Z1}$ & TVS Diode & Maybe Optional & - & - & DO-214AC & 78-BZG04-33 & $\$ 0.24$ & 1 & $\$ 0.24$ \\
\hline MOV1 & MOV & Maybe Optional & - & - & $5 \mathrm{~mm}$ Dia. $0.6 \mathrm{~mm}$ holes & 652-MOV-07D270K & $\$ 0.13$ & 1 & $\$ 0.13$ \\
\hline \multirow[t]{2}{*}{$\mathrm{PCB}$} & - & - & - & - & - & expresspcb.com & $\$ 91.41$ & 0.33333 & $\$ 30.47$ \\
\hline & & & & & & & & Total & $\$ 77.97$ \\
\hline
\end{tabular}




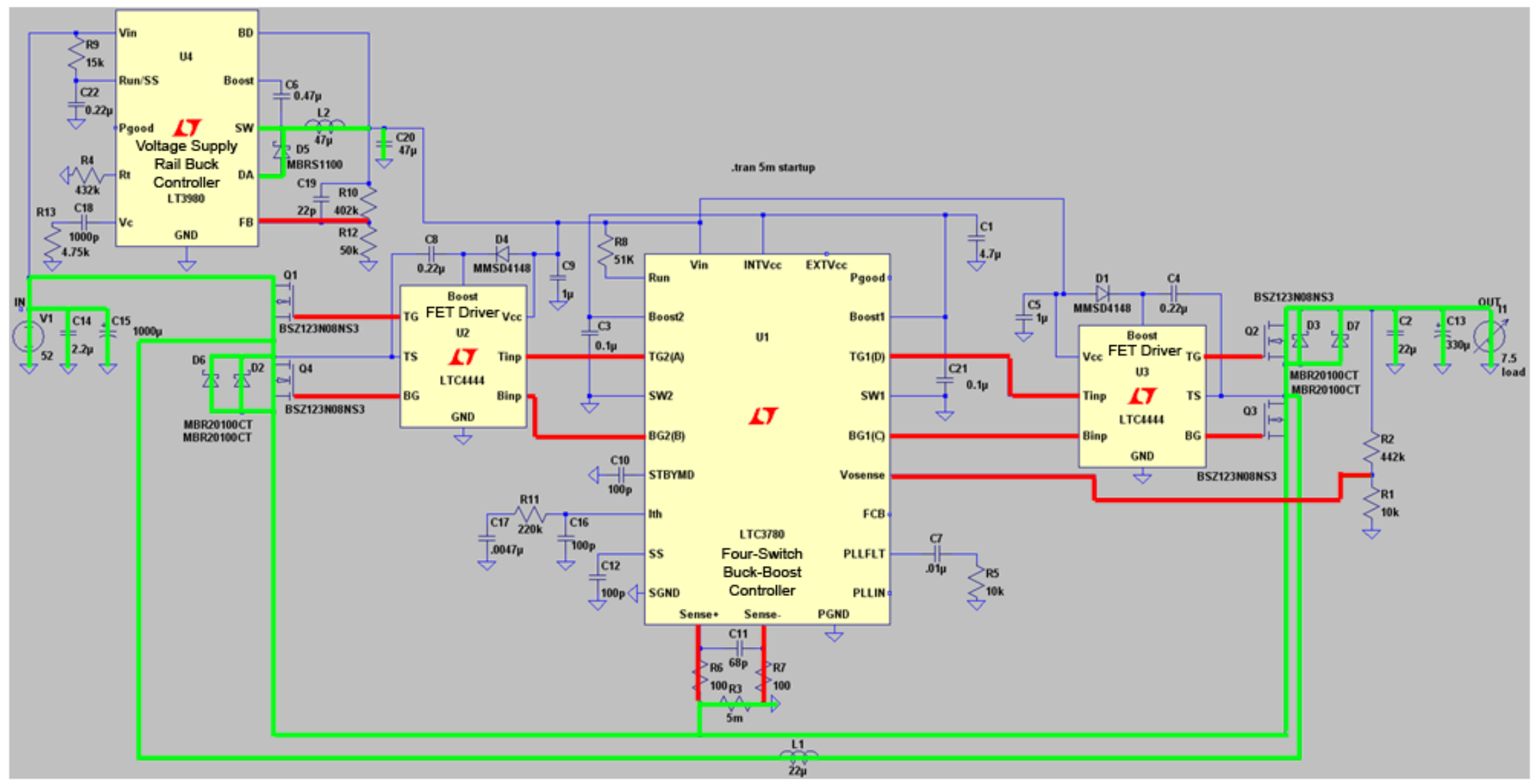

Figure 31: Second Revision Converter Design 


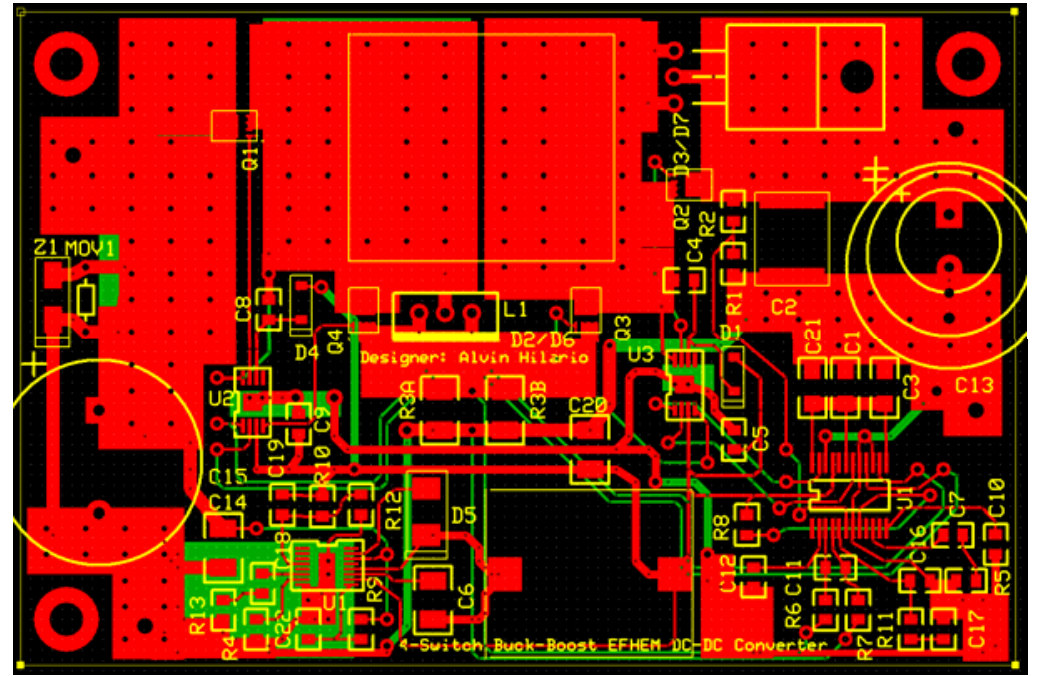

Figure 35: PCB Layout All Layers

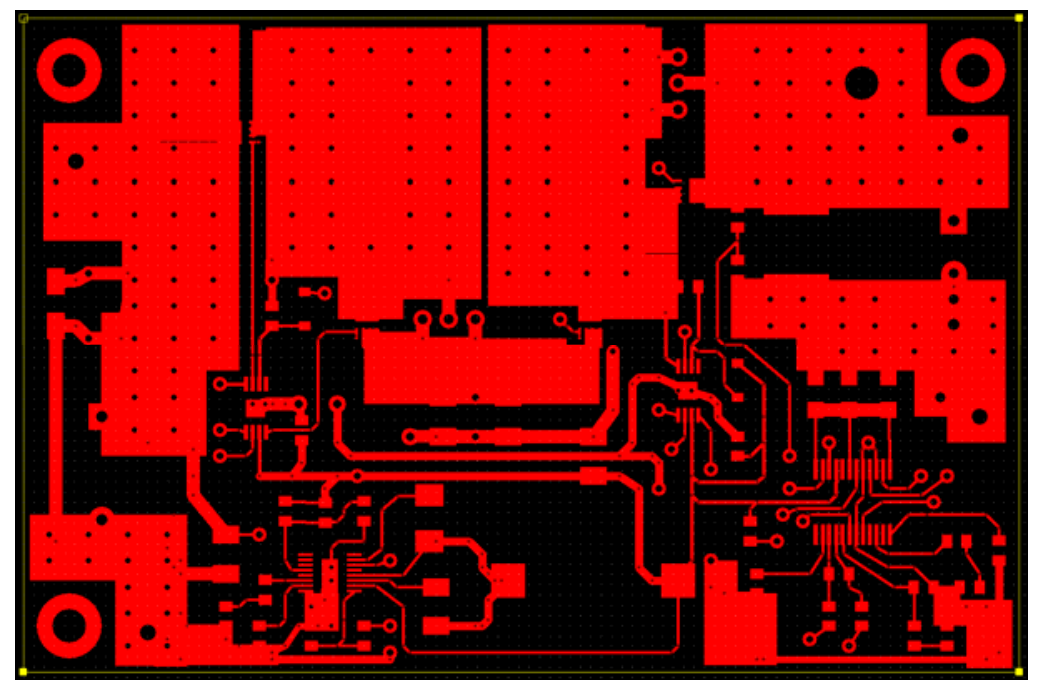

Figure 33: PCB Layout Top Layer

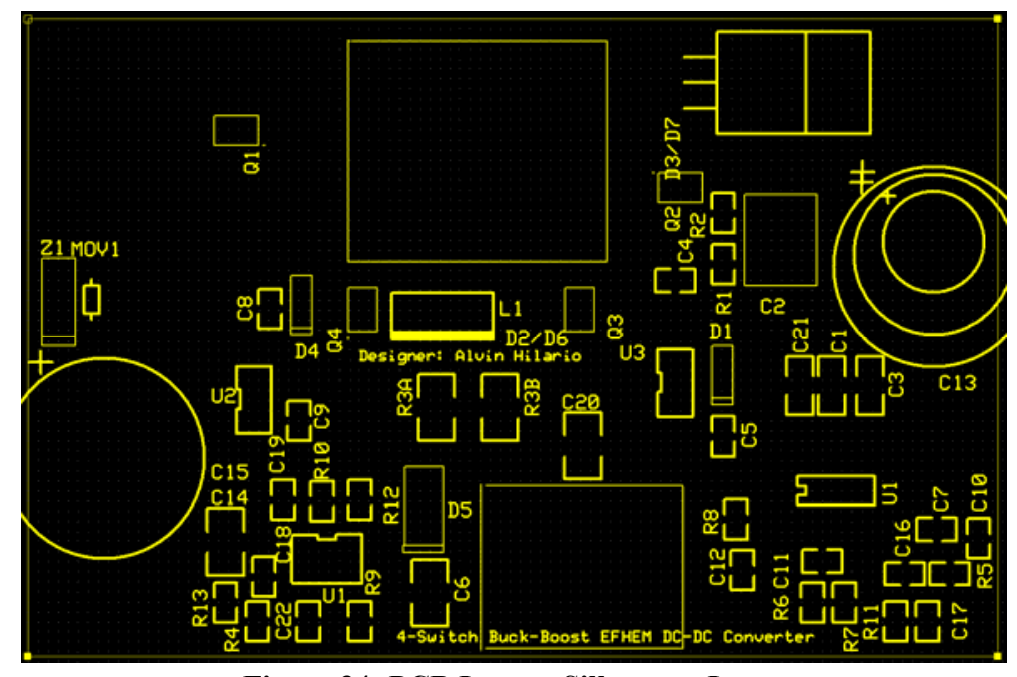

Figure 34: PCB Layout Silkscreen Layer

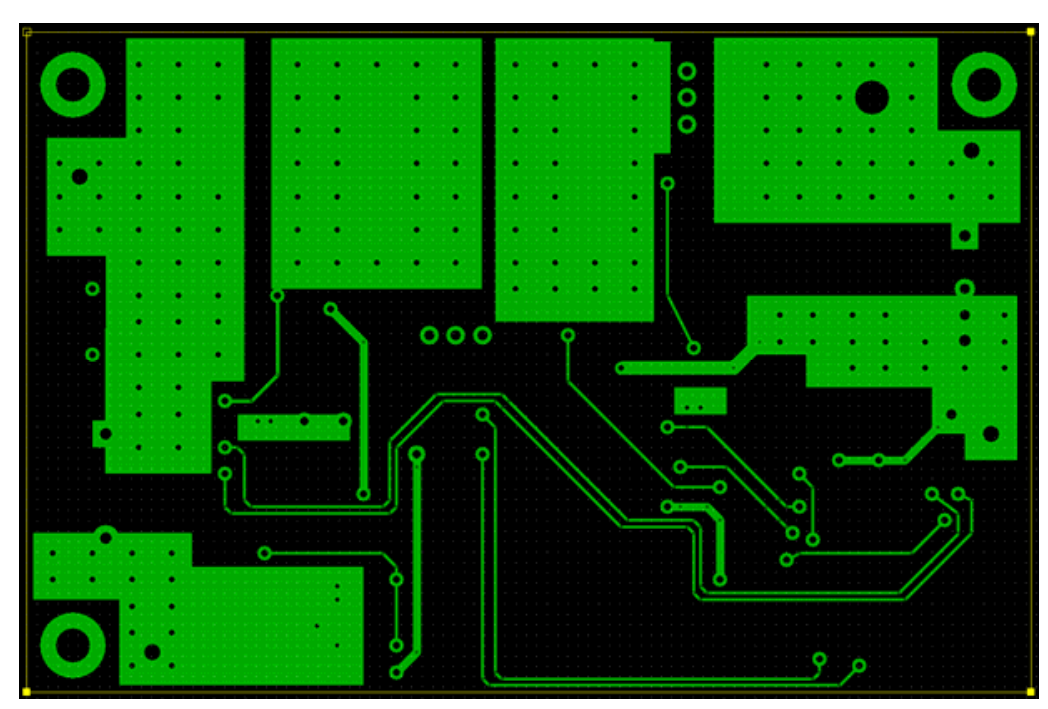

Figure 32: PCB Layout Bottom Layer 
After reading a couple references and speaking with Professor Taufik about switch mode power supply PCB layout, the previous revision needs many alterations to function optimally. First these papers address the need for mapping out the critical current paths of the DC-DC converter [23,24]. The design needs no alterations regarding these paths, since they already implement large wide traces as shown in Figure 33 through Figure 35. The light blue traces on Figure 36 represent these high current paths. Other considerations include the orange voltage divider feedback trace, purple current limit traces, and dark blue gate drive traces. This signal line must stay clear of noise sources, such as diodes and inductors, as well as minimize length [24]. Placing the resistor divider as close to the controller as possible while having the output voltage trace long, solves the problem. Another concern regards the power and signal ground plane. In the first revision these planes look minimal. These nodes need as large an area as possible to provide enough paths for the high frequency current waveforms. After talking with a Linear Technology Engineer Charlie Zhao, the LTC4444 ICs connect to the power ground, instead of the signal ground as shown in the previous revision. Lastly, the main problem stems from the relatively long MOSFET gate driving signals as proposed by the first revision of the board. Due to the high frequency and precise nature of the signals, they require minimal trace lengths. Figure 36 shows the second revision. The board layout implemented a vertical stacking of the power portion of the four-switch buck-buck boost, its controlling circuitry, and the LT3980 buck portion to accommodate all the considerations. 


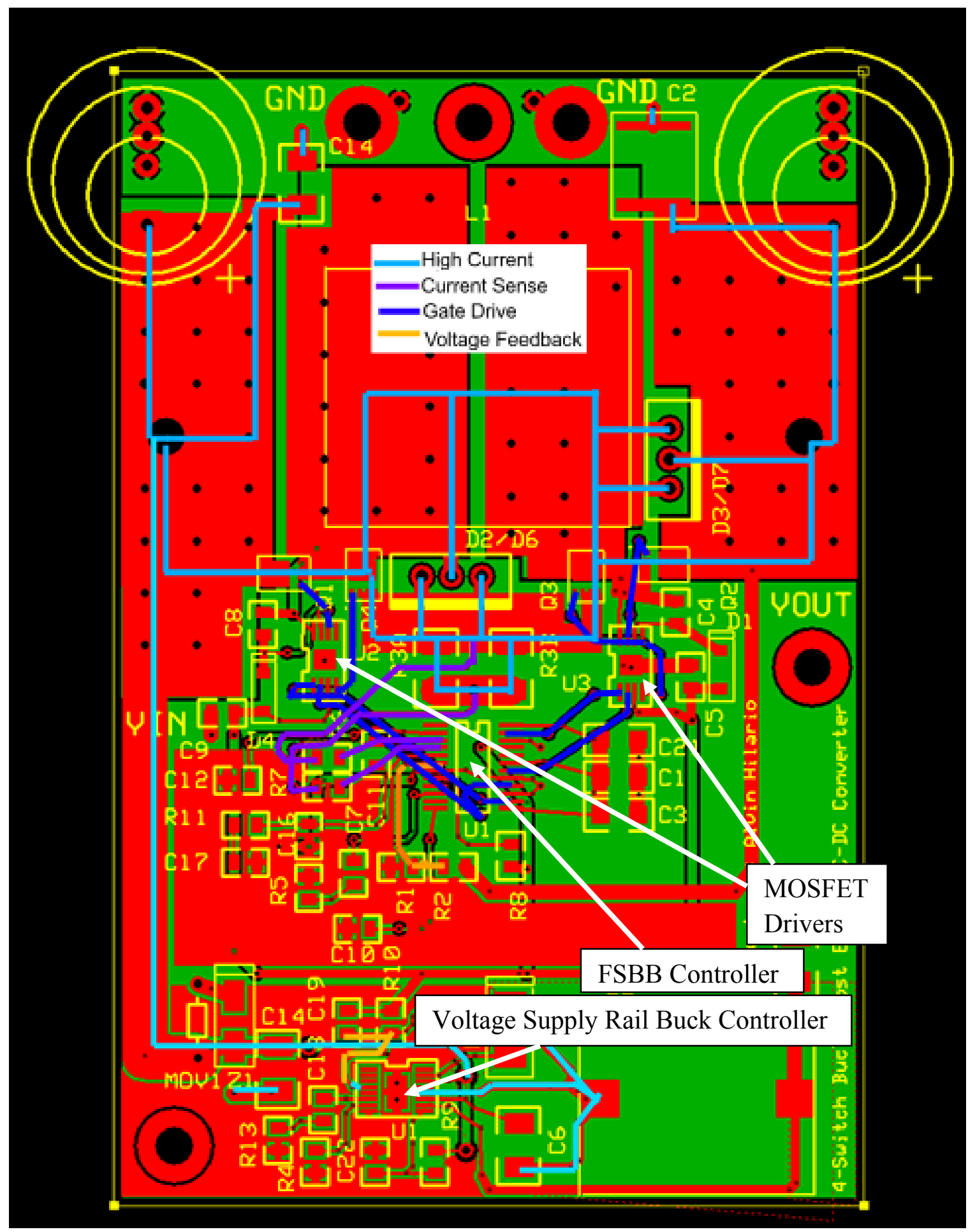

Figure 36: Second PCB Revision 


\subsection{Reflow Oven Profile}

Choosing components with QFN and exposed bottom pads requires surface mount soldering with the help of a reflow oven. Professor Jianbiao Pan, of the Industrial and Manufacturing Engineering Department, provided access and training for the Heller 1500XLM S Reflow Oven. Each board necessitates a unique reflow profile. The WinKIC software allows for data acquisition of the temperature characteristics of the board as it passes through the oven using a thermocouple soldered to the board. To avoid the detachment of the thermocouple during the reflow process, the thermocouple needs an $80 \%$ gold alloy solder with a melting temperature of $284^{\circ} \mathrm{C}$ for attachement. This melting temperature exceeds the lead-free solder paste which melts at $220^{\circ} \mathrm{C}$. The program allows for modification of the temperatures for each section of the oven as well as conveyor belt speed.

For a proper solder joint, the profile must steadily ramp as a rate of roughly 2$3^{\circ} \mathrm{C} / \mathrm{s}$, pre-heat the board to about $150^{\circ} \mathrm{C}$ for $1-2$ minutes, expose the board to temperatures above $220^{\circ} \mathrm{C}$ for a minimum of thirty seconds, and then cool down. Figure 37 and Figure 38 show the optimized reflow settings and profile for the PCB. In the final reflow profile, the board pre-heats with a rate of $2.86^{\circ} \mathrm{C} / \mathrm{s}$ for 2 minutes, melts the solder for 63.46 seconds, and then cools down. 


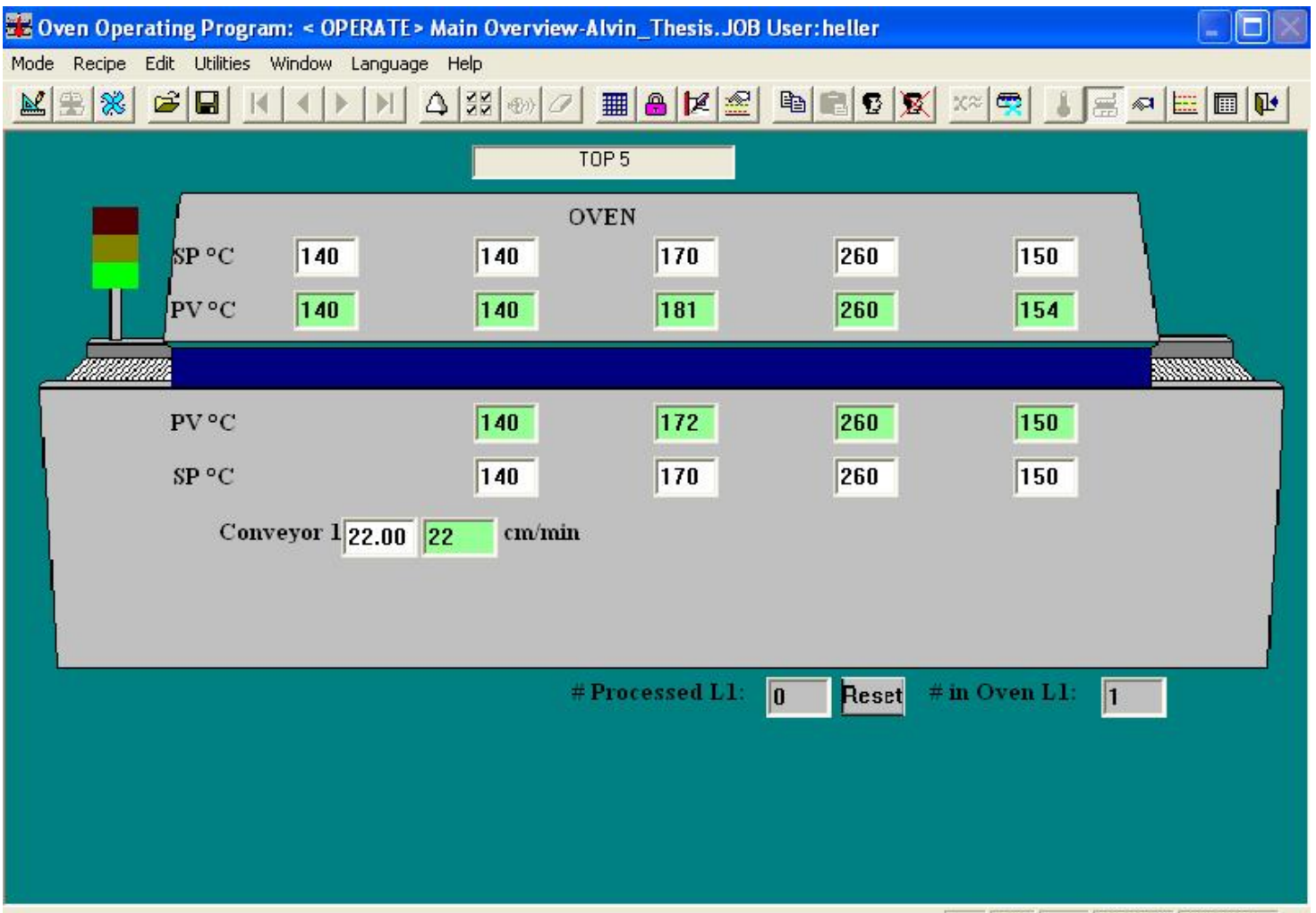

Figure 37: Final Reflow Oven Settings

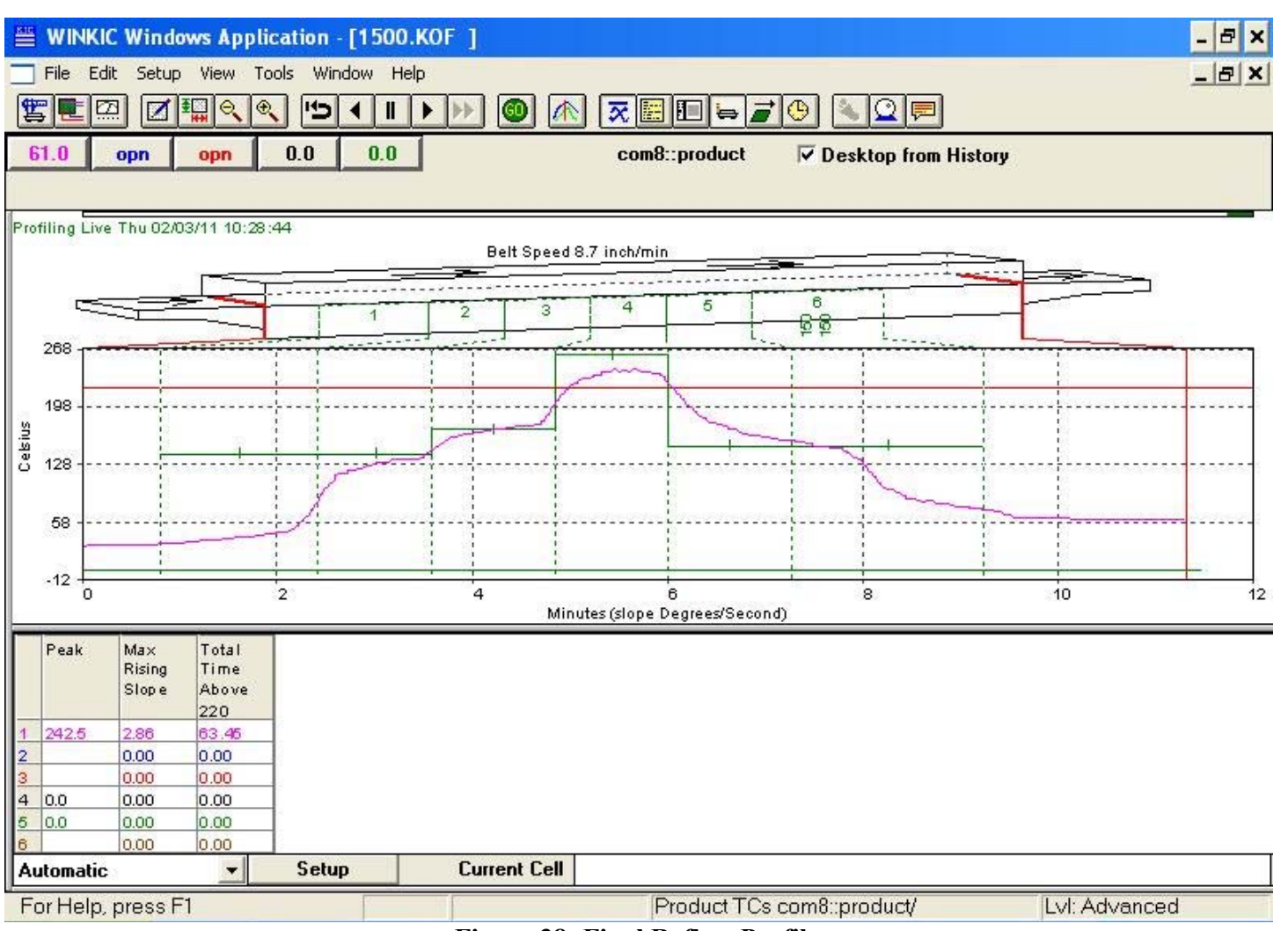

Figure 38: Final Reflow Profile 
To solder components onto the board, the user must manually apply solder paste by painting it on the individual pads. Next, the user reflows the board and applies tacky flux to place and hold each component for the second reflow. This process proved difficult and time inefficient due to the fine pitched packages. Some of the pins of these packages solder bridged together during the reflow process. Also during the second reflow process, the tacky flux did not ensure alignment of pins to their designated pads.

\subsection{Third Revision of PCB Layout}

After reflowing the transistors onto the board, a few tests showed they did not operate correctly. The MOSFETs pinout switched the gate and source pins. Being a QFN package, no modification fixes the problem. This requires a new revision of the board, rerouting the gate drive traces as shown in Figure 39 through Figure 41.

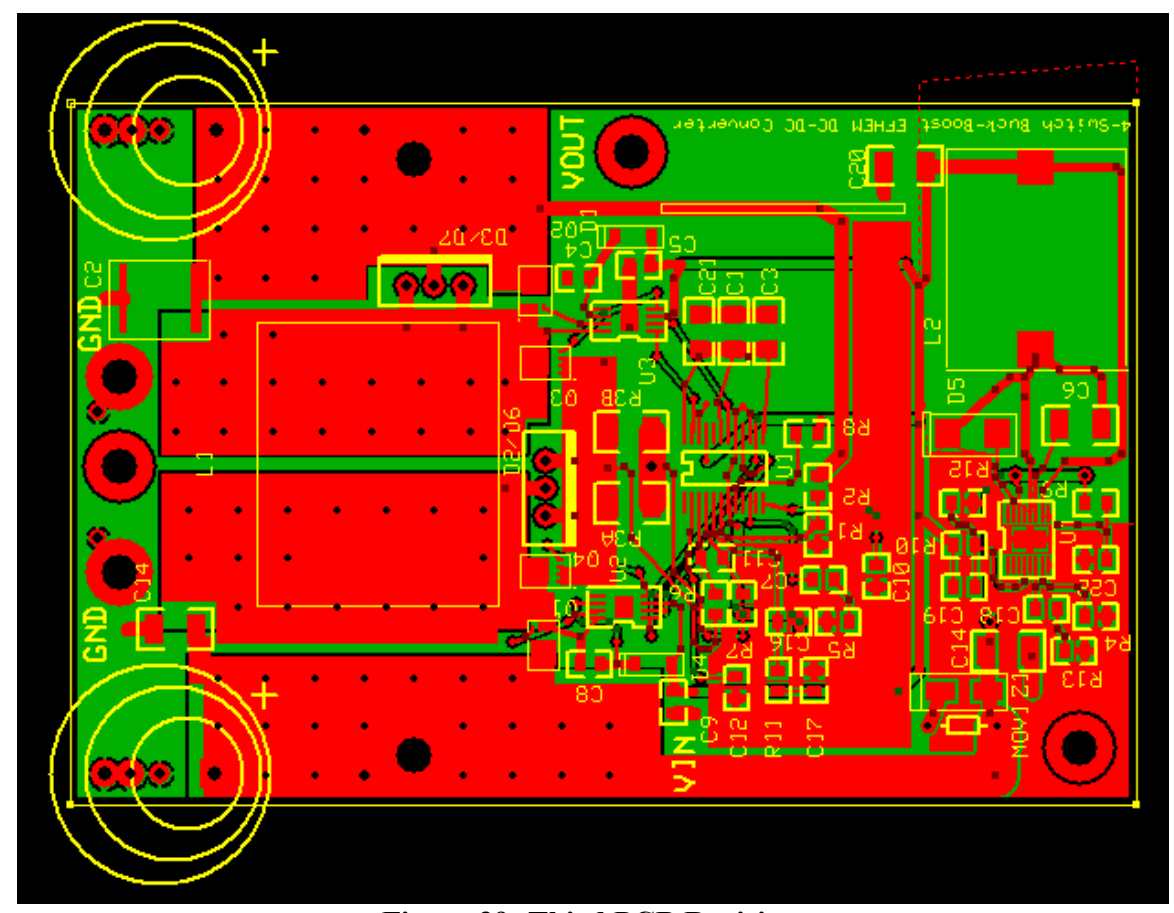

Figure 39: Third PCB Revision 


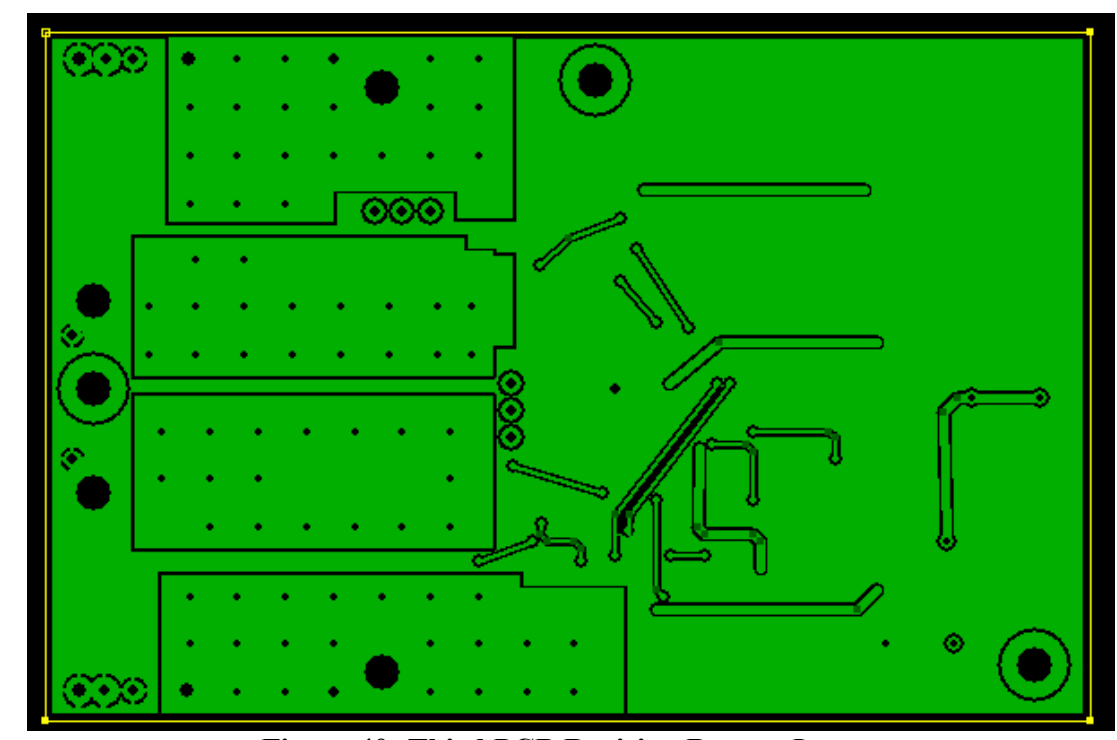

Figure 40: Third PCB Revision Bottom Layer

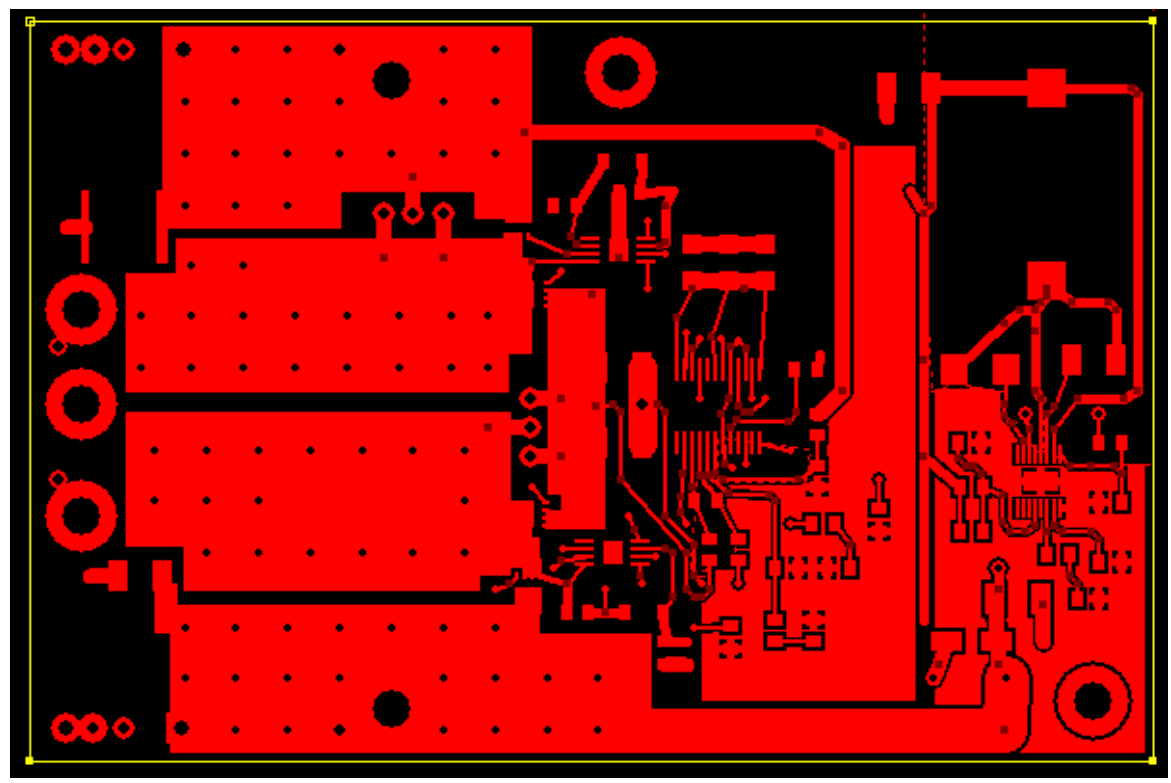

Figure 41: Third PCB Revision Top Layer

With the new revision, the soldering process requires a stencil for precision and time efficiency. Metal stencils cost upwards of $\$ 100$, but a Mylar plastic stencil provides a cheap alternative at $\$ 31$ for the dimensions of this PCB. A 3mil thick stencil provides an optimal amount of solder paste for $0.5 \mathrm{~mm}$ pitched packages [25]. Figure 42shows the outline to make the Mylar stencil. 


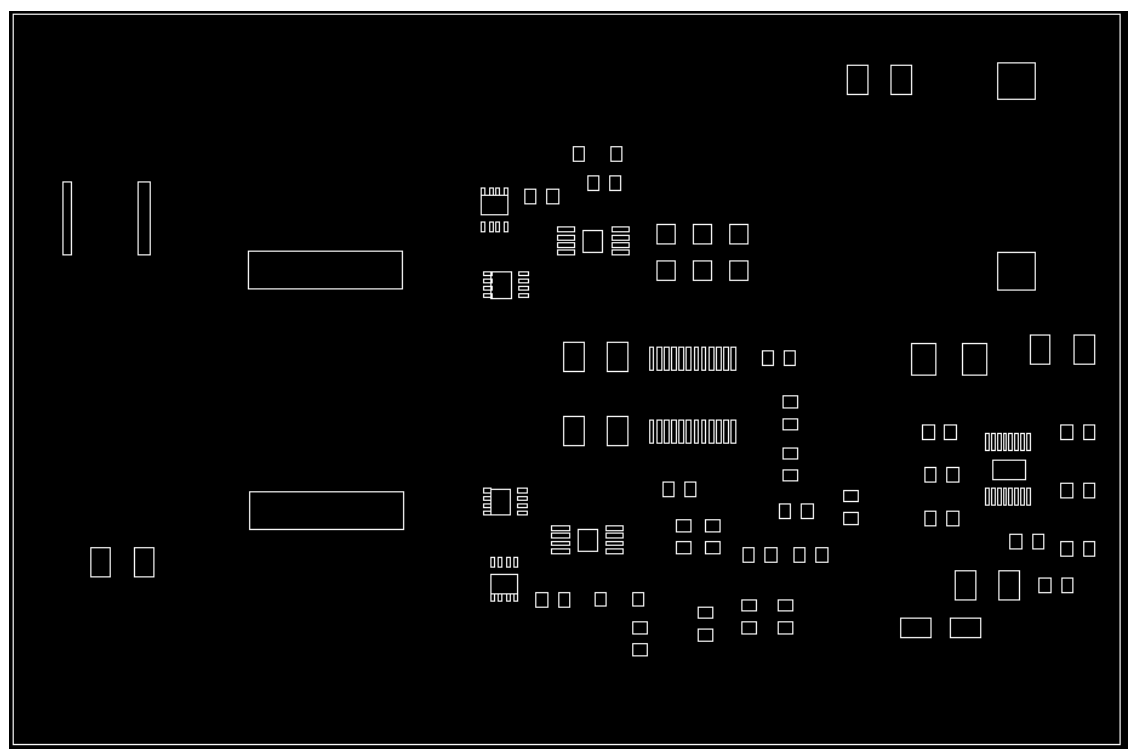

Figure 42: Solder Paste Stencil Outline 


\section{CHAPTER 5: TESTING}

\subsection{Introduction}

This chapter walks through the testing of the three design-build-test cycles. These tests mainly deal with the efficiencies and compliance of the design specifications. Each round of testing reveals areas for improvement and subsequent revisions to the design. Figure 43 shows the configuration for testing the design. The HP 6574A power supply voltage and BK Precision 8510 electronic load current set to values to maintain $10 \Omega$ across the whole $2.5-275 \mathrm{~W}$ power range. Full system testing replaces the power supply and electronic load with the Precor elliptical machine and Enphase microinverter. The GW Instek GPR-6060D power supply provides the IC supply rail for the second and third revision testing.

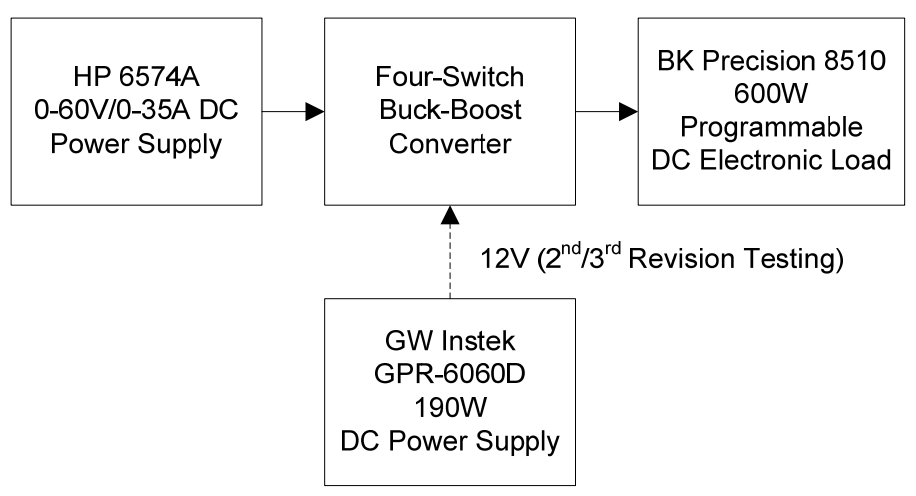

Figure 43: Converter Testing Schematic Block Diagram

\subsection{First Revision Testing}

First off, while testing the LT3980 circuit that supplies the Vcc rail for the other ICs, the converter only provides $7.12 \mathrm{~V}$ with the $402 \mathrm{k} \Omega$ resistor in the feedback resistor divider. The LTC4444 chips need above $7.2 \mathrm{~V}$ to operate so the $432 \mathrm{k} \Omega$ resistor replaced it to achieve $7.6 \mathrm{~V}$ out. 
Table 24 shows the efficiency of the Four-Switch Buck-Boost converter at various input voltages and power levels provided by a power supply and DC electronic load. Figure 43 without the $12 \mathrm{~V}$ power supply shows the system test setup. The converter delivers power at efficiencies around $90 \%$. At the same power level, the efficiency of the converter decreases as voltage increases as shown in Figure 44. Figure 45, on the other hand, illustrates that at constant input impedance to the converter at different power levels, the efficiency increases steadily up till $94 \%$ at $90 \mathrm{~W}$. At about a power demand of $105 \mathrm{~W}$, the converter starts to deregulate. Although the converter cannot handle power levels above $100 \mathrm{~W}$, in the typical $60-100 \mathrm{~W}$ output power range of a human, this converter maintains efficiencies above $93 \%$.

Table 24: Efficiency Data at Various Input Voltages and Power Levels

\begin{tabular}{|c|c|c|c|c|c|c|c|}
\hline Vin [V] & lin [A] & Zin [ $\Omega$ & Pin [W] & Vo [V] & lo [A] & Po [W] & Efficiency \\
\hline 10 & 0.73 & 13.70 & 7.30 & 36.12 & 0.175 & 6.32 & $86.59 \%$ \\
\hline 10 & 0.709 & 14.10 & 7.09 & 36.12 & 0.177 & 6.39 & $90.17 \%$ \\
\hline 10 & 0.698 & 14.33 & 6.98 & 36.14 & 0.175 & 6.32 & $90.61 \%$ \\
\hline 10 & 0.773 & 12.94 & 7.73 & 36.13 & 0.196 & 7.08 & $91.61 \%$ \\
\hline 9.94 & 0.901 & 11.03 & 8.96 & 36.13 & 0.226 & 8.17 & $91.17 \%$ \\
\hline 9.936 & 0.976 & 10.18 & 9.70 & 36.13 & 0.245 & 8.85 & $91.28 \%$ \\
\hline 9.929 & 1.105 & 8.99 & 10.97 & 36.13 & 0.275 & 9.94 & $90.56 \%$ \\
\hline 19.97 & 0.548 & 36.44 & 10.94 & 36.11 & 0.275 & 9.93 & $90.74 \%$ \\
\hline 30 & 0.366 & 81.97 & 10.98 & 36.16 & 0.276 & 9.98 & $90.89 \%$ \\
\hline 36 & 0.313 & 115.02 & 11.27 & 36.13 & 0.277 & 10.01 & $88.82 \%$ \\
\hline 40 & 0.286 & 139.86 & 11.44 & 36.14 & 0.276 & 9.97 & $87.19 \%$ \\
\hline 14 & 0.816 & 17.16 & 11.42 & 36.11 & 0.297 & 10.72 & $93.88 \%$ \\
\hline 14 & 0.955 & 14.66 & 13.37 & 36.1 & 0.346 & 12.49 & $93.42 \%$ \\
\hline 14 & 1.094 & 12.80 & 15.32 & 36.1 & 0.395 & 14.26 & $93.10 \%$ \\
\hline 14 & 1.233 & 11.35 & 17.26 & 36.09 & 0.447 & 16.13 & $93.46 \%$ \\
\hline 14 & 1.372 & 10.20 & 19.21 & 36.09 & 0.497 & 17.94 & $93.38 \%$ \\
\hline 14 & 1.543 & 9.07 & 21.60 & 36.09 & 0.556 & 20.07 & $92.89 \%$ \\
\hline 20 & 1.147 & 17.44 & 22.94 & 36.07 & 0.595 & 21.46 & $93.56 \%$ \\
\hline 20 & 1.35 & 14.81 & 27.00 & 36.06 & 0.696 & 25.10 & $92.95 \%$ \\
\hline 19.91 & 1.533 & 12.99 & 30.52 & 36.05 & 0.797 & 28.73 & $94.13 \%$ \\
\hline 19.87 & 2.143 & 9.27 & 42.58 & 36.03 & 1.107 & 39.89 & $93.67 \%$ \\
\hline 24.35 & 2.656 & 9.17 & 64.67 & 35.97 & 1.688 & 60.72 & $93.88 \%$ \\
\hline 29.381 & 3.212 & 9.15 & 94.37 & 35.88 & 2.49 & 89.34 & $94.67 \%$ \\
\hline 36 & 2.72 & 13.24 & 97.92 & 22.49 & 3.58 & 80.51 & $82.22 \%$ \\
\hline
\end{tabular}




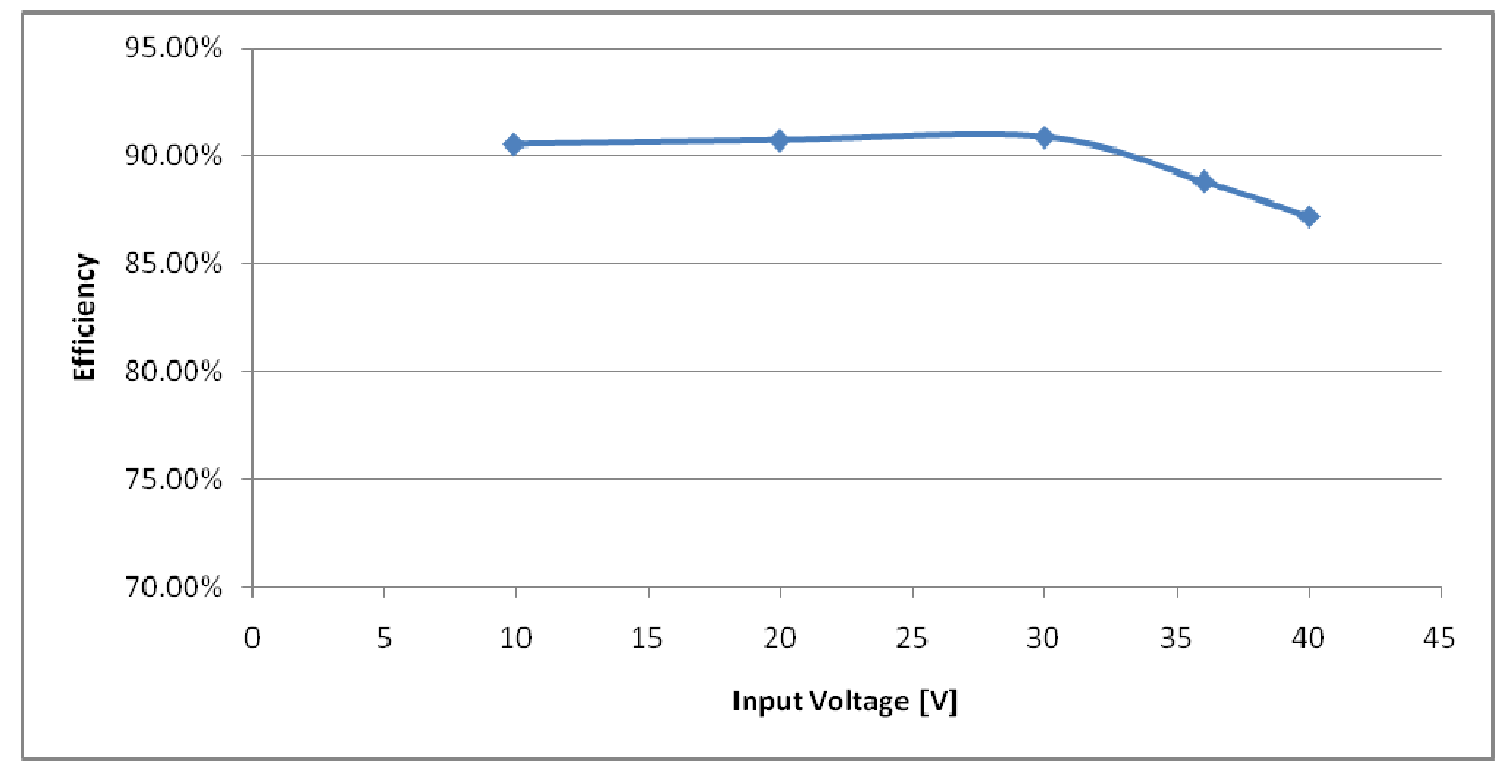

Figure 44: Efficiency Vs Input Voltage at 10W Output

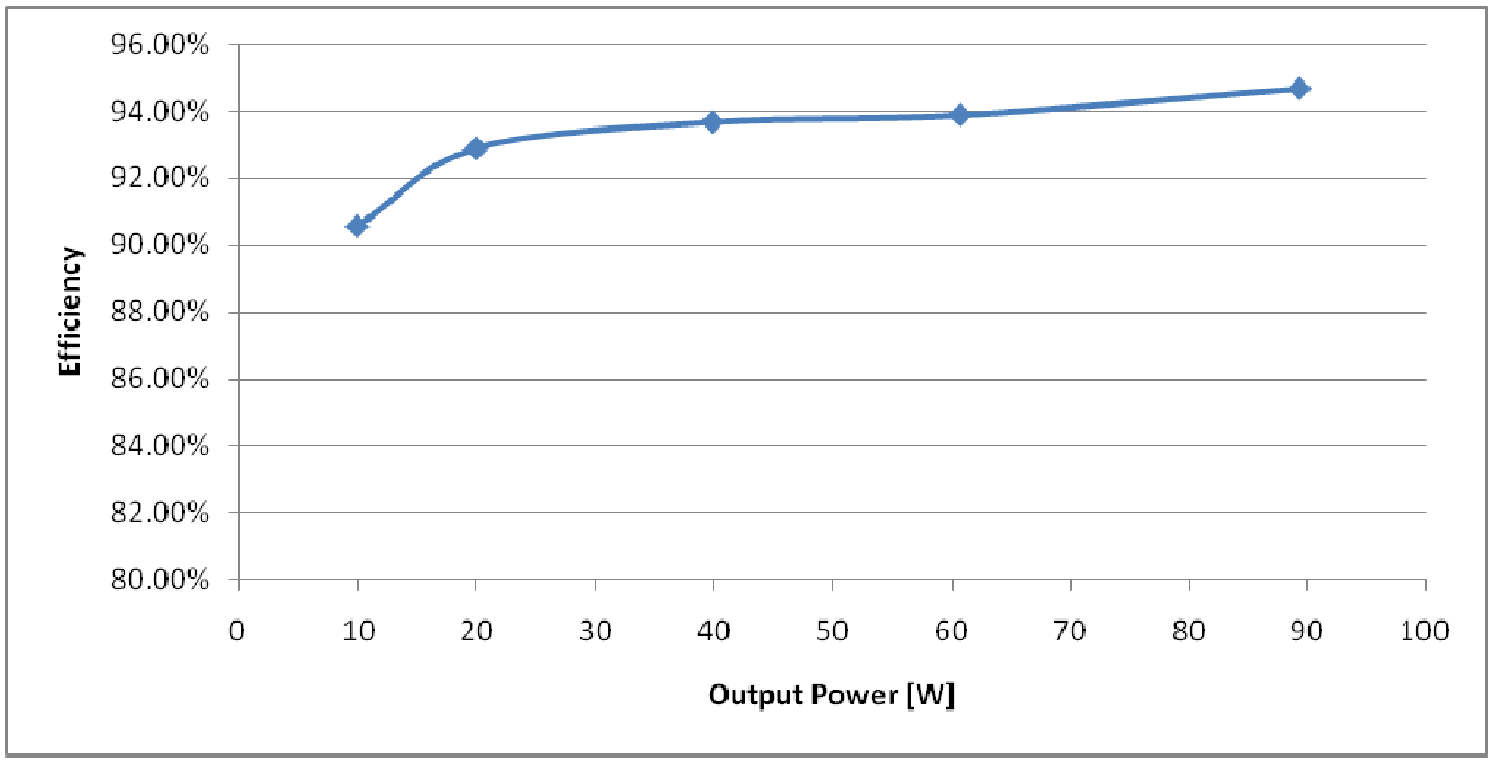

Figure 45: Efficiency Vs Output Power at $29 \Omega$ Input Impedance

Further testing shows at an input voltage of $40 \mathrm{~V}$ and output current demand of $3 \mathrm{~A}$, the converter took a several seconds, on the order of 15 seconds, to ramp up to $36 \mathrm{~V}$. After raising the load current, the converter did not regulate $36 \mathrm{~V}$, and only provided about $22 \mathrm{~V}$. Leaving the converter on in this state damaged some of the components. The converter no longer regulates the output voltage for more than a few seconds. This deregulation at higher load currents indicates a problem with the current handling 
capacity of one or more components. The MOSFETs and inductor handle the high currents. Determining the root cause of failure requires simulation, since the damaged components did not allow for testing the currents via the current sense resistor.

\subsubsection{Inrush Current Analysis}

In Figure 46, the current through the inductor during startup hits currents as high as $40 \mathrm{~A}$. The inductor currently in use by the system saturates at 13A [26]. Due to this saturation and deregulation of inductance, the converter takes longer to ramp up, thus exposing the inductor and MOSFETs to high currents. According to the BSZ123N08NS3G MOSFET datasheet, the maximum continuous drain current sits right at the 40A mark [20]. The strain of high currents over a couple seconds may damage the transistors causing the converter to deregulate even at low power levels. Charlie Zhao, an Applications Engineer from Linear Technology, also predicts that the high current damaged the MOSFETs. 


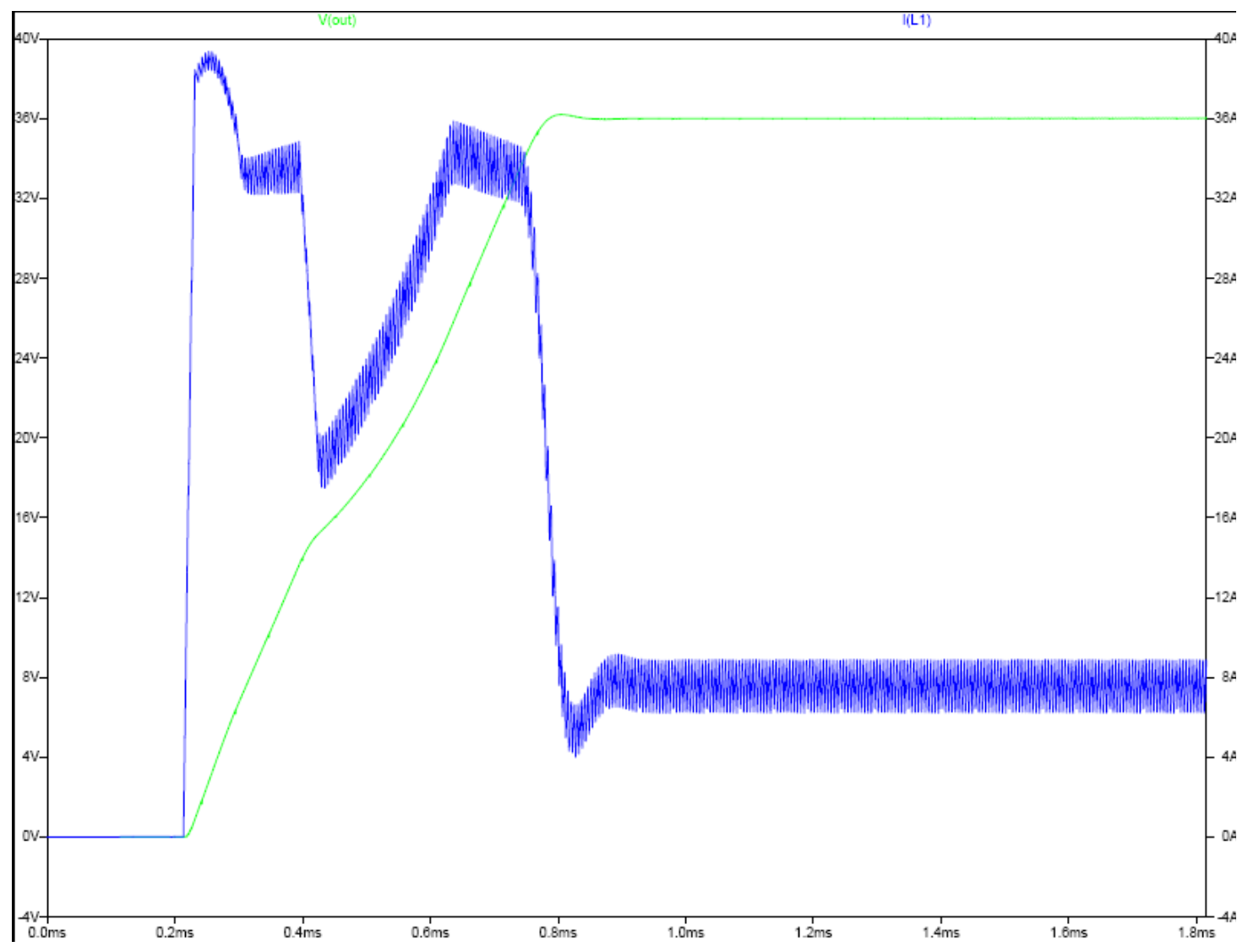

Figure 46: Startup Vout (Green) and Inductor L1 Current (Blue) Waveforms

With this finding, only one commercially available inductor exists with similar inductance and a higher saturation current. The CTX20-16-52-R, made by Coiltronics, maintains a $20 \mathrm{uH}$ inductance and saturates at 29.5A [27]. Future testing will determine if the application requires a custom wound inductor with a higher current saturation rating.

\subsubsection{Output Voltage Transients}

Figure 47 shows the output voltage transients in yellow and 7.6V IC supply rail from the LT3980 in blue. The output voltage transient peaks at $15 \mathrm{~V}$ above $36 \mathrm{~V}$, but only lasts about 10ns. Smaller oscillations occur and last for 350ns at the most. To reduce this, I added a $1000 \mathrm{uF}$ capacitor in for $\mathrm{C} 2$, the output capacitor, and added a $2.1 \mathrm{uF}$ ceramic capacitor essentially doubling the capacitance and halving the effective series resistance 
of C14. Lowering the ESR allows for some transient suppression. C14 originally lies in close proximity to the LT3980 circuit, but the converter may need a ceramic capacitor closer to MOSFET Q1 for its inherent faster response compared to an electrolytic capacitor. Table 24shows the improvement in the first and third lines with an efficiency rise from $86.59 \%$ to $90.61 \%$. Figure 48 shows much lower peak voltages.

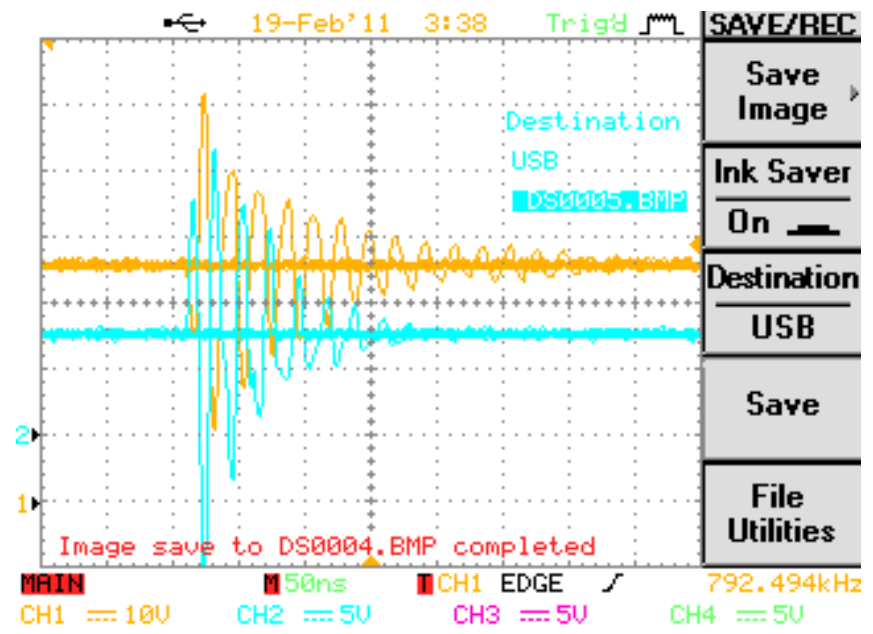

Figure 47: Vout(Yellow) Vcc(Blue) Transients Original Design

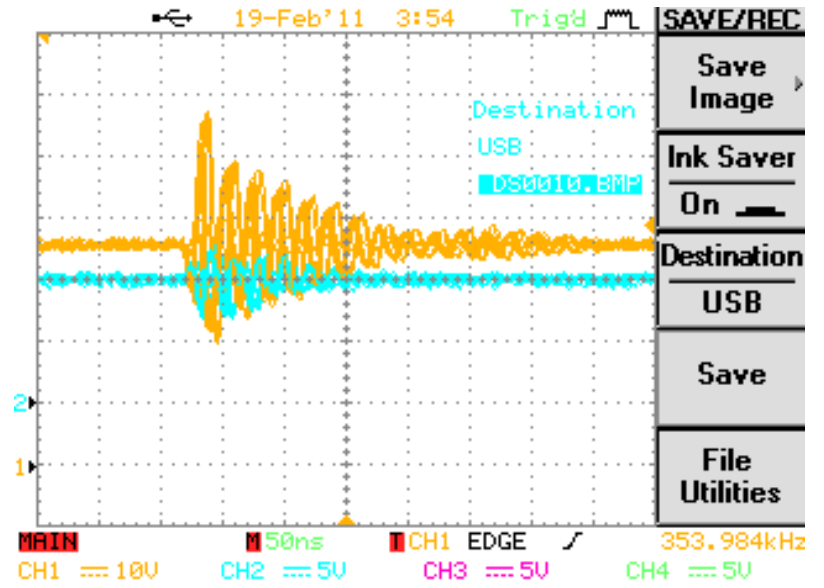

Figure 48: Vout(Yellow) Vec(Blue) Transients with added capacitors

\subsubsection{Design Modifications}

The LTC4444 datasheet reveals a similar application with an output power capability of $288 \mathrm{~W}$ [17]. This circuit utilizes many $2.2 \mathrm{uF}$ ceramic capacitors in parallel 
for the input and output capacitors, as well as raising $\mathrm{C} 13$ to $1000 \mathrm{uF}$. Placing capacitors in parallel not only increases the effective capacitance, but also reduces the effective internal resistance so that they can supply current faster. This technique reduces the large ripple voltages, and Figure 49 shows its incorporation into the next revision.

The Precor elliptical machine does have a $12 \mathrm{~V}$ battery on board to provide the necessary voltage for the MOSFET drivers and LTC3780 chips to operate on. This way, the battery replaces the buck converter, thus reducing the cost of the parts as well as frees up real estate on the PCB. A 12V AC adapter can also replace the buck converter.

Using this route, the 'RUN' circuit of the LTC3780 needs modification. As it stands now, the LTC3780 turns on as long as the buck converter supplies $7.5 \mathrm{~V}$. Since the new supply rail always stays at $12 \mathrm{~V}$, the LTC3780 always runs and consumes energy even without input power. Figure 9 shows the next design with the new 'RUN' circuitry consisting of R4, R5, D5, and C6 from a typical LTC4444 application [17]. This circuit turns on the LTC3780 at voltages above $5 \mathrm{~V}$ using a resistor divider, and pins the RUN pin to $4.7 \mathrm{~V}$ with the zener diode D5, since the RUN pin can only handle $6 \mathrm{~V}$ maximum.

Including these modifications into the parts list, in Table 25, raised the total price from $\$ 77.97$ to $\$ 79.47$, roughly a dollar, even with removing the buck converter circuit. The more expensive inductor and additional $100 \mathrm{~V}$ rated capacitors cause this seemingly unchanged price.

Figure 49 through Figure 51 show the fourth revision of the board. The new inductor takes up much more real estate than the one in the previous revision. In addition to the 'RUN' circuit, input/output capacitors, new inductor, I removed the buck converter 
and replaced it with a connector for a $12 \mathrm{~V}$ supply. I left the capacitor for this rail voltage as well as the phase lock loop filter circuit optional. Also, I added metal-oxide varistor footprints for transient suppression, instead of transient voltage suppressing diodes since MOVs inherently can handle more power.

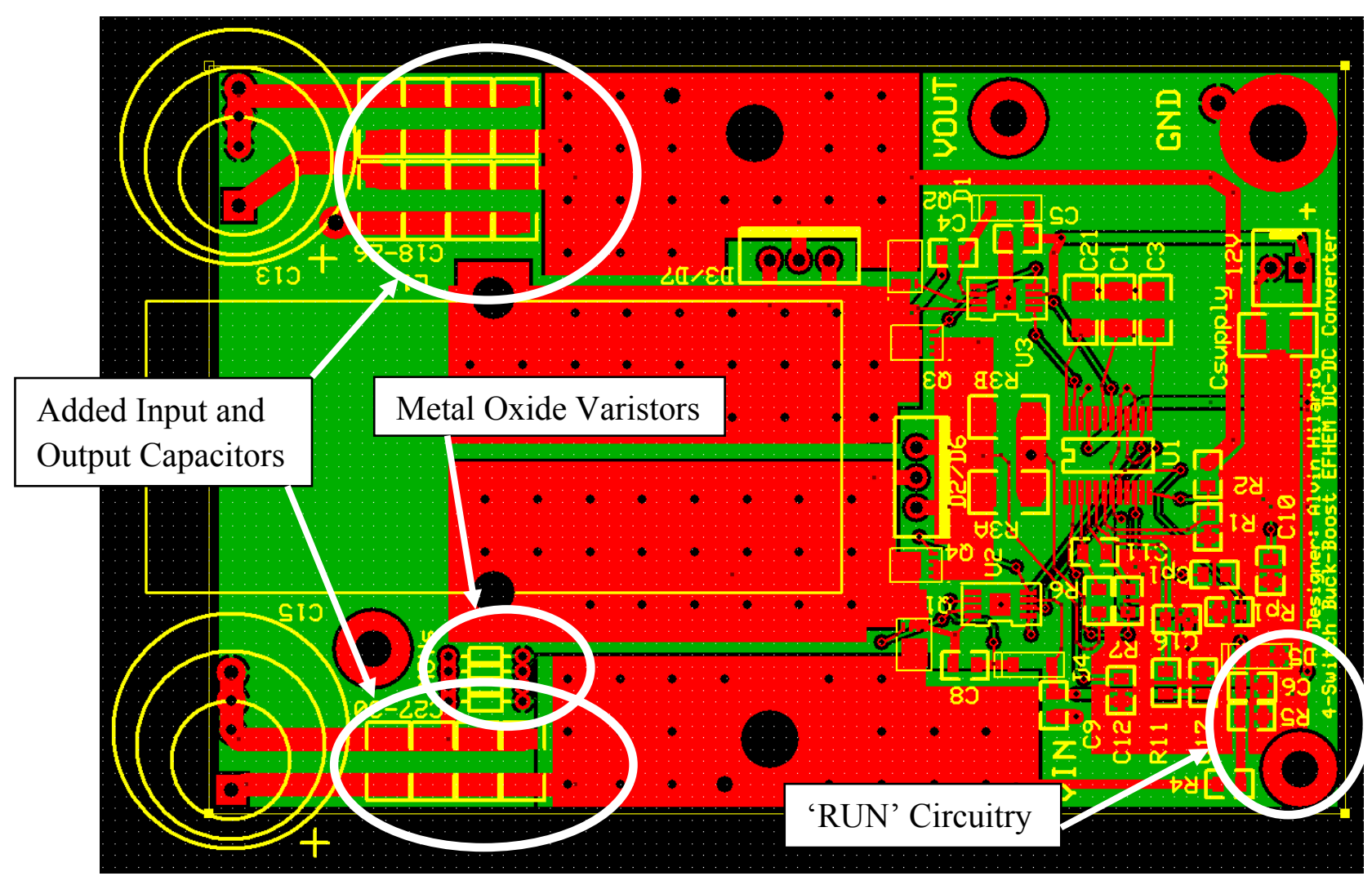

Figure 49: PCB Layout Fourth Revision 


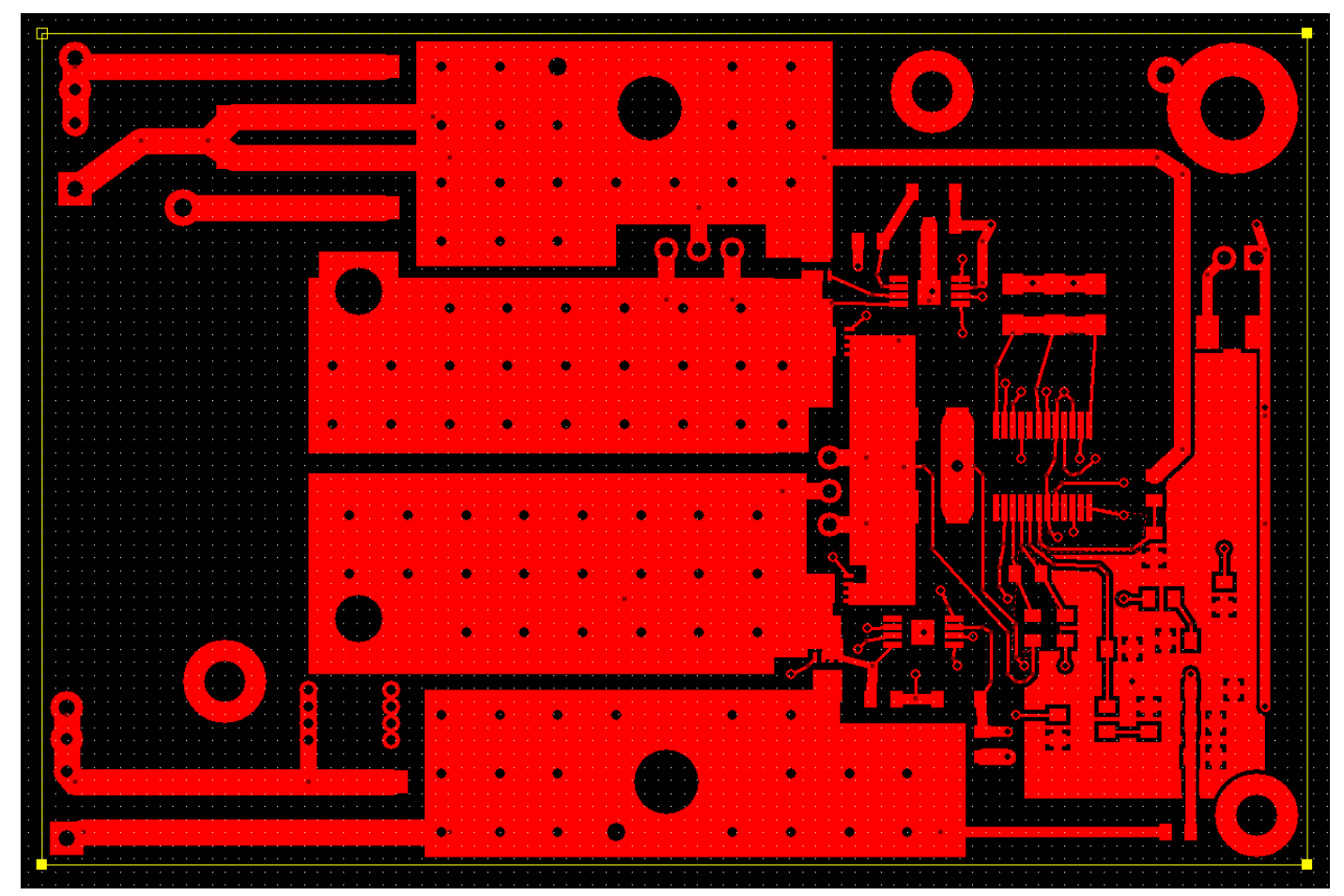

Figure 50: PCB Layout Fourth Revision Top Layer

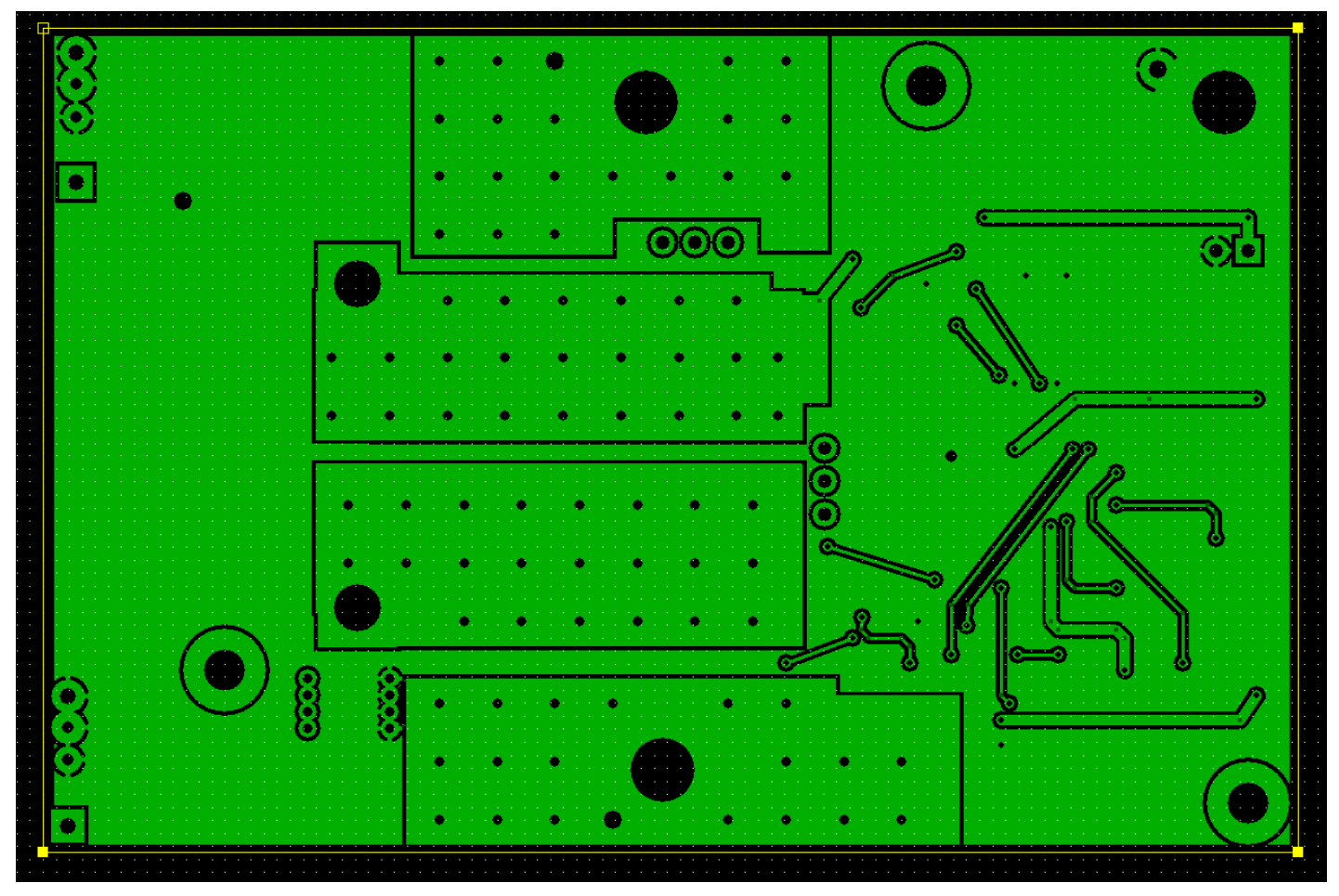

Figure 51: PCB Layout Fourth Revision Bottom Layer 


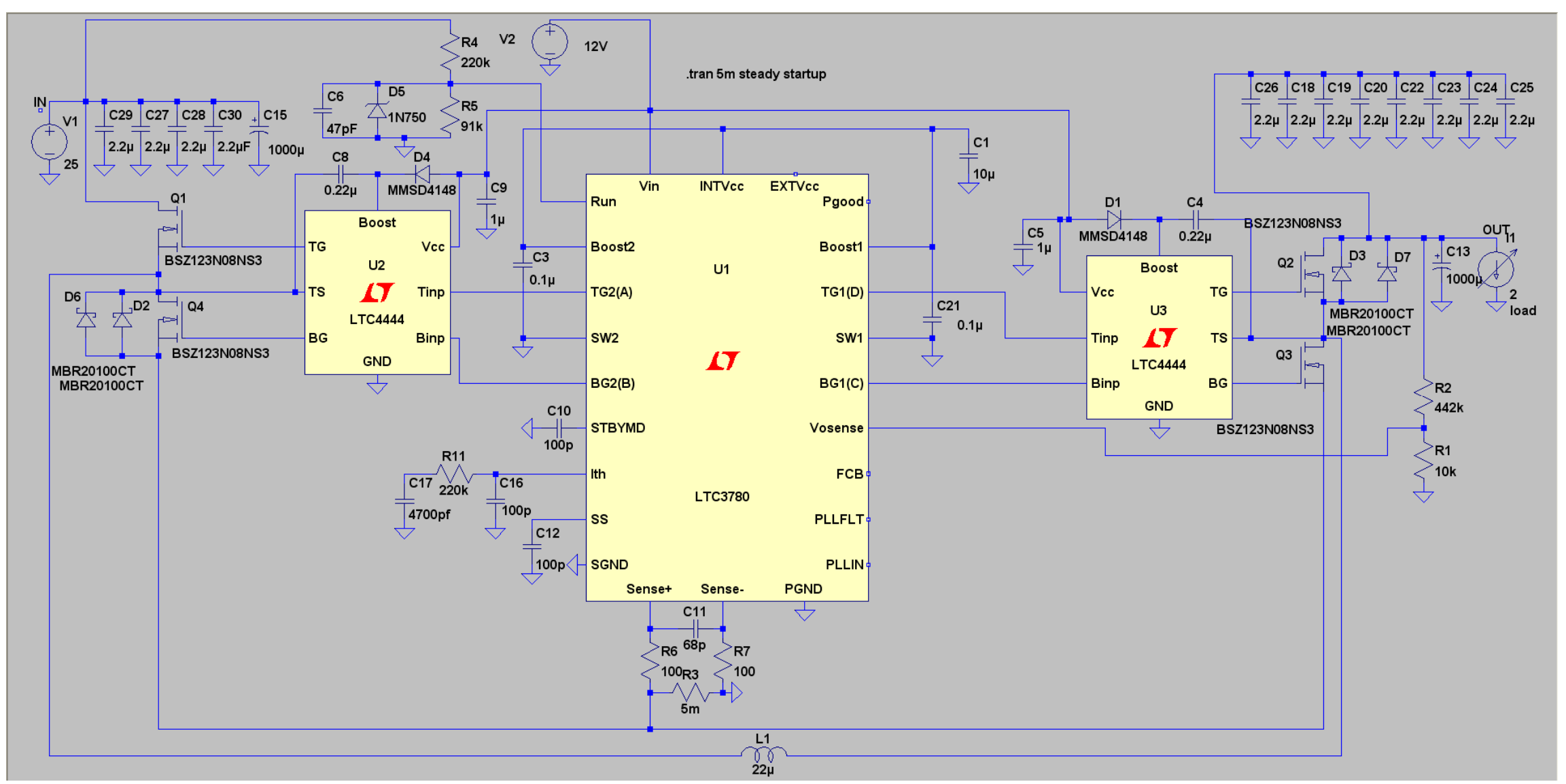

Figure 52: Design with First Modifications 
Table 25: New Parts List

\begin{tabular}{|c|c|c|c|c|c|c|c|c|c|}
\hline Reference Designator & Value & Note 1 & Note 2 & Note3 & Package Footprint & $\mathrm{P} / \mathrm{N}$ & Price & Quantity & Total Price/Part \\
\hline $\mathrm{C} 1$ & $4.7 \mathrm{uF}$ & Tantalum & - & $6 \mathrm{Vpk}$ & 1206 & 647-F931A475KAA & $\$ 0.15$ & 1 & $\$ 0.15$ \\
\hline $\mathrm{C} 3, \mathrm{C} 21$ & $0.1 \mathrm{uF}$ & Ceramic & $\mathrm{X} 7 \mathrm{R}$ or $\mathrm{X} 5 \mathrm{R}$ & 60Vpk & 1206 & 81-GRF31MR72A104KA1L & $\$ 0.06$ & 2 & $\$ 0.12$ \\
\hline $\mathrm{C} 4, \mathrm{C} 8$ & $0.22 \mathrm{uF}$ & Ceramic & X7R or X5R & $60 \mathrm{~V}$ & 0805 & 81-GRM21AR72A224KC5L & $\$ 0.38$ & 2 & $\$ 0.76$ \\
\hline $\mathrm{C} 5, \mathrm{C9}$ & $1 \mathrm{uF}$ & Ceramic & - & $8 \mathrm{Vpk}$ & 0805 & 810-C2012Y5V1C105Z-2 & $\$ 0.05$ & 2 & $\$ 0.10$ \\
\hline $\mathrm{C} 6$ & $47 p F$ & Ceramic & - & $5 \mathrm{Vpk}$ & 0805 & 80-C0805C470J5G & $\$ 0.05$ & 1 & $\$ 0.05$ \\
\hline $\mathrm{C} 10, \mathrm{C} 12, \mathrm{C} 16$ & $100 \mathrm{pF}$ & Ceramic & - & $5 \mathrm{Vpk}$ & 0805 & 81-GRM2167U1H101JZ1D & $\$ 0.13$ & 3 & $\$ 0.39$ \\
\hline $\mathrm{C} 11$ & $68 \mathrm{pF}$ & Ceramic & - & $1 \mathrm{Vpk}$ & 0805 & 81-GRM2167U1H680JZ1D & $\$ 0.15$ & 1 & $\$ 0.15$ \\
\hline C18-30 & $2.2 \mathrm{uF}$ & Ceramic & X7R or X5R & $52 \mathrm{Vpk}$ & 1210 & 587-1778-1-ND & $\$ 0.88$ & 12 & $\$ 10.56$ \\
\hline $\mathrm{C} 15, \mathrm{C} 13$ & $1000 \mathrm{uF}$ & Electrolytic & - & $52 \mathrm{Vpk}$ & $7.5 \mathrm{~mm}$ Dia. $0.8 \mathrm{~mm}$ holes & 647-UVR2A102MRD6 & $\$ 1.21$ & 2 & $\$ 2.42$ \\
\hline $\mathrm{C} 17$ & $0.0047 \mathrm{uF}$ & Ceramic & - & $1 \mathrm{Vpk}$ & 0805 & 140-CC501B472K-RC & $\$ 0.04$ & 1 & $\$ 0.04$ \\
\hline R1 & $10 \mathrm{~K}$ & - & - & - & 0805 & 667-ERJ-6GEYJ103V & $\$ 0.04$ & 1 & $\$ 0.04$ \\
\hline $\mathrm{R} 2$ & $442 \mathrm{~K}$ & - & - & - & 0805 & 292-442K-RC & $\$ 0.04$ & 1 & $\$ 0.04$ \\
\hline R3A/B & $5 \mathrm{~m}$ (two $10 \mathrm{~m}$ in parallel) & Sensing Resistor & - & - & 1210 & 652-CRA2010FZR010ELF & $\$ 0.46$ & 2 & $\$ 0.92$ \\
\hline R5 & $91 K$ & - & - & - & 0805 & 260-91K-RC & $\$ 0.04$ & 1 & $\$ 0.04$ \\
\hline $\mathrm{R} 6, \mathrm{R7}$ & 100 & - & - & - & 0805 & 667-ERJ-6GEYJ101V & $\$ 0.04$ & 2 & $\$ 0.08$ \\
\hline R8 & $51 \mathrm{~K}$ & - & - & - & 0805 & 260-51K-RC & $\$ 0.04$ & 1 & $\$ 0.04$ \\
\hline R11, R4 & $220 \mathrm{~K}$ & - & - & - & 0805 & $260-220 \mathrm{~K}-\mathrm{RC}$ & $\$ 0.04$ & 2 & $\$ 0.08$ \\
\hline $\mathrm{L} 1$ & $20 \mathrm{uH}$ & 7.5ADC & 9Apk & - & Through Hole & h.com/pdf/4935b080-1881 & $\$ 8.56$ & 1 & $\$ 8.56$ \\
\hline D1,D4 & MMSD4148 & - & - & - & SOD-123 & MMSD4148T1GOSCT-ND & $\$ 0.42$ & 2 & $\$ 0.84$ \\
\hline D2/D6,D3/D7 parallel & MBR20100CT & - & - & - & TO-220 & MBR20100CT-BPMS-ND & $\$ 0.88$ & 2 & $\$ 1.76$ \\
\hline D5 & BZT52C4V7 & - & - & - & SOD-123 & BZT52C4V7-V-GS08 & $\$ 0.04$ & 1 & $\$ 0.04$ \\
\hline Q1,Q2.Q3.Q4 & BSZ123N08NS3 & - & - & - & 8-PowerVDFN & BSZ123N08NS3GINCT-ND & $\$ 1.39$ & 4 & $\$ 5.56$ \\
\hline U1 & LTC3780 & - & - & - & 24-SSOP & LTC3780EG\#PBF-ND & $\$ 9.50$ & 1 & $\$ 9.50$ \\
\hline U2, U3 & LTC4444 & - & - & - & 8-MSOP & LTC4444EMS8E\#PBF-ND & $\$ 3.38$ & 2 & $\$ 6.76$ \\
\hline \multirow[t]{2}{*}{$\mathrm{PCB}$} & - & - & - & - & - & expresspcb.com & $\$ 91.41$ & 0.33333 & $\$ 30.47$ \\
\hline & & & & & & & & Total & $\$ 79.47$ \\
\hline
\end{tabular}




\subsection{Second Revision Testing}

\subsubsection{RUN Circuitry}

The newly revised 'RUN' circuitry performed as expected with one exception. The converter turned on at $8.3 \mathrm{~V}$ instead of $5 \mathrm{~V}$. Figure 53 shows a $100 \mathrm{k} \Omega$ resistor lies in parallel with resistor R5, $91 \mathrm{k} \Omega$, in the 'RUN' circuit resistor divider effectively bringing the resistance down to $48 \mathrm{k} \Omega$, thus turning on the IC at $8.3 \mathrm{~V}$ [9]. The new 'RUN' circuitry excludes resistor R5, leaving one less part and allowing the circuit to turn on at $4.8 \mathrm{~V}$.

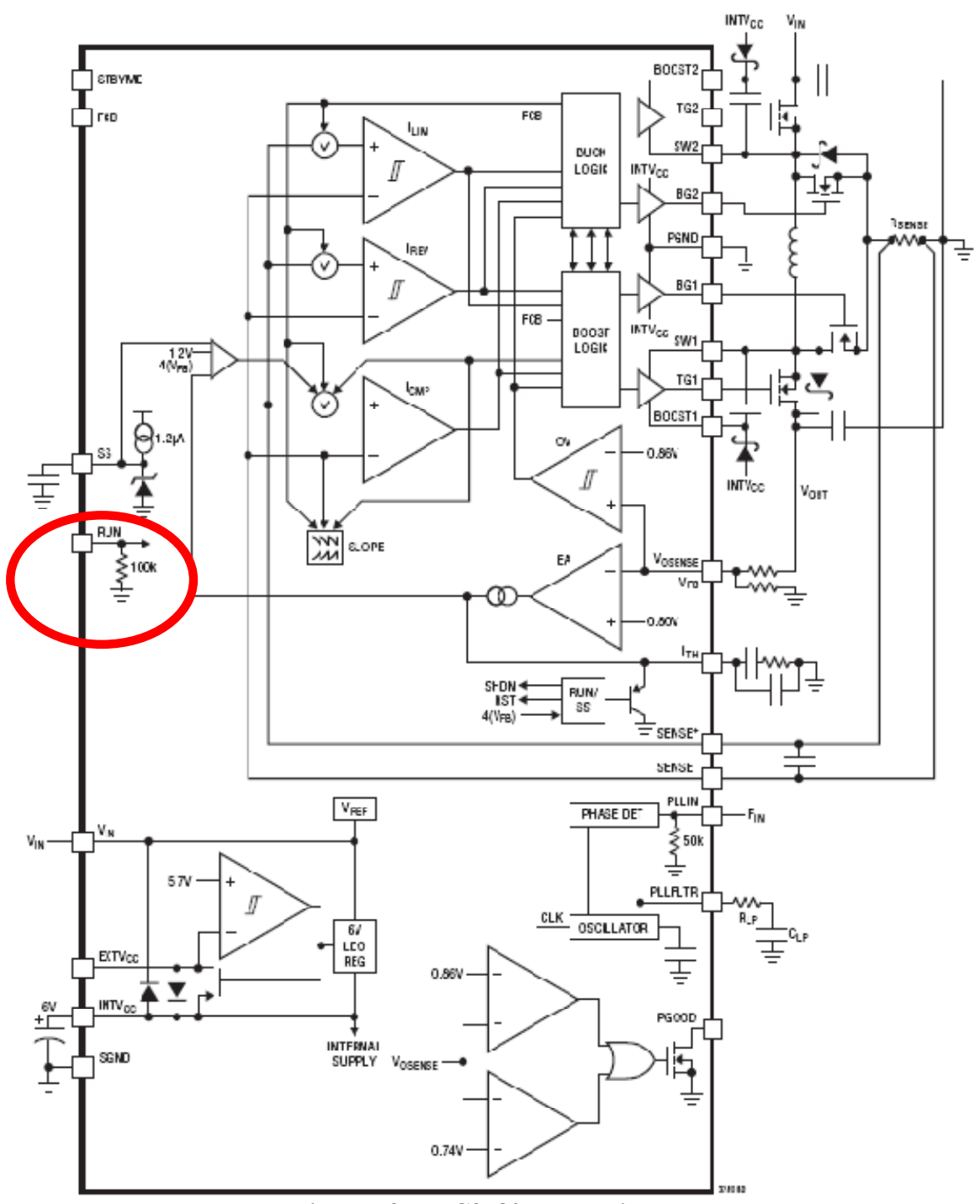

Figure 53: LTC3780 Block Diagram 


\subsubsection{Efficiency}

Table 26 shows the efficiency data of the Four-Switch Buck-Boost converter at typical operation, various power levels with the input impedance of the converter equal to $10 \Omega$. The converter connected to a power supply and electronic load. The converter averages $94 \%$ efficiency throughout the design specified power range. During the normal load of 60-100W, it maintains efficiencies around 96\%. Figure 54 illustrates efficiencies above $97 \%$ for power levels above $90 \mathrm{~W}$. This revision doesn't deliver power as efficiently at lower power levels. The new inductor may have caused this drop due to higher series resistance and core losses.

Table 26: Second Revision Testing Efficiency Data

\begin{tabular}{|c|c|c|c|c|c|c|c|}
\hline Vin [V] & lin [A] & Zin [ $\Omega$ ] & Pin [W] & Vo [V] & Io [A] & Po [W] & Efficiency \\
\hline 8.3 & 0.806 & 10.29777 & 6.6898 & 36.33 & 0.16 & 5.8128 & $86.89 \%$ \\
\hline 10 & 1.0795 & 9.263548 & 10.795 & 36.23 & 0.26 & 9.4198 & $87.26 \%$ \\
\hline 15 & 1.505 & 9.966777 & 22.575 & 36.24 & 0.57 & 20.6568 & $91.50 \%$ \\
\hline 20 & 2.013 & 9.93542 & 40.26 & 36.21 & 1.01 & 36.5721 & $90.84 \%$ \\
\hline 25 & 2.4614 & 10.15682 & 61.535 & 36.22 & 1.61 & 58.3142 & $94.77 \%$ \\
\hline 30 & 2.9935 & 10.02171 & 89.805 & 36.21 & 2.41 & 87.2661 & $97.17 \%$ \\
\hline 35 & 3.53 & 9.915014 & 123.55 & 36.2 & 3.34 & 120.908 & $97.86 \%$ \\
\hline 40 & 4.05 & 9.876543 & 162 & 36.19 & 4.4 & 159.236 & $98.29 \%$ \\
\hline 45 & 4.53 & 9.933775 & 203.85 & 36.18 & 5.5 & 198.99 & $97.62 \%$ \\
\hline 52 & 5.23 & 9.942639 & 271.96 & 36.18 & 7.4 & 267.732 & $98.45 \%$ \\
\hline
\end{tabular}




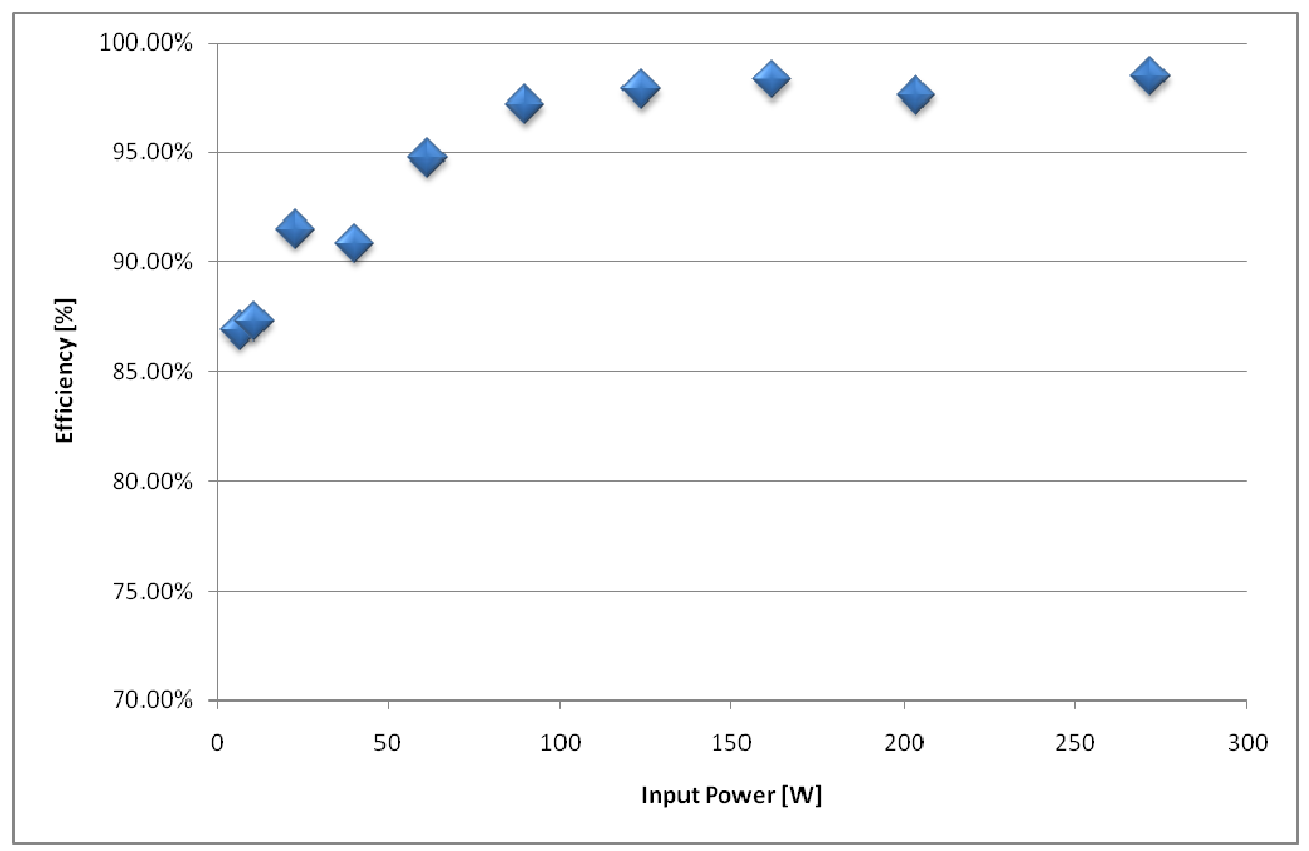

Figure 54: 2nd Rev. Efficiency Vs Input Power with Input Resistance = $10 \Omega$

Figure 55 shows the output voltage regulation with respect to input power. Across the whole power range, the converter regulates the output voltage at $0.41 \%$.

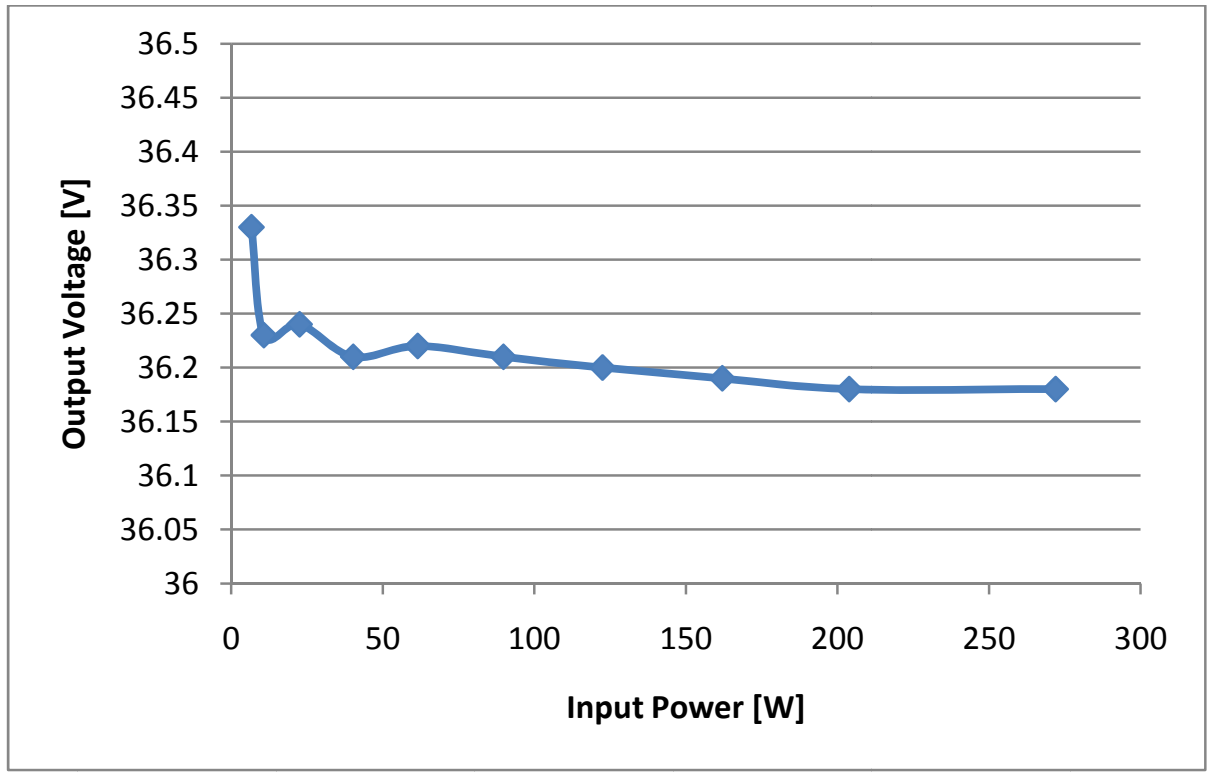

Figure 55: 2nd Rev. Output Voltage Vs Input Power with Input Resistance $=10 \Omega$ 


\subsubsection{Design Modifications}

The next revision for the PCB layout, shown by Figure 56 through Figure 58, incorporates an optional low dropout voltage regulator, TL750L10CLPR, for the IC supply rail. This voltage regulator stabilizes the battery voltage down to $10 \mathrm{~V}$ as well as provides protection from possible high voltage stresses. Also, I removed the phase lock loop filter circuitry and resistor R5. Figure 59 displays the final design revision.

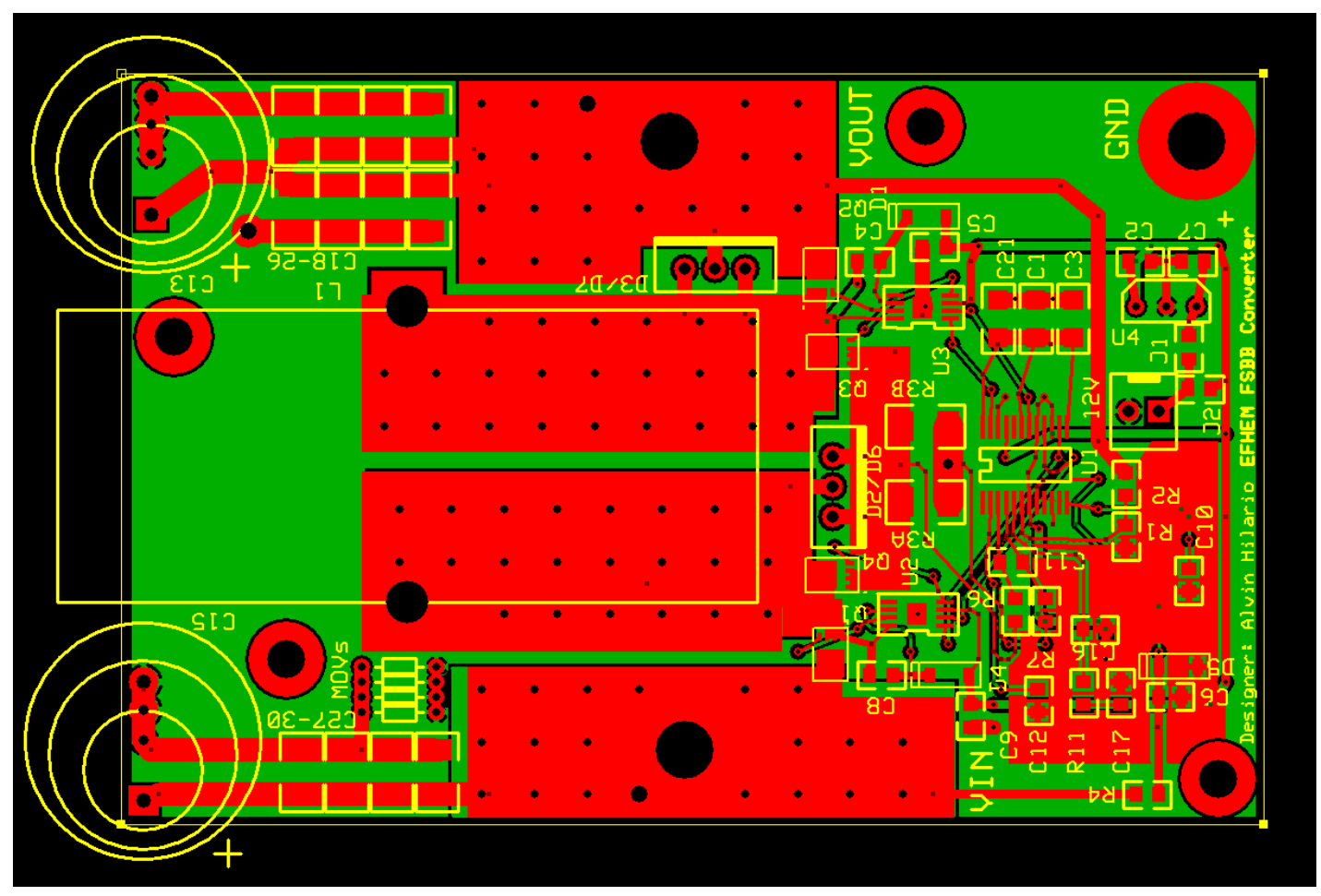

Figure 56: PCB Layout Fifth Revision 


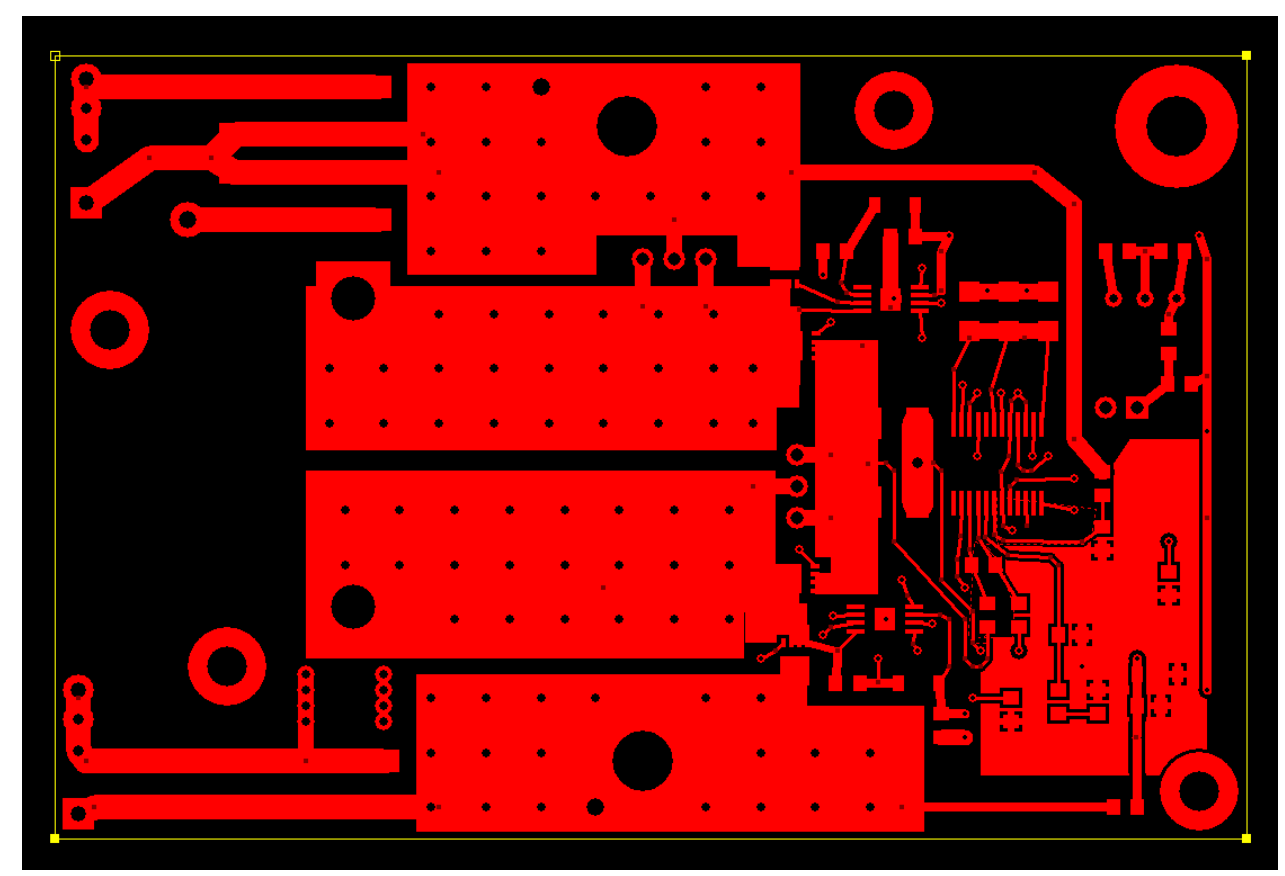

Figure 57: PCB Layout Fifth Revision Top Layer

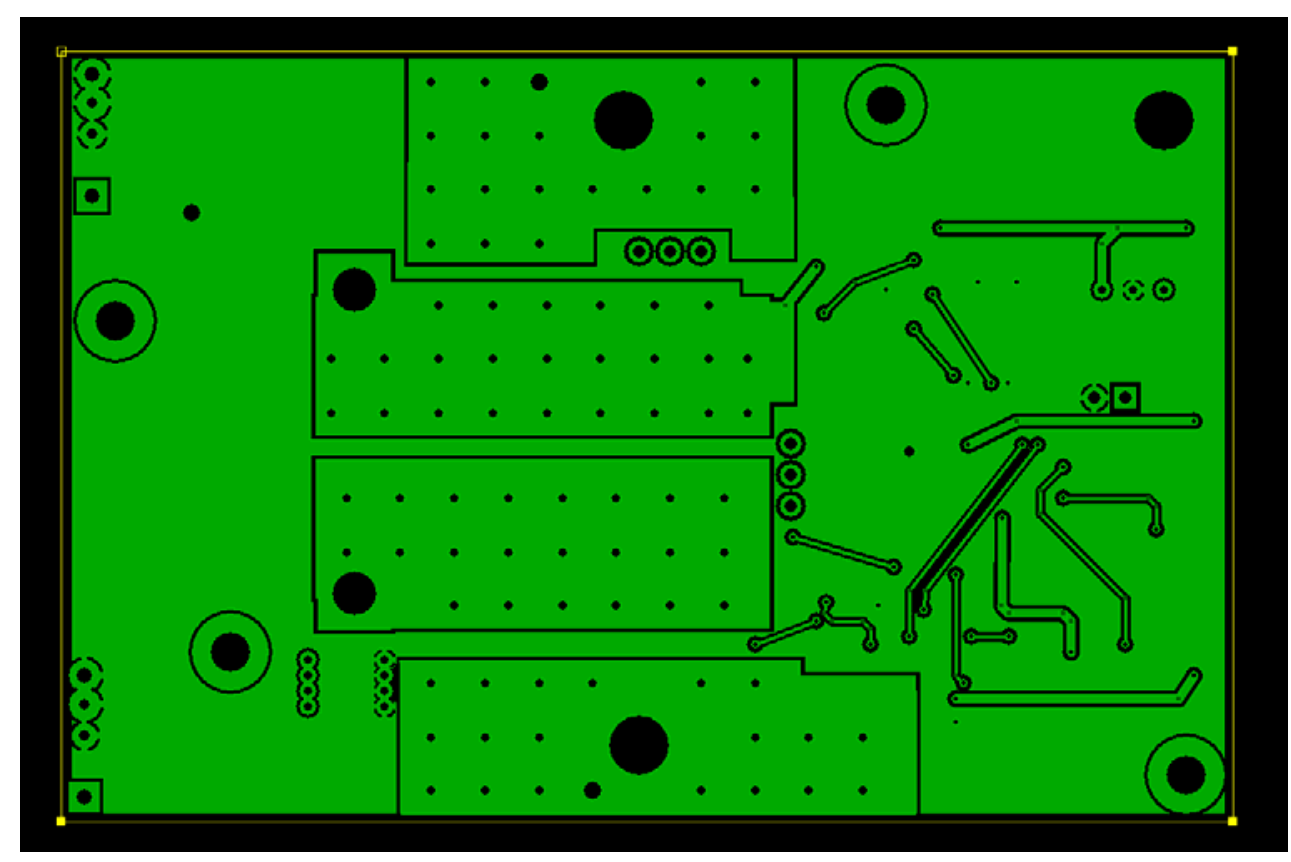

Figure 58: PCB Layout Fifth Revision Bottom Layer 


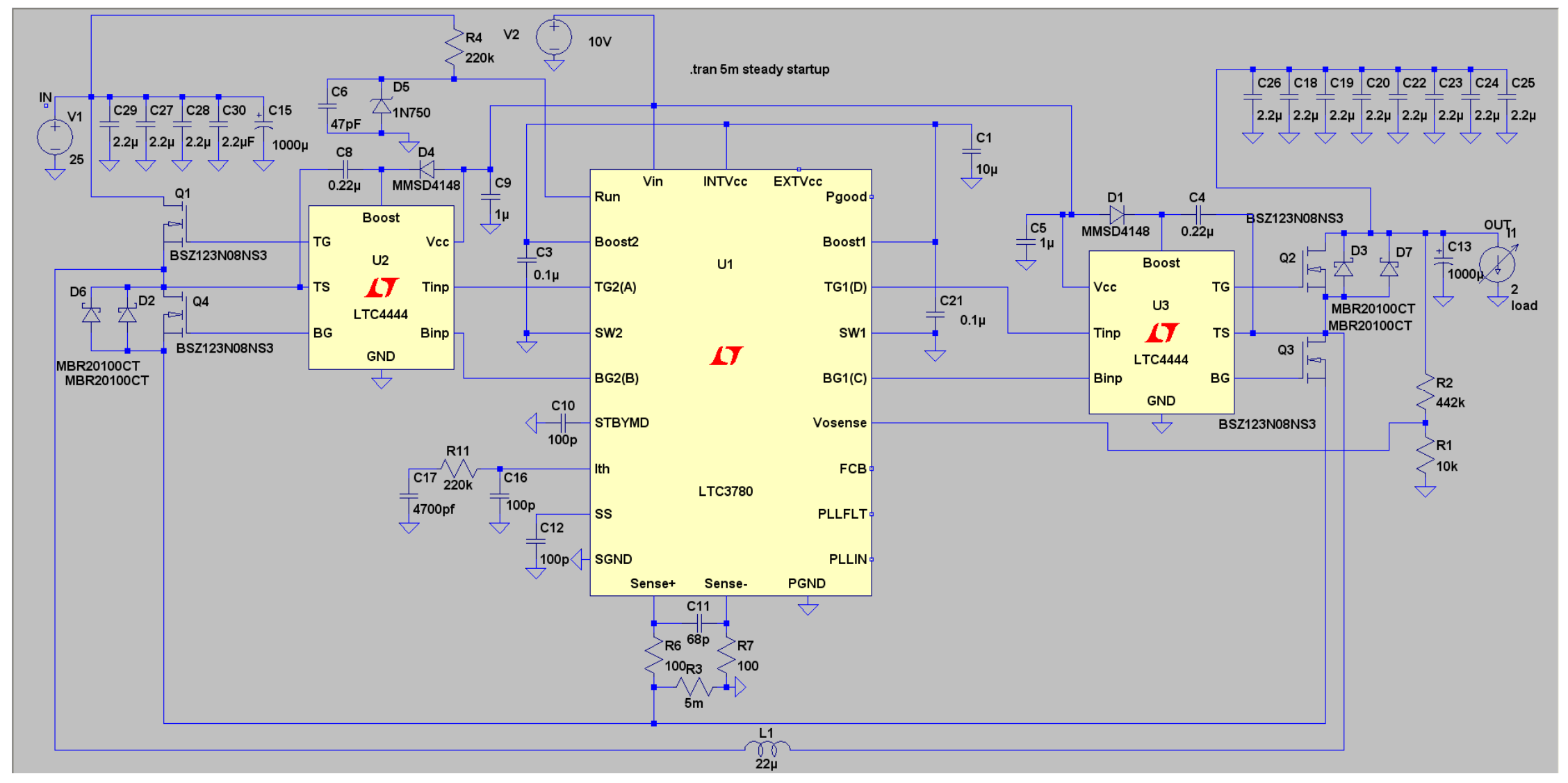

Figure 59: Final FSBB Converter Design 


\subsection{Third Revision Testing}

\subsubsection{Full System Testing}

In the third round of testing, the converter runs with the full system with the elliptical machine and microinverter, since only a limited number of testing scenarios to do with each component separately for a system that contains two "black boxes" exist. Table 27 shows the data for testing the converter with both the Precor elliptical machine and Enphase microinverter. Testing with the electronic load replacing the microinverter did not yield a similar response.

Table 27: Third Revision Testing Data

\begin{tabular}{|c|c|c|c|c|c|c|c|c|}
\hline Resistance Level & Vin [V] & lin [A] & Zin [ [ & Pin [W] & Vo [V] & Io [A] & Po [W] & Efficiency \\
\hline 2 & 4.8 & 0.96 & 5 & 4.608 & 29.73 & 0.073 & 2.17029 & $47.10 \%$ \\
\hline 3 & 5 & 1.6 & 3.125 & 8 & 36.13 & 0.154 & 5.56402 & $69.55 \%$ \\
\hline 4 & 5.1 & 2.05 & 2.487805 & 10.455 & 29.44 & 0.18 & 5.2992 & $50.69 \%$ \\
\hline 5 & 5.2 & 2.66 & 1.954887 & 13.832 & 31.9 & 0.28 & 8.932 & $64.57 \%$ \\
\hline 6 & 5.4 & 3.2 & 1.6875 & 17.28 & 25.1 & 0.39 & 9.789 & $56.65 \%$ \\
\hline 7 & 5.5 & 3.63 & 1.515152 & 19.965 & 24.04 & 0.482 & 11.58728 & $58.04 \%$ \\
\hline 8 & 5.7 & 4.18 & 1.363636 & 23.826 & 24.02 & 0.58 & 13.9316 & $58.47 \%$ \\
\hline 9 & 5.8 & 4.77 & 1.215933 & 27.666 & 24.23 & 0.66 & 15.9918 & $57.80 \%$ \\
\hline
\end{tabular}

Firstly, this response of this system acts similarly to the Wilmore converter demonstrated by a previous group [3]. The input impedance to the converter also approaches $1 \Omega$. Some solar inverters implement a hill climbing MPPT algorithm. They start off at a point probably in the center of its voltage range, $33 \mathrm{~V}$, and tests if a step in voltage in either way provides a higher power. If so, the input voltage set point changes. This process continues until the voltage point reaches the "hilltop." For a synchronous generator, the source performs as a pulsed current source. To achieve maximum power transfer, the DC-DC converter must provide as little resistance as possible. This happens at the converter's dropout voltage near $5 \mathrm{~V}$. The microinverter accomplishes this by 
drawing too much current, forcing the output voltage of the converter to deregulate. The deregulation in turn drives up the duty cycle, which lowers the input resistance.

In a system perspective, the DC-DC converter provided high efficiencies for its full power range out of the system, but needs modification to regulate the input impedance at $10 \Omega$. This impedance regulation replaces the maximum power point tracking algorithm, thus requiring a separate application specific inverter and converter. The next chapter describes a possible control scheme for this.

\subsubsection{DC-DC Converter Final Characterization}

For research as a suitable topology, the project necessitates a complete characterization of the converter in the normal operation with a constant input impedance of $10 \Omega$. Table 28 displays the data for the converter. 
Table 28: Final Characterization Data

\begin{tabular}{|c|c|c|c|c|c|c|}
\hline Vin [V] & $\operatorname{lin}[A]$ & $\operatorname{Zin}[\Omega]$ & Pin [W] & $\mathrm{Vcc}[\mathrm{V}]$ & $\operatorname{Icc}[\mathrm{A}]$ & Pcc [W] \\
\hline 5 & 0.502 & 9.96 & 2.51 & 12 & 0.01 & 0.12 \\
\hline 10 & 1.073 & 9.32 & 10.73 & 12 & 0.01 & 0.12 \\
\hline 15 & 1.533 & 9.78 & 23.00 & 12 & 0.01 & 0.12 \\
\hline 20 & 2.175 & 9.20 & 43.50 & 12 & 0.02 & 0.24 \\
\hline 25 & 2.528 & 9.89 & 63.20 & 12 & 0.02 & 0.24 \\
\hline 30 & 3.009 & 9.97 & 90.27 & 12 & 0.02 & 0.24 \\
\hline 35 & 3.501 & 10.00 & 122.54 & 12 & 0.02 & 0.24 \\
\hline 40 & 4.068 & 9.83 & 162.72 & 12 & 0.02 & 0.24 \\
\hline 45 & 4.507 & 9.98 & 202.82 & 12 & 0.02 & 0.24 \\
\hline 52 & 5.203 & 9.99 & 270.56 & 12 & 0.02 & 0.24 \\
\hline Vin [V] & Vo [V] & $10[\mathrm{~A}]$ & Po [W] & Efficiency & Vripple [V] & \%Vripple \\
\hline 5 & 36.21 & 0.05 & 1.81 & $68.84 \%$ & 0.06 & $0.17 \%$ \\
\hline 10 & 36.21 & 0.26 & 9.41 & $86.77 \%$ & 0.18 & $0.50 \%$ \\
\hline 15 & 36.2 & 0.58 & 21.00 & $90.83 \%$ & 0.18 & $0.50 \%$ \\
\hline 20 & 36.19 & 1.08 & 39.09 & $89.36 \%$ & 0.32 & $0.88 \%$ \\
\hline 25 & 36.19 & 1.63 & 58.99 & $92.99 \%$ & 0.24 & $0.66 \%$ \\
\hline 30 & 36.18 & 2.38 & 86.11 & $95.14 \%$ & 0.24 & $0.66 \%$ \\
\hline 35 & 36.16 & 3.27 & 118.24 & $96.31 \%$ & 0.38 & $1.05 \%$ \\
\hline 40 & 36.14 & 4.33 & 156.49 & $96.03 \%$ & 0.06 & $0.17 \%$ \\
\hline 45 & 36.12 & 5.38 & 194.33 & $95.70 \%$ & 0.06 & $0.17 \%$ \\
\hline 52 & 36.1 & 7.19 & 259.56 & $95.85 \%$ & 0.06 & $0.17 \%$ \\
\hline
\end{tabular}

As shown in Table 28, the converter regulates the voltage at $0.31 \%$ across the whole voltage and power range. Furthermore, the converter averages $94.07 \%$ efficiency in the typical human power range, 60-100W. Regarding output voltage ripple, the converter displays minimal ripple in buck mode, followed by boost mode, then buckboost mode. This logically follows the models. The buck converter's inherent filtering by an output inductor helps the ripple, while the boost and buck-boost converters do not.

Figure 60 through Figure 62 illustrate this phenomenon. The Agilent DSO3202A oscilloscope captured these waveforms using AC coupling. 


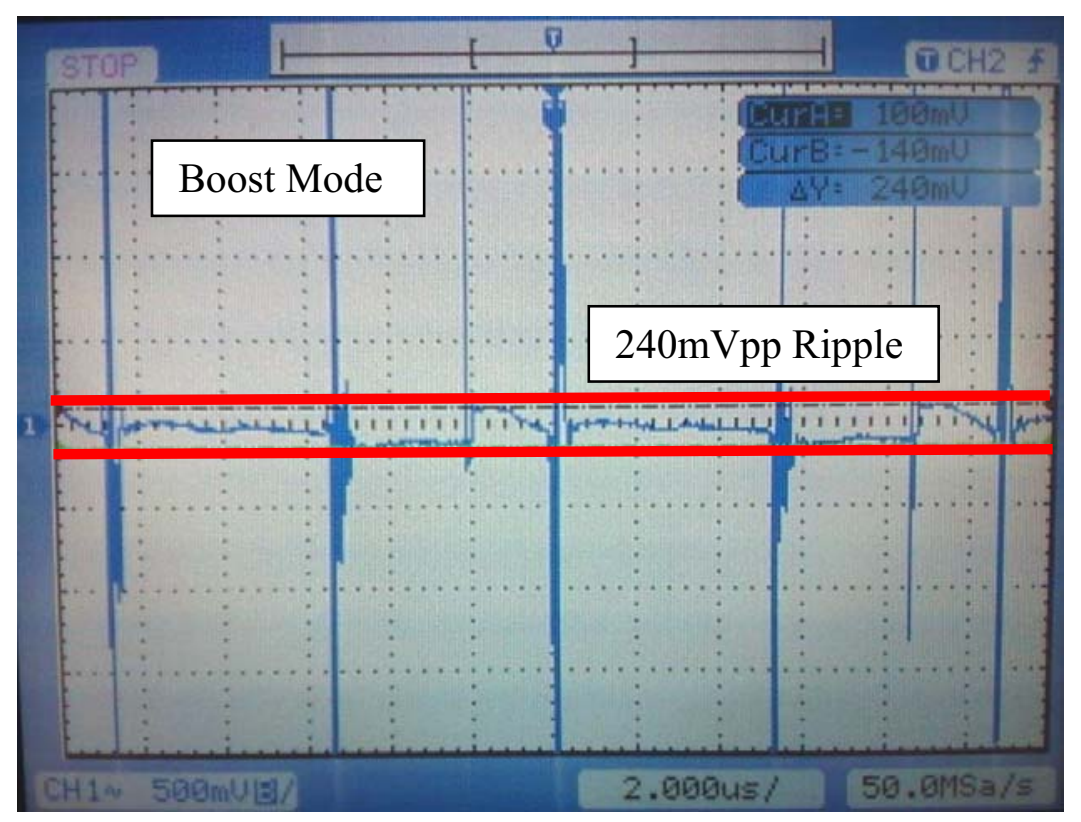

Figure 60: Output Voltage Ripple 25Vin

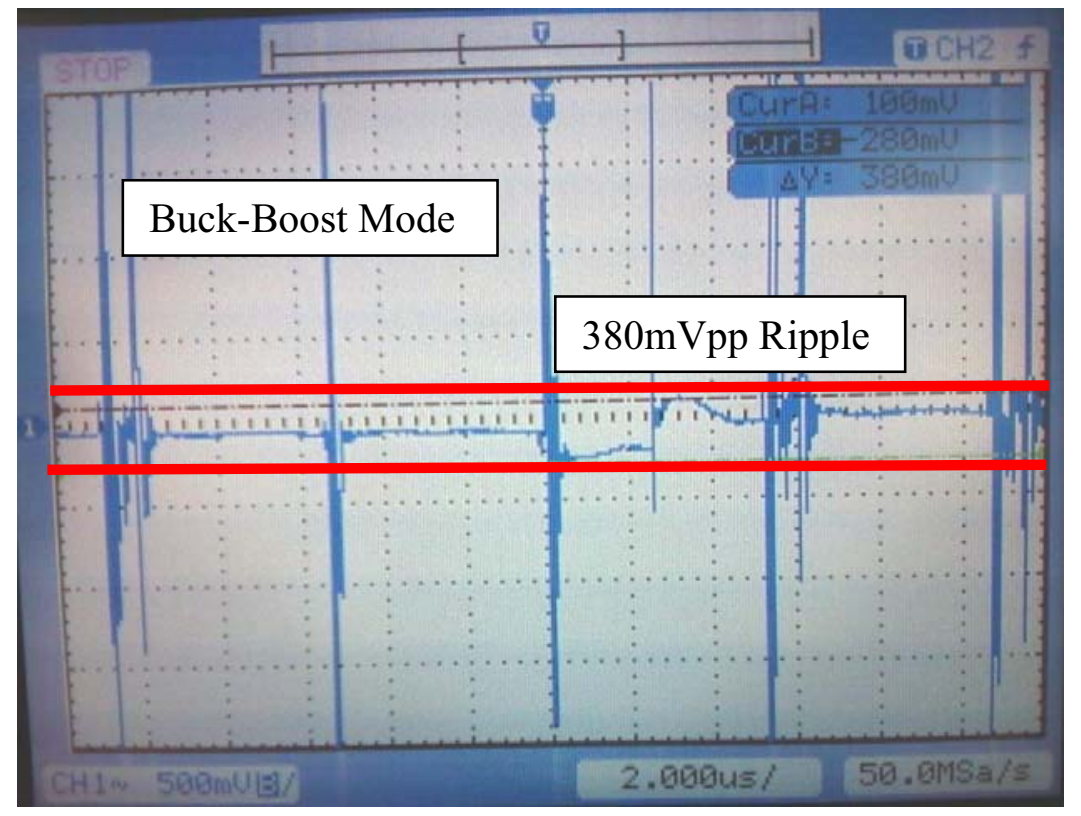

Figure 61: Output Voltage Ripple 35Vin 


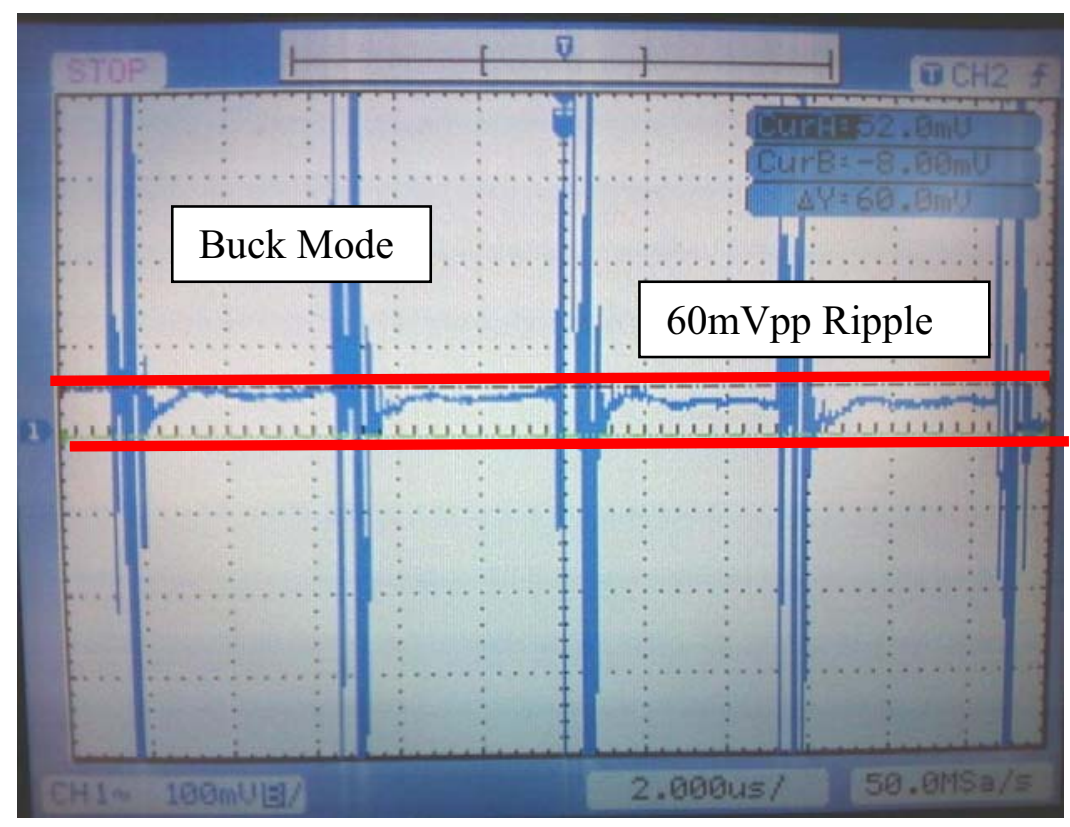

Figure 62: Output Voltage Ripple 45Vin

\subsection{Testing Conclusion}

After several testing revisions, the Four-Switch Buck-Boost converter met the design specifications. The converter maintained efficiencies above $90 \%$ during typical load operation. At worst, the output voltage ripple reached $1.05 \%, 380 \mathrm{mV}$. The first revision testing showed the inductor's inadequate current saturation rating and the need for higher input and output capacitance. Replacing the buck converter with the elliptical machine's $12 \mathrm{~V}$ battery reduced costs and freed up PCB real estate. Second revision testing showed high efficiencies for the $20-275 \mathrm{~W}$ power range. And during the last revision testing, the converter did not function as needed while connected to the elliptical machine and microinverter. As the root cause, the Enphase microinverter did not allow the converter to maintain $10 \Omega$ input impedance or regulate its output at $36 \mathrm{~V}$. Thus, the system does not function compatibly with inverters using a solar power based MPPT algorithm. The project needs a top-down system level design. 


\section{CHAPTER 6: PROPOSED CONSTANT IMPEDANCE CONTROL SCHEME}

\subsection{Introduction}

As concluded by the third revision testing, the Enphase microinverter's MPPT algorithm does not function as needed with the Precor elliptical machine. The system requires a new inverter with a control system similar to that of a wind inverter, since a wind inverter also harvests energy from an AC machine. This chapter proposes architectures for the system, as well as derives the fundamental control functions for the architectures.

\subsection{Possible Architectures}

Three possible architectures for energy harvesting for this application exist. The green blocks denote power electronics components needed for synchronous power generation. The first utilizes the FSBB converter as a voltage regulator, a new application specific inverter, and a low frequency transformer to step up the voltage to $120 \mathrm{VAC}$ or 240VAC depending on hook-ups available in the REC center. UL1741 dictates the disconnection of the low frequency step-up transformer for anti-islanding requirements. This also prevents standby power loss from having the transformer's secondary winding constantly connected to the AC grid. 


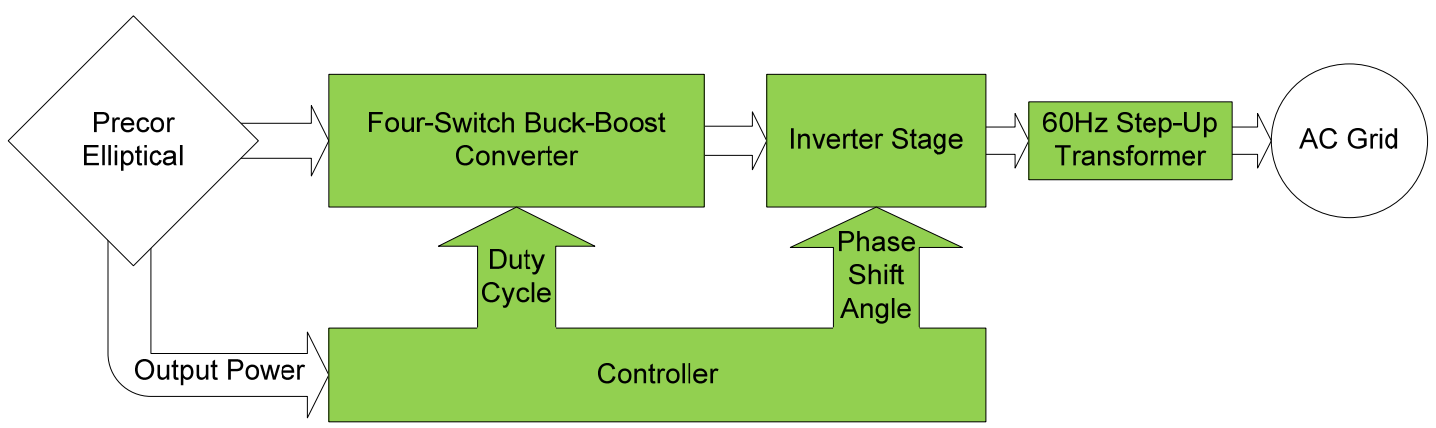

Figure 63: First Proposed Architecture

The next option still uses the FSBB converter as a voltage preregulator, but then employs an isolated topology to step up the voltage for direct grid-tie inversion. This approach eliminates the use of a large, low efficiency, and costly low frequency transformer while still providing isolation for UL safety standards.

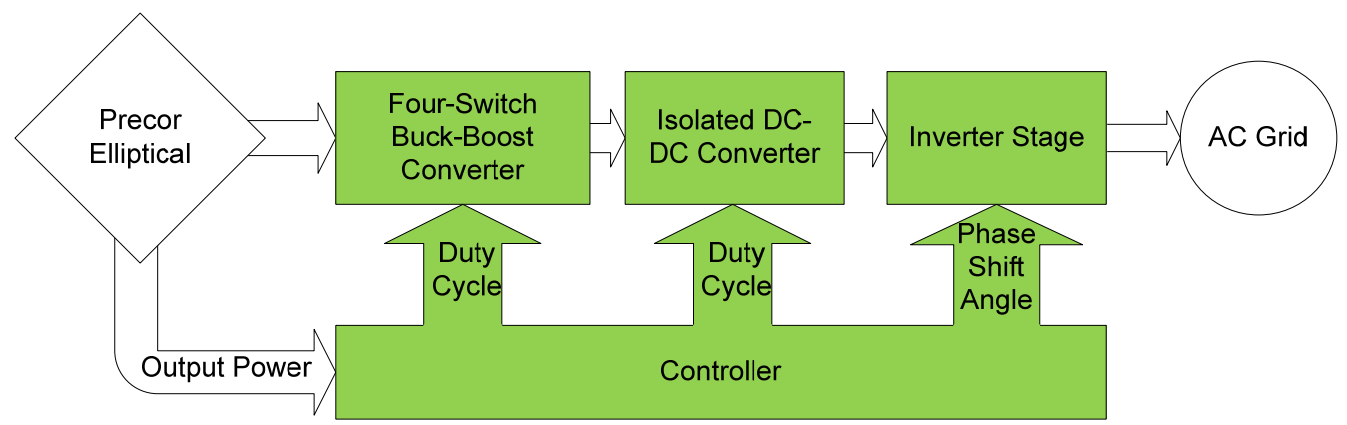

Figure 64: Second Proposed Architecture

The last approach uses one stage for DC-DC conversion then a direct gird-tie inversion stage. This minimizes parts by eliminating the FSBB converter, but feasibility may come into play. The feasibility depends mainly the demanding wide output voltage and power range of the elliptical machine, and whether one can make a cost effective transformer suitable for this application. 


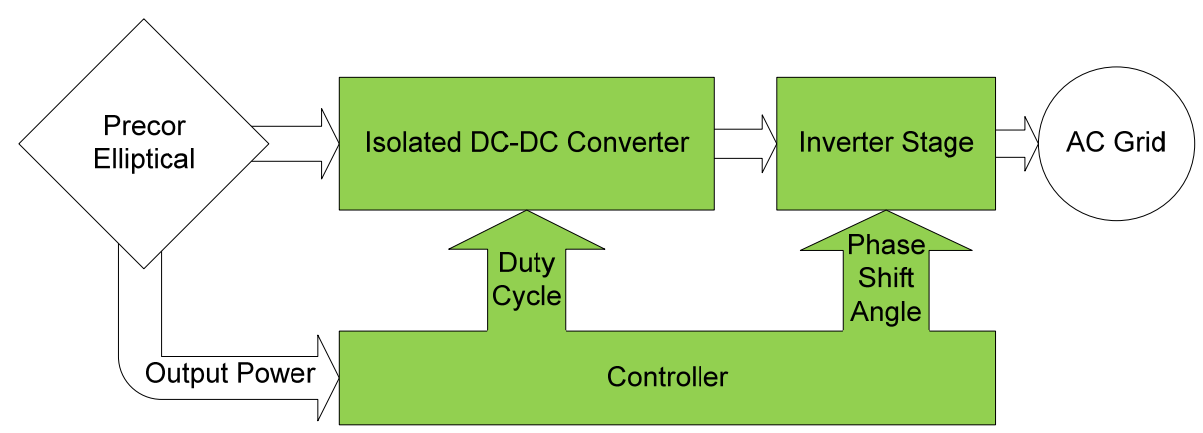

Figure 65: Third Proposed Architecture

An alteration to possibly make the third option feasible may lie with increasing the lower voltage limit. The minimum input voltage sets the inductance requirements and turns ratios high, making for a more costly magnetic component. By increasing the minimum input voltage, the magnetic requirements allow for more practical options. The Four-Switch Buck-Boost topology may also employ this method to decrease costs. This option requires cost analysis. If it does prove cost effect, the power generated at lower levels would need addressing. This method would either implement a boost stage or dissipating the power as heat. In any case, the project requires further research and comparison of these options.

\subsection{Control Algorithm}

For controlling the DC-DC converter stage(s) and inverter, the system requires a way to sense the output power of the elliptical machine. Sensing the output of the elliptical machine allows for a feed forward control system, which ideally tracks the sporadic power characteristics of the machine. This better suits the application, since the changes in power levels occur faster than in wind and solar applications. Also, a separate data acquisition device could take this data and display the power generated and other performance metrics. One option relies on sensing the speed, SPM, of the synchronous 
generator and somehow determining the resistance level setting from the onboard power electronics unit. The other way approaches the elliptical machine as a black box. Using an analog multiplying IC, such as the AD633, the elliptical machine output voltage and current can give the elliptical machine output power. An operational amplifier can sense the voltage, and a current sense amplifier IC determines the output current. Equation 10 shows the elliptical machine's output power in terms of SPM and resistance level setting using the elliptical machine output voltage from Equation 2.

\section{Equation 10: Elliptical machine Output Power}

$$
\begin{aligned}
& P_{\text {oElliptical }} \\
= & V_{\text {inConv }} I_{\text {inConv }} \\
= & \frac{V_{\text {inConv }}^{2}}{Z_{\text {inConv }}}=\frac{[(0.0108 * S P M+.9695) * \text { Resistance Level }+3.143]^{2}}{10 \Omega}
\end{aligned}
$$

To adjust the output power of the inverter, the control system must vary the phase angle between the output voltage of the inverter and the AC Grid. By setting the phase angle with a constant input voltage, the input current and impedance of the inverter hold constant. The two voltage waveforms should match in amplitude and frequency.

Equation 11 through Equation 15 shows the case for a single DC-DC converter stage. For the most part, the grid voltage, inverter output voltage, inverter input voltage, efficiencies, converter input impedance, and turns ratios hold constant. For additional stages, the efficiencies must cascade. Equation 11 and Equation 12 find the phase shift angle of the inverter for a given elliptical machine output power and known efficiencies of the converter and inverter. 
Equation 11: Inverter Output Power

$$
P_{\text {oInv }}=V_{\text {Grid }} V_{\text {oInv }} \sin \theta=\eta_{\text {Conv }} \eta_{\text {Inv }} P_{\text {oElliptical }}
$$

Equation 12: Inverter Phase Shift Angle

$$
\theta=\sin ^{-1} \frac{\eta_{\text {Conv }} \eta_{\text {Inv }} P_{\text {oElliptical }}}{V_{\text {Grid }} V_{\text {oInv }}}
$$

Equation 13 and Equation 14 show the input impedance for a set elliptical machine output power and inverter input voltage.

\section{Equation 13: Inverter Input Power}

$$
P_{\text {inInv }}=\eta_{\text {Conv }} P_{\text {oElliptical }}
$$

Equation 14: Inverter Input Impedance

$$
Z_{\text {inInv }}=\frac{V_{\text {inInv }}^{2}}{P_{\text {inInv }}}=\frac{V_{\text {inInv }}^{2}}{\eta_{\text {Conv }} P_{\text {oElliptical }}}
$$

The following equations derive the duty cycle of a constant conduction mode Boost converter in terms of efficiency, input impedance, and output impedance. This allows setting constant input impedance for a given efficiency and inverter input impedance. Appendix F shows the successful proof of full controllability and observability of all modes of the FSBB converter via state space analysis. It also, derives the state space equations for each mode, and a state space controller. The controller allows for specific pole placement for desired performance criteria.

Equation 15: Boost Converter Duty Cycle Derivation

$$
\begin{gathered}
V_{o C o n v}=V_{\text {inInv }} \\
I_{\text {oConv }}=I_{\text {inInv }} \\
Z_{o C o n v}=Z_{\text {inInv }} \\
V_{\text {oConv }} I_{o C o n v}=\eta_{\text {Conv }} V_{\text {inConv }} I_{\text {inConv }} \\
I_{\text {oConv }}=\frac{V_{\text {oConv }}}{Z_{\text {inInv }}}
\end{gathered}
$$




$$
\begin{aligned}
I_{\text {inConv }} & =\frac{V_{\text {inConv }}}{Z_{\text {inConv }}} \\
V_{\text {oConv }} & =\frac{V_{\text {inConv }}}{1-D} \\
\frac{\left(V_{\text {inConv }}\right)^{2}}{(1-D)^{2} Z_{\text {inInv }}} & =\frac{\eta_{\text {Conv }} V_{\text {inConv }}^{2}}{Z_{\text {inConv }}} \\
\text { Boost Converter: } D & =1-\sqrt{\frac{Z_{\text {inConv }}}{\eta_{\text {Conv }} Z_{\text {inInv }}}}
\end{aligned}
$$

Through similar derivations, the equations below show the duty cycle for other converters in constant conduction mode. The architecture utilizing a Four-Switch BuckBoost converter would sense the input power and switch between boost, buck, and buckboost modes as the LTC3780 controller.

Equation 16: Buck Converter Duty Cycle Equation

$$
\text { Buck Converter: } D=\sqrt{\frac{\eta_{\text {Conv }} Z_{\text {inInv }}}{Z_{\text {inConv }}}}
$$

Equation 17: Buck-Boost Converter Duty Cycle Equation

$$
\text { Buck - Boost Converter: } D=\frac{\sqrt{\frac{\eta_{\text {Conv }} Z_{\text {inInv }}}{Z_{\text {inConv }}}}}{1+\sqrt{\frac{\eta_{\text {Conv }} Z_{\text {inInv }}}{Z_{\text {inConv }}}}}
$$

Equation 18: Flyback Converter Duty Cycle Equation

$$
\text { Flyback Converter: } D=\frac{\sqrt{\frac{\eta_{\text {Conv }} Z_{\text {inInv }}}{n^{2} Z_{\text {inConv }}}}}{1+\sqrt{\frac{\eta_{\text {Conv }} Z_{\text {inInv }}}{n^{2} Z_{\text {inConv }}}}} \text { where } n=\frac{N p}{N s}
$$

Equation 19: Forward Converter Duty Cycle Equation

$$
\text { Forward Converter: } D=n \sqrt{\frac{\eta_{\text {Conv }} Z_{\text {inInv }}}{Z_{\text {inConv }}}} \text { where } n=\frac{N p}{N S}
$$


For cascaded DC-DC converter stages, examined converter uses the input impedance of the successive converter.

In addition to these new architectures, the power range of the Four-Switch BuckBoost converter may increase with the replacement of higher rated components. The Enphase microinverter no longer limits the maximum output current of the converter 7.5, thus eliminating the maximum input power. Still, this project requires further study on feasible and cost effective solutions to energy harvesting from an elliptical machine. 


\section{CHAPTER 7: CONCLUSION}

This thesis defends the Four-Switch Buck-Boost topology as a suitable DC-DC converter for regulating the wide input power range of the Precor elliptical machine at constant input impedance for a modular energy harvesting approach.

In order to choose the correct topology for this application, the project calls for an accurate characterization of the system in place. Past teams' research indicated a typical output power for an elliptical machine workout of $60-100 \mathrm{~W}$. Also, teams have thought the elliptical machine outputs a flat DC voltage to the $10 \Omega$ heat dissipating resistor. Further testing reveals that the elliptical machine's output voltage contains high peak to peak ripples that require filtering. Also, attaching different load resistances changes the output voltage and current characteristics as well as drastically changing the physical resistance experienced by the user. To maintain this resistance, the converter must handle the input voltages and currents associated by this constant input impedance. The Enphase microinverter tests reveal an optimal converter output voltage for the design specification. In addition, the efficiency takes a steep drop for power levels under $80 \mathrm{~W}$.

Six topologies met the design specifications derived from the characterization. The design excluded isolated topologies mainly due to costly transformers. The $5 \mathrm{~V}$ minimum input voltage set turns ratios high for a forward converter, and the critical magnetizing inductance high for a flyback topology. These requirements necessitate a custom and costly transformer design. The buck-boost and Cuk converters output negative voltages, and the SEPIC suffers from costs associated with two inductors. The 
Four-Switch Buck-Boost meets the full input voltage range, and delivers power with $94.07 \%$ efficiency in the typical workout power range, $60-100 \mathrm{~W}$.

The size constraint from both the ExpressPCB MiniBoardPro service restricted the size and number of components, but only using one inductor greatly helped fit all necessary components on the board. Even with limited real estate, the PCB allowed allocation for sufficient board space for heat sinking through careful selection of the MOSFETs. Particular trace layout of vital paths for high current and noise susceptible nodes allowed for smooth operation. Replacing the onboard buck converter with a linear regulator and a tap to the $12 \mathrm{~V}$ Precor elliptical battery helped bring the cost down. In the end, the converter cost roughly $\$ 80$ in parts alone. This leaves about $\$ 345$ left to spend on installation and parts for the DC-DC converter and/or microinverter to achieve zero lifecycle cost.

From the design and test phases, magnetics factors in heavily. On the surface, one must consider the size and cost. In more depth, the specifications must balance the high inductance for the low minimum input voltage, saturation current ratings, operation frequency, and turns ratios for transformers. A custom inductor/transformer design may increase the cost significantly as to weaken the cost effectiveness. The use of a readily available inductor for the FSBB converter helped decrease design time and converter cost.

After the full system test, results show the microinverter does not perform as expected. The maximum power point tracking algorithm doesn't allow the circuit to mimic a constant resistance. Instead, it draws too much current, causing the converter to deregulate. In other words, a solar inverter functions incompatibly with the system. A 
wind inverter may work, but needs a centralized infrastructure since they usually handle much higher power ranges. This project needs higher level approach for energy harvesting by designing a DC-DC converter working in concert with an inverter. 


\section{Works Cited}

[1] ReRev, "A Renewable Energy Revolution,” 2009. [Online].

http://www.rerev.com

[2] D. Braun. "Soft Switching DC-DC Conversion to Harvest Exercise Machine Electricty EISG Proposal," 2010.

[3] J. Yuen; M. Lum; C. Cinkornpumin; J. Chan. "Energy Harvesting From Exercise Machines (EHFEM) Self-generator Elliptial Machine," Cal Poly Digital

Commons. 2008. [Online].

http://digitalcommons.calpoly.edu/eesp/12

[4] Enphase Energy, “Enphase Micro-Inverter,” M175-24-240 datasheet. [Online]. http://enphase.com/downloads/8261_Datasheet_24_32.pdf

[5] A. Nakamura, J. Arakaki, P. Lawrence, "Energy Harvesting from Exercise Machines Cal Poly Implementation," Cal Poly Digital Commons. 2010. [Online]. http://digitalcommons.calpoly.edu/eesp/41

[6] X. Ren; X. Ruan; H. Qian; M. Li; Q. Chen. "Three-Mode Dual-Frequency TwoEdge Modulation Scheme for Four-Switch Buck-Boost Converter," IEEE Transactions On Power Electronics, vol. 3, no.2, pp. 1527, 2009.

[7] X. Ren; Z. Tang; X. Ruan; J. Wei; G. Hua. "Four Switch Buck-Boost Converter for Telecom DC-DC power supply applications," Applied Power Electronics Conference and Exposition, 2008. APEC 2008. Twenty-Third Annual IEEE, pp. $1527,2008$.

[8] Linear Technology, "Breakthrough Buck-Boost Controller Provides up to 10A from a Wide 4V-36V Input Range," Linear Technology Journal, vol. 15, no. 3, 2005. [Online]. http://cds.linear.com/docs/LT\%20Magazine/2005_09-01LTC3780-Phillips.pdf

[9] Linear Technology, "High Efficiency, Synchronous, 4-Switch Buck-Boost Controller," LTC3780 datasheet, 2005. [Online]. http://cds.linear.com/docs/Datasheet/3780fe.pdf

[10] National Semiconductor, "Wide Voltage Range Buck-Boost Controller," LM5118 datasheet, 2010. [Online]. http://www.national.com/ds/LM/LM5118.pdf

[11] Linear Technology, "High Efficiency, Synchronous, 4-Switch Buck-Boost Controller," LTC3780 product page, 2010. [Online]. http://www.linear.com/product/LTC3780 


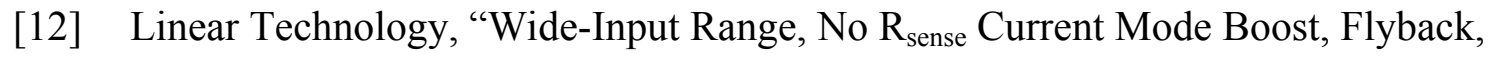
and SEPIC Controller" LT1781 product page, 2010. [Online].

http://www.linear.com/product/LTC1871

[13] Linear Technology, "100V Current Mode Synchronous Switching Regulator Controller," LTC3810 datasheet, 2007. [Online]. http://cds.linear.com/docs/Datasheet/3810fb.pdf

[14] Linear Technology, “100V Synchronous Step-Up Controller,” LTC3813 datasheet, 2007. [Online]. http://cds.linear.com/docs/Datasheet/3813fb.pdf

[15] Linear Technology, “100V Synchronous Step-Up Controller,” LTC3813 product page, 2010. [Online]. http://www.linear.com/product/LTC3813

[16] Linear Technology, “100V Current Mode Synchronous Switching Regulator Controller," LTC3810 product page, 2010. [Online].

http://www.linear.com/product/LTC3810

[17] Linear Technology, "High Voltage Synchronous N-Channel MOSFET Driver," LTC4444 datasheet, 2007. [Online].

http://cds.linear.com/docs/Datasheet/4444fapdf

[18] Linear Technology, “58V, 2A, 2.4MHz Step-Down Switching Regulator," LT3980 datasheet, 2009. [Online]. http://cds.linear.com/docs/Datasheet/3980f.pdf

[19] Infineon Technologies, “Optimos3 Power Transistor,” BSC042NE7NS3G datasheet, 2009. [Online].

http://www.infineon.com/dgdl/BSC042NE7NS3G_Rev2.21.pdf?folderId=db3a30 4313b8b5a60113cee8763b02d7\&fileId $=$ db3a304320d39d590121a5f8baf30c25

[20] Infineon Technologies, "Optimos3 Power Transistor,” BSZ123N08NS3G datasheet, 2009. [Online].

http://www.infineon.com/dgd1/BSZ123N08NS3G_rev2.0.pdf?folderId=db3a3043 13b8b5a60113cee8763b02d7\&fileId $=$ db3a30431ddc9372011e5ec96fdc0a00

[21] Infineon Technologies, “Optimos3 Power Transistor," IPB039N10N3G datasheet, 2009. [Online].

http://www.infineon.com/dgdl/IPB039N10N3+G_Rev2.03.pdf?folderId=db3a304 313b8b5a60113cee8763b02d7\&fileId=db3a30431 ce5fb52011d1ed1fd3915e0

[22] ExpressPCB, "Tips for Designing PCBs." ExpressPCB - Free PCB Layout Software - Low Cost Circuit Boards - Top Quality PCB Manufacturing. 2010. [Online]. http://expresspcb.com/ExpressPCBHtm/Tips.htm

[23] D. Rhodes; M. Davis-Marsh. "Proper PCB Layout Techniques Maximize Power Module Performance,” 2010. [Online].

http://i.cmpnet.com/powermanagementdesignline/2010/08/C0610posted.pdf 
[24] S. Maniktala. "Proper Board Layout Makes Switchers Work Right the First Time." EE Times. 2002. [Online]. http://www.eetimes.com/electronicsnews/4164323/Proper-board-layout-makes-switchers-work-right-the-first-time

[25] Pololu, "Pololu - Laser-Cut Mylar SMT Stencil." Pololu Robotics and Electronics. 2001. [Online]. http://www.pololu.com/catalog/product/446

[26] Pulse Electronics, "SMT Power Inductors," PB2020.223NL datasheet, 2007. [Online]. http://ww2.pulseeng.com/products/datasheets/SPM2007_14.pdf

[27] Cooper Bussmann/Coiltronics, "Low Cost Power Inductors," CTX20-16-52-R datasheet, 2007. [Online]. http://www.cooperbussmann.com/pdf/4935b080-188143db-b73d-e2176f2c5e73.pdf 


\section{Appendix A: LTC3780 First Design Netlist}

* C: :Documents and Settings $\backslash$ Rem $\backslash$ Desktop $\backslash$ Master $\backslash$ Old Circuits $\backslash$ Master.asc

XU1 N007 N018 N019 N020 N017 N014 0 N006 0 0 NC_01 N013 N008 N002 N003 N004 0 N012 N005 0 N001 N011 N010 N009 LTC3780

M§Q1 IN N002 N003 N003 SUD40N04-10A

M§Q2 N003 N004 N015 N015 SUD40N04-10A

M§Q3 OUT N010 N011 N011 SUD40N04-10A

M§Q4 N011 N012 N015 N015 SUD40N04-10A

L1 N003 N011 $1000 \mu$ Rser $=0.005$ Rpar $=2 \mathrm{~K}$

R1 N015 0.018

R2 N015 0.018

C2 IN $027 \mu$ Rser $=0.1$

C3 N005 $04.7 \mu$

C4 N018 $0.001 \mu$

R3 N017 N016 100K

C5 N016 $0.01 \mu$

R4 N015 N019 100

R5 0 N020 100

V1 IN 060

R6 N001 N006 51K

R7 OUT N014 440k

R8 N014 0 10k

C6 N009 N011.22 $\mu$

C7 N008 N003.22 $\mu$

C8 N013 $0.001 \mu$

R9 N005 N007 100K

D1 N011 OUT 30BQ060

D2 N015 N003 MBRS1100

C9 OUT $022 \mu$ Rser $=0.01$

C10 IN $03.3 \mu$ Rser $=0.01$

C11 N020 N019 100p

C12 N017 0 100p

D3 0 N006 1N750

D4 N005 N009 PMEG6010AED

D5 N005 N008 MBRS1100

C1 OUT $0390 \mu$ Rser $=0.05$

I1 OUT 07.5 load

V2 N001 030

.model D D

.lib C: IPROGRA $\sim 1 \backslash$ LTC $\backslash$ LTSPIC $\sim 1 \backslash$ lib $\backslash \mathrm{cmp} \backslash$ standard.dio

.model NMOS NMOS

.model PMOS PMOS

.lib C: IPROGRA $\sim 1 \backslash$ LTC $\backslash$ LTSPIC $\sim 1 \backslash$ lib $\backslash \mathrm{cmp} \backslash$ standard.mos

.tran $6 \mathrm{~m}$ steady startup

.lib LTC3780.sub

.backanno

.end 


\section{Appendix B: LT1871 Design Netlist}

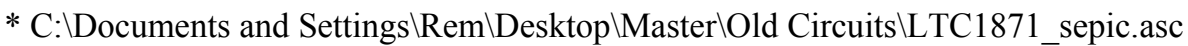
M§Q1 N003 N007 00 SUD40N04-10A

R1 N008 $080.6 \mathrm{~K}$

R2 N009 0 4k

R3 OUT N009 113.25k

L1 IN N003 $10 \mu$ Rser $=0.010$

D1 N004 OUT MBR20100CT

R4 N006 N005 33.2K

C1 N005 0 6800p

$\mathrm{C} 2 \mathrm{~N} 006050 \mathrm{p}$

XU1 N002 N006 N009 N008 N001 0 N007 N001 IN N003 LTC1871

V1 IN 052

C3 N001 $04.7 \mu$ Rser $=0.05$

L2 0 N004 $10 \mu$ Rser $=0.010$

I1 OUT 07.5 load

C4 IN $033 \mu$ Rser $=0.002$

C5 N004 N003 $10 \mu$ Rser $=0.002$

C6 OUT $0150 \mu$ Rser $=.01$

R5 N002 $0133 \mathrm{~K}$

R6 IN N002 274K

C7 0 OUT $10 \mu$ Rser $=0.002$

.model D D

.lib C:IPROGRA $\sim 1 \backslash$ LTC $\backslash$ LTSPIC $\sim 1 \backslash$ lib $\backslash \mathrm{cmp} \backslash$ standard.dio

.model NMOS NMOS

.model PMOS PMOS

.lib C:|PROGRA $\sim 1 \backslash$ LTC $\backslash$ LTSPIC $\sim 1 \backslash$ lib $\backslash \mathrm{cmp} \backslash$ standard.mos

K1 L1 L2 1

.tran $10 \mathrm{~m}$ steady startup

.lib LTC1871.sub

.backanno

.end 


\section{Appendix C: LTC3813 Netlist}

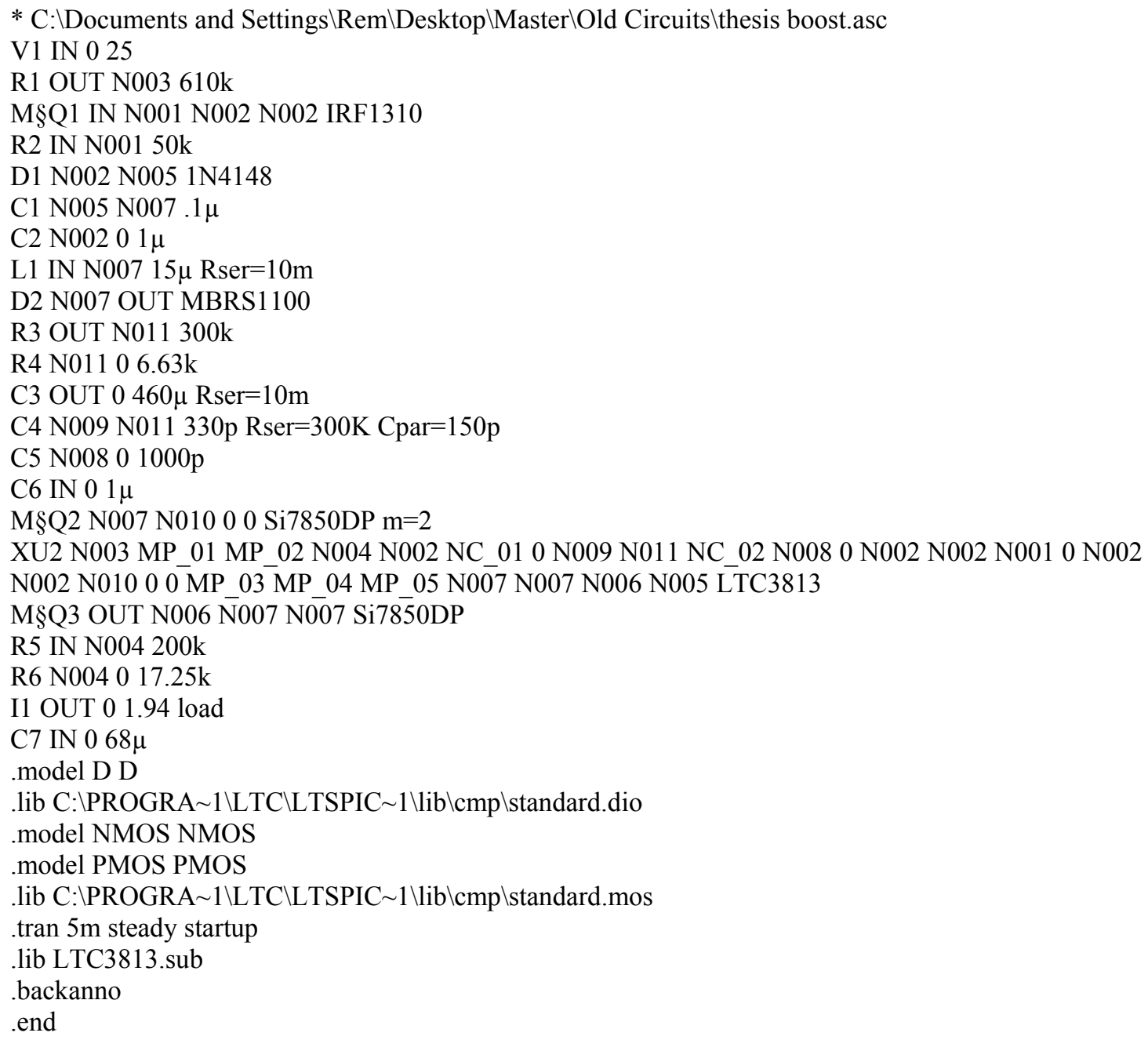




\section{Appendix D: LTC3810 Netlist}

* C: $\backslash$ Documents and Settings $\backslash$ Rem $\backslash$ Desktop $\backslash$ Master $\backslash$ Old Circuits $\backslash$ thesis.asc

R1 IN N003 681k

M§Q1 IN N001 N002 N002 BSH114

R2 IN N001 70k

D1 N002 N004 1N4148

C1 N004 N006 .1 $\mu$

M§Q2 IN N005 N006 N006 Si7852DP

M§Q3 N006 N009 00 Si7852DP

$\mathrm{C} 2 \mathrm{~N} 00201 \mu$

L1 N006 OUT $15 \mu$

D2 0 N006 MBRS1100

R3 OUT N010 300k

R4 N010 $07.947 \mathrm{k}$

C3 OUT $0270 \mu$ Rser $=10 \mathrm{~m}$

C4 N008 N010 33p

C5 N007 0 1000p

XU1 N003 MP_01 MP_02 N002 N002 NC_01 0 N008 N010 NC_02 N007 0 N002 N002 N001 OUT N002

N002 N009 00 MP_03 MP_04 MP_05 N006 N006 N005 N004 LTC3810

R6 N011 N010 90.9k

C7 N008 N011 220p

V1 IN 050

I1 OUT 07.5 load

C6 OUT $010 \mu$

C8 IN $01 \mu$

C9 IN $068 \mu$

.model D D

.lib C:IPROGRA $\sim 1 \backslash$ LTC $\backslash$ LTSPIC $\sim 1 \backslash$ lib $\backslash \mathrm{cmp} \backslash$ standard.dio

.model NMOS NMOS

.model PMOS PMOS

.lib C: $\backslash$ PROGRA $\sim 1 \backslash$ LTC $\backslash$ LTSPIC $\sim 1 \backslash$ lib $\backslash \mathrm{cmp} \backslash$ standard.mos

.tran $5 \mathrm{~m}$ startup

.lib LTC3810.sub

.backanno

.end 


\section{Appendix E: LTC3780 Final Design Netlist}

* C: $:$ Documents and Settings $\backslash$ Rem $\backslash$ Desktop $\backslash$ Master $\backslash$ Master.asc

XU1 NC 01 N029 N032 N033 N028 N026 0 N013 NC 02 N030 NC 03 N025 N007 N017 0 N021 0 N023 N007 NC_04 N001 0 N018 N007 LTC3780

M§Q1 IN N016 N011 N011 BSZ123N08NS3

C1 N007 $04.7 \mu$

M§Q2 OUT N019 N015 N015 BSZ123N08NS3

M§Q3 N015 N024 N022 N022 BSZ123N08NS3

V1 IN 025

C2 OUT $022 \mu$ Rser $=0.003$

R1 N026 0 10k

R2 OUT N026 442k

R3 N022 $05 \mathrm{~m}$

C3 N007 $00.1 \mu$

M§Q4 N011 N020 N022 N022 BSZ123N08NS3

D2 N022 N011 MBR20100CT

D3 N015 OUT MBR20100CT

L1 N011 N015 $22 \mu$ Rser $=0.005$

XU2 N017 N021 N001 N020 MP_01 N012 N016 N011 0 LTC4444

D4 N001 N012 MMSD4148

C8 N012 N011 $0.22 \mu$

C9 N001 $01 \mu$

C10 N025 0 100p

R6 N032 N022 100

R7 N033 0100

C11 N033 N032 68p

R8 N001 N013 51K

C12 N029 0 100p

C13 OUT $0330 \mu$ Rser $=0.005$

C14 IN $02.2 \mu$

$\mathrm{C} 15$ IN $01000 \mu$

$\mathrm{C} 160 \mathrm{~N} 028$ 100p

$\mathrm{C} 170 \mathrm{~N} 027.0047 \mu$

R11 N028 N027 220k

I1 OUT 02 load

XU3 N018 N023 N001 N024 MP_02 N014 N019 N015 0 LTC4444

C4 N015 N014 0.22 $\mu$

D1 N001 N014 MMSD4148

C5 N001 $01 \mu$

XU4 N001 N003 N004 IN N002 N006 NC_05 N010 N009 N005 0 LT3980

R4 N005 $0432 \mathrm{k}$

R10 N010 N001 402k

R12 0 N010 50k

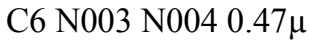

C19 N010 N001 22p

C18 N009 N008 1000p Rser $=4.75 \mathrm{k}$

D5 N006 N004 MBRS1100

L2 N004 N001 $47 \mu$

$\mathrm{C} 20 \mathrm{~N} 001047 \mu$

C21 N007 $00.1 \mu$

R9 IN N002 15k

C22 N002 $00.22 \mu$

C7 N031 N030 .01 $\mu$ 
R5 N031 0 10k

R13 N008 $04.75 \mathrm{k}$

D6 N022 N011 MBR20100CT

D7 N015 OUT MBR20100CT

.model D D

.lib C: $\mid$ PROGRA $\sim 1 \backslash$ LTC $\backslash$ LTSPIC $\sim 1 \backslash$ lib $\backslash$ cmp $\backslash$ standard.dio .model NMOS NMOS

.model PMOS PMOS

.lib C: \PROGRA $\sim 1 \backslash$ LTC $\backslash$ LTSPIC $~ 1 \backslash$ lib $\backslash$ cmp $\backslash$ standard.mos

tran $2 \mathrm{~m}$ steady startup

.lib LT3980.sub

.lib LTC3780.sub

.lib LTC4444.sub

.backanno

.end 


\section{Appendix F: EE513 FSBB Controller Design Project Excerpt}

\section{Derivations}

Currently, I was not able to find the state equations for all three modes of operation of the FSBB. Thus, this project will aim to find these state equations and see if the proposed idea is viable. Since the FSBB converter will be modeled in the three different modes, these equations hold true to the typical boost, buck, and positive output voltage buck-boost converters. The final results will also be kept in terms of variables of the system since for the EHFEM application the duty cycle and output resistance $\mathrm{R}$ change because of the variable input voltage and power. This also is providing analysis for the general boost, buck, and buck-boost cases.

\section{State Space Equations}

To derive the state space equations for this converter, each mode needs to be evaluated separately. Then in each mode, each state of the switch needs to be analyzed to find their respective state space equations. Using these equations, the state matrix $\mathbf{A}$, input matrix $\mathbf{B}$, output matrix $\mathbf{C}$, and feed through matrix $\mathbf{D}$ can be determined for the block diagram representation as shown in Figure 66 to match the following equations.

$$
\begin{aligned}
\dot{\boldsymbol{x}}(t) & =\boldsymbol{A} \boldsymbol{x}(t)+\boldsymbol{B} \boldsymbol{u}(t) \\
\boldsymbol{y}(t) & =\boldsymbol{C} \boldsymbol{x}(t)+\boldsymbol{D} \boldsymbol{u}(t)
\end{aligned}
$$

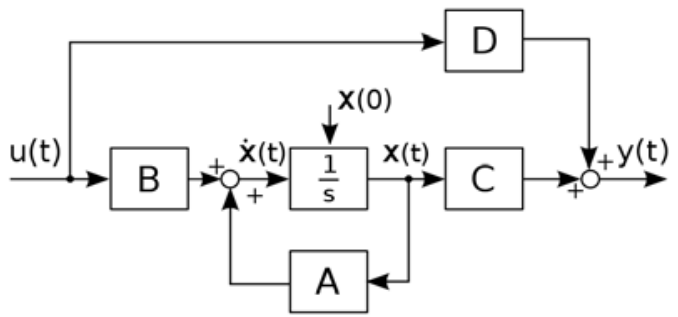

Figure 66: Block Diagram Representation of State Space Equations

Since each mode has two states in which they operate, closed switch and opened switch, the equivalent matrices are calculated by the state averaging method [1]. The duty cycle is used to proportion the matrices to give the equivalent matrix. The following equations show how this is done. The non-bold ' $\mathrm{D}$ ' represents the duty cycle, percentage in a period that the switch is closed. The matrices with the subscript 1 are the matrices that describe the state equations when the switch is closed, and the subscript 2 denotes an open switch. The feed through matrix for these modes is always the null matrix.

$$
\begin{aligned}
& \boldsymbol{A}=D \boldsymbol{A}_{\mathbf{1}}+(1-D) \boldsymbol{A}_{\mathbf{2}} \\
& \boldsymbol{B}=D \boldsymbol{B}_{\mathbf{1}}+(1-D) \boldsymbol{B}_{\mathbf{2}} \\
& \boldsymbol{C}=D \boldsymbol{A} \boldsymbol{C}_{\mathbf{1}}+(1-D) \boldsymbol{C}_{\mathbf{2}} \\
& \boldsymbol{D}=D \boldsymbol{D}_{\mathbf{1}}+(1-D) \boldsymbol{D}_{\mathbf{2}}
\end{aligned}
$$

The following pages are the derivations of these matrices. 


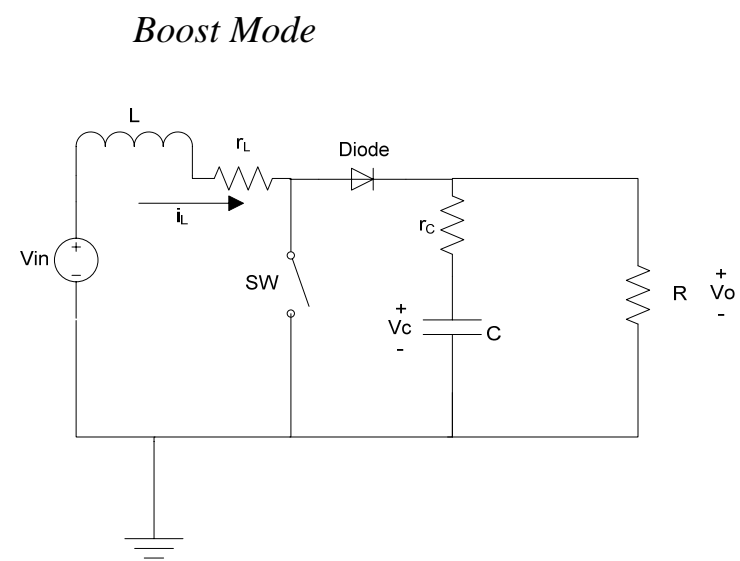

Figure 67: Boost Converter Schematic

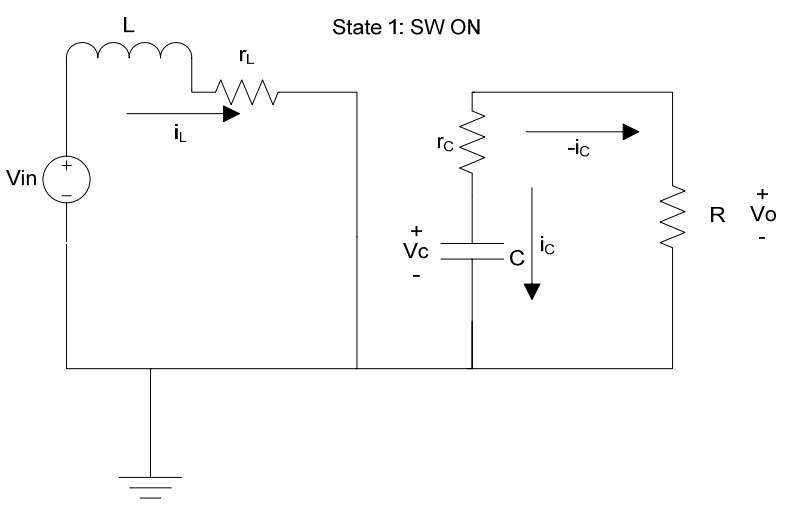

Figure 68: Boost Converter with Closed Switch

$$
\begin{gathered}
v_{\text {in }}=L \frac{d i_{L}}{d t}+i_{L} r_{L} \\
i_{C}=C \frac{d v_{C}}{d t} \\
v_{C}=-i_{C}\left(R+r_{C}\right) \\
v_{O}=v_{C}+r_{C} i_{C} \\
i_{\text {in }}=i_{L}
\end{gathered}
$$

let $\left[\begin{array}{l}i_{L} \\ v_{C}\end{array}\right]=\left[\begin{array}{l}x_{1} \\ x_{2}\end{array}\right],\left[\begin{array}{c}\frac{d i_{L}}{d t} \\ \frac{d v_{C}}{d t}\end{array}\right]=\left[\begin{array}{l}\dot{x_{1}} \\ \dot{x_{2}}\end{array}\right],\left[\begin{array}{l}i_{i n} \\ v_{O}\end{array}\right]=\left[\begin{array}{l}y_{1} \\ y_{2}\end{array}\right]$

$$
\begin{gathered}
V_{i n}=L \dot{x_{1}}+x_{1} r_{L} \\
i_{C}=C \dot{x_{2}} \\
x_{2}=-\dot{i}_{C}\left(R+r_{C}\right) \\
y_{2}=x_{2}+r_{C} i_{C} \\
\dot{x_{1}}=\frac{-r_{L}}{L} x_{1}+\frac{1}{L} v_{i n}
\end{gathered}
$$

$$
\begin{aligned}
& x_{2}=-C \dot{x_{2}}\left(R+r_{C}\right) \\
& \dot{x}_{2}=\frac{-1}{C\left(R+r_{C}\right)} x_{2} \\
& y_{2}=x_{2}+r_{C} C \dot{x_{2}} \\
& y_{2}=x_{2}+r_{C} C \frac{-1}{C\left(R+r_{C}\right)} x_{2} \\
& y_{2}=\frac{R}{R+r_{C}} x_{2} \\
& y_{1}=x_{1} \\
& \boldsymbol{A}_{\text {1Boost }}=\left[\begin{array}{cc}
\frac{-r_{L}}{L} & 0 \\
0 & \frac{-1}{C\left(R+r_{C}\right)}
\end{array}\right] \\
& B_{1 \text { Boost }}=\left[\begin{array}{l}
\frac{1}{L} \\
0
\end{array}\right] \\
& \boldsymbol{C}_{\text {1Boost }}=\left[\begin{array}{cc}
1 & 0 \\
0 & \frac{R}{R+r_{C}}
\end{array}\right] \\
& D_{1 \text { Boost }}=\left[\begin{array}{l}
0 \\
0
\end{array}\right]
\end{aligned}
$$

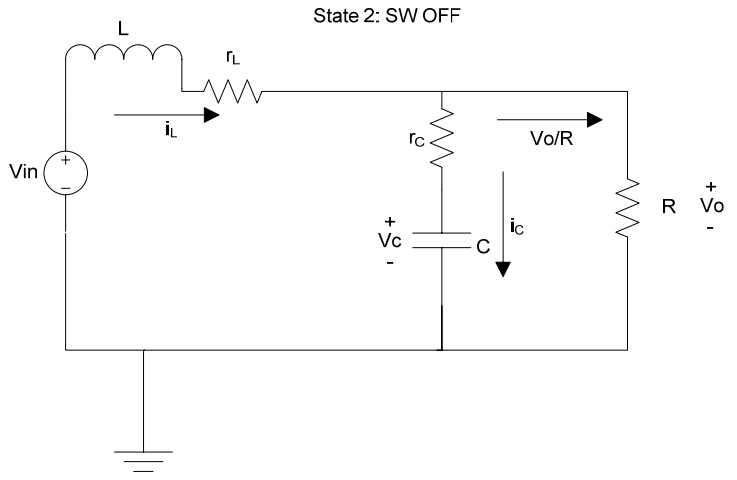

Figure 69: Boost Converter with Open Switch

$$
\begin{gathered}
v_{i n}=L \frac{d i_{L}}{d t}+i_{L} r_{L}+v_{o} \\
i_{C}=C \frac{d v_{C}}{d t} \\
i_{L}=i_{C}+\frac{v_{o}}{R} \\
v_{O}=v_{C}+r_{C} i_{C} \\
i_{\text {in }}=i_{L}
\end{gathered}
$$




$$
\begin{aligned}
& \text { let }\left[\begin{array}{l}
i_{L} \\
v_{C}
\end{array}\right]=\left[\begin{array}{l}
x_{1} \\
x_{2}
\end{array}\right],\left[\begin{array}{c}
\frac{d i_{L}}{d t} \\
\frac{d v_{C}}{d t}
\end{array}\right]=\left[\begin{array}{c}
\dot{x_{1}} \\
\dot{x_{2}}
\end{array}\right],\left[\begin{array}{c}
i_{i n} \\
v_{O}
\end{array}\right]=\left[\begin{array}{l}
y_{1} \\
y_{2}
\end{array}\right] \\
& \dot{x_{1}}=\frac{-r_{L}}{L} x_{1}+\frac{1}{L} v_{\text {in }}-\frac{1}{L}\left[\frac{R r_{C}}{R+r_{C}} x_{1}\right. \\
& V_{\text {in }}=L \dot{x_{1}}+x_{1} r_{L}+y_{2} \\
& i_{C}=C \dot{x_{2}} \\
& x_{1}=i_{C}+\frac{y_{2}}{R} \\
& v_{O}=x_{2}+r_{C} i_{C} \\
& \dot{x_{1}}=\frac{-r_{L}}{L} x_{1}+\frac{1}{L} v_{\text {in }}-\frac{1}{L} y_{2} \\
& x_{1}=C \dot{x_{2}}+\frac{y_{2}}{R} \\
& \dot{x_{2}}=\frac{1}{C} x_{1}-\frac{y_{2}}{R C} \\
& y_{2}=x_{2}+r_{C} C \dot{x_{2}} \\
& y_{2}=x_{2}+r_{C} C\left[\frac{1}{C} x_{1}-\frac{v_{o}}{R C}\right] \\
& y_{2}=\frac{R r_{C}}{R+r_{C}} x_{1}+\frac{R}{R+r_{C}} x_{2} \\
& y_{1}=x_{1} \\
& \left.+\frac{R}{R+r_{C}} x_{2}\right] \\
& \dot{x_{1}}=\left[\frac{-r_{L}}{L}-\frac{R r_{C}}{L\left(R+r_{C}\right)}\right] x_{1}-\frac{R}{L\left(R+r_{C}\right)} x_{2} \\
& +\frac{1}{L} v_{i n} \\
& \dot{x_{2}}=\frac{1}{C} x_{1}-\frac{\frac{R r_{C}}{R+r_{C}} x_{1}+\frac{R}{R+r_{C}} x_{2}}{R C} \\
& \dot{x_{2}}=\frac{R}{C\left(R+r_{C}\right)} x_{1}+\frac{-1}{C\left(R+r_{C}\right)} x_{2} \\
& \boldsymbol{A}_{2 \text { Boost }}=\left[\begin{array}{cc}
\frac{-r_{L}}{L}-\frac{R r_{C}}{L\left(R+r_{C}\right)} & \frac{-R}{L\left(R+r_{C}\right)} \\
\frac{R}{C\left(R+r_{C}\right)} & \frac{-1}{C\left(R+r_{C}\right)}
\end{array}\right] \\
& \boldsymbol{B}_{2 \text { Boost }}=\left[\begin{array}{l}
\frac{1}{L} \\
0
\end{array}\right] \\
& \boldsymbol{C}_{\text {2Boost }}=\left[\begin{array}{cc}
1 & 0 \\
\frac{R r_{c}}{R+r_{C}} & \frac{R}{R+r_{C}}
\end{array}\right] \\
& D_{2 B o o s t}=\left[\begin{array}{l}
0 \\
0
\end{array}\right] \\
& \boldsymbol{A}_{\text {Boost }}=D \boldsymbol{A}_{1 \text { Boost }}+(1-D) \boldsymbol{A}_{2 B o o s t}=\left[\begin{array}{cc}
\frac{-r_{L}}{L}-\frac{(1-D) R r_{C}}{L\left(R+r_{C}\right)} & \frac{-(1-D) R}{L\left(R+r_{C}\right)} \\
\frac{(1-D) R}{C\left(R+r_{C}\right)} & \frac{-1}{C\left(R+r_{C}\right)}
\end{array}\right] \\
& \boldsymbol{B}_{\text {Boost }}=D B_{1 \text { Boost }}+(1-D) \boldsymbol{B}_{2 \text { Boost }}=\left[\begin{array}{l}
\frac{1}{L} \\
0
\end{array}\right] \\
& \boldsymbol{C}_{\text {Boost }}=D \boldsymbol{C}_{1 \text { Boost }}+(1-D) \boldsymbol{C}_{\text {2Boost }}=\left[\begin{array}{cc}
1 & 0 \\
\frac{(1-D) R r_{C}}{R+r_{C}} & \frac{R}{R+r_{C}}
\end{array}\right] \\
& \boldsymbol{D}_{\text {Boost }}=D \boldsymbol{D}_{1 \text { Boost }}+(1-D) \boldsymbol{D}_{2 \text { Boost }}=\left[\begin{array}{l}
0 \\
0
\end{array}\right]
\end{aligned}
$$




\section{Buck Mode}

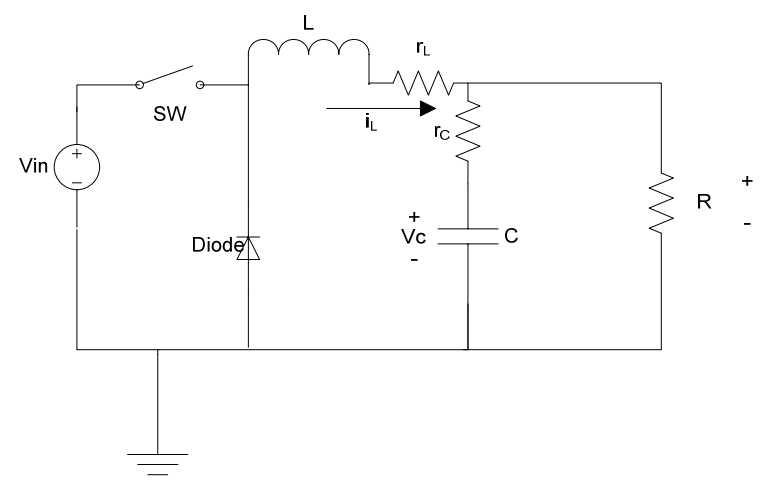

Figure 70: Buck Converter Schematic

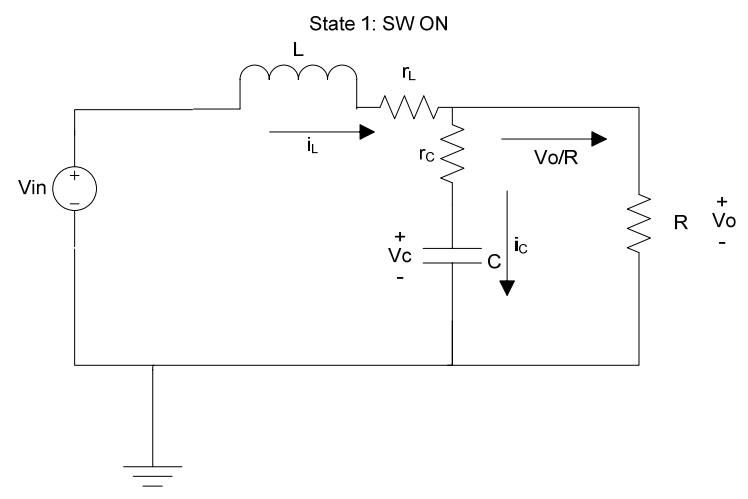

Figure 71: Buck Converter with Closed Switch

For the buck converter when the switch is closed, the state equations are exactly the same as the boost converter when the switch is open, as shown by Figures 8 and 10 .

$$
\begin{gathered}
\dot{x_{1}}=\left[\frac{-r_{L}}{L}-\frac{R r_{C}}{L\left(R+r_{C}\right)}\right] x_{1}-\frac{R}{L\left(R+r_{C}\right)} x_{2} \\
+\frac{1}{L} v_{\text {in }} \\
\dot{x_{2}}=\frac{R}{C\left(R+r_{C}\right)} x_{1}+\frac{-1}{C\left(R+r_{C}\right)} x_{2} \\
v_{O}=\frac{R r_{C}}{R+r_{C}} x_{1}+\frac{R}{R+r_{C}} x_{2} \\
y_{1}=x_{1}
\end{gathered}
$$

$$
\begin{gathered}
\boldsymbol{A}_{\text {1Buck }}=\left[\begin{array}{cc}
\frac{-r_{L}}{L}-\frac{R r_{C}}{L\left(R+r_{C}\right)} & \frac{-R}{L\left(R+r_{C}\right)} \\
\frac{R}{C\left(R+r_{C}\right)} & \frac{-1}{C\left(R+r_{C}\right)}
\end{array}\right] \\
\boldsymbol{B}_{\mathbf{1 B u c k}}=\left[\begin{array}{l}
\frac{1}{L} \\
0
\end{array}\right] \\
\boldsymbol{C}_{\mathbf{1 B u c k}}=\left[\begin{array}{cc}
1 & 0 \\
\frac{R r_{C}}{R+r_{C}} & \frac{R}{R+r_{C}}
\end{array}\right] \\
\boldsymbol{D}_{\mathbf{1 B u c k}}=\left[\begin{array}{l}
0 \\
0
\end{array}\right]
\end{gathered}
$$

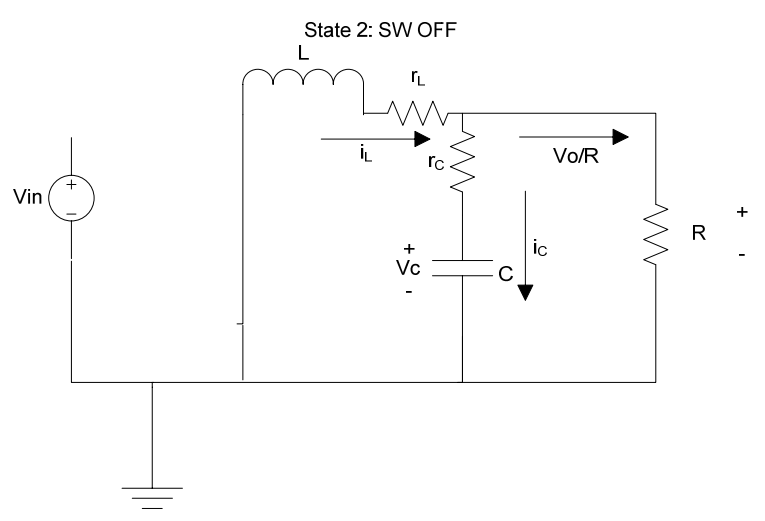

Figure 72: Buck Converter with Open Switch

$$
\begin{gathered}
0=L \frac{d i_{L}}{d t}+i_{L} r_{L}+v_{O} \\
i_{C}=C \frac{d v_{C}}{d t} \\
i_{L}=i_{C}+\frac{v_{O}}{R} \\
v_{O}=v_{C}+r_{C} i_{C} \\
i_{i n}=0
\end{gathered}
$$




$$
\begin{aligned}
& i_{C}=C \dot{x_{2}} \\
& x_{1}=i_{C}+\frac{y_{2}}{R} \\
& y_{2}=x_{2}+r_{C} i_{C} \\
& \dot{x_{2}}=\frac{R}{C\left(R+r_{C}\right)} x_{1}+\frac{-1}{C\left(R+r_{C}\right)} x_{2} \\
& y_{2}=\frac{R r_{c}}{R+r_{C}} x_{1}+\frac{R}{R+r_{C}} x_{2} \\
& y_{1}=0 \\
& \dot{x_{1}}=\frac{-r_{L}}{L} x_{1}-\frac{1}{L} y_{2} \\
& \dot{x}_{1}=\frac{-r_{L}}{L} x_{1}-\frac{1}{L}\left[\frac{R r_{C}}{R+r_{C}} x_{1}+\frac{R}{R+r_{C}} x_{2}\right] \\
& \dot{x_{1}}=\left[\frac{-r_{L}}{L}-\frac{R r_{c}}{L\left(R+r_{C}\right)}\right] x_{1}-\frac{R}{L\left(R+r_{C}\right)} x_{2} \\
& \boldsymbol{A}_{2 B u c k}=\left[\begin{array}{cc}
\frac{-r_{L}}{L}-\frac{R r_{C}}{L\left(R+r_{C}\right)} & \frac{-R}{L\left(R+r_{C}\right)} \\
\frac{R}{C\left(R+r_{C}\right)} & \frac{-1}{C\left(R+r_{C}\right)}
\end{array}\right] \\
& B_{2 \text { Buck }}=\left[\begin{array}{l}
0 \\
0
\end{array}\right] \\
& \boldsymbol{C}_{2 B u c k}=\left[\begin{array}{cc}
0 & 0 \\
\frac{R r_{C}}{R+r_{C}} & \frac{R}{R+r_{C}}
\end{array}\right] \\
& D_{2 B u c k}=\left[\begin{array}{l}
0 \\
0
\end{array}\right] \\
& \boldsymbol{A}_{\text {Buck }}=D \boldsymbol{A}_{1 \text { Buck }}+(1-D) \boldsymbol{A}_{\mathbf{2 B u c k}}=\left[\begin{array}{cc}
\frac{-r_{L}}{L}-\frac{R r_{C}}{L\left(R+r_{C}\right)} & \frac{-R}{L\left(R+r_{C}\right)} \\
\frac{R}{C\left(R+r_{C}\right)} & \frac{-1}{C\left(R+r_{C}\right)}
\end{array}\right] \\
& \boldsymbol{B}_{\text {Buck }}=D B_{1 B u c k}+(1-D) B_{2 B u c k}=\left[\begin{array}{c}
D \\
L \\
0
\end{array}\right] \\
& \boldsymbol{C}_{\text {Buck }}=D \boldsymbol{C}_{1 \text { Buck }}+(1-D) \boldsymbol{C}_{2 \text { Buck }}=\left[\begin{array}{cc}
D & 0 \\
\frac{R r_{c}}{R+r_{C}} & \frac{R}{R+r_{C}}
\end{array}\right] \\
& \boldsymbol{D}_{\text {Buck }}=D \boldsymbol{D}_{1 \text { Buck }}+(1-D) \boldsymbol{D}_{2 \text { Buck }}=\left[\begin{array}{l}
0 \\
0
\end{array}\right]
\end{aligned}
$$




\section{Buck-Boost Mode}

For the buck-boost mode, the converter operates as state 1 in boost mode when switches Q1 and Q2 are closed and acts like state 2 in buck mode when they're open. Thus, the state equations are the same as in those states.

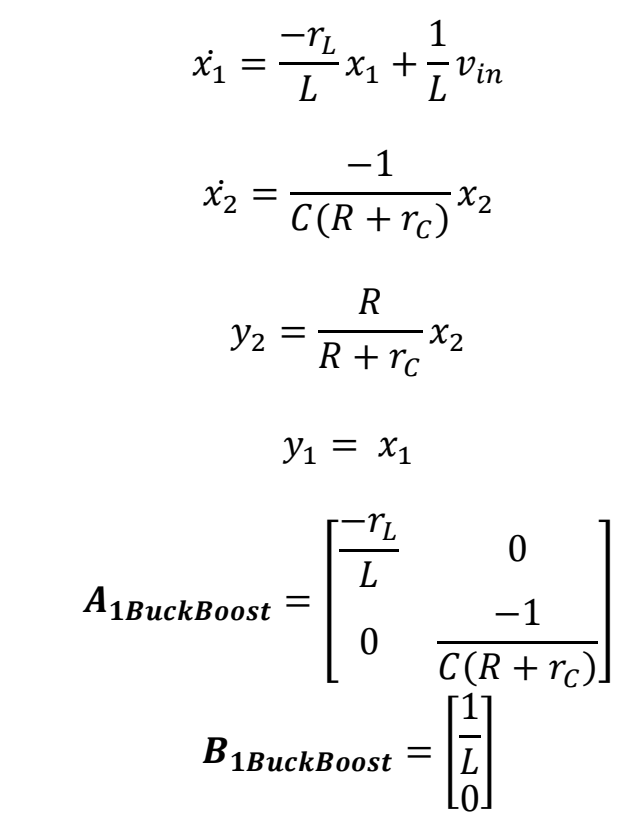

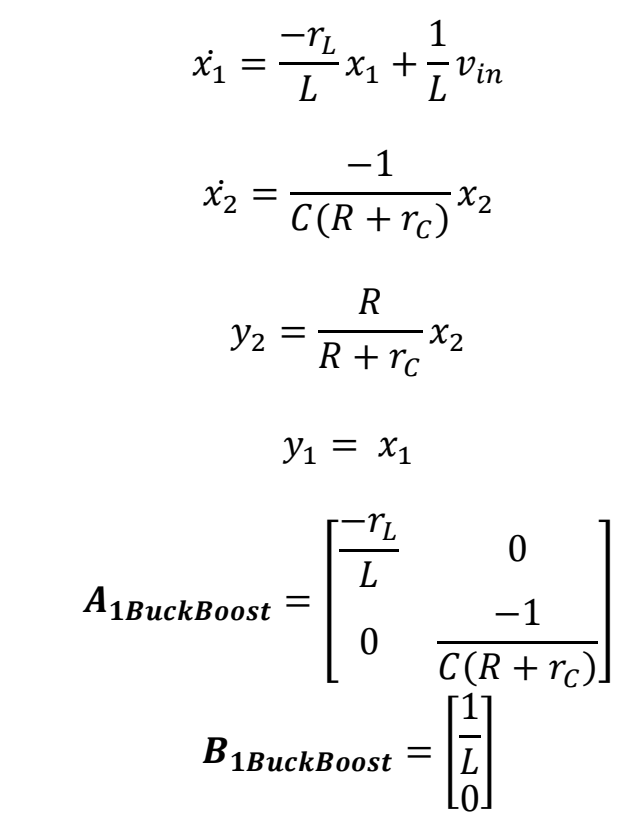

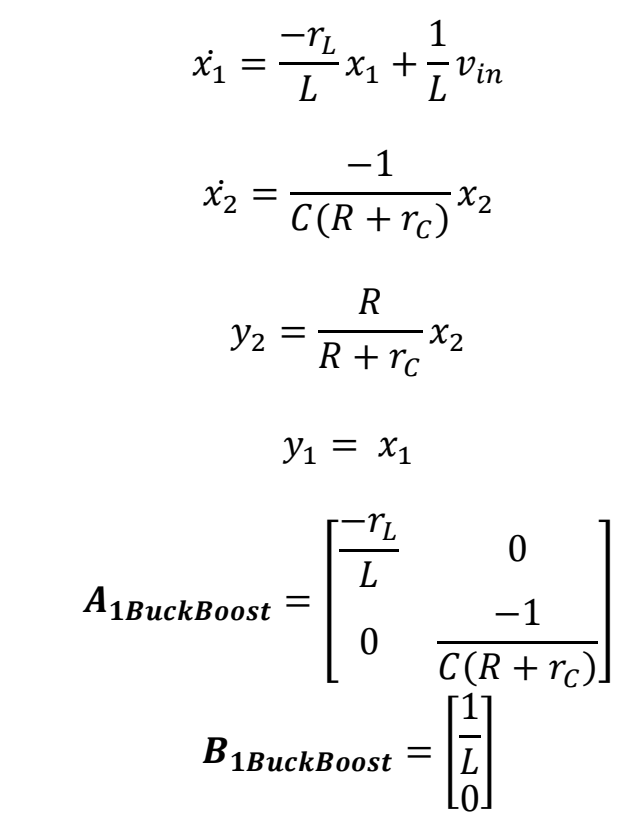

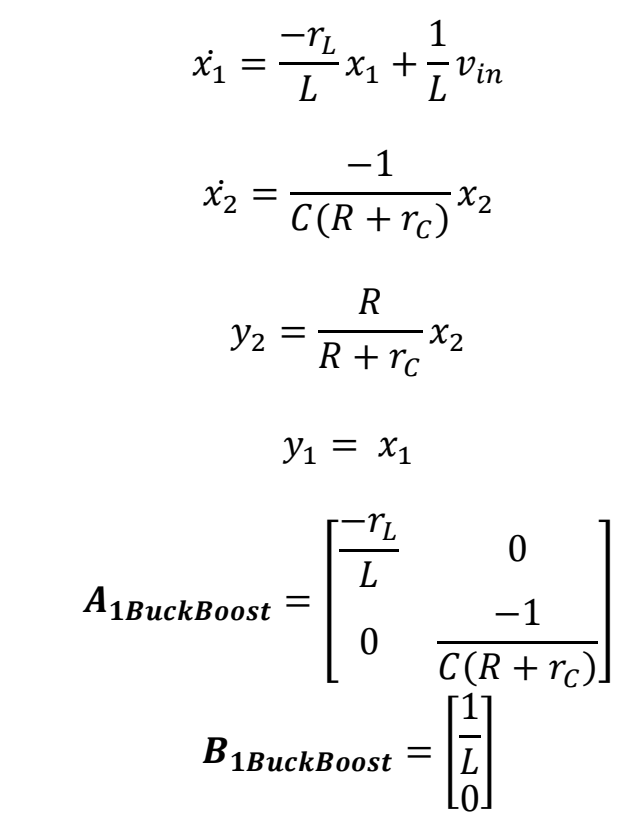

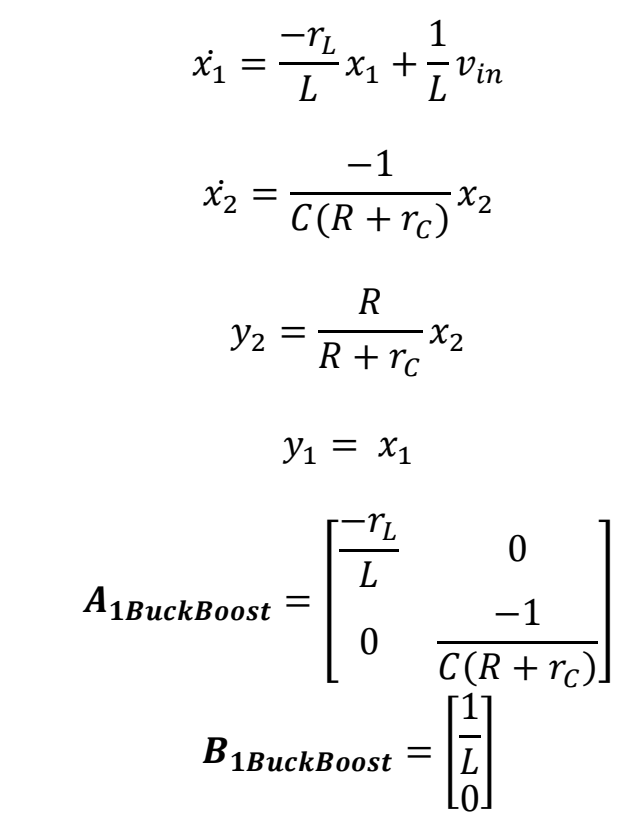

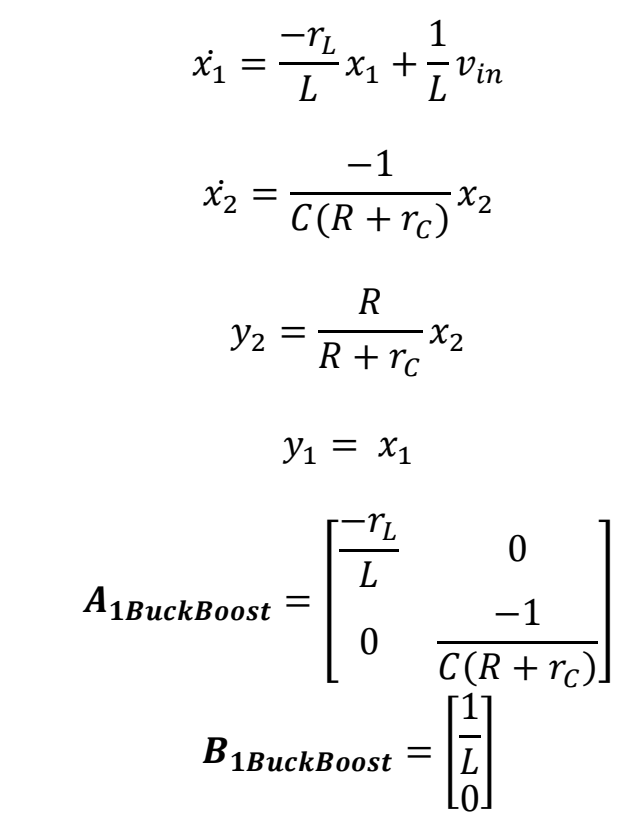

$$
\begin{aligned}
& \boldsymbol{A}_{\text {BuckBoost }}=D \boldsymbol{A}_{1 \text { BuckBoost }}+(1-D) \boldsymbol{A}_{2 B u c k B o o s t}=\left[\begin{array}{cc}
\frac{-r_{L}}{L}-\frac{(1-D) R r_{C}}{L\left(R+r_{C}\right)} & \frac{-(1-D) R}{L\left(R+r_{C}\right)} \\
\frac{(1-D) R}{C\left(R+r_{C}\right)} & \frac{-1}{C\left(R+r_{C}\right)}
\end{array}\right] \\
& \begin{array}{c}
\boldsymbol{B}_{\text {BuckBoost }}=D \boldsymbol{B}_{1 \text { BuckBoost }}+(1-D) \boldsymbol{B}_{2 B u c k B o o s t}=\left[\begin{array}{l}
\frac{D}{L} \\
0
\end{array}\right] \\
\boldsymbol{C}_{\text {BuckBoost }}=D \boldsymbol{C}_{1 \text { BuckBoost }}+(1-D) \boldsymbol{C}_{2 B u c k B o o s t}=\left[\begin{array}{cc}
D & 0 \\
\frac{(1-D) R r_{C}}{R+r_{C}} & \frac{R}{R+r_{C}}
\end{array}\right]
\end{array} \\
& \begin{array}{c}
\boldsymbol{B}_{\text {BuckBoost }}=D \boldsymbol{B}_{1 \text { BuckBoost }}+(1-D) \boldsymbol{B}_{2 B u c k B o o s t}=\left[\begin{array}{l}
\frac{D}{L} \\
0
\end{array}\right] \\
\boldsymbol{C}_{\text {BuckBoost }}=D \boldsymbol{C}_{1 \text { BuckBoost }}+(1-D) \boldsymbol{C}_{2 B u c k B o o s t}=\left[\begin{array}{cc}
D & 0 \\
\frac{(1-D) R r_{C}}{R+r_{C}} & \frac{R}{R+r_{C}}
\end{array}\right]
\end{array} \\
& D_{\text {BuckBoost }}=D D_{1 \text { BuckBoost }}+(1-D) D_{2 B u c k B o o s t}=\left[\begin{array}{l}
0 \\
0
\end{array}\right]
\end{aligned}
$$




\section{Open Loop Transfer Functions}

The following equation is used to find the transfer functions from the state space equation matrices. The feed through matrix can be neglected since it is the null matrix for all modes.

$$
\boldsymbol{H}(s)=\boldsymbol{C}(s \boldsymbol{I}-\boldsymbol{A})^{-1} \boldsymbol{B}+\boldsymbol{D}
$$

The following is a step-by-step derivation of the transfer function using variables in each matrix to ease computation. Variables $c_{2}$ and $b_{2}$ are zero for all state space equations.

$$
\begin{gathered}
\boldsymbol{H}(s)=\left[\begin{array}{ll}
c_{1} & c_{2} \\
c_{3} & c_{4}
\end{array}\right]\left(\left[\begin{array}{ll}
s & 0 \\
0 & s
\end{array}\right]-\left[\begin{array}{cc}
a_{1} & a_{2} \\
a_{3} & a_{4}
\end{array}\right]\right)^{-1}\left[\begin{array}{l}
b_{1} \\
b_{2}
\end{array}\right] \\
\boldsymbol{H}(s)=\left[\begin{array}{ll}
c_{1} & 0 \\
c_{3} & c_{4}
\end{array}\right]\left[\begin{array}{cc}
s-a_{1} & -a_{2} \\
-a_{3} & s-a_{4}
\end{array}\right]^{-1}\left[\begin{array}{c}
b_{1} \\
0
\end{array}\right] \\
\boldsymbol{H}(s)=\left[\begin{array}{ll}
c_{1} & 0 \\
c_{3} & c_{4}
\end{array}\right] \frac{1}{\left(s-a_{4}\right)\left(s-a_{1}\right)-a_{2} a_{3}}\left[\begin{array}{cc}
s-a_{4} & a_{2} \\
a_{3} & s-a_{1}
\end{array}\right]\left[\begin{array}{c}
b_{1} \\
0
\end{array}\right] \\
\boldsymbol{H}(s)=\frac{1}{\left(s-a_{4}\right)\left(s-a_{1}\right)-a_{2} a_{3}}\left[\begin{array}{cc}
c_{1} & 0 \\
c_{3} & c_{4}
\end{array}\right]\left[\begin{array}{c}
\left(s-a_{4}\right) b_{1} \\
a_{3} b_{1}
\end{array}\right] \\
\left.\begin{array}{c}
\frac{\boldsymbol{I}_{\boldsymbol{i n}}(s)}{\boldsymbol{U}(s)} \\
\boldsymbol{V}_{\boldsymbol{o}}(s) \\
\boldsymbol{U}(s)
\end{array}\right]=\frac{1}{\left(s-a_{4}\right)\left(s-a_{1}\right)-a_{2} a_{3}}\left[\begin{array}{c}
\left(s-a_{4}\right) b_{1} c_{1} \\
\left(s-a_{4}\right) b_{1} c_{3}+b_{1} a_{3} c_{4}
\end{array}\right]
\end{gathered}
$$

For further simplification, the equivalent series resistances of the capacitors and inductors shall be assumed to be zero. This simplifies the matrices into the following:

$$
\begin{gathered}
\boldsymbol{A}_{\text {Boost }}=\left[\begin{array}{cc}
0 & \frac{-(1-D)}{L} \\
\frac{1-D}{C} & \frac{-1}{R C}
\end{array}\right] \quad \boldsymbol{B}_{\text {Boost }}=\left[\begin{array}{l}
\frac{1}{L} \\
0
\end{array}\right] \quad \boldsymbol{C}_{\text {Boost }}=\left[\begin{array}{ll}
1 & 0 \\
0 & 1
\end{array}\right] \\
\boldsymbol{A}_{\text {Buck }}=\left[\begin{array}{cc}
0 & \frac{-1}{L} \\
\frac{1}{C} & \frac{-1}{R C}
\end{array}\right] \quad \boldsymbol{B}_{\text {Buck }}=\left[\begin{array}{l}
\frac{D}{L} \\
0
\end{array}\right] \quad \boldsymbol{C}_{\text {Buck }}\left[\begin{array}{ll}
D & 0 \\
0 & 1
\end{array}\right] \\
\boldsymbol{A}_{\text {BuckBoost }}=\left[\begin{array}{cc}
0 & \frac{-(1-D)}{L} \\
\frac{1-D}{C} & \frac{-1}{R C}
\end{array}\right] \quad B_{B u c k B o o s t}=\left[\begin{array}{l}
\frac{D}{L} \\
0
\end{array}\right] \quad C_{B u c k B o o s t}=\left[\begin{array}{ll}
D & 0 \\
0 & 1
\end{array}\right]
\end{gathered}
$$


Using these simplified the values the transfer functions are as follows:

$$
\begin{aligned}
& \boldsymbol{H}(s)=\left[\begin{array}{c}
\boldsymbol{I}_{\boldsymbol{i n}}(s) \\
\boldsymbol{U}(s) \\
\frac{\boldsymbol{V}_{\boldsymbol{O}}(s)}{\boldsymbol{U}(s)}
\end{array}\right]=\frac{1}{s\left(s-a_{4}\right)-a_{2} a_{3}}\left[\begin{array}{c}
\left(s-a_{4}\right) b_{1} c_{1} \\
b_{1} a_{3}
\end{array}\right] \\
& \boldsymbol{H}_{\text {Boost }}(s)=\left[\begin{array}{c}
\boldsymbol{I}_{\text {in }}(s) \\
\boldsymbol{U}(s) \\
\frac{\boldsymbol{V}_{\boldsymbol{o}}(s)}{\boldsymbol{U}(s)}
\end{array}\right]=\left[\begin{array}{c}
\frac{\frac{1}{L}\left(s+\frac{1}{R C}\right)}{s\left(s+\frac{1}{R C}\right)+\frac{(1-D)^{2}}{L C}} \\
\frac{1-D}{L C} \\
s\left(s+\frac{1}{R C}\right)+\frac{(1-D)^{2}}{L C}
\end{array}\right] \\
& \boldsymbol{H}_{\text {Buck }}(s)=\left[\begin{array}{c}
\frac{\boldsymbol{I}_{\text {in }}(s)}{\boldsymbol{U}(s)} \\
\frac{\boldsymbol{V}_{\boldsymbol{o}}(s)}{\boldsymbol{U}(s)}
\end{array}\right]=\left[\begin{array}{c}
\frac{\frac{D^{2}}{L}\left(s+\frac{1}{R C}\right)}{s\left(s+\frac{1}{R C}\right)+\frac{1}{L C}} \\
\frac{D}{L C} \\
s\left(s+\frac{1}{R C}\right)+\frac{1}{L C}
\end{array}\right] \\
& \boldsymbol{H}_{\text {BuckBoost }}(s)=\left[\begin{array}{c}
\frac{\boldsymbol{I}_{\text {in }}(s)}{\boldsymbol{U}(s)} \\
\frac{\boldsymbol{V}_{\boldsymbol{o}}(s)}{\boldsymbol{U}(s)}
\end{array}\right]=\left[\begin{array}{c}
\frac{D^{2}}{L}\left(s+\frac{1}{R C}\right) \\
s\left(s+\frac{1}{R C}\right)+\frac{(1-D)^{2}}{L C} \\
\frac{D(1-D)}{L C} \\
s\left(s+\frac{1}{R C}\right)+\frac{(1-D)^{2}}{L C}
\end{array}\right]
\end{aligned}
$$




\section{Controllability}

For these modes to be controllable the rank controllability matrix $\mathbf{P}$ must be equal or greater than the dimension of the state matrix A. The dimension of these state matrices is 2 . The controllability matrix for $\mathrm{n}=2$ is as follows:

$$
\begin{gathered}
\boldsymbol{P}=[\boldsymbol{B} \mid \boldsymbol{A B}]=\left[\begin{array}{cc}
b_{1} & b_{1} a_{1} \\
0 & b_{1} a_{3}
\end{array}\right] \\
\boldsymbol{P}_{\text {Boost }}=\left[\begin{array}{cc}
\frac{1}{L} & 0 \\
0 & \frac{1-D}{L C}
\end{array}\right] ; \operatorname{rank}\left(\boldsymbol{P}_{\text {Boost }}\right)=2=n \therefore \text { Completely Controllable } \\
\boldsymbol{P}_{\text {Buck }}=\left[\begin{array}{ll}
\frac{1}{L} & 0 \\
0 & \frac{1}{L C}
\end{array}\right] ; \operatorname{rank}\left(\boldsymbol{P}_{\text {Boost }}\right)=2=n \therefore \text { Completely Controllable } \\
\boldsymbol{P}_{\text {BuckBoost }}=\left[\begin{array}{cc}
\frac{1}{L} & 0 \\
0 & \frac{1-D}{L C}
\end{array}\right] ; \operatorname{rank}\left(\boldsymbol{P}_{\text {Boost }}\right)=2=n \therefore \text { Completely Controllable }
\end{gathered}
$$

\section{Output Controllability}

For these modes to be output controllable the rank matrix Po must be equal to the dimension of the output matrix $\mathbf{C}$. The dimension of these output matrices is 1 . The controllability matrix for $n=2$ is as follows:

$$
\begin{gathered}
\boldsymbol{P o}=[\boldsymbol{C B} \mid \boldsymbol{C A B}]=\left[\begin{array}{cc}
0 & 0 \\
b_{1} c_{3} & b_{1} a_{3} c_{3}+b_{1} a_{3} c_{4}
\end{array}\right] \\
\boldsymbol{P o}_{\text {Boost }}=\left[\begin{array}{cc}
0 & 0 \\
0 & \frac{1}{L C}
\end{array}\right] ; \operatorname{rank}\left(\boldsymbol{P o}_{\text {Boost }}\right)=1=m \therefore \text { Output Controllable } \\
\boldsymbol{P o}_{\text {Buck }}=\left[\begin{array}{cc}
0 & 0 \\
0 & \frac{D}{L C}
\end{array}\right] ; \operatorname{rank}\left(\boldsymbol{P o}_{\text {Boost }}\right)=1=m \therefore \text { Output Controllable } \\
\boldsymbol{P o}_{\text {BuckBoost }}=\left[\begin{array}{cc}
0 & 0 \\
0 & \frac{D(1-D)}{L C}
\end{array}\right] ; \operatorname{rank}\left(\boldsymbol{P o}_{\text {Boost }}\right)=1=m \therefore \text { Output Controllable }
\end{gathered}
$$

\section{Observability}

For these modes to be observable the rank observability matrix $\mathbf{Q}$ must be equal or greater than the dimension of the state matrix $\mathbf{A}$. The dimension of these state matrices is 2 . The controllability matrix for $\mathrm{n}=2$ is as follows:

$$
\boldsymbol{Q}=\left[\begin{array}{c}
C \\
C A
\end{array}\right]=\left[\begin{array}{rl}
c_{1} & c_{2} \\
c_{3} & c_{4} \\
c_{1} a_{1}+c_{2} a_{3} & c_{1} a_{2}+c_{2} a_{4} \\
c_{3} a_{1}+c_{4} a_{3} & c_{3} a_{2}+c_{4} a_{4}
\end{array}\right]
$$




$$
\begin{gathered}
\boldsymbol{Q}_{\text {Boost }}=\left[\begin{array}{c}
C \\
C A
\end{array}\right]=\left[\begin{array}{ccc}
1 & 0 \\
0 & 1 \\
0 & \frac{-(1-D)}{L} \\
\frac{1-D}{C} & \frac{-1}{R C}
\end{array}\right] ; \operatorname{rank}\left(\boldsymbol{Q}_{\text {Boost }}\right)=2=n \therefore \text { Completely Observable } \\
\boldsymbol{Q}_{\text {Buck }}=\left[\begin{array}{c}
C \\
C A
\end{array}\right]=\left[\begin{array}{cc}
D & 0 \\
0 & 1 \\
0 & \frac{-1}{L} \\
\frac{1}{C} & \frac{-1}{R C}
\end{array}\right] ; \operatorname{rank}\left(\boldsymbol{Q}_{\text {Boost }}\right)=2=n \therefore \text { Completely Observable } \\
\boldsymbol{Q}_{\text {BuckBoost }}=\left[\begin{array}{c}
C \\
C A
\end{array}\right]=\left[\begin{array}{cc}
D & 0 \\
0 & \frac{1}{0} \\
\frac{1-D}{C} & \frac{-1}{R C}
\end{array}\right] ; \operatorname{rank}\left(\boldsymbol{Q}_{\text {Boost }}\right)=2=n \therefore \text { Completely Observable }
\end{gathered}
$$

\section{Controller Design}

For simplification of the controller design, the following matrices are substituted in for matrices $\mathbf{A}, \mathbf{B}$, and $\mathbf{C}$, since they do not contain specific values and some values are either one or zero for all modes. The following equations are the derivation for the feedback matrix K using Ackerman's formula, in Figure 73.

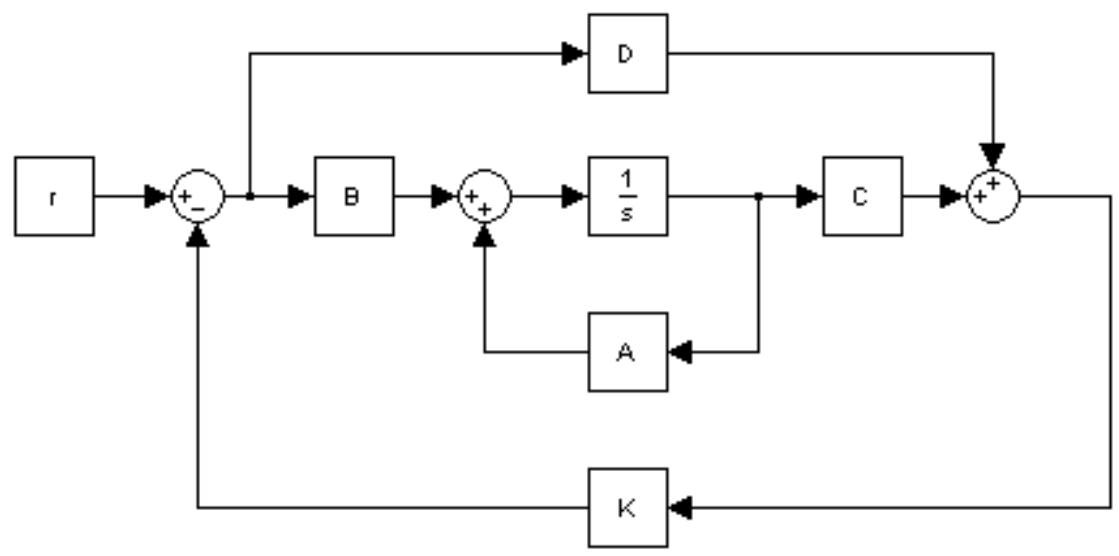

Figure 73: State Space Model with Feedback

$$
\boldsymbol{A}=\left[\begin{array}{cc}
0 & a_{2} \\
a_{3} & a_{4}
\end{array}\right] \quad \boldsymbol{B}=\left[\begin{array}{c}
b_{1} \\
0
\end{array}\right] \quad \boldsymbol{C}=\left[\begin{array}{cc}
c_{1} & 0 \\
0 & 1
\end{array}\right]
$$




$$
\begin{gathered}
\text { Ackerman's Formula: } \boldsymbol{K}=\boldsymbol{I n}^{T} * \boldsymbol{M}_{\boldsymbol{C}}{ }^{-1} * \Delta^{\prime}(\boldsymbol{A}) \\
\boldsymbol{l n}^{T}=\left[\begin{array}{ll}
0 & 1
\end{array}\right] \\
\boldsymbol{M}_{\boldsymbol{C}}=[\boldsymbol{B} \mid \boldsymbol{A} \boldsymbol{B}]=\left[\begin{array}{cc}
b_{1} & 0 \\
0 & b_{1} a_{3}
\end{array}\right] \\
\boldsymbol{M}_{\boldsymbol{C}}{ }^{-\mathbf{1}}=\left[\begin{array}{cc}
\frac{1}{b_{1}} & 0 \\
0 & \frac{1}{a_{3} b}
\end{array}\right]
\end{gathered}
$$

Let the desired characteristic equation have poles at $\mathrm{s}$ equals $-\mathrm{p}_{1}$ and $-\mathrm{p}_{2}$. The following is the characteristic equation.

$$
\begin{aligned}
& \Delta^{\prime}(\lambda)=\left(\lambda+p_{1}\right)\left(\lambda+p_{2}\right)=\lambda^{2}+\left(p_{1}+p_{2}\right) \lambda+p_{1} p_{2} \\
& \Delta^{\prime}(\boldsymbol{A})=\boldsymbol{A}^{2}+\left(p_{1}+p_{2}\right) \boldsymbol{A}+p_{1} p_{2} \boldsymbol{I} \\
& =\left[\begin{array}{lc}
a_{2} a_{3} & a_{2} a_{4} \\
a_{3} a_{4} & a_{2} a_{3}+a_{3} a_{4}
\end{array}\right]+\left[\begin{array}{cc}
0 & \left(p_{1}+p_{2}\right) a_{2} \\
\left(p_{1}+p_{2}\right) a_{3} & \left(p_{1}+p_{2}\right) a_{4}
\end{array}\right]+\left[\begin{array}{cc}
p_{1} p_{2} & 0 \\
0 & p_{1} p_{2}
\end{array}\right] \\
& =\left[\begin{array}{cc}
a_{2} a_{3}+p_{1} p_{2} & a_{2} a_{4}+\left(p_{1}+p_{2}\right) a_{2} \\
a_{3} a_{4}+\left(p_{1}+p_{2}\right) a_{3} & a_{2} a_{3}+a_{3} a_{4}+p_{1} p_{2}+\left(p_{1}+p_{2}\right) a_{4}
\end{array}\right] \\
& \boldsymbol{K}=\left[\begin{array}{ll}
0 & 1
\end{array}\right] *\left[\begin{array}{cc}
\frac{1}{b_{1}} & 0 \\
0 & \frac{1}{a_{3} b_{1}}
\end{array}\right] *\left[\begin{array}{cc}
a_{2} a_{3}+p_{1} p_{2} & a_{2} a_{4}+\left(p_{1}+p_{2}\right) a_{2} \\
a_{3} a_{4}+\left(p_{1}+p_{2}\right) a_{3} & a_{2} a_{3}+a_{3} a_{4}+p_{1} p_{2}+\left(p_{1}+p_{2}\right) a_{4}
\end{array}\right] \\
& =\frac{1}{b_{1}}\left[a_{4}+p_{1}+p_{2} \quad a_{2}+a_{4}+\frac{p_{1} p_{2}+\left(p_{1}+p_{2}\right) a_{4}}{a_{3}}\right] \\
& \boldsymbol{K}_{\text {Boost }}=L\left[\frac{-1}{R C}+p_{1}+p_{2} \frac{-(1-D)}{L}+\frac{-1}{R C}+\frac{p_{1} p_{2}+\left(p_{1}+p_{2}\right) \frac{-1}{R C}}{\frac{1-D}{C}}\right] \\
& \boldsymbol{K}_{\text {Buck }}=\frac{L}{D}\left[\frac{-1}{R C}+p_{1}+p_{2} \frac{-1}{L}+\frac{-1}{R C}+\frac{p_{1} p_{2}+\left(p_{1}+p_{2}\right) \frac{-1}{R C}}{\frac{1}{C}}\right] \\
& \boldsymbol{K}_{\text {Buck }}=\frac{L}{D}\left[\frac{-1}{R C}+p_{1}+p_{2} \frac{-(1-D)}{L}+\frac{-1}{R C}+\frac{p_{1} p_{2}+\left(p_{1}+p_{2}\right) \frac{-1}{R C}}{\frac{1-D}{C}}\right]
\end{aligned}
$$

The following equations are used to find the equivalent matrices A', B', and C' for the closed loop form, where $\mathbf{r}$ is the identity matrix and $\mathbf{D}$ is the zero matrix.

$$
A^{\prime}=A-B K ; \quad B^{\prime}=B r=B ; C^{\prime}=C-D K=C
$$




$$
\begin{aligned}
& \boldsymbol{A}^{\prime}=\left[\begin{array}{cc}
0 & a_{2} \\
a_{3} & a_{4}
\end{array}\right]-\left[\begin{array}{c}
b_{1} \\
0
\end{array}\right] \frac{1}{b_{1}}\left[a_{4}+p_{1}+p_{2} \quad a_{2}+a_{4}+\frac{p_{1} p_{2}+\left(p_{1}+p_{2}\right) a_{4}}{a_{3}}\right] \\
& =a_{3}\left[\begin{array}{cc}
0 & 0 \\
a_{4}+p_{1}+p_{2} & a_{2}+a_{4}+\frac{p_{1} p_{2}+\left(p_{1}+p_{2}\right) a_{4}}{a_{3}}
\end{array}\right]
\end{aligned}
$$

Using this new state matrix, it is apparent that the new controllability matrix $\mathbf{P}$ will be a diagonal matrix with rank two as long as $a_{4}+p_{1}+p_{2} \neq 0$, proving that the new system with feedback will also be completely controllable. This is shown below.

$$
\boldsymbol{P}=[\boldsymbol{B} \mid \boldsymbol{A B}]=\left[\begin{array}{cc}
b_{1} & 0 \\
0 & b_{1} a_{3}\left(a_{4}+p_{1}+p_{2}\right)
\end{array}\right]
$$

It is also apparent from the following equation that the new observability matrix $\mathrm{Q}$ also has rank two, making the system completely observable.

$$
\boldsymbol{Q}=\left[\begin{array}{c}
C \\
C A
\end{array}\right]=\left[\begin{array}{ccc}
c_{1} & 0 \\
0 & c_{4} & \\
0 & & 0 \\
c_{4} a_{3}\left(a_{4}+p_{1}+p_{2}\right) & c_{4} a_{3}\left(a_{2}+a_{4}+\frac{p_{1} p_{2}+\left(p_{1}+p_{2}\right) a_{4}}{a_{3}}\right)
\end{array}\right]
$$

\section{Closed Loop Transfer Functions}

The following equation is used to find the transfer functions from the state space equation matrices with the feedback matrix $\mathbf{K}$. The feed through matrix can be neglected since it is the null matrix for all modes.

$$
\begin{aligned}
& \boldsymbol{H}^{\prime}(s)=\left[\begin{array}{c}
\frac{\boldsymbol{I}_{\boldsymbol{i n}}(s)}{\boldsymbol{U}(s)} \\
\frac{\boldsymbol{V}_{\boldsymbol{o}}(s)}{\boldsymbol{U}(s)}
\end{array}\right] \\
& =\frac{1}{s\left(s-a_{3}\left(a_{2}+a_{4}+\frac{p_{1} p_{2}+\left(p_{1}+p_{2}\right) a_{4}}{a_{3}}\right)\right)}\left[\left(s-a_{3}\left(a_{2}+a_{4}+\frac{p_{1} p_{2}+\left(p_{1}+p_{2}\right) a_{4}}{a_{3}}\right)\right) b_{1} c_{1}\right]
\end{aligned}
$$

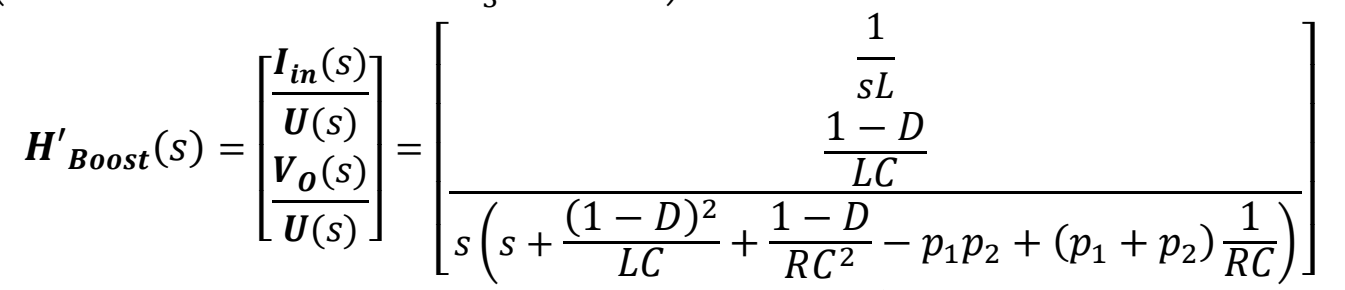

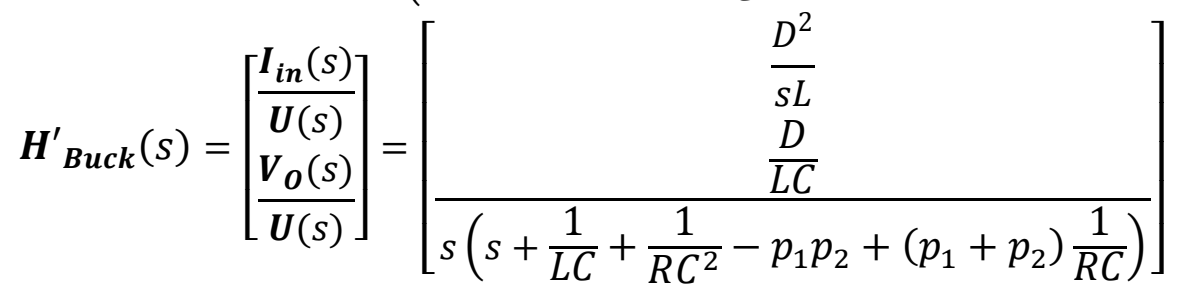




$$
\boldsymbol{H}_{\text {BuckBoost }}^{\prime}(s)=\left[\begin{array}{c}
\frac{\boldsymbol{I}_{\text {in }}(s)}{\boldsymbol{U}(s)} \\
\frac{\boldsymbol{V}_{\boldsymbol{o}}(s)}{\boldsymbol{U}(s)}
\end{array}\right]=\left[\begin{array}{c}
\frac{D^{2}}{s L} \\
\frac{D(1-D)}{L C} \\
\frac{D\left(s+\frac{(1-D)^{2}}{L C}+\frac{1-D}{R C^{2}}-p_{1} p_{2}+\left(p_{1}+p_{2}\right) \frac{1}{R C}\right)}{s(s)}
\end{array}\right]
$$

